



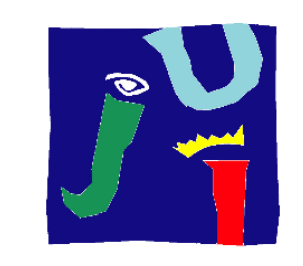

$\mathbf{U}_{\text {NIVERSITAT }}$

JAUME•I

\section{KINEMATIC AND MUSCULAR \\ CHARACTERISATION OF THE HAND \\ DURING ACTIVITIES OF DAILY LIVING}

Author:

Néstor J. Jarque Bou

Supervisors:

Joaquín L. Sancho Bru

Margarita Vergara Monedero

Castellón (Spain), September 2019 



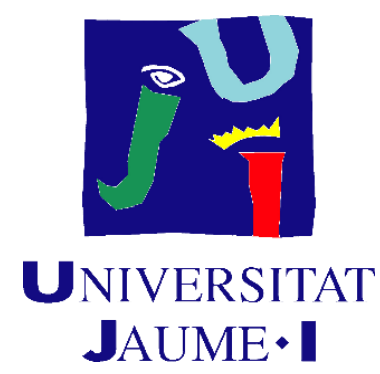

Doctoral programme in Industrial Technologies and Materials

Universitat Jaume I Doctoral School

Kinematic and muscular characterisation of the hand during activities of daily living

Report submitted by Néstor J. Jarque Bou in order to be eligible for a doctoral degree awarded by the Universitat Jaume I
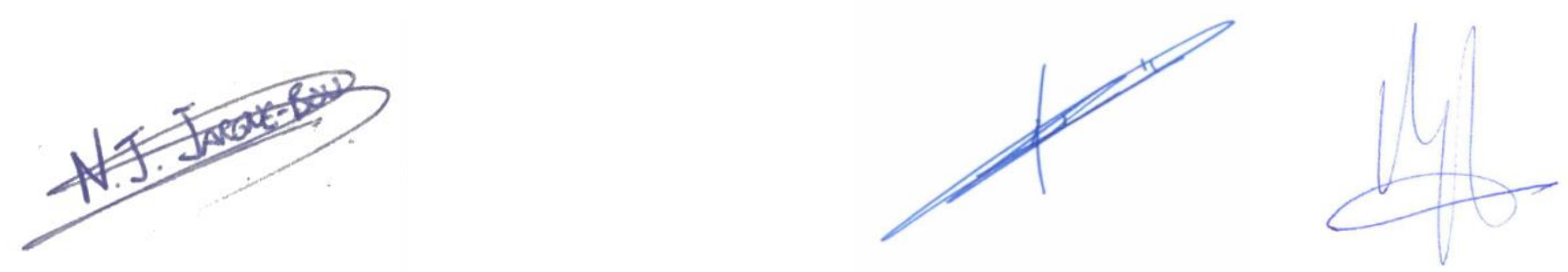

Castelló de la Plana, September 2019 



\section{Funding}

Funding agencies for the doctoral student:

- Universitat Jaume I through the project P1-B2014-10.

- Ministry of Economy and Competitiveness (project DPI2014-52095-P).

- FPI-MINECO pre-doctoral contract 2016-2019 (FPI BES-2015-072480). 



\section{Abstract}

The aim of this thesis, which is the result of the studies in which I have participated in the Biomechanics and Ergonomics Group of the Universitat Jaume I, is to contribute to the kinematic and muscular characterisation of the hand while performing activities of daily living (ADL). The results of this thesis can be applied in hand biomechanical modelling, functional assessment, and rehabilitation or for prostheses control.

Firstly, a robust optimisation method is used for the in vivo location of the rotation axes in joints with 1 and 2 degrees of freedom (DoF), by using reflective markers on the skin. As a result, the orientation and position of the axes of rotation of the metacarpophalangeal joint of the index finger are obtained considering a kinematic model consisting of two non-orthogonal and non-intersecting rotation axes. Likewise, the rotation axes of the interphalangeal (IP) joints of all the fingers are located in a parametric way by using common hand anthropometric parameters. The repeatability of the proposed method is also provided.

Then, principal component analysis (PCA) method is proposed to reduce the dimensionality of hand kinematics in terms of synergies. The mentioned method is applied to 14 static grasps postures (with 23 anatomical angles) and to 26 functional activities (with 16 anatomical angles), with special emphasis in the use of the temporal evolution of the synergies for characterizing hand kinematics. The results confirm that the whole hand kinematics is low dimensional and can be efficiently described by a small number of reduced variables (digit arch, closeness, palmar arch, thumb opposition and thumb arch). The temporal evolution of the reduced variables is provided for a wide sample of healthy subjects (22) during reaching per intended grasp and during manipulation per ADL. The analysis of these data shows that reaching requires modulation of the closeness, digit arch and thumb opposition synergies, with different control patterns per grasp, while thumb arch and palmar arch are kept almost unchanged. On the contrary, during manipulation all the reduced variables need to be modulated during all tasks.

A basis of knowledge about the hand/forearm muscles role and muscle synergy extraction of the upper limb is provided from a literature review. Methodological inconsistences identified hinders to deepen in the knowledge of the role of the muscles in ADL. To address one of the gaps, a novel functional PCA (FPCA) and clustering method is applied to identify forearm areas with similar muscle activity profiles during ADL. The proposed method reduces the number of forearm spot areas from 30 to 7, as representative spots of the muscular activity of the entire forearm in ADL, which may be related to seven different movements: 1) wrist flexion and ulnar deviation; 2) wrist flexion and radial deviation; 3) fingers flexion; 4) thumb extension and abduction/adduction; 5) finger extension; 6) wrist extension and ulnar deviation; 7) wrist extension and radial deviation.

Afterwards, forearm muscular activity during grasp performance is studied from two different approaches: 1) by studying the muscular activity contribution of specific forearm muscles recorded by intramuscular electromyography (EMG); and 2) by studying 
the muscular activity contribution of the seven proposed representative spot forearm areas recorded by surface EMG. Results from both studies have allowed deepening on the role of these muscles/spots during grasp performance, and have also helped to verify which muscle information is obtained from each of the aforementioned forearm spots.

To foster the relationship between hand kinematics and forearm muscle activity, a well-synchronised database is presented, containing a total of 572 recordings with anatomical angles and forearm muscle activity from 22 subjects while performing 26 representative and standardised ADL. From descriptive analyses, it is verified that the data are not affected by experimental procedures and that they are similar to data acquired under real-life conditions. In general, a low level of muscle activity is observed during all ADL. Muscle activity levels while performing the same task are different among subjects.

Finally, the aforementioned database is used, together with the knowledge gained throughout the thesis, in order to provide an insight into the relationships between hand kinematics and forearm muscle activity. The results suggest that hand motor control in day-to-day life can be characterised with a limited set of kinematic and muscular patterns. During reaching, correlations observed between kinematics and muscle activity are different depending on the intended grasp. During manipulation, ADL may be clustered into six groups with similar mean and range values for the muscle activity and kinematics. This is a preliminary study; however, the results obtained open an interesting via of research.

Summing up, the most relevant contributions of the thesis are: 1) Hand kinematics has been found to be low dimensional and can be described by the temporal evolution of just five parameters (determined by PCA); 2) The forearm muscle activity during ADL can be described by recording surface EMG signals from just seven representative spots; 3) A well-synchronised database of hand kinematics and muscle activity of 22 subjects while performing representative and standardised ADL is provided; 4) An insight into the relationships between hand kinematics and forearm muscle activity is provided, suggesting that hand motor control in day-to-day life can be characterised with a limited set of kinematic and muscular patterns. These results can help, among other purposes, to choose the most appropriate muscles/areas for placing the surface electrodes (in robotic devices or prosthetics). And also to plan the necessary exercises for increasing the muscular capacity of those muscles/areas that contribute most to the selected grasp, either through specific exercises, or through electro-stimulation. Furthermore, the kinematic and muscular patterns provided could be used as normal patterns in rehabilitation (for tracking function recovery) as well as to consider quantitative parameters to evaluate kinematics and muscular activity (e.g. normal ranges of muscle activity for each of the spots studied during the selected ADLs). Given the promising results presented, further research might be undertaken in order to improve existing hand biomechanical models through the consideration of the kinematic and muscular synergies, to deepen in the relationship between hand kinematics and muscle activity, to propose quantitative metrics of the kinematics and muscular activity of the upper limb, or to elaborate guidelines for using kinematic and dynamic parameters in the objective analysis of loss of hand function for carrying out ADL. 


\section{Resumen}

El objetivo de esta tesis, fruto de los estudios en los que he participado en el Grupo de Biomecánica y Ergonomía de la Universitat Jaume I, es contribuir en la caracterización cinemática y muscular de la mano durante la realización de actividades de la vida diaria. (AVD). Los resultados de esta tesis se pueden aplicar en el modelado biomecánico, la evaluación funcional y la rehabilitación o para el control de prótesis.

En primer lugar, se utiliza un método de optimización robusto para la ubicación in vivo de los ejes de rotación en articulaciones con 1 y 2 grados de libertad (DoF), mediante el uso de marcadores reflectantes en la piel. Como resultado, la orientación y la posición de los ejes de rotación de la articulación metacarpofalángica del dedo índice se obtienen considerando un modelo cinemático que consta de dos ejes de rotación no ortogonales y no intersectantes. Del mismo modo, los ejes de rotación de las articulaciones interfalángicas (IP) de todos los dedos se ubican de forma paramétrica mediante el uso de parámetros antropométricos comunes. También se proporciona la repetibilidad del método propuesto.

A continuación, se propone un método de análisis de componentes principales (ACP) para reducir la dimensión de la cinemática de la mano en términos de sinergias. El método mencionado se aplica a 14 posturas de agarre estático (23 ángulos anatómicos) y a 26 actividades funcionales (16 ángulos anatómicos), con especial énfasis en el uso de la evolución temporal de las sinergias para caracterizar la cinemática de la mano. Los resultados confirman que toda la cinemática de la mano se puede describir de manera eficiente mediante un reducido número de sinergias (arqueo de los dedos, cierre de la mano, arqueo palmar, oposición del pulgar y arqueo del pulgar). Se proporciona la evolución temporal de las variables reducidas para una amplia muestra de sujetos sanos (22) durante el alcance (por tipo de agarre previsto), y durante la manipulación (por AVD). El análisis de estos datos muestra que el alcance requiere la modulación de las sinergias de cierre de la mano, arqueo de los dedos y oposición del pulgar, con diferentes patrones de control por agarre, mientras que el arqueo del pulgar y arqueo palmar se mantienen casi sin cambios. Por el contrario, durante la manipulación, todas las variables reducidas deben modularse durante todas las tareas.

A partir de una revisión sobre la caracterización de la electromiografía (EMG) de la mano, se proporciona una base de conocimiento sobre el papel de los músculos de la mano/antebrazo y sobre la extracción de las sinergias musculares de la extremidad superior. Sin embargo, se identifican inconsistencias metodológicas que dificultan profundizar en el conocimiento del papel de los músculos en las AVD. Por lo tanto, para abordar una de estas inconsistencias, se desarrolla un nuevo método funcional de ACP (FACP) y clústeres para identificar áreas del antebrazo con perfiles temporales musculares similares. El método propuesto reduce el número de zonas del antebrazo de 30 a 7, como áreas representativas de la actividad muscular de todo el antebrazo durante AVD, que pueden estar relacionado con siete movimientos: 1) flexión de la muñeca y desviación cubital; 2) flexión de la muñeca y desviación radial; 3) flexión de los dedos; 
4) extensión y abducción/aducción del pulgar; 5) extensión de los dedos; 6) extensión de la muñeca y desviación cubital; y 7) extensión de la muñeca y desviación radial).

Seguidamente, se estudia la actividad muscular del antebrazo durante el agarre desde dos enfoques diferentes: 1) mediante el estudio de la actividad muscular de unos músculos específicos del antebrazo, registrado por EMG intramuscular; y 2) mediante el estudio de la actividad muscular de las siete áreas representativas del antebrazo, anteriormente propuestas y registradas mediante EMG superficial. Los resultados de ambos estudios nos permiten verificar qué información muscular se obtiene de cada una de las áreas del antebrazo mencionadas anteriormente, así como profundizar sobre el papel de algunos de estos músculos/áreas durante la realización de diferentes agarres.

Además, para fomentar el estudio de la relación entre la cinemática de la mano y la actividad muscular del antebrazo, se presenta una base de datos perfectamente sincronizada de actividad muscular y cinemática, que contiene un total de 572 grabaciones, con ángulos anatómicos de la mano y con la actividad muscular del antebrazo de 22 sujetos mientras realizan 26 AVD estandarizadas y representativas. A partir de análisis descriptivos, se verifica que los datos no se ven afectados por los procedimientos experimentales y que son similares a los datos adquiridos en condiciones de la vida real. En general, se observa un bajo nivel de actividad muscular durante todas las AVD. Los niveles de actividad muscular mientras se realiza la misma tarea son diferentes entre los sujetos.

Finalmente, se realiza un estudio introductorio de las relaciones entre la cinemática de la mano y la actividad muscular del antebrazo utilizando la base de datos mencionada anteriormente. Esto proporciona una idea de las relaciones entre la cinemática de la mano y la actividad muscular del antebrazo. Los resultados sugieren que el control motor de la mano en la vida cotidiana se puede caracterizar con un conjunto limitado de patrones cinemáticos y musculares. Durante el alcance, las correlaciones observadas entre la cinemática y la actividad muscular son diferentes dependiendo del alcance previsto. Durante la manipulación, las AVD puede agruparse en seis grupos con valores medios y de rango similares para la actividad muscular y la cinemática. Este es un estudio preliminar; sin embargo, los resultados obtenidos abren una interesante vía de investigación.

En resumen, las contribuciones más relevantes de la tesis son: 1) La cinemática de la mano es de baja dimensionalidad, pudiéndose describir mediante la evolución temporal de solo cinco parámetros (determinados por ACP); 2) La actividad muscular del antebrazo durante AVD se puede describir registrando las señales EMG superficial de solo siete zonas representativas; 3) Se proporciona una base de datos bien sincronizada con ángulos anatómicos de la mano y con la actividad muscular del antebrazo de 22 sujetos mientras se realizan AVD representativas y estandarizadas; 4) Se proporciona una primera aproximación a las relaciones entre la cinemática de la mano y la actividad muscular del antebrazo, que sugiere que el control motor de la mano en la vida cotidiana se puede caracterizar con un conjunto limitado de patrones cinemáticos y musculares. Específicamente, estos resultados pueden ayudar, entre otros propósitos, a elegir los 
músculos/áreas más apropiados para colocar los electrodos EMG (en dispositivos robóticos o prótesis). Y también para planificar los ejercicios necesarios para aumentar la capacidad muscular de aquellos músculos/áreas que contribuyen más al agarre seleccionado, ya sea a través de ejercicios específicos o mediante electro-estimulación. Además, los patrones cinemáticos y musculares proporcionados podrían usarse como patrones normales en la rehabilitación (para monitorizar la recuperación de la función), así como para considerar parámetros cuantitativos para evaluar la cinemática y la actividad muscular (por ejemplo, rangos normales de actividad muscular para cada uno de los puntos estudiados durante AVD). Dados los prometedores resultados presentados, se podrían realizar más investigaciones para mejorar los actuales modelos biomecánicos de mano a través de la consideración de las sinergias cinemáticas y musculares, para profundizar en la relación entre la cinemática de la mano y la actividad muscular, para proponer métricas cuantitativas de la cinemática y la actividad muscular de la extremidad superior, o para elaborar directrices para utilizar parámetros cinemáticos y dinámicos en el análisis objetivo de la pérdida de la función de la mano para llevar a cabo las AVD. 



\section{Resum}

L'objectiu d'aquesta tesi, fruit dels estudis en què he participat en el Grup de Biomecànica i Ergonomia de la Universitat Jaume I, és contribuir a la caracterització cinemàtica i muscular de la mà durant la realització d'activitats de la vida diària. (AVD). Els resultats d'aquesta tesi es poden aplicar en el modelatge biomecànic, l'avaluació funcional i la rehabilitació o per al control de pròtesis.

En primer lloc, s'utilitza un mètode d'optimització robust per a la ubicació in vivo dels eixos de rotació en articulacions amb 1 i 2 graus de llibertat (DoF), mitjançant l'ús de marcadors reflectants a la pell. Com a resultat, l'orientació i la posició dels eixos de rotació de l'articulació metacarpofalàngica del dit índex s'obtenen considerant un model cinemàtic que consta de dos eixos de rotació no ortogonals i no intersectants. De la mateixa manera, els eixos de rotació de les articulacions interfalàngiques (IP) de tots els dits se situen de forma paramètrica mitjançant l'ús de paràmetres antropomètrics comuns. També es proporciona la repetibilitat del mètode proposat.

A continuació, es proposa un mètode d'anàlisi de components principals $(\mathrm{ACP})$ per reduir la dimensió de la cinemàtica de la mà en termes de sinergies. El mètode esmentat s'aplica a 14 postures d'agafada estàtic (23 angles anatòmics) i a 26 activitats funcionals (16 angles anatòmics), amb especial èmfasi en l'ús de l'evolució temporal de les sinergies per caracteritzar la cinemàtica de la mà. Els resultats confirmen que tota la cinemàtica de la mà es pot descriure de manera eficient mitjançant un reduït nombre de sinergies (arqueig dels dits, tancament de la mà, arqueig palmar, oposició del polze i arqueig del polze). Es proporciona l'evolució temporal de les variables reduïdes per a una àmplia mostra de subjectes sans (22) durant l'abast (per tipus d'agafada prevista), i durant la manipulació (per AVD). L'anàlisi d'aquestes dades mostra que l'abast requereix la modulació de les sinergies de tancament de la mà, arqueig dels dits i oposició del polze, amb diferents patrons de control per agafada, mentre que l'arqueig del polze $i$ arqueig palmar es mantenen gairebé sense canvis. Per contra, durant la manipulació, totes les variables reduïdes han de modular durant totes les tasques.

A partir d'una revisió sobre la caracterització de l'electromiografia (EMG) de la mà, es proporciona una base de coneixement sobre el paper dels músculs de la mà/avantbraç i sobre l'extracció de les sinergies musculars de l'extremitat superior. No obstant això, s'identifiquen inconsistències metodològiques que dificulten aprofundir en el coneixement del paper dels músculs en les AVD. Per tant, per abordar una d'aquestes inconsistències, es desenvolupa un nou mètode funcional d'ACP (FACP) i clústers per identificar àrees de l'avantbraç amb perfils temporals musculars similars. El mètode proposat redueix el nombre de zones de l'avantbraç de 30 a 7, com a àrees representatives de l'activitat muscular de tot l'avantbraç durant AVD, que poden estar relacionat amb set moviments: 1) flexió del canell i desviació cubital; 2) flexió del canell i desviació radial; 3) flexió dels dits; 4) extensió i abducció/adducció del polze; 5) extensió dels dits; 6) extensió del canell i desviació cubital; i 7) extensió del canell i desviació radial). 
Seguidament, s'estudia l'activitat muscular de l'avantbraç durant l'agafada des de dos enfocaments diferents: 1) mitjançant l'estudi de l'activitat muscular d'uns músculs específics de l'avantbraç, registrat per EMG intramuscular; i 2) mitjançant l'estudi de l'activitat muscular de les set àrees representatives de l'avantbraç, anteriorment propostes i registrades mitjançant EMG superficial. Els resultats d'ambdós estudis ens permeten verificar quina informació muscular s'obté de cadascuna de les àrees de l'avantbraç esmentades anteriorment, així com aprofundir sobre el paper d'alguns d'aquests músculs/àrees durant la realització de diferents agafades.

A més, per fomentar l'estudi de la relació entre la cinemàtica de la mà i l'activitat muscular de l'avantbraç, es presenta una base de dades perfectament sincronitzada d'activitat muscular i cinemàtica, que conté un total de 572 enregistraments, amb angles anatòmics de la mà i amb l'activitat muscular de l'avantbraç de 22 subjectes mentre realitzen 26 AVD estandarditzades i representatives. A partir d'anàlisis descriptives, es verifica que les dades no es veuen afectats pels procediments experimentals i que són similars a les dades adquirides en condicions de la vida real. En general, s'observa un baix nivell d'activitat muscular durant totes les AVD. Els nivells d'activitat muscular mentre es realitza la mateixa tasca són diferents entre els subjectes.

Finalment, es realitza un estudi introductori de les relacions entre la cinemàtica de la mà i l'activitat muscular de l'avantbraç utilitzant la base de dades esmentada anteriorment. Això proporciona una idea de les relacions entre la cinemàtica de la mà i l'activitat muscular de l'avantbraç. Els resultats suggereixen que el control motor de la mà en la vida quotidiana es pot caracteritzar amb un conjunt limitat de patrons cinemàtics $i$ musculars. Durant l'abast, les correlacions observades entre la cinemàtica i l'activitat muscular són diferents depenent de l'agafada prevista. Durant la manipulació, les AVD poden agrupar-se en sis grups amb valors mitjans i de rang similars per a l'activitat muscular i la cinemàtica. Aquest és un estudi preliminar; però, els resultats obtinguts obren una interessant via d'investigació.

En resum, les contribucions més rellevants de la tesi són: 1) La cinemàtica de la mà és de baixa dimensionalitat, podent-se descriure mitjançant l'evolució temporal de només cinc paràmetres (determinats per $\mathrm{ACP}$ ); 2) L'activitat muscular de l'avantbraç durant AVD es pot descriure registrant els senyals EMG superficial de només set zones representatives; 3) Es proporciona una base de dades ben sincronitzada amb angles anatòmics de la mà i amb l'activitat muscular de l'avantbraç de 22 subjectes mentre es realitzen AVD representatives i estandarditzades; 4) Es proporciona una primera aproximació de les relacions entre la cinemàtica de la mà i l'activitat muscular de l'avantbraç, que suggereix que el control motor de la mà en la vida quotidiana es pot caracteritzar amb un conjunt limitat de patrons cinemàtics i musculars. Específicament, aquests resultats poden ajudar, entre d'altres propòsits, a triar els músculs/àrees més apropiats per a col-locar els elèctrodes EMG (en dispositius robòtics o pròtesis). I també per planificar els exercicis necessaris per augmentar la capacitat muscular d'aquells músculs/àrees que contribueixen més a l'agafada seleccionada, ja sigui a través d'exercicis específics o mitjançant electro-estimulació. A més, els patrons cinemàtics i musculars proporcionats podrien usar-se com a patrons normals en la rehabilitació (per 
monitoritzar la recuperació de la funció), així com per a considerar paràmetres quantitatius per avaluar la cinemàtica i l'activitat muscular (per exemple, rangs normals d'activitat muscular per cadascun dels punts estudiats durant AVD). Donats els prometedors resultats presentats, es podrien realitzar més investigacions per millorar els actuals models biomecànics de mà a través de la consideració de les sinergies cinemàtiques i musculars, per aprofundir en la relació entre la cinemàtica de la mà i l'activitat muscular, per proposar mètriques quantitatives de la cinemàtica i l'activitat muscular de l'extremitat superior, o per elaborar directrius per utilitzar paràmetres cinemàtics i dinàmics en l'anàlisi objectiu de la pèrdua de la funció de la mà per dur a terme les AVD. 



\section{Agradecimientos}

En primer lugar, me gustaría dar las gracias a mis directores de tesis por la confianza, por la paciencia, por el apoyo ofrecido desde el primer momento, por los consejos, por el tiempo dedicado, por ser un referente para mí y por permitirme desarrollarme tanto profesional como personalmente a su lado.

En segundo lugar, me gustaría agradecer a la Dra. Wendy Murray, al Dr. Manfredo Atzori y Dr. Henning Müller por la hospitalidad y el apoyo durante mi estancia en sus instituciones (Shirley Ryan AbilityLab y University of Applied Sciences Western Switzerland), así como a los miembros de sus equipos que me ofrecieron su ayuda en todo momento y me sirvieron de apoyo en aquellos momentos más difíciles lejos de casa.

En tercer lugar, también me gustaría agradecer a todos los miembros del Grupo de Biomecánica y Ergonomía con los que ha sido un placer trabajar durante estos años. En especial a Verónica y a Alba, que, sin ese café a media mañana, todo hubiera sido más difícil. Además, agradecer a toda la gente del departamento de Ingeniería Mecánica y Construcción y colaboradores que han ofrecido sus manos desinteresadamente y que sin su ayuda esta tesis no hubiera sido posible.

En cuarto lugar, quiero agradecer el apoyo de mi familia, pues ellos han hecho posible que llegue a ser doctor. Me han dado cariño, ánimo, y me han transmitido unos valores y educación de los cuales estoy inmensamente agradecido. También quiero agradecer a Esther su esfuerzo para el diseño de la maravillosa portada y contraportada de esta tesis, y que sin duda alguna, es y será una gran artista.

Por último y no por ello menos importante, me gustaría mencionar a Silvia. La persona que más me ha soportado durante estos 4 años, mi compañera, mi amiga, mi pareja. Gracias por tu paciencia, por tu confianza, por tu ayuda incondicional, por tu amor y cariño, en definitiva, gracias por estar ahí. 



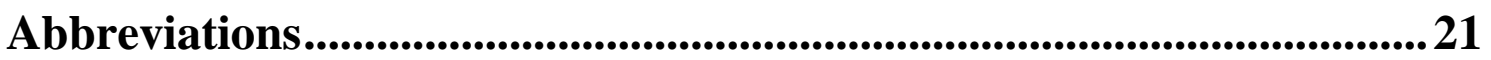

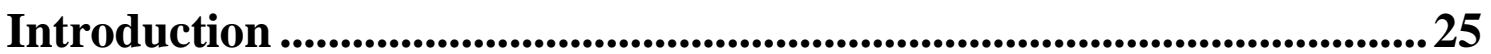

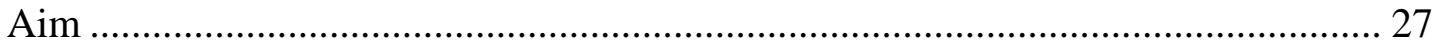

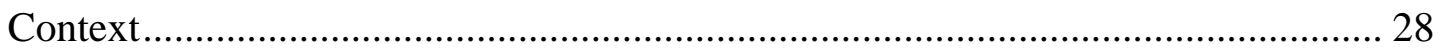

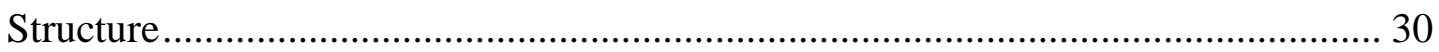

Other publications and congresses............................................................................. 34

1. Contributions on obtaining rotation axes .......................................37

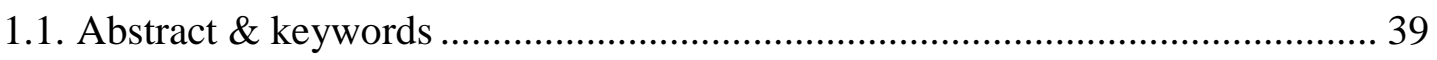

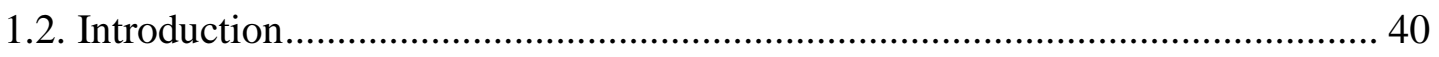

1.3. Kinematic modelling of index metacarpophalangeal joint .................................. 43

1.4. Repeatability of rotation axes location of interphalangeal joints, and goodness of considering rotation axes parallel to flexion/extension creases ........................... 53

1.5. In search of a parametric representation of the rotation axes of the

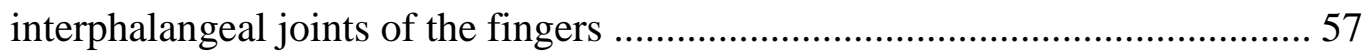

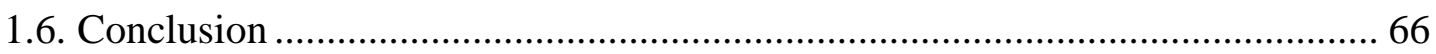

\section{Contributions on hand kinematic reduction (I): an application to} static power and precision grasps postures ..........................................69

2.1. Abstract \& keywords .................................................................................... 71

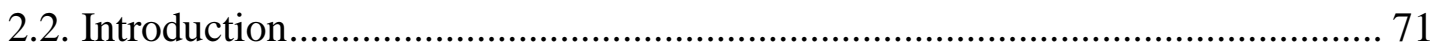

2.3. Material and methods ………………………………………………..... 74

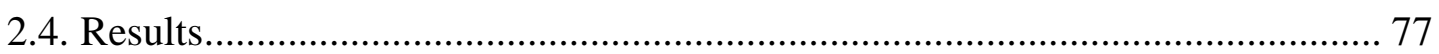

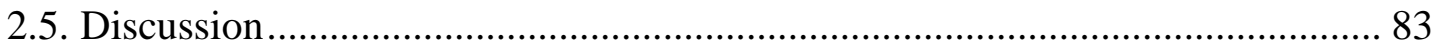

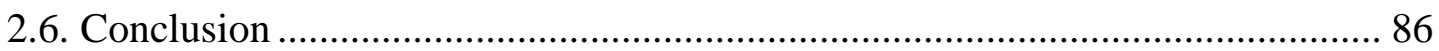

3. Contributions on hand kinematic reduction (II): application to activities of daily living using temporal data .......................................87

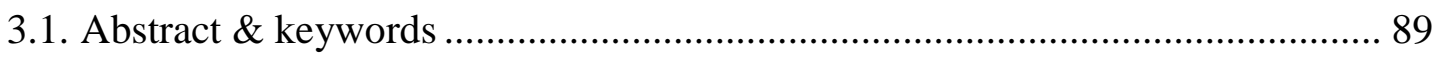

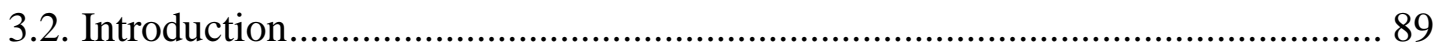

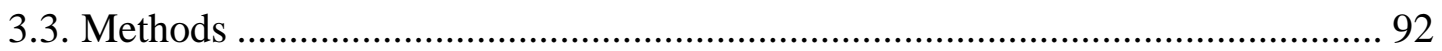

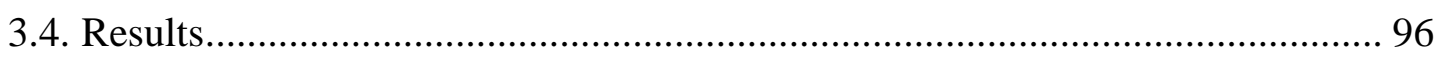

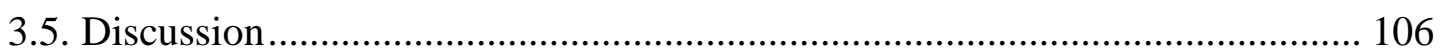

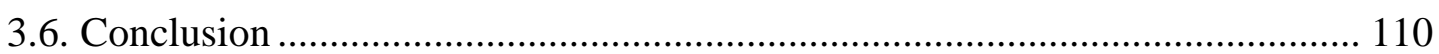

4. Characterisation of the electromyography of the hand in activities of daily living: state of art ..........................................113

4.1. Abstract \& keywords ................................................................................. 115

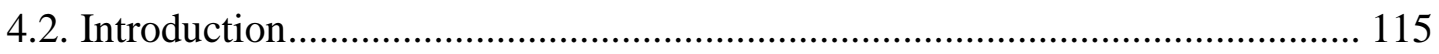

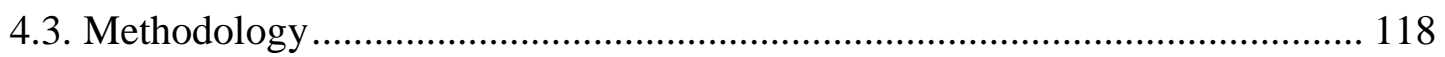

4.4. Muscles activation in different activities ...................................................... 119

4.5. Hand muscle synergies ......................................................................... 128

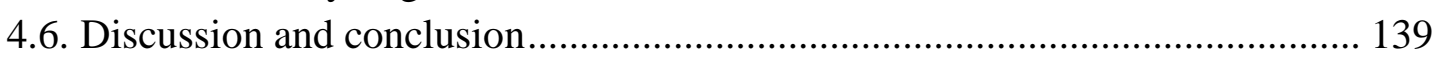


5. Identification of forearm skin zones with similar muscle activation patterns during activities of daily living ................................................... 141

5.1. Abstract \& keywords ............................................................................. 143

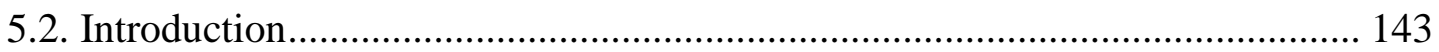

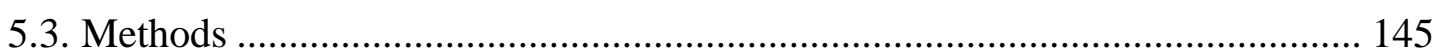

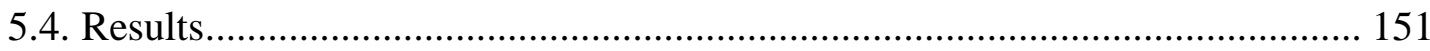

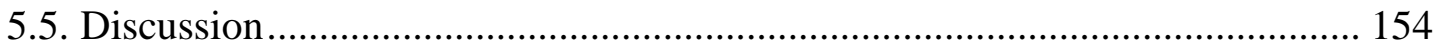

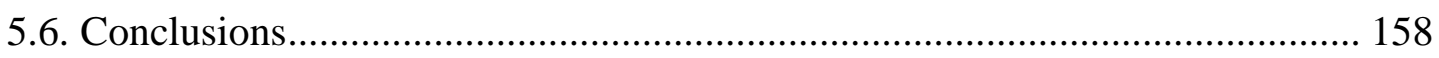

6. Contribution of forearm muscles to different grasp types............... 159

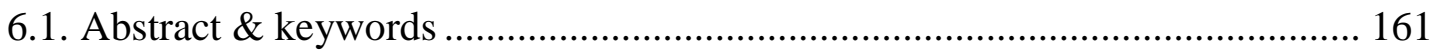

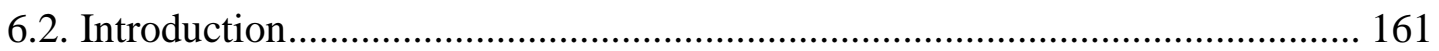

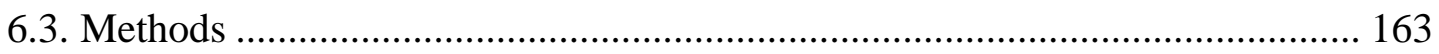

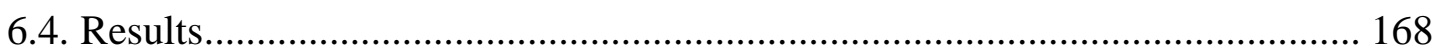

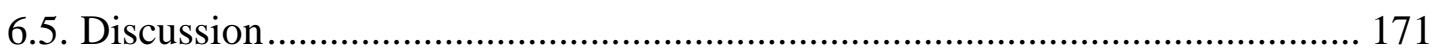

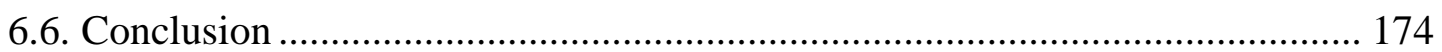

7. A database of kinematics and EMG of the forearm and hand

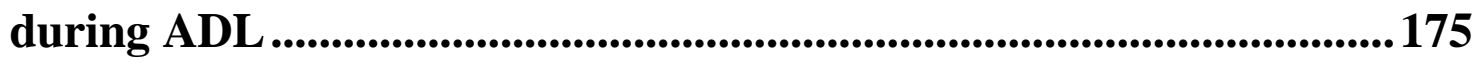

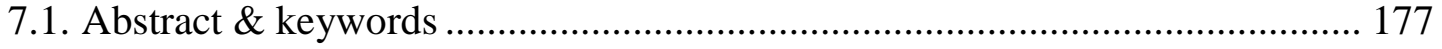

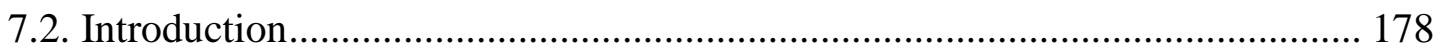

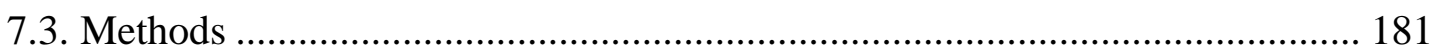

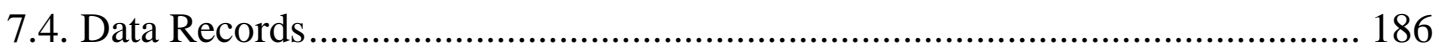

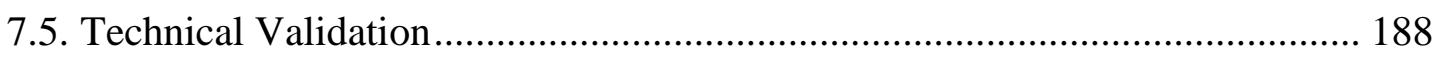

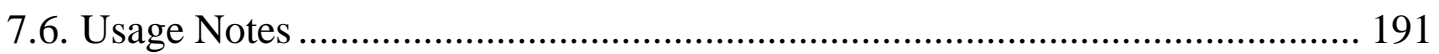

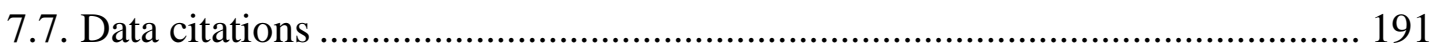

8. An insight into the relationship between kinematic and muscular activity of the hand during ADL.........................................................193

8.1. Abstract \& keywords ………………………………………………..... 195

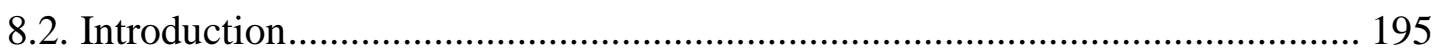

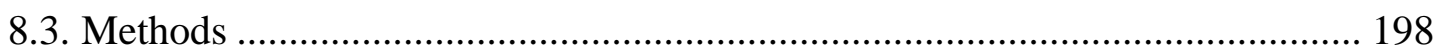

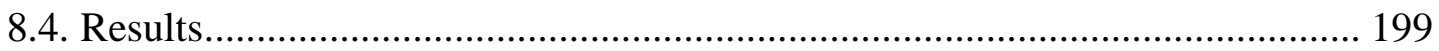

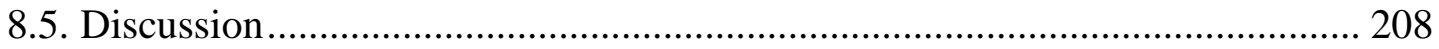

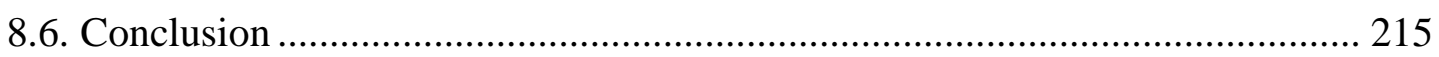

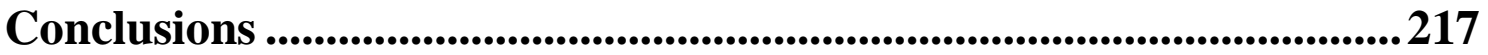

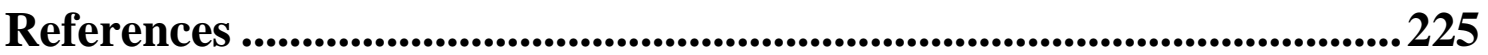

Appendix ....................................................................................................................... 243

Appendix I. Method for obtaining the position and orientation of joint rotation axes

Appendix II: Temporal evolution of the reduced kinematic variables during

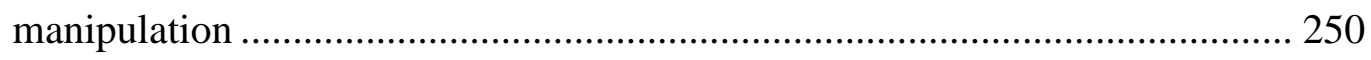

Appendix III: Temporal evolution of the muscle activity of each spot during manipulation 
Abbreviations 

3D: $\quad 3$ dimensional

$\alpha_{f}: \quad$ Inclination angle with the frontal plane

$\alpha_{s}: \quad$ Inclination angle with the sagittal plane

$\alpha_{t}$ : Inclination angle with the transversal plane

Ab/Ad: Abduction/adduction

AD: $\quad$ Anterior Deltoid

ADL: $\quad$ Activities of daily living

ANOVA: Analysis of variance

APL: $\quad$ Abductor Policis Longus

APB: $\quad$ Abductor Policis Brevis

ADD: $\quad$ Thumb Adductor

BB: $\quad$ Biceps Branchii

Br: Brachioradialis

CI: $\quad$ Confidence intervals

CS: $\quad$ Coordinate system

CMC: Carpometacarpal

Cyl: $\quad$ Cylindrical grasp

DIP: Distal interphalangeal

DoF: $\quad$ Degrees of freedom

ECR: $\quad$ Extensor Carpi Radialis

ECRB: $\quad$ Extensor Carpi Radialis Brevis

ECRL: Extensor Carpi Radialis Longus

ECU: $\quad$ Extensor Carpi Ulnaris

EDC: $\quad$ Extensor Digitorum Communis

EI: $\quad$ Extensor Indicis

EMG: Electromyography

EPB: $\quad$ Extensor Policis Brevis

EPL: $\quad$ Extensor Policis Longus

F/E: $\quad$ Flexion/extension

FCR: Flexor Carpi Radialis

FCU: $\quad$ Flexor Carpi Ulnaris

FDP: $\quad$ Flexor Digitorum Profundus

FDS: $\quad$ Flexor Digitorum Superficialis

FDI: $\quad$ First Dorsal Interosseous

FLUM: $\quad$ First Lumbrical

FPCA: $\quad$ Functional Principal Component Analysis

FPCs: $\quad$ Functional Principal Components

FPI: $\quad$ First Palmar Interosseous

Fw-EMG: Fine-wire EMG

HCA: Hierarchical Clustering Analysis

HL: $\quad$ Hand length

HB: $\quad$ Hand breadth

IntPP: Intermediate power-precision grasp 
iEMG: intramuscular Electromyography

ICF: International Classification of Functioning, Disability and Health

IP: Interphalangeal

JT: $\quad$ Joint Thickness

LatP: $\quad$ Lateral pinch

Lum: Lumbrical grasp

MANOVA: Multiple analysis of variance

MCP: $\quad$ Metacarpophalangeal

MRI: $\quad$ Magnetic resonance imaging

MSV: $\quad$ Mean square variance explained

MUAPs: Motor unit action potentials

MVC: $\quad$ Maximum Voluntary Contractions

NINO: Non-Intersecting and Non-Orthogonal

NonP: $\quad$ Nonprehensile grasp

Obl: Oblique palmar grasp

OPP: $\quad$ Opponens policis

P_Arch: Palmar Arch

PCA: $\quad$ Principal component analysis

PC: $\quad$ Principal component

PD: $\quad$ Posterior Deltoid

PIP: $\quad$ Proximal interphalangeal

PL: $\quad$ Palmaris Longus

PpPinch: Pad-to-pad pinch

PT: $\quad$ Pronator Teres

RKVs/

RKV-PCs: Reduced kinematic variables

RMS: $\quad$ Root Mean Square

RVs: $\quad$ Reduced Variables

SD: $\quad$ Standard deviation

SEMG: $\quad$ Surface Electromyography

SENIAM: Surface electromyography for the non-invasive assessment of muscles

SHFT: $\quad$ Sollerman Hand Function Test

Sig.: $\quad$ Significance level.

SpP: $\quad$ Special pinch

$T_{x}$ : $\quad$ Coordinate $\mathrm{X}$

Ty: $\quad$ Coordinate $\mathrm{Y}$

Tr: $\quad$ Trapezius

TriB: $\quad$ Triceps Branchii

UJ: $\quad$ Universal Joint

WHO: World Health Organisation

WMSD: Work-related musculoskeletal disorders 
Introduction 

The ability of the hand to grasp and manipulate is essential for humans in the development of activities of daily living (ADL). A fundamental part of this capacity lies in the kinematic and muscular complexity of the hand, with more than 25 degrees of freedom (DoF) controlled by more than 38 muscles (intrinsic, those located in the hand, and extrinsic muscles located in the forearm), tendons and ligaments (Yu et al., 2004).

This complexity turns into different limitations. Firstly, current biomechanical models of the hand present kinematic limitations such as using approximate location and orientation of the anatomical rotation axes, or ignoring the palmar arch required for grasping and manipulation. In addition, the high number of DoF of the hand hinders its functional kinematic characterisation. Principal component analysis (PCA) is a method of general application to simplify systems with a high number of variables, which has been already proposed to make affordable the kinematic characterisation of the hand. Several researchers (Liu et al., 2016; Mason et al., 2001; Patel et al., 2017; Santello et al., 1998; Thakur et al., 2008) have addressed the analysis of the coordination that exist between the different DoF of the hand during grasping, although these studies did not considered all hand DoF, and the movements considered lacked of representativeness of ADL requirements, as they consisted mainly in static grasp postures or simulated actions without object interaction.

Hence, the first main objective of this thesis is to contribute and deepen the kinematic characterisation of the hand during ADL. It is intended to contribute from two main aspects: providing in vivo methods and data of location and orientation of rotation axes in order to improve current biomechanical models; and using dimensionality reduction for characterising hand kinematics during ADL.

On the other hand, the complexity of the hand musculoskeletal system hinders the analysis of the specific role of the different muscles in ADL (Oatis, 2009). The measurement and interpretation of the muscle activation signals is cumbersome but of high importance to deepening the knowledge of the role of the muscles in ADL (Lee and Jung, 2015a). Surface electromyography (sEMG) is a non-invasive approach that allows both structural and functional characterisation of the neuromuscular system, and enables to quantify variations of this system in different situations. sEMG is applied in many fields such as motor control of human movement, myoelectric control of prosthetic and orthotic devices, and rehabilitation (Castellini et al., 2009; Hogrel, 2005; Kumar et al., 2013; Rojas-Martínez et al., 2012). However, methodological inconsistences found in the literature difficult the deepening on the role of the muscles in ADL, such as the difficulty of comparing the muscular activity of the forearm muscles due to the lack of consensus when selecting the areas to place the sEMG electrodes, the lack of representativeness of the tasks used for the sEMG characterisation or the lack of linked EMG-kinematic datasets at the hand level to foster the study of the relationships between hand kinematics and forearm muscles, among others. 
Therefore, the second main objective is to contribute to the muscular characterisation of the hand during ADL, deepening the knowledge of the role of each muscle or group of muscles. This contribution is intended from four main aspects: making the characterisation affordable through the identification of the forearm skin zones with similar sEMG activation patterns during ADL, thus reducing the recording spots required; characterising the contribution of forearm muscles to the most relevant grasps for ADL; providing a database with simultaneous data of hand kinematics and forearm sEMG during a representative set of ADL; and linking hand kinematics (using reduction methods) and muscle activity during ADL, differentiating between reaching and manipulation.

\section{Context}

The idea originates from the research carried out within the research group of Biomechanics \& Ergonomics at the Universitat Jaume I (Castellón, Spain) with which I have been collaborating in different periods since 2011. The thesis is framed within two research projects funded by different public entities, and it is worth mentioning that throughout the development of this thesis I made two abroad research stays where I came into contact with different professionals involved in hand rehabilitation and prostheses control.

\section{Research group}

The research fields of the Biomechanics \& Ergonomics Group cover biomechanics of the foot and the knee, emotional design, dental biomechanics, ergonomics of hand tools and biomechanics of the human hand. Focusing on the human hand, the group has an extensive background in knowledge, both from an ergonomic and a biomechanical point of view. A better understanding of the human hand can be applied in surgery to improve clinical decision-making, in disability assessment, or in rehabilitation to select the best strategy for the best possible recovering of a pathologic or injured hand. Also, lately the group has started to apply its knowledge to the design and evaluation of anthropomorphic hands. Nevertheless, the work presented in this thesis is focused on achieving a better knowledge of the behaviour of the human hand during ADL. More specifically, it is intended to provide axes data to improve current biomechanical hand models as well as to establish relationships between kinematics and muscle activity, during reaching and manipulation in ADL, separately. The results could be applied to rehabilitation, hand function assessment, to improve biomechanical hand models or to the design of hand prostheses.

\section{Research projects}

This thesis was part of two research projects funded by different public institutions, in which I was participating as a first stage researcher (Table 0.1) and as a PhD student under a grant from the Spanish MINECO (FPI grant BES-2015-072480). 
Table 0.1 Research projects in which the Thesis is framed in.

\begin{tabular}{|c|c|c|}
\hline \multicolumn{3}{|r|}{ Research projects } \\
\hline \multirow{7}{*}{1} & Reference & P1·1B2013-33 \\
\hline & Title & $\begin{array}{l}\text { Caracterización cinemática de la mano sana y patológica } \\
\text { (Kinematic characterisation of the healthy and pathological } \\
\text { hand) }\end{array}$ \\
\hline & Institution & Universitat Jaume I \\
\hline & Period & 01/01/ $2014-31 / 12 / 2016$ (3 years) \\
\hline & Funding & $15.918 €$ \\
\hline & Main Researcher & Joaquín L. Sancho Bru \\
\hline & Participants & $\begin{array}{l}\text { Antonio Pérez González } \\
\text { Néstor J. Jarque Bou }\end{array}$ \\
\hline \multirow{7}{*}{2} & Reference & DPI2014-52095-P \\
\hline & Title & $\begin{array}{l}\text { Kinematic characterisation of the hand aimed to functional } \\
\text { assessment of products in activities of daily living }\end{array}$ \\
\hline & Institution & Ministry of Economy and Competitiveness \\
\hline & Period & 2015-2017 (3 years) \\
\hline & Funding & $95000.00 €$ \\
\hline & Main Researchers & $\begin{array}{l}\text { Joaquín Luis Sancho Bru } \\
\text { Margarita Vergara Monedero }\end{array}$ \\
\hline & Participants & $\begin{array}{l}\text { Verónica Gracia Ibáñez } \\
\text { Néstor J. Jarque Bou } \\
\text { Wendy M. Murray } \\
\text { Alba Roda Sales }\end{array}$ \\
\hline
\end{tabular}

\section{Research stays}

In the fulfilment of the requirements for applying for an international mention in my $\mathrm{PhD}$, I performed a three months research stay at the Information Systems Institute, (MedGIFT group) University of Applied Sciences Western Switzerland (HES-SO) under the supervision of Dr. Manfredo Atzori.

The stay was focused on the analysis of kinematic synergies of the hand for its use in rehabilitation as well as for the prostheses control. MedGIFT group recorded various data on hand movements and postures, including electromyography and kinematic data, widely cited in the scientific literature. Due to the limitations of the acquisition protocol, they did not calibrate appropriately the Cyberglove, which prevented the use of these data. In the research group of the UJI, we have experience in kinematic models of the hand and we have developed a calibration protocol for the Cyberglove that once calibrated requires only a reference hand posture for obtaining joint angles (Gracia-Ibáñez et al., 2017a). Therefore, my work was focused on the calibration of their Cyberglove and the subsequent analysis of data to obtain representative and individualised hand synergies using the new calibrated database, which enabled the preparation of a paper recently 
published in Journal of NeuroEngineering and Rehabilitation. In addition, the resulting database has been also submitted to a scientific data journal to make it publicly available to other researchers. The results from this research stay are not included in this thesis.

Apart from this research stay, I stayed for one month at the Shirley Ryan AbilityLab in Chicago (USA), under the supervision of Wendy Murray, in the fulfilment of the requirements of the collaboration between the groups framed in the project DPI201452095-P. This short stay was focused on the characterisation of specific forearm muscles by means of intramuscular electromyography during the performance of ADL and grasps. Part of the results from the stay are found in Chapter 6, and others were presented in several international conferences but are not included in this thesis.

\section{Structure}

The chapters of the thesis can be structured in two parts, according to two clearly different objectives:

Chapters 1 to 3 make up the first part, related to the main objective of deepening the kinematic characterisation of the hand. These chapters are intended to contribute on two main aspects: firstly, trying to improve the current biomechanical hand models and, secondly, using methods of dimensional reduction to find kinematic patterns and study the temporal evolution of these patterns as a basis for characterizing hand kinematics during ADL. This part is structured in three chapters that summarise the results of a set of studies corresponding to international papers and communications in national and international conferences, as detailed in Table 0.2.

1. Contributions on obtaining rotation axes

2. Contributions on hand kinematic reduction (I): An application to power and precision grasps postures

3. Contributions on hand kinematic reduction (II): application to ADL using temporal data

Chapter 1 summarises the results of three studies submitted to international and national conferences, focused on obtaining accurate rotation axes of metacarpophalangeal and interphalangeal joints of the hand, considered as 2 and 1 DoF joints, respectively, with the aim of improving existing hand biomechanical models. The applied methods use reflective markers on the skin and a robust optimisation method for locating the axes parameters. The parametric representation of the axes location using common hand anthropometric parameters is also studied. The studies evaluate the goodness of the results of using the applied methods in comparison with those obtained when using the simplifications commonly considered in most hand kinematic models. 
Chapter 2 corresponds exactly to a paper published in the Applied Ergonomics journal that presents a method of kinematics dimensional reduction for all joints of the hand, and explores its use for the analysis of power and precision grasps of cylinders.

Finally, in Chapter 3, the temporal data from the kinematics reduction method presented in the second chapter is used for characterising the hand kinematics during a wide set of representative ADL by means of studying the temporal evolution of kinematic patterns. The study is being prepared to be published to the IEEE Transactions on Neural Systems and Rehabilitation Engineering.

Chapters 4 to 8 make up the second part, related to the main objective of deepening the knowledge of the role of forearm and hand muscles for developing ADL. This part is structured in five chapters that summarise the results of a set of studies that in some cases correspond exactly to international papers published or under revision, or, in other cases, merge and/or deepen communications presented in conferences, as detailed in Table 0.2. Specifically, the following objectives were pursued, with objectives 5 to 8 identified from the review established as $4^{\text {th }}$ objective:

4. Characterisation of the electromyography of the hand in ADL: state of art

5. Identification of forearm skin zones with similar muscle activation patterns during ADL

6. Contribution of forearm muscles to different grasp types

7. A database of hand kinematics and forearm EMG during ADL

8. Relationship between kinematic and muscular activity of the hand during ADL.

Chapter 4 reviews the state of art about electromyography characterisation of the hand during ADL: it provides a basis of knowledge about the hand and forearm muscles role and muscle synergy extraction of the upper limb. Some of the most important gaps that were identified have been addressed in the following chapters.

Chapter 5 corresponds exactly to a paper published in the Journal of NeuroEngineering and Rehabilitation. This chapter addresses one of the main gaps found in the state of art: the lack of consensus when selecting the areas to record sEMG from the forearm muscles. Therefore, this chapter aims to establish the minimum number of areas of the forearm to be considered when recording sEMG in order to characterise the forearm muscular activity during ADL without losing much relevant information. To do this, I identified forearm areas with similar muscle activation (sEMG) patterns during a set of ADL by means of functional PCA and cluster analysis.

Another gap found in the literature concerns the lack of representativeness of the tasks used for the EMG characterisation. Most studies found in the literature are focused on studying the role of specific muscles during simple tasks. Therefore, looking for representativeness of ADL performance, Chapter 6 aims to study the forearm muscles role during the performance of the most used grasps in ADL. This goal was addressed 
from two different approaches: by means of intramuscular EMG, and using sEMG on the forearm areas identified in the previous chapter. The first study was possible thanks to the collaboration with the Shirley Ryan AbilityLab in Chicago (USA), and my short stay there. The first study was presented in the XL Congreso de la sociedad Ibérica de Biomecánica y Biomateriales and the last study is in preparation to be submitted to IEEE Transactions on Neural Systems and Rehabilitation Engineering.

As previously mentioned, most studies found in the literature are focused on studying the role of specific muscles during simple tasks (hand postures or free finger movements), during single activities (such as writing or typing), or during small sets of very controlled activities (few grasps, sport movements...). However, only few studies deal with the analysis of the forearm and hand muscles during ADL, none of them consider a wide representative set of standardised ADL. In addition, simultaneous measurement of hand kinematics is not usually performed, so that linked EMG-kinematic datasets, at hand level, are still lacking. Hence, Chapter 7 aims to provide a database of simultaneous sEMG and kinematics data recorded during the performance of a representative set of realistic and standardised ADLs. The dataset consists of 572 recordings performed on 22 subjects while performing a representative set of 26 standardised ADL. Each record contains kinematics data from 18 hand DoF (flexions and abductions of the fingers and thumb, and wrist flexion and radioulnar deviation movements), provided as anatomical angles, and muscle activity (sEMG) data from the seven representative spots identified in Chapter 5, properly normalised and easily reproducible (following the procedure presented there). The study is under review in Scientific Data Journal.

Finally, few studies have attempted a relationship between hand kinematics and muscle activation, since establishing that link is not straightforward. The existing studies have focused on the analysis of specific muscles for developing few grasping movements in a very controlled environment, so that the results don't resemble and can't be extrapolated to functional activities. Therefore, little is known about the contribution of muscle activation and hand kinematics patterns and their relation to the performance of ADL. Hence, Chapter 8 aims to establish an insight into the relationships between hand kinematics and forearm muscle activity, by using the aforementioned database (Chapter 7). Although it is a preliminary study, the results glimpse some of the existing difficulties.

Table 0.2 List of chapters and their corresponding publications

\begin{tabular}{|c|c|c|}
\hline Title & Publication & Authors \\
\hline \multicolumn{3}{|c|}{ Chapter 1. Contributions on obtaining rotation axes } \\
\hline $\begin{array}{l}\text { Kinematic modelling of index } \\
\text { metacarpophalangeal joint }\end{array}$ & $\begin{array}{l}\text { Communication to the } 21 \text { st Congress } \\
\text { of the European Society of } \\
\text { Biomechanics (ESB). } 2015\end{array}$ & $\begin{array}{l}\text { N. Jarque-Bou, } \\
\text { J. L. Sancho Bru, } \\
\text { A. Pérez-González, } \\
\text { M. Vergara }\end{array}$ \\
\hline
\end{tabular}

Kinematic and muscular characterisation of the hand during ADL 


\begin{tabular}{|c|c|c|}
\hline Title & Publication & Authors \\
\hline $\begin{array}{l}\text { Determining the position and } \\
\text { orientation of rotation axes of } \\
\text { interphalangeal joints from skin } \\
\text { markers }\end{array}$ & $\begin{array}{l}\text { Communication to the 22nd Congress } \\
\text { of the European Society of } \\
\text { Biomechanics (ESB). } 2016\end{array}$ & $\begin{array}{l}\text { N. Jarque-Bou, } \\
\text { J. L. Sancho Bru, } \\
\text { M. Vergara } \\
\text { A. Pérez-González, } \\
\text { A. Roda-Sales, } \\
\text { S. Mestre-Vicent }\end{array}$ \\
\hline $\begin{array}{l}\text { Determinación paramétrica de los } \\
\text { ejes de rotación de las } \\
\text { articulaciones interfalángicas de } \\
\text { los dedos }\end{array}$ & $\begin{array}{l}\text { Communication to the XXI Congreso } \\
\text { Nacional de Ingeniería Mecánica. } \\
2016\end{array}$ & $\begin{array}{l}\text { N. Jarque-Bou, } \\
\text { J. L. Sancho Bru, } \\
\text { M. Vergara } \\
\text { A. Pérez-González, } \\
\text { A. Roda-Sales, } \\
\text { S. Mestre-Vicent }\end{array}$ \\
\hline \multicolumn{3}{|c|}{ Chapter 2. Contributions on hand kinematic reduction (I): } \\
\hline $\begin{array}{l}\text { Using kinematic reduction for } \\
\text { studying grasping postures. An } \\
\text { application to power and precision } \\
\text { grasp of cylinders }\end{array}$ & $\begin{array}{l}\text { Paper published in Applied } \\
\text { Ergonomics. 2016; 56:52-61. doi: } \\
\text { 10.1016/j.apergo.2016.03.003. }\end{array}$ & $\begin{array}{l}\text { N. Jarque-Bou, } \\
\text { V. Gracia-Ibáñez, } \\
\text { J.L. Sancho-Bru, } \\
\text { M. Vergara, } \\
\text { A. Pérez-González, } \\
\text { F.J. Andrés }\end{array}$ \\
\hline \multicolumn{3}{|c|}{$\begin{array}{l}\text { Chapter 3. Contributions on hand kinematic reduction (II): } \\
\text { Application to activities of daily living using temporal data }\end{array}$} \\
\hline $\begin{array}{l}\text { Hand kinematic characterisation } \\
\text { during ADL through kinematics } \\
\text { reduction }\end{array}$ & $\begin{array}{l}\text { Paper in preparation to be submitted to } \\
\text { IEEE Transactions on Neural Systems } \\
\text { and Rehabilitation Engineering }\end{array}$ & $\begin{array}{l}\text { N. Jarque-Bou, } \\
\text { J.L. Sancho-Bru, } \\
\text { M. Vergara, } \\
\text { V. Gracia-Ibáñez, } \\
\text { A. Roda-Sales }\end{array}$ \\
\hline \multicolumn{3}{|c|}{$\begin{array}{l}\text { Chapter 4. Characterisation of the electromyography of the hand } \\
\text { in activities of daily living: state of art }\end{array}$} \\
\hline \multicolumn{3}{|c|}{$\begin{array}{l}\text { Chapter 5. Identification of forearm skin zones with similar muscle activation patterns during } \\
\text { activities of daily living }\end{array}$} \\
\hline $\begin{array}{l}\text { Identification of forearm skin } \\
\text { zones with similar muscle } \\
\text { activation patterns during } \\
\text { activities of daily living }\end{array}$ & $\begin{array}{l}\text { Paper published in Journal of } \\
\text { NeuroEngineering and Rehabilitation, } \\
2018 \text { 15:91. doi: } 10.1186 / \text { s12984-018- } \\
0437-0\end{array}$ & $\begin{array}{l}\text { N. Jarque-Bou, } \\
\text { M. Vergara, } \\
\text { J.L. Sancho-Bru, } \\
\text { A. Roda-Sales, } \\
\text { V. Gracia-Ibáñez } \\
\end{array}$ \\
\hline \multicolumn{3}{|c|}{ Chapter 6. Contribution of forearm muscles to different grasp types } \\
\hline $\begin{array}{l}\text { Forearm muscular contribution in } \\
\text { different grasps }\end{array}$ & $\begin{array}{l}\text { Paper in preparation to be submitted to } \\
\text { IEEE Transactions on Neural Systems } \\
\text { and Rehabilitation Engineering }\end{array}$ & $\begin{array}{l}\text { N. Jarque-Bou, } \\
\text { M. Vergara, } \\
\text { J.L. Sancho-Bru, } \\
\text { V. Gracia-Ibáñez, } \\
\text { A. Roda-Sales }\end{array}$ \\
\hline $\begin{array}{l}\text { Analysis of specific muscular } \\
\text { contribution in different grasps }\end{array}$ & $\begin{array}{l}\text { Communication to the XL Congreso de } \\
\text { la sociedad Ibérica de Biomecánica y } \\
\text { Biomateriales. } 2017\end{array}$ & $\begin{array}{l}\text { N. Jarque-Bou, } \\
\text { A. Adkins, } \\
\text { V. Darbhe, } \\
\text { M. Vergara, } \\
\text { W. Murray, } \\
\text { J.L. Sancho-Bru }\end{array}$ \\
\hline
\end{tabular}

Kinematic and muscular characterisation of the hand during ADL 
A database of hand kinematics and forearm EMG during ADL

\section{Other publications and congresses}

Apart from the publications that integrate this thesis, I contributed in the development of other articles or congress communications related to the research presented in the thesis. They are listed in Table 0.3 .

Table 0.3 Other publications and congresses that the author took part during the development of the thesis

\begin{tabular}{|c|c|}
\hline \multicolumn{2}{|r|}{ Other publications and congresses } \\
\hline Paper & $\begin{array}{l}\text { A. Roda Sales, M. Vergara, J. L. Sancho Bru, V. Gracia Ibáñez, N. J. Jarque } \\
\text { Bou. Human hand kinematic data during feeding and cooking tasks } \\
\text { Scientific Data. Vol. 6. pp. 1-10. } 2019 .\end{array}$ \\
\hline Paper & $\begin{array}{l}\text { N.J. Jarque Bou, A. Scano, M. Atzori, H. Müller. (2019). Kinematic } \\
\text { synergies of hand grasps: a comprehensive study on a large publicly } \\
\text { available dataset. Journal of NeuroEngineering and Rehabilitation. Vol. } 16 . \\
\text { pp. 2-14. }\end{array}$ \\
\hline Paper & $\begin{array}{l}\text { A. Roda Sales, M. Vergara, J.L. Sancho Bru, V. Gracia Ibáñez, N.J. Jarque } \\
\text { Bou (2019). Effect of assistive devices on hand and arm posture during } \\
\text { activities of daily living. Applied Ergonomics. Vol. 76. pp. 64-72. }\end{array}$ \\
\hline Congress & $\begin{array}{l}\text { V. Gracia Ibáñez, M. Vergara, J.L. Sancho Bru, A. Roda Sales, N.J. Jarque } \\
\text { Bou (2019). Kinematic synergies of Sollerman hand function test. } \\
\text { 25th Congress of the ESB 2019. Vienna (Àustria). }\end{array}$ \\
\hline Congress & $\begin{array}{l}\text { N. J. Jarque Bou, J. L. Sancho Bru, M. Vergara ., M. Atzori, H. Müller, A. } \\
\text { Scano (2019). Kinematic synergies of hand grasps. 25th Congress of the } \\
\text { European Society of Biomechanics (ESB 2019). Vienna (Àustria) }\end{array}$ \\
\hline Congress & $\begin{array}{l}\text { V. Gracia Ibáñez, J.L. Sancho Bru, M. Vergara, A. Roda Sales, N.J. Jarque } \\
\text { Bou. (2018). Sollerman Hand Function Test: estudio cinemático en base a } \\
\text { acciones de vida diaria. VIII Reunión del Capítulo Español de la Sociedad } \\
\text { Europea de Biomecánica. Castellón (Spain). }\end{array}$ \\
\hline Congress & $\begin{array}{l}\text { N.J. Jarque Bou, V. Gracia Ibáñez, M. Vergara, J.L. Sancho Bru. (2018). } \\
\text { Estudio de la función de los músculos del antebrazo durante AVD. VIII } \\
\text { Reunión del Capítulo Español de la Sociedad Europea de Biomecánica } \\
\text { (ESB). Castellón (Spain) }\end{array}$ \\
\hline Congress & $\begin{array}{l}\text { N.J. Jarque Bou, A. Adkins, V. Darhbe, V. Gracia Ibáñez, W. Murray, M. } \\
\text { Vergara, J.L. Sancho Bru. (2018). Exploration of the role of forearm } \\
\text { muscles during activities of daily living. 27th Annual meeting of the } \\
\text { European Society for Movement Analysis in Adults and Children (ESMAC } \\
\text { 2018). Prague (Czech Republique). }\end{array}$ \\
\hline
\end{tabular}




\begin{tabular}{|c|c|}
\hline Congress & $\begin{array}{l}\text { N.J. Jarque Bou, M. Vergara, J.L. Sancho Bru. (2018). Identification of } \\
\text { optimum spots for recording EMG by using functional principal } \\
\text { component analysis and clustering. 8th World Congress of Biomechanics } \\
\text { (WCB 2018). Dublin (Ireland). }\end{array}$ \\
\hline Congress & $\begin{array}{l}\text { F.J. Andrés de la Esperanza, C. Cunha-Matos, N.J. Jarque Bou, J L. Sancho } \\
\text { Bru, A. Buis, S. Day. (2017). Evaluation of a motion tracking model of the } \\
\text { upper limb, including the hand. XIII Congresso Ibero-americano de } \\
\text { Ingeniería Mecánica. Lisboa (Portugal). }\end{array}$ \\
\hline Congress & $\begin{array}{l}\text { N.J. Jarque Bou, J.L. Sancho Bru, M. Vergara. (2017). Distribución de la } \\
\text { actividad muscular del antebrazo en actividades de la vida diaria. XIII } \\
\text { Congresso Ibero-americano de Ingeniería Mecánica. Lisboa (Portugal). }\end{array}$ \\
\hline Congress & $\begin{array}{l}\text { J.L. Sancho Bru, M. Vergara, N.J. Jarque Bou, V. Gracia Ibáñez. (2017). } \\
\text { Simulación de sinergias cinemáticas para el control intuitivo de prótesis } \\
\text { de mano. XIII Congresso Ibero-americano de Ingeniería Mecánica. Lisboa } \\
\text { (Portugal). }\end{array}$ \\
\hline Congress & $\begin{array}{l}\text { N.J. Jarque Bou, J.L. Sancho Bru, M. Vergara, S. Wohlman, M. de Bruin, W. } \\
\text { Murray. (2016). Synergy-based characterisation of kinematics and EMG } \\
\text { of the thumb during reaching. 23rd Congress of the European Society of } \\
\text { Biomechanics. Sevilla (Spain). }\end{array}$ \\
\hline Congress & $\begin{array}{l}\text { N.J. Jarque Bou, M. Vergara, J. L. Sancho Bru. Caracterización de la } \\
\text { cinemática de la mano y de la actividad EMG durante AVD. (2016). VI } \\
\text { Reunión del Capítulo Español de la Sociedad Europea de Biomecánica. } \\
\text { Badajoz (Spain). }\end{array}$ \\
\hline Congress & $\begin{array}{l}\text { J.L. Sancho Bru, M. Bruin, S. Wohlman, W. Murray, N.J. Jarque Bou. } \\
\text { Feasibility of the Intuitive Control of Hand Prostheses through } \\
\text { Dimensional Kinematics Reduction. 7th World Congress of Biomechanics } \\
\text { (WCB 2014). Boston, Massachussetts (USA). }\end{array}$ \\
\hline Congress & $\begin{array}{l}\text { J.L. Sancho Bru, N.J. Jarque Bou, W. Murray. Factibilidad del control } \\
\text { intruitivo de prótesis de mano diestras mediante reducción cinemática } \\
\text { dimensional. XX Congreso Nacional de Ingeniería Mecánica (CNIM 2014). } \\
\text { Málaga (Spain). }\end{array}$ \\
\hline Congress & $\begin{array}{l}\text { A. Pérez González, N.J. Jarque Bou, F. J. Andrés de la Esperanza, J.L. } \\
\text { Sancho Bru. Distribución de las presiones de contacto en la mano humana } \\
\text { en el agarre de objetos cilíndricos. XX Congreso Nacional de Ingeniería } \\
\text { Mecánica (CNIM 2014). Málaga (Spain). }\end{array}$ \\
\hline Congress & $\begin{array}{l}\text { N.J. Jarque Bou, J.L. Sancho Bru, A. Pérez González. Influencia del peso y } \\
\text { diámetro del objetivo sobre la postura de agarre, mediante reducción } \\
\text { dimensional de la cinemática de la mano. III Reunión del Capítulo } \\
\text { Nacional Español de la Sociedad Europea de Biomecánica (ESB). Barcelona } \\
\text { (Spain). }\end{array}$ \\
\hline Congress & $\begin{array}{l}\text { J.L. Sancho Bru, M. Vergara, N.J. Jarque Bou, A. Pérez González, F.J. } \\
\text { Andrés de la Esperanza. Human grasp kinematics reduction: influence of } \\
\text { the size and weight of the grasped object. 19th Congress of the European } \\
\text { Society of Biomechanics (ESB 2013). Patrass (Greece). }\end{array}$ \\
\hline
\end{tabular}

Kinematic and muscular characterisation of the hand during ADL 



\section{CHAPTER 1}

Contributions on obtaining rotation axes 

This chapter corresponds to three studies submitted to international and national conferences, focused on obtaining accurate rotation axes of metacarpophalangeal and interphalangeal joints of the hand, considered as 2 and 1 degrees of freedom joints, respectively, with the aim of improving existing hand biomechanical models.

\subsection{Abstract \& keywords}

In this chapter, I focused on obtaining accurate rotation axes of metacarpophalangeal and interphalangeal joints of the hand with the aim of improving current hand biomechanical models. I presented a novel and robust mathematical method to obtain the orientation and position of the axes of rotation by using reflective markers on the skin. This aim is undertaken through the development of three studies: 1) Using the novel method to evaluate a model for the index metacarpophalangeal joint with two non-intersecting and non-orthogonal rotation axes in comparison with a classic universal joint model. 2) To check the repeatability of a modification (improved set of markers) of the proposed method for estimating rotation axes location, when using it for estimating the rotation axes of the interphalangeal joints of the index finger, and also to check the goodness of considering the rotation axes parallel to the flexion/extension creases. 3) To locate the rotation axes of the interphalangeal joints of all the fingers, and analyse their possible parametric presentation from common anthropometric parameters of the hand.

From the different studies, I may conclude that: 1) the kinematics of the metacarpophalangeal joint can be described accurately with a model consisting of two non-orthogonal and non-intersecting rotation axes that should be taken into account when implementing biomechanical models. 2) Considering the interphalangeal rotation axes parallel to the flexion/extension creases is not a good assumption. 3.1) The center of the rotation axes of the interphalangeal joints are at approximately null longitudinal distance from the joint centers and at a depth from dorsal surface than can be obtained from the thickness of the joints. 3.2) Anatomical variability between subjects has been observed in the inclination of the interphalangeal rotation axes, which seems to be addressed using a finite number of types of biomechanical models. However, more accurate techniques are needed for obtaining reliable data for the improvement of the existing biomechanical models, since the inclination angles are of the same order of magnitude as the errors.

Keywords: axes location, hand joints, reflective markers, rotation axes, joint mathematical model 


\subsection{Introduction}

Grasping and manipulation skills of the hands are key for the development of activities of daily living (ADL) of the human being. An essential part of this capacity lies in the kinematic complexity of the hand, with 25 predominant degrees of freedom (DoF) (Brand and Hollister, 1999). Several researchers have developed biomechanical models of the human hand to simulate different aspects related to grasp and manipulation (Sancho-Bru et al., 2003; Valero-Cuevas, 2000; Vigouroux et al., 2011b; Wu et al., 2010). Biomechanical models allow analysing problems that cannot be analysed directly in people, or that would have a high experimental cost. Specifically, the biomechanical simulation of grasps is interesting for the study of new alternatives for the restoration of hand pathologies, to clarify the functionality of different anatomical elements and causes and effects of pathologies, to simulate neuromuscular abnormalities, to plan rehabilitation, or to simulate transferences of tendons, among others. On the contrary, ergonomic hand models are used to study the adaptability of the size and shape of the objects to the different anthropometry of the potential users that will interact with them.

The quality of the results obtained from the use of biomechanical and ergonomic models will especially depend on the adequacy of the kinematic model considered. From the kinematic point of view, the hand is usually considered as consisting of five skeletal chains, corresponding to each one of the fingers, all of them joined to the carpus or wrist. In these chains, the bones are connected to one another by the joint surfaces and soft structures, mainly consisting of the joint capsule and ligaments. These elements restrict the relative movement between the bone segments. The combined action of the restrictions imposed by the shape of the joint surfaces in contact and by the restrictions incorporated by the soft structures defines the kinematic behaviour of each joint.

The movement of the hand joints is usually described in the clinical and biomechanical fields as a combination of flexion/extension (F/E), and abduction/adduction (Ab/Ad) movements. The interphalangeal (IP) joints of the fingers are trochlear, thus basically allowing a predominant DoF (corresponding to $\mathrm{F} / \mathrm{E}$ ), and are commonly modelled as revolute joints with a fixed axis of rotation. The carpometacarpal (CMC) joint of the thumb (saddle joint) and the metacarpophalangeal (MCP) joints (condylar joints) allow F/E and Ab/Ad movements, being usually modelled as universal joints, with two fixed axes of rotation perpendicular to each other (Cerveri et al., 2007; Cobos et al., 2008; Dragulescu et al., 2007; Harris and Dias, 2003; Lee and Kunii, 1995; Stillfried and van der Smagt, 2010). However, there are more complex kinematic descriptions of the MCP, e.g., tilting the ab/ad hinge 20/30 from that of the universal joint (Brand and Hollister, 1999), or adding a third supination-pronation hinge (Berme et al., 1977). Several studies have proposed that considering two fixed non-intersecting and not perpendicular rotation axes would be more appropriate (Brand and Hollister, 1999): one axis would remain fixed with respect to the proximal bone, and the other with respect to the distal bone, so that the position and orientation of the second one is a function of 
the angle rotated about the first one. This is equivalent to considering two revolute joints connected by a virtual rigid link (Figure 1.1).

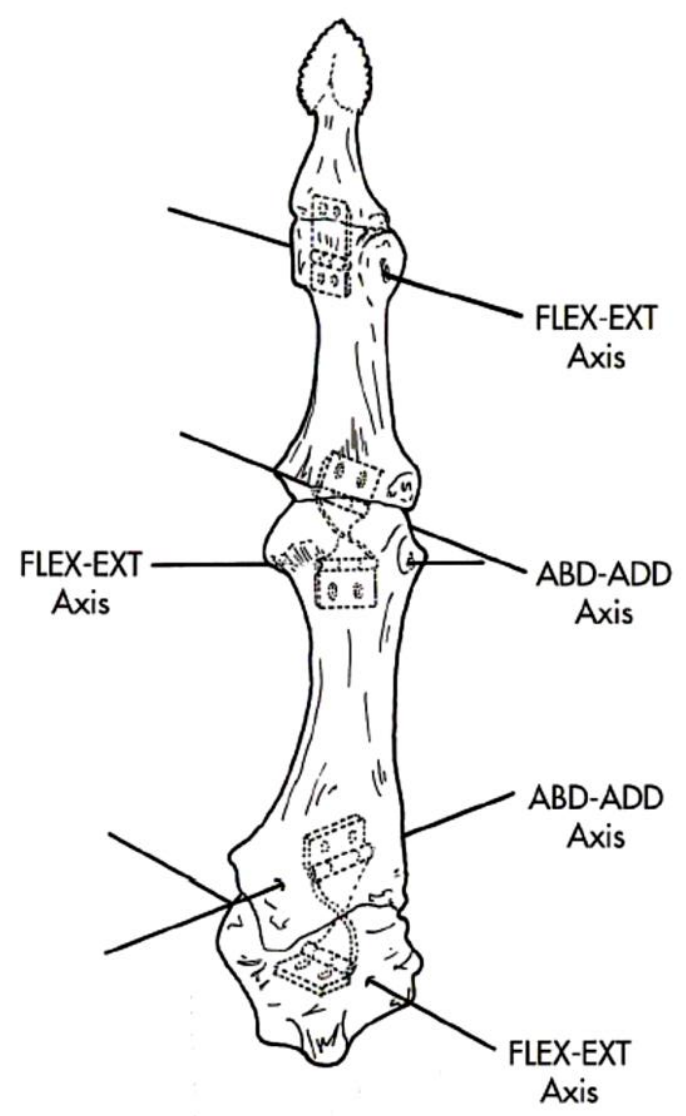

Figure 1.1 Thumb rotation axes, according to (Brand and Hollister, 1999)

Some researchers have studied different aspects related to the kinematics of the hand joints. It is especially interesting the proposal of Santos and collaborators (Santos and Valero-Cuevas, 2006) regarding thumb kinematics, who states that the anatomical variability between subjects can be undertaken considering a finite number of biomechanical models. The consideration of the variability between subjects requires obtaining particularised rotation axes in vivo. One possibility is obtaining the rotation axes from data of magnetic resonance imaging (MRI) techniques. A simple method is to estimate the axis position from the centre of curvature of the bone head (Berme et al., 1977; Chao et al., 1976). More recently, optimisation techniques have been used with precision errors ranging from 0.7 to $2 \mathrm{~mm}$ (Cerveri et al., 2010; Stillfried and Hillenbrand, 2014). As for IP joints, studies based on the MRI analysis report inclinations of about $14^{\circ}$ between the rotation axes of the proximal (PIP) and distal (DIP) interphalangeal joints of the middle finger (Miyata et al., 2005). It has been also reported that the rotation axes of the IP joints are not parallel to the F/E axes of the MCP joints (Tsai et al., 2011), and that they experience small changes in their orientation during $\mathrm{F} / \mathrm{E}$ movements (Casolo and Lorenzi, 1994; Miyata et al., 2005). Some studies (Brand and Hollister, 1999) also state 
that the axes are approximately parallel to the F/E creases existing on the palm of the hand.

However, in the absence of specific data that define the locations and orientations of the different rotation axes, recent biomechanical and ergonomic models continue considering rotation axes perpendicular to the segments. Despite the corroborated evidence that the results of these models can vary significantly with the inclination of the rotation axes (Sancho-Bru et al., 2001; Valero-Cuevas, 2000).

As MRI technique is not available in all laboratories, other more common techniques have been tested for axis location. Cerveri et al (Cerveri et al., 2008) estimated the position and orientation of the two rotation axes (non-orthogonal and nonintersecting) of the CMC joint in vivo, by tracking reflective markers located on the skin, with intra-subject repeatability errors of less than $5 \mathrm{~mm}$ in the location of the axes and less than $6^{\circ}$ in their orientation. Therefore, although the errors are greater than those obtained through the use of MRI, it is an alternative to be considered to obtain the position and orientation of the axes of the remaining joints of the fingers (MCP and IP joints).

The objective of this chapter is to study the in vivo location and orientation of the rotation axes of the finger joints by using reflective markers on the skin. This is undertaken through the development of three studies, presented in the following sections, with these specific objectives:

- To propose a robust method for obtaining rotation axes, and using it to evaluate a model for the index MCP joint with 2 non-intersecting and non-orthogonal rotation axes (NINO model), in comparison with a classic universal joint model. (N. Jarque-Bou, J.L. Sancho-Bru, A. Pérez, M. Vergara. Kinematic modelling of index MCP. 21st Congress of the European Society of Biomechanics (ESB). Prague (Czech Republic), 2015).

- To check the repeatability of a modification of the proposed method for estimating rotation axes location (improved set of markers), when using it for estimating the rotation axes of the IP joints (1DoF) of the index finger. And also to check the goodness of considering the rotation axes parallel to the F/E creases. (N. JarqueBou, J.L. Sancho-Bru, M. Vergara, A. Pérez, A. Roda-Sales, S. Mestre-Vicent, Determining the position and orientation of rotation axes of interphalangeal joints from skin markers. 22nd Congress of the European Society of Biomechanics. Lyon (France), 2016).

- To locate the rotation axes of the IP joints of the fingers, and analyse their possible parametric presentation from the analysis of correlations with common anthropometric parameters of the hand. (N. Jarque-Bou, J.L Sancho-Bru, M. Vergara, A. Pérez, A. Roda-Sales, S. Mestre-Vicent. Determinación paramétrica de los ejes de rotación de las articulaciones interfalángicas de los dedos XXI Congreso Nacional de Ingeniería Mecánica. Elche (Spain),2016) 


\subsection{Kinematic modelling of index metacarpophalangeal joint}

In order to evaluate a model for the index MCP joint with 2 non-intersecting and non-orthogonal rotation axes (NINO model), an experiment for the index finger has been performed, comparing the proposed model to a classic universal joint (UJ) model.

\section{Methods}

\section{Experiment description}

Three subjects (two male and one female subjects), free of hand pathologies, participated in the experiment, after providing written consent. A Vicon ${ }^{\circledR}$ system was used to track 12 markers (Figure 1.2): 4 spherical landmarks (CMC2, MCP2, MCP3 and PIP2) and 8 semi-spherical tracking markers on each segment (metacarpal and proximal phalange). The landmarks were used to define the coordinate systems (CSs) of the segments. Both CSs were defined with origin on MCP2, Y-axes aligned with the segments, pointing distally, and X-axes defined by the normal vector of the YZ-plane, which was set by CMC2, MCP2 and MCP3 for the metacarpal, and by PIP2, MCP2 and MCP3 for the phalange. Finally, Z-axes were set perpendicular to both Y-axes and Xaxes, pointing radially. $\mathrm{XY}$ axes defined the sagittal plane; $\mathrm{ZX}$ the transverse plane; and YZ the frontal plane.

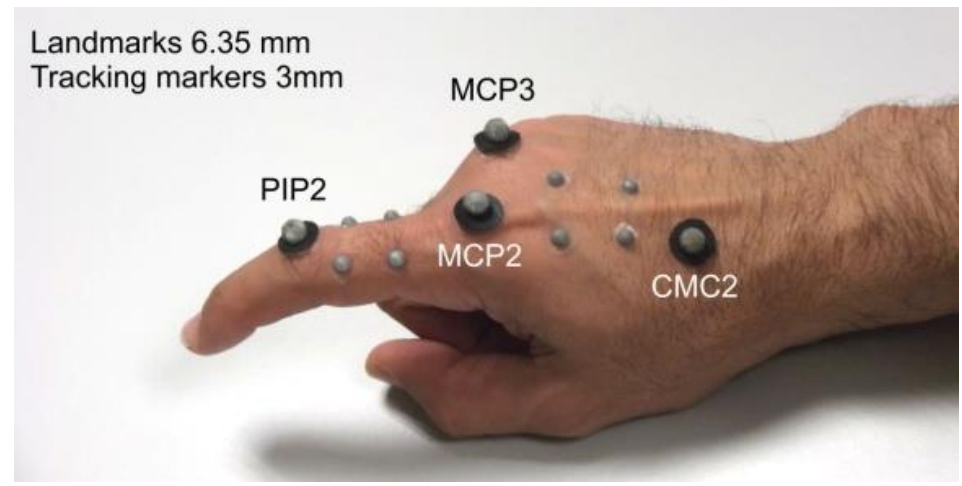

Figure 1.2 Four landmarks and 8 tracking markers

The subjects were seated in front of a table, with the elbow at table height and the arm resting on it in a relaxed position, and the static reference posture was recorded (flat hand with phalanges and metacarpals aligned) with all the markers (tracking and landmarks) attached to the finger (Figure 1.3, A). After removing the landmarks, three different movements of the MCP joint were recorded: 1 trial for the MCP F/E movement, starting from the maximum MCP extension and up to maximum MCP flexion (Figure 1.3, B); 1 trial for the MCP Ab/Ad movement, with IP joints of the index finger completely extended and starting from maximum radial deviation up to maximum ulnar deviation (Figure 1.3, C); and 1 trial for the circumduction movement in counterclockwise direction (movement of the index finger so that the distal end of the finger describes a circle in counter-clockwise while the proximal end of the finger remains fixed) 
(Figure 1.3, D). The subjects were asked to perform the movements at a moderate speed and trying to achieve their maximum range of motion. Each subject was measured in two different sessions and two of them performed three different repetitions of each movement in one of the sessions.
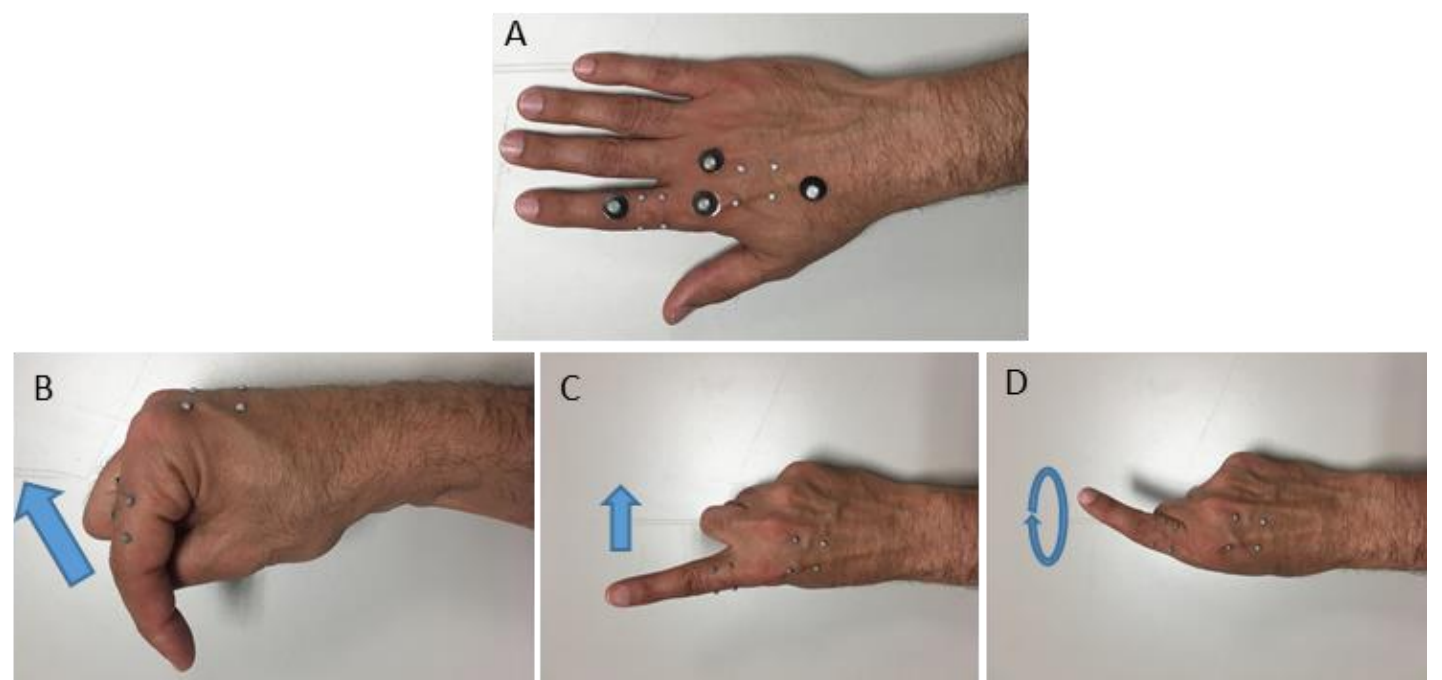

Figure 1.3 A: Reference posture recorded; B: MCP F/E movement; $C$ : MCP Ab/Ad movement; $D$ : circumduction movement in counter-clockwise direction

In addition, 5 static postures (grasping a cone, and the American Sign Language letters A, O, V, \& R) were recorded (Figure 1.4) because they bring the fingers into most of their available range of motion (Jerde et al. 2003). The recorded 3D coordinates were filtered with a $2^{\text {nd }}$ order Butterworth low pass filter with a cut-off frequency of $10 \mathrm{~Hz}$.

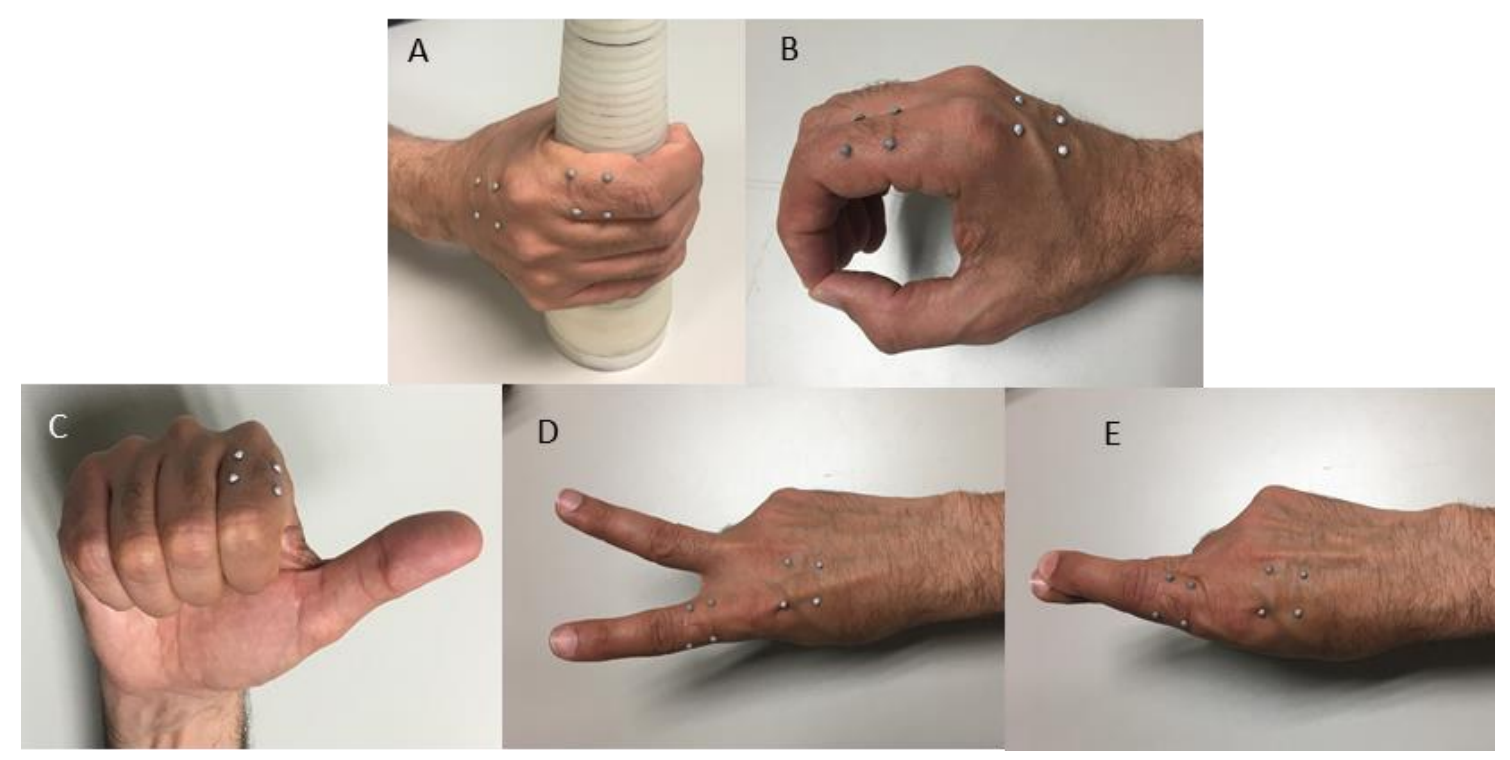

Figure 1.4 Five static postures performed. A: grasping a cone; B: American Sign Language letter A; C: American Sign Language letter O; D: American Sign Language letter V; E: American Sign Language letter $R$ 


\section{Location of NINO rotation axes and calculation of joint angles}

The non-intersecting and non-orthogonal (NINO) model considers an F/E axis attached to the metacarpal bone (proximal segment), and an Ab/Ad axis attached to the proximal phalange (distal segment).

Appendix I contains the complete method for obtaining the position and orientation of the joint axes of the hand. The location of the $\mathrm{F} / \mathrm{E}$ axis with respect to the proximal segment was described by 4 parameters (Appendix I, Figure A.2): coordinates of the intersection of the axis with the sagittal plane $\left(T_{x}\right.$ and $\left.T_{y}\right)$; and the inclination angles with the frontal and transversal planes $\left(\alpha_{f}\right.$ and $\left.\alpha_{t}\right)$ of the metacarpal CS. Analogously, the location of the Ab/Ad axis with respect to the distal segment was described by the coordinates of the intersection of the axis with the frontal plane $\left(T_{x}\right.$ and $\left.T_{y}\right)$; and the inclination angles with the frontal and sagittal planes $\left(\alpha_{f}\right.$ and $\left.\alpha_{s}\right)$ (Appendix I, Figure A.3).

To obtain these 8 parameters, the three dynamic trials were used. Reference posture was used to define a neutral posture allowing the calculation of rotation angles comparable between different sessions and subjects. For computational efficiency, only ten frames were considered for each $\mathrm{F} / \mathrm{E}$ and $\mathrm{Ab} / \mathrm{Ad}$ cycle, and 20 for the circumduction cycle, equidistant along the whole movement. At each time, the experimental transformation matrices between the proximal and distal segments were obtained from the 3D coordinates of the tracking markers of both segments, using the method based on the singular value decomposition presented by Söderkvist in a previous work (Söderkvist and Wedin, 1993). Finally, the axis parameters, together with the joint angles at each frame, were obtained by matching the experimental transformation matrices to the ones computed with the proposed model (see Appendix I). This was achieved using the evolutionary optimisation method (CMAES) presented by Hansen and Kern in a previous study (Hansen and Kern, 2004). This method is a robust stochastic method (it avoids local minimums) based on the principle of biological evolution, where in each generation the new candidate solutions (offspring) are obtained from considering a variation of the current ones (parents), becoming parents of new solutions. For the generation of new solutions (children) a normal distribution is considered, and the mutations are introduced by adaptation of the covariance matrix (Figure 1.5). 


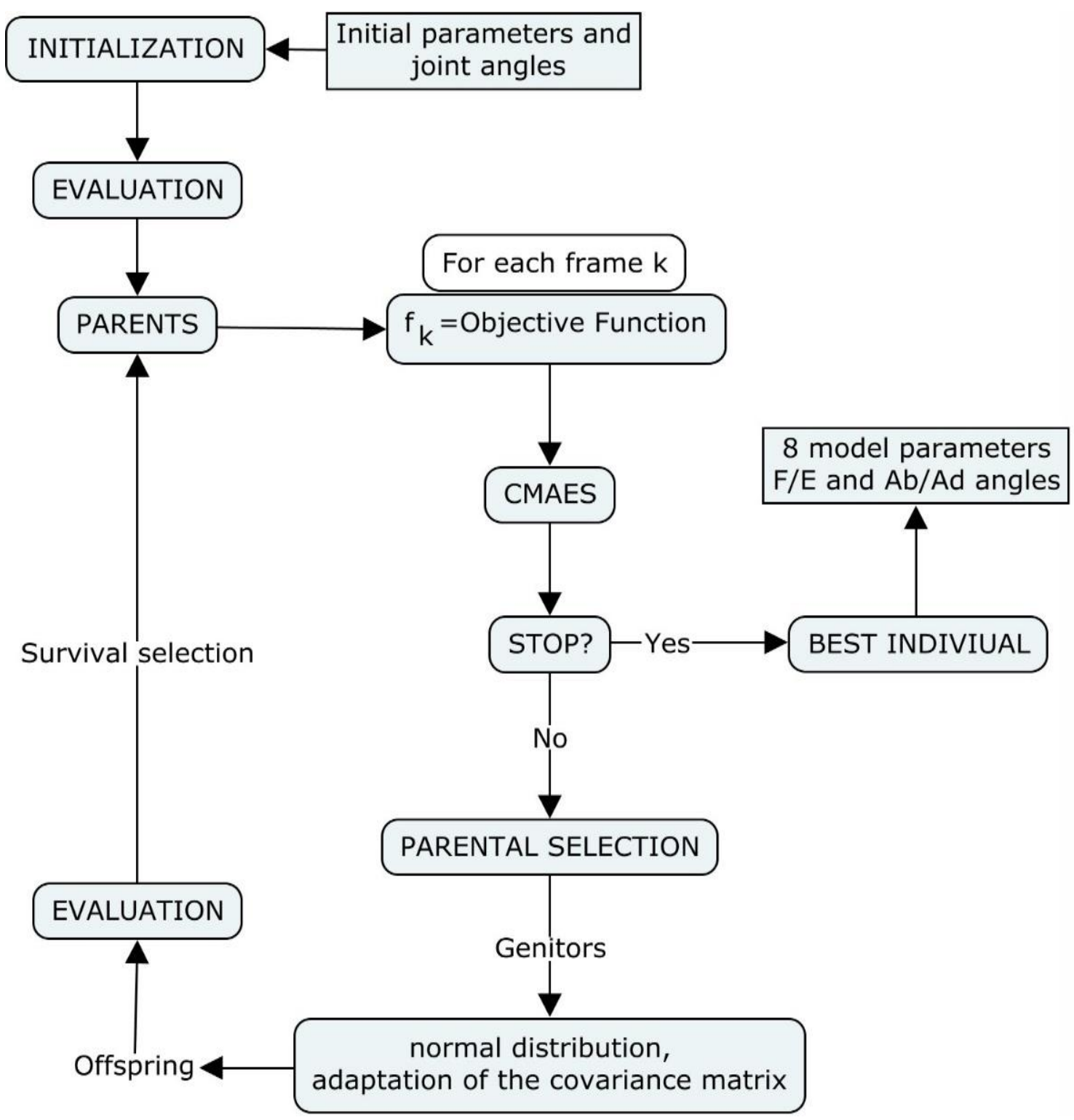

Figure 1.5 Flowchart of the evolutionary optimisation method to obtain the final parameters and joint angles

The flowchart shown in Figure 1.5 describes the procedure for obtaining the 8 model parameters. The objective function to be minimised (Equation 1) using the CMAES method was the mean across frames of the RMSE at each frame $k$ between the elements of the model transformation matrix $\left(\mathrm{M} \_\right.$model $_{\mathrm{k}}$, matching the mathematical model proposed) and the experimental transformation matrix (M_experimental $\mathrm{k}_{\mathrm{k}}$, calculated from the tracking markers). The transformation matrices consisted of the 9 elements of the rotation matrix and 3 elements of the displacement vector (Cerveri et al., 2001), with the distances in $\mathrm{cm}$, in order to have a similar order of magnitude between elements of rotation matrix and displacement vector. 


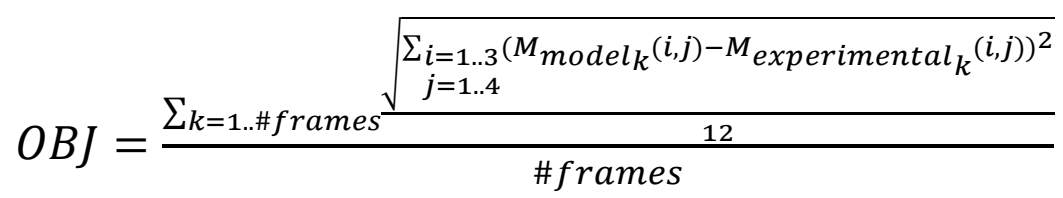

Twenty offspring solutions were considered from each parent solution, 5 parents to be considered in the next generation, and normal distribution with variance value of 2 for the generation of the solutions.

Finally, once the model parameters were obtained, joint angles for each frame were obtained from these model parameters by matching the experimental transformation matrices to the ones computed with the proposed model at each frame. In addition, the same procedure was performed to obtain the joint angles for the 5 additional static postures recorded.

\section{Calculation of joint angles with UJ model}

Universal joint (UJ) model (Sancho-Bru et al., 2014) axes used were defined as follows: a CS for the index finger metacarpal (proximal CS) was defined with the Y axis as the vector pointing from the distal to the proximal metacarpal markers (CMC2, MCP2). The $\mathrm{X}$ axis was obtained by forcing the markers of the metacarpal (CMC2, MCP2) and the marker on the knuckle of the middle finger (MCP3) to lay on the plane $X=0$. And the $\mathrm{Z}$ axis was the cross product between the $\mathrm{X}$ and $\mathrm{Y}$ axes. For the index finger phalange (distal CS), the $\mathrm{Y}$ axis was the vector pointing from the distal to the proximal phalange markers (PIP2, MCP2). The $\mathrm{X}$ axis was obtained by forcing the markers of the phalange (PIP2, MCP2) and the marker MCP3 to lay on the plane $\mathrm{X}=0 . \mathrm{Z}$ axis was the cross product between $\mathrm{X}$ and $\mathrm{Y}$ axes. The axes of the proximal CS were considered coincident with the rotation axes: $\mathrm{Z}$ axis corresponding to $\mathrm{F} / \mathrm{E}$ and $\mathrm{X}$ axis to $\mathrm{Ab} / \mathrm{Ad}$. Finally, the rotation angles at MCP joint were obtained by calculating the rotation angles between the distal $\mathrm{CS}$ and proximal CS according to Euler convention with sequence Z-X-Y axes.

This procedure was applied to calculate the joint angles for the same frames of the dynamic records used for obtaining the parameters of the NINO model, and also to calculate the joint angles for the 5 additional static postures recorded.

\section{Data analysis}

The 8 axes parameters describing the NINO model were calculated for each subject/repetition/session. Intra-session and inter-session repeatability errors for each parameter were computed as the RMSEs in two ANOVAs on the parameters with factor 'subject x session' and 'subject', respectively. 
The effect of the joint model (NINO vs UJ) on the recorded joint angles computed was analysed through the comparison of joint angles computed for each frame of the dynamic trials and for the 5 additional static postures (grasping a cone, and the American Sign Language letters A, O, V, \& R). The RMS of the differences across subjects, repetitions and sessions for $\mathrm{F} / \mathrm{E}$ and $\mathrm{Ab} / \mathrm{Ad}$ angles were computed for each static posture, and across subjects, repetitions, sessions and frames for the dynamic trials.

\section{Results}

Optimisation took about two hours for each of the analyses performed. The maximum of the values of the objective function calculated across subjects, sessions and repetitions was 0.052 .

The model parameters computed for each subject and session/repetition are shown in Table 1.1. Different values are observed between subjects, and also between repetitions and sessions for a given subject, finding the greater differences for the inclination angles of the $\mathrm{Ab} / \mathrm{Ad}$ axis.

Table 1.1 Model parameters obtained for each subject: Tx and Ty in $m m, \alpha_{f}, \alpha_{t}$ and $\alpha_{s}$ in degrees

\begin{tabular}{|c|c|c|c|c|c|c|c|c|c|c|}
\hline \multirow[b]{2}{*}{ subject } & \multirow[b]{2}{*}{ session } & \multirow[b]{2}{*}{ Rep } & \multicolumn{4}{|c|}{ F/E axis } & \multicolumn{4}{|c|}{$\mathrm{Ab} / \mathrm{Ad}$ axis } \\
\hline & & & $T x$ & Ty & $\alpha_{\mathrm{f}}$ & $\alpha_{t}$ & $T x$ & Ty & $\alpha_{\mathrm{f}}$ & $\alpha_{s}$ \\
\hline 1 & 1 & 1 & -10.07 & 3.64 & 0.87 & -4.27 & -13.87 & 0.53 & -50.56 & -30.94 \\
\hline 1 & 2 & 1 & -8.24 & 4.15 & -6.15 & -5.75 & -17.14 & 4.11 & -69.49 & -16.61 \\
\hline 2 & 1 & 1 & -7.74 & 4.98 & -17.67 & -10.23 & -16.97 & 2.28 & -71.91 & -15.85 \\
\hline 2 & 1 & 2 & -8.53 & 5.32 & -13.18 & -8.66 & -17.19 & 4.97 & -64.11 & -21.02 \\
\hline 2 & 1 & 3 & -11.19 & 4.36 & 2.10 & -2.85 & -16.34 & 5.56 & -61.99 & -23.37 \\
\hline 2 & 2 & 1 & -8.15 & 3.71 & -18.11 & -10.66 & -15.85 & -2.69 & -77.75 & -11.22 \\
\hline 3 & 1 & 1 & -10.22 & 4.66 & -13.22 & 0.52 & -15.04 & 2.71 & -94.17 & -4.07 \\
\hline 3 & 1 & 2 & -10.31 & 4.64 & -23.95 & -6.02 & -15.47 & 2.67 & -57.18 & -22.95 \\
\hline 3 & 1 & 3 & -7.33 & 2.53 & -32.19 & -13.98 & -14.92 & 3.41 & -106.68 & -16.34 \\
\hline 3 & 2 & 1 & -9.10 & 5.45 & -21.77 & -4.58 & -15.85 & -2.69 & -29.79 & -57.21 \\
\hline
\end{tabular}

Intra-session and inter-session errors are shown in Table 1.2. Maximum repeatability errors of $3.23 \mathrm{~mm}$ are found for the coordinate parameters and $24^{\circ}$ for the inclination angles, which are bigger for the Ab/Ad axis. 
Table 1.2 Intra-session and inter-session repeatability errors

\begin{tabular}{c|c|c|c} 
& Parameter & Intra-session error & Inter-session error \\
\hline \multirow{4}{*}{ F/E axis } & Tx $(\mathrm{mm})$ & 1.75 & 1.45 \\
& Ty $(\mathrm{mm})$ & 0.93 & 0.95 \\
& $\alpha_{\mathrm{f}}\left(^{\circ}\right)$ & 9.95 & 8.25 \\
& $\alpha_{\mathrm{t}}\left({ }^{\circ}\right)$ & 5.82 & 4.60 \\
\hline \multirow{3}{*}{$\mathrm{Ab} / \mathrm{Ad}$ axis } & $\mathrm{Tx}(\mathrm{mm})$ & 0.37 & 1.00 \\
& $\mathrm{Ty}(\mathrm{mm})$ & 1.27 & 3.23 \\
& $\alpha_{\mathrm{f}}\left(^{\circ}\right)$ & 18.57 & 24.00 \\
& $\alpha_{\mathrm{s}}\left({ }^{\circ}\right)$ & 7.30 & 15.79 \\
\hline
\end{tabular}

Joint angles obtained for the 5 static postures are shown in Table 1.3 together with the RMS differences between NINO and UJ models for F/E and Ab/Ad angles. The mean RMS across static postures were $8.17^{\circ}$ and $9.45^{\circ}$, for $\mathrm{F} / \mathrm{E}$ and $\mathrm{Ab} / \mathrm{Ad}$ angles respectively. In addition, the mean across subjects of the RMS difference for the 40 frames used in the axes search (dynamic trials), were $11.66^{\circ}$ for $\mathrm{F} / \mathrm{E}$ and $10.04^{\circ}$ for $\mathrm{Ab} / \mathrm{Ad}$ angles.

Table 1.3 Joint angles of static postures $\left({ }^{\circ}\right)$ between subjects (Subj), sessions (Sess) and repetitions (Rep).

\begin{tabular}{|c|c|c|c|c|c|c|c|c|c|}
\hline Subj & Sess & Rep & & Model & Cone & $\mathbf{A}$ & O & $\mathbf{V}$ & $\mathbf{R}$ \\
\hline \multirow{4}{*}{1} & \multirow{4}{*}{1} & \multirow{4}{*}{1} & \multirow{2}{*}{$\mathrm{F} / \mathrm{E}$} & NINO & 58.85 & 47.33 & 78.18 & 1.59 & -11.34 \\
\hline & & & & UJ & 62.14 & 49.91 & 74.20 & 10.48 & -0.64 \\
\hline & & & \multirow{2}{*}{$\mathrm{Ab} / \mathrm{Ad}$} & NINO & 10.45 & 7.35 & 0.15 & -5.35 & 12.62 \\
\hline & & & & UJ & 12.25 & 7.89 & -0.13 & -13.37 & 15.32 \\
\hline \multirow{4}{*}{1} & \multirow{4}{*}{2} & \multirow{4}{*}{1} & \multirow{2}{*}{$\mathrm{F} / \mathrm{E}$} & NINO & 42.62 & 47.21 & 98.97 & -9.96 & -4.45 \\
\hline & & & & UJ & 38.81 & 45.59 & 86.26 & 0.10 & 1.47 \\
\hline & & & \multirow{2}{*}{$\mathrm{Ab} / \mathrm{Ad}$} & NINO & 5.35 & 4.85 & 0.71 & 1.00 & 6.74 \\
\hline & & & & UJ & 8.42 & 7.36 & 7.13 & -8.49 & 15.50 \\
\hline \multirow{4}{*}{2} & \multirow{4}{*}{1} & \multirow{4}{*}{1} & \multirow[b]{2}{*}{$\mathrm{F} / \mathrm{E}$} & NINO & 60.07 & 70.02 & 89.42 & 26.21 & 9.24 \\
\hline & & & & UJ & 53.28 & 63.02 & 78.80 & 27.57 & 10.08 \\
\hline & & & \multirow{2}{*}{$\mathrm{Ab} / \mathrm{Ad}$} & NINO & -1.04 & 2.13 & 0.55 & 13.13 & -3.61 \\
\hline & & & & UJ & 3.07 & 1.15 & -1.36 & -10.01 & 15.65 \\
\hline \multirow{4}{*}{2} & \multirow{4}{*}{1} & \multirow{4}{*}{2} & \multirow{2}{*}{$\mathrm{F} / \mathrm{E}$} & NINO & 58.29 & 72.98 & 86.80 & -4.93 & 9.93 \\
\hline & & & & UJ & 50.91 & 63.86 & 80.36 & 2.44 & 13.69 \\
\hline & & & \multirow{2}{*}{$\mathrm{Ab} / \mathrm{Ad}$} & NINO & -0.21 & -3.60 & -2.93 & $\overline{5.86}$ & 9.16 \\
\hline & & & & UJ & -1.78 & 0.21 & -2.30 & -1.52 & 16.97 \\
\hline \multirow{4}{*}{2} & \multirow{4}{*}{1} & \multirow{4}{*}{3} & \multirow{2}{*}{$\mathrm{F} / \mathrm{E}$} & NINO & 32.51 & 63.00 & 73.73 & 7.87 & 0.75 \\
\hline & & & & UJ & 53.91 & 60.25 & 78.90 & 20.37 & 8.44 \\
\hline & & & \multirow[b]{2}{*}{$\mathrm{Ab} / \mathrm{Ad}$} & NINO & -31.15 & -11.46 & -11.59 & -3.13 & -13.51 \\
\hline & & & & UJ & 7.68 & 2.68 & -1.70 & -3.24 & 17.09 \\
\hline \multirow{4}{*}{2} & \multirow{4}{*}{2} & \multirow{4}{*}{1} & \multirow{2}{*}{$\mathrm{F} / \mathrm{E}$} & NINO & 64.59 & 72.02 & 90.72 & 11.69 & 7.13 \\
\hline & & & & UJ & 53.49 & 61.97 & 78.26 & 16.70 & 8.25 \\
\hline & & & \multirow{2}{*}{$\mathrm{Ab} / \mathrm{Ad}$} & NINO & 8.69 & 9.21 & 10.28 & -1.20 & 15.72 \\
\hline & & & & $\mathrm{UJ}$ & 6.49 & 9.34 & 0.31 & -2.78 & 22.96 \\
\hline
\end{tabular}

Kinematic and muscular characterisation of the hand during ADL 


\begin{tabular}{|c|c|c|c|c|c|c|c|c|c|}
\hline Subj & Sess & Rep & & Model & Cone & A & O & $\mathbf{V}$ & $\mathbf{R}$ \\
\hline \multirow{4}{*}{3} & \multirow{4}{*}{1} & \multirow{4}{*}{1} & \multirow{2}{*}{$\mathrm{F} / \mathrm{E}$} & NINO & 41.83 & 42.15 & 80.56 & 9.79 & 5.43 \\
\hline & & & & UJ & 51.47 & 48.30 & 78.25 & 16.55 & 15.95 \\
\hline & & & \multirow{2}{*}{$\mathrm{Ab} / \mathrm{Ad}$} & NINO & 12.82 & 12.38 & 12.36 & -1.25 & 18.76 \\
\hline & & & & UJ & 19.57 & 14.10 & 11.90 & -7.81 & 19.88 \\
\hline \multirow{4}{*}{3} & \multirow{4}{*}{1} & \multirow{4}{*}{2} & \multirow{2}{*}{$\mathrm{F} / \mathrm{E}$} & NINO & 34.90 & 46.11 & 56.25 & -0.80 & 18.75 \\
\hline & & & & UJ & 52.71 & 52.85 & 62.23 & 8.04 & 32.49 \\
\hline & & & \multirow{2}{*}{$\mathrm{Ab} / \mathrm{Ad}$} & NINO & 19.39 & 8.03 & 8.63 & 1.48 & 19.52 \\
\hline & & & & UJ & 20.96 & 13.34 & 14.10 & -11.36 & 24.40 \\
\hline \multirow{4}{*}{3} & \multirow{4}{*}{1} & \multirow{4}{*}{3} & \multirow{2}{*}{$\mathrm{F} / \mathrm{E}$} & NINO & 39.19 & 45.06 & 78.00 & 8.45 & 4.30 \\
\hline & & & & UJ & 44.81 & 48.83 & 81.58 & 16.58 & 5.83 \\
\hline & & & \multirow{2}{*}{$\mathrm{Ab} / \mathrm{Ad}$} & NINO & 13.57 & 13.63 & 18.89 & -3.85 & 14.53 \\
\hline & & & & UJ & 20.59 & 17.36 & 13.20 & -8.11 & 21.38 \\
\hline \multirow{4}{*}{3} & \multirow{4}{*}{2} & \multirow{4}{*}{1} & \multirow{2}{*}{$\mathrm{F} / \mathrm{E}$} & NINO & 40.22 & 46.72 & 90.58 & 0.69 & 8.66 \\
\hline & & & & UJ & 48.46 & 49.19 & 83.30 & 12.31 & 13.21 \\
\hline & & & \multirow{2}{*}{$\mathrm{Ab} / \mathrm{Ad}$} & NINO & 9.08 & 5.69 & 13.00 & -4.39 & 12.28 \\
\hline & & & & UJ & 14.19 & 8.41 & 4.00 & -13.55 & 14.79 \\
\hline & \multirow{2}{*}{ RMS } & & $\mathrm{F} / \mathrm{E}$ & & 11.03 & 5.95 & 7.88 & 8.62 & 7.40 \\
\hline & & & $\mathrm{Ab} / \mathrm{Ad}$ & & 12.92 & 5.24 & 6.21 & 10.28 & 12.58 \\
\hline
\end{tabular}

Figure 1.6 shows the joint angles during the 40 frames (10 frames for F/E, 10 for $\mathrm{Ab} / \mathrm{Ad}$ and 20 for circumduction) considered in the dynamic trials.

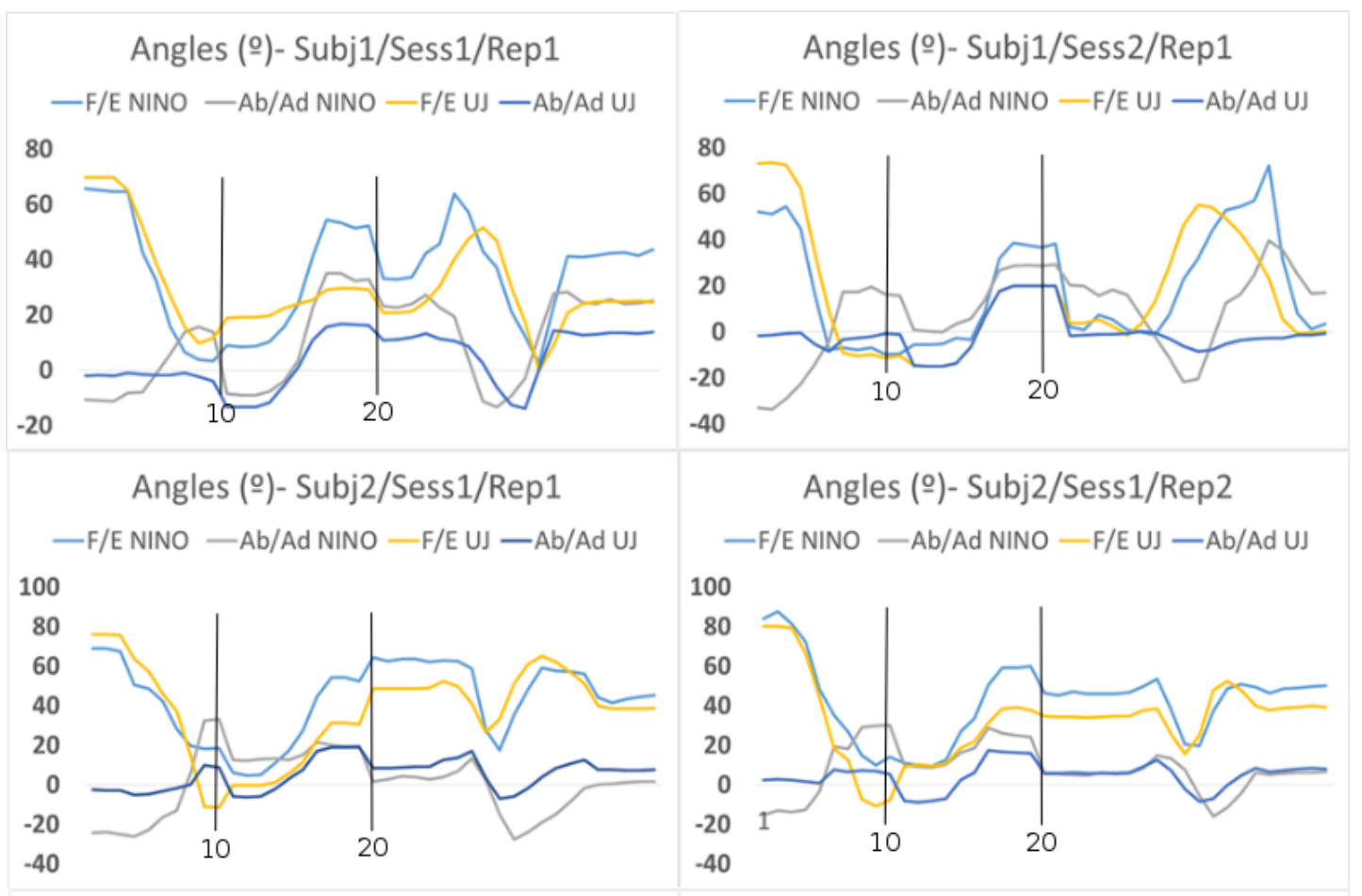

Kinematic and muscular characterisation of the hand during ADL 


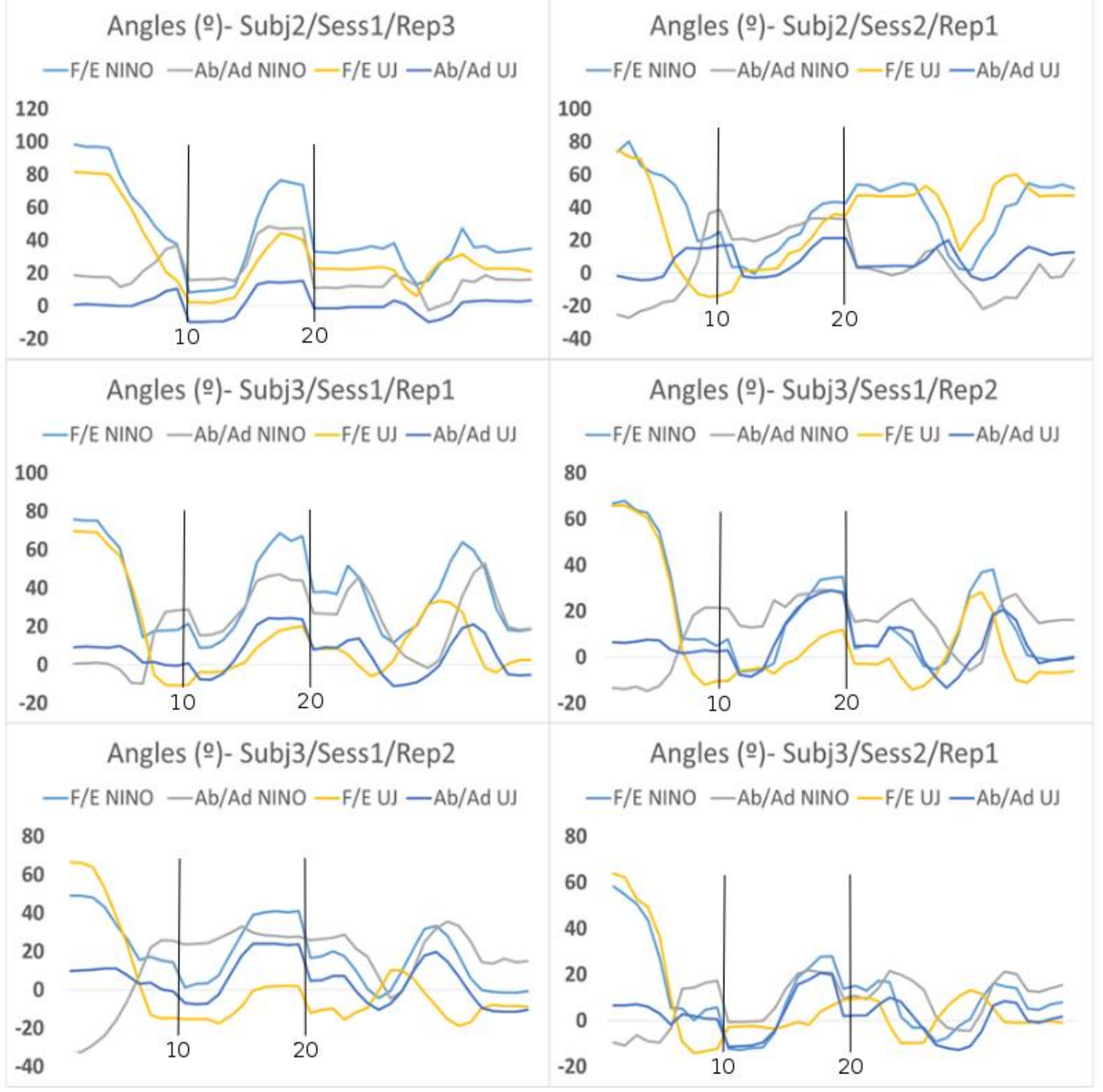

Figure 1.6 F/E and Ab/Ad angles for each subject (Subj), session (Sess) and repetition (Rep) during the 40 frames considered in the dynamic trials used in the axes search

\section{Discussion}

In this study, I checked a model for the index MCP joint with 2 non-intersecting and non-orthogonal rotation axes (NINO model). The NINO model reproduces the experimental kinematics of the index MCP joint with high accuracy (very low values for the objective function), and the orientation of the axes found differ considerably from those used by the universal joint model, and therefore, the angles obtained show notable differences (about $10^{\circ}$ ). Broadly speaking, F/E axes could have a slight inclination with the planes defined as frontal and transversal (approx. $10^{\circ}$ ). On the other hand, $\mathrm{Ab} / \mathrm{Ad}$ axes could have a greater inclination on the planes defined as frontal (approx. $60^{\circ}$ ) and sagittal (approx. $21^{\circ}$ ). Results are in accordance with others MCP models assumptions as the proposed by (Brand and Hollister, 1999), tilting the ab/ad hinge 20/30 from that of the universal joint.

Kinematic and muscular characterisation of the hand during ADL 
These differences could affect the estimation of muscles forces during the performance of ADL when using biomechanical models. The differences in the location of the axes may affect the moment arms of the different tendons that pass through the joint, and therefore the balances that the model use for the estimation of muscular efforts. Further research should quantify these effects when incorporating the NINO model into finger musculoskeletal models. In particular, it is interesting to analyse whether the NINO model may generate more realistic estimations of muscle activations, as the coactivation of interossei muscles for medial and lateral force production on the fingertip, which is not reproduced with the UJ model (Sancho-Bru et al., 2001).

However, the precision of the technique used (high intra-session and inter-session repeatability errors) is not enough to provide sufficiently accurate orientation data for the improvement of existing biomechanical models. It is suspected that part of the precision problems found may be due to repeatability problems associated with the placement of markers, both landmarks and tracking markers, but especially with relative motion of the tracking markers due to the skin movement and partial occlusion of these markers because of their size (small) and shape (semi-spherical). Also, the low amplitude of the Ab/Ad motion does not help for obtaining precise results.

The complexity of the optimisation problem, which produces large computational times, hinders the analysis of the error source. One solution to analyse the different sources of error is to address this analysis on joints with only $1 \mathrm{DoF}$, such as IP joints, which can simplify the procedure, making the analysis more intuitive, and with a more reduced computational time. Therefore, the following section investigates the repeatability when estimating the rotation axes of the IP joints (1DoF) of the index finger using a new set of markers (more repeatable and avoiding relative motion because of skin movement), and it also checks the goodness of considering the rotation axes parallel to the F/E creases. 


\subsection{Repeatability of rotation axes location of interphalangeal joints, and goodness of considering rotation axes parallel to flexion/extension creases}

An experiment for investigating the location of rotation axes of the interphalangeal joints of the index finger has been performed, with special emphasis in the repeatability provided by the selection of markers on the skin. It also checks the error of considering the rotation axes parallel to the F/E creases.

\section{Methods}

\section{Experiment description}

Four male and four female healthy subjects, free of hand pathologies, participated in the experiment, after providing written consent. The age of the subjects was controlled to avoid kinematic alterations due to the degeneration of the joints because of ageing (28.4 \pm 6.46 years). A Vicon ${ }^{\circledR}$ system with 8 infrared cameras was used to track 15 markers of $4 \mathrm{~mm}$ of diameter on the index finger (Figure 1.7) at $100 \mathrm{~Hz}$ : semi-spherical landmarks S1-S6 and spherical tracking markers P1-P9. Markers P1 to P9 were used for tracking the position and orientation of the segments, and markers S1 to S6 were used as landmarks to define the CS: S1-S2 were positioned midway between the dorsal and palmar finger sides, $5 \mathrm{~mm}$ proximal to the fingertip; S3-S6 at the apex of the F/E creases.

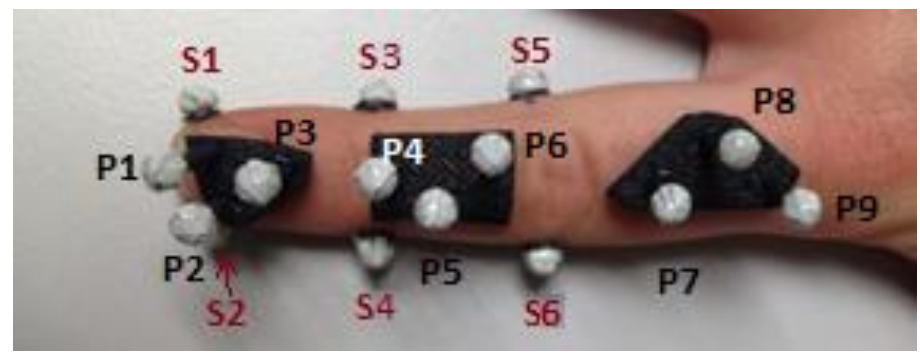

Figure 1.7 Landmarks S1-S6 \& tracking markers P1-P9

Unlike the previous section, elevated tracking markers (a base with three markers, Figure 1.8) were used to avoid hiding problems, and at the same time to ensure no relative motion between tracking markers despite the deformation of the skin during movement.

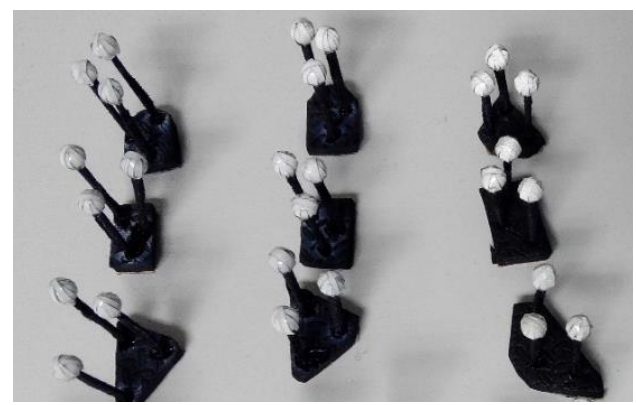

Figure 1.8 Set of bases with three markers used as tracking markers 
In addition, looking for more repeatable location of the landmarks, the endpoints of the creases (Figure 1.9) were considered in this case.

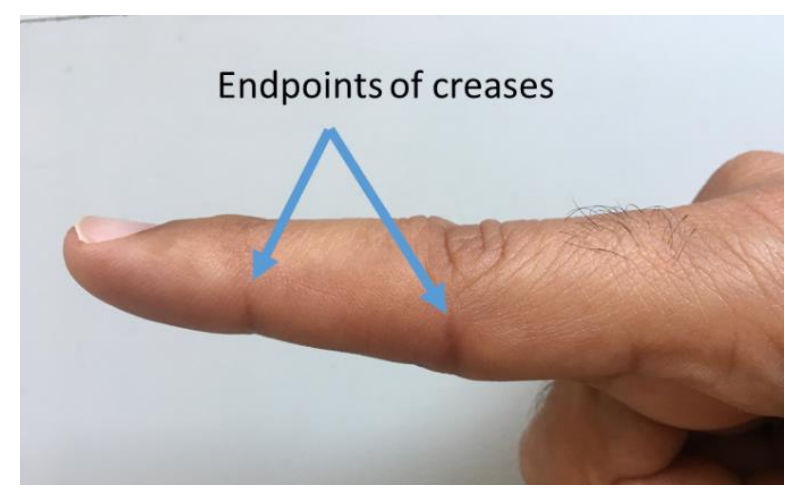

Figure 1.9 Endpoints of the F/E creases

Landmarks defined the CS with origin at the mid-points of S3-S4 and S5-S6, respectively for the DIP and PIP joints (Figure 1.10). Both CS of the medial and distal phalanges were coincident in the reference posture. Z-axes of distal and medial phalanges were defined by S3-S4 and S5-S6, respectively, pointing radially. X-axes were defined by plane YZ obtained by 3 markers: midpoint S1-S2, S3 and S4; and midpoint S3-S4, S5 and $\mathrm{S} 6$, respectively, pointing palmar. Y-axes were defined perpendicular to the $\mathrm{X}$-axes and Z-axes, pointing proximally.

DIP Coordinate system (CS)

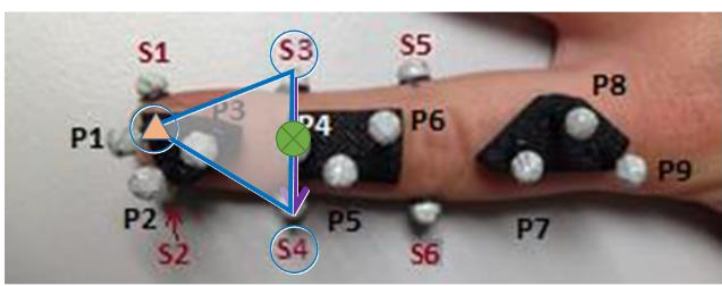

Plane $X=0$

$Z$ axis

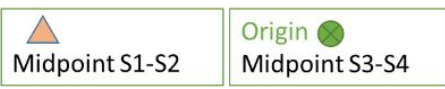

\section{PIP Coordinate system (CS)}

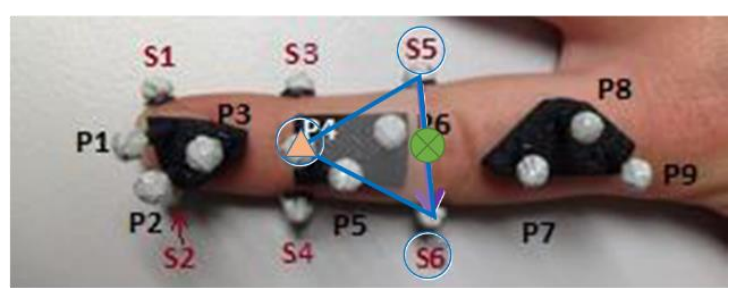

Plane $\mathrm{X}=0$

$\mathrm{Z}$ axis
Origin

Midpoint S5-S6

Figure 1.10 DIP and PIP coordinate systems definition

\section{Axes location}

F/E axis location was described, as in the previous section 1.3, by 4 parameters: coordinates of the intersection of the axis with the sagittal plane $\left(T_{x}\right.$ and $\left.T_{y}\right)$; and the inclination angles with respect to the frontal and transversal planes ( $\alpha_{f}$ and $\left.\alpha_{t}\right)$ (Appendix I, Figure A.2).

To obtain the 4 parameters defining each axis location, 1 dynamic trial (with only the tracking markers) with 75 frames (from fully flexed to fully extended posture) and a 
reference posture (flat hand with both tracking markers and landmarks) were used. For each frame, the segment transformation matrices were obtained from the tracking markers as in previous section (Section 1.3), using the method presented by (Söderkvist and Wedin, 1993). The parameters were calculated within the evolutionary optimisation approach (Hansen and Kern, 2004) analogously to the method explained in the previous section (Section 1.3), by minimizing the mean across frames of the RMSE at each frame $k$ between the elements of the model transformation matrix $\left(\mathrm{M}_{-}\right.$model $_{\mathrm{k}}$, matching the mathematical model proposed) and the experimental transformation matrix (M_experimental $k_{k}$, calculated from the tracking markers) (Cerveri et al., 2008). The whole procedure was repeated three times in 3 different sessions, thus providing 9 different estimations of axes location per subject.

\section{Data analysis}

Intra-session and inter-session repeatability errors for the parameters describing each axis location were computed as the RMSEs in two ANOVAs on each axis parameter with factor 'subject $x$ session' and 'subject', respectively. Finally, the angles between the axes found and the Z-axes (defined by the creases) were calculated to check for the goodness of considering rotation axes parallel to the creases.

\section{Results}

Table 1.4 shows mean and SD values across subjects and repetitions of the axes location parameters, along with intra- and inter-session repeatability errors computed. Values for the angle between the F/E axis and the Z-axis (Angz) are also shown.

Table 1.4 Mean and SD values across subjects along with intra- and inter-session repeatability errors

\begin{tabular}{|c|c|c|c|c|c|c|}
\hline & \multicolumn{3}{|c|}{ PIP axis } & & \multicolumn{2}{|c|}{ DIP axis } \\
\hline & \multirow[b]{2}{*}{$\begin{array}{l}\text { Mean } \\
\text { (SD) }\end{array}$} & \multicolumn{2}{|l|}{ Error } & \multirow[b]{2}{*}{$\begin{array}{l}\text { Mean } \\
\text { (SD) }\end{array}$} & \multicolumn{2}{|c|}{ Error } \\
\hline & & $\begin{array}{l}\text { Intra } \\
\text { sess }\end{array}$ & $\begin{array}{l}\text { Inter } \\
\text { sess }\end{array}$ & & $\begin{array}{l}\text { Intra } \\
\text { sess }\end{array}$ & $\begin{array}{l}\text { Inter } \\
\text { sess }\end{array}$ \\
\hline $\mathrm{T}_{\mathrm{x}}(\mathrm{mm})$ & $\begin{array}{l}-4.75 \\
(2.33)\end{array}$ & 0.45 & 1.57 & $\begin{array}{l}-7.37 \\
(2.22)\end{array}$ & 0.54 & 1.60 \\
\hline $\mathrm{T}_{\mathrm{y}}(\mathrm{mm})$ & $\begin{array}{l}5.39 \\
(3.54)\end{array}$ & 0.61 & 2.13 & $\begin{array}{l}-2.53 \\
(2.75)\end{array}$ & 0.51 & 2.01 \\
\hline$\alpha_{\mathrm{f}}\left({ }^{\circ}\right)$ & $\begin{array}{l}-1.96 \\
(5.85)\end{array}$ & 1.53 & 3.72 & $\begin{array}{l}2.26 \\
(6.04)\end{array}$ & 1.20 & 4.14 \\
\hline$\alpha_{t}\left({ }^{o}\right)$ & $\begin{array}{l}6.65 \\
(4.33)\end{array}$ & 1.69 & 4.00 & $\begin{array}{l}-2.4 \\
(8.58)\end{array}$ & 2.43 & 7.23 \\
\hline $\operatorname{Ang}_{Z}\left(^{(o}\right)$ & $\begin{array}{l}10.81 \\
(5.21)\end{array}$ & 1.84 & 3.68 & $\begin{array}{l}9.01 \\
(6.18)\end{array}$ & 2.25 & 4.25 \\
\hline
\end{tabular}


For the location, mean coordinates in the range between 2 to $7 \mathrm{~mm}$ were obtained, with very small intra-session repeatability errors (less than $0.62 \mathrm{~mm}$ ), but with intersession errors of about $2 \mathrm{~mm}$.

For the orientation, mean rotation angles in the range between $2^{\circ}$ to $7^{\circ}$ were obtained, with very small intra-session repeatability errors (less than $2.44^{\circ}$ ), but with inter-session repeatability errors reaching $7^{\circ}$. Furthermore, I have shown that the angle between the rotation axis and $\mathrm{Z}$-axis defined by the FE creases is about $9^{\circ}$ and $11^{\circ}$, which would correspond to the errors of assuming the rotation axes parallel to these creases.

\section{Discussion}

Following the method proposed in previous section, I obtained the location of the rotation axes of the IP joints of the index finger of 8 healthy subjects. In this case, the set of markers considered provided very low repeatability errors, somewhat higher for the DIP rotation axis, probably due to a lower repeatability in the location of markers S1-S2 (these were the only markers not located on creases).

The SD values across subjects for the location parameters of the rotation axes are of the same order of magnitude in both joints, distal and proximal. These SD values are lower than $3 \mathrm{~mm}$ for the coordinate parameters, and lower than $7^{\circ}$ for the inclination ones.

In addition, using the F/E creases to approximate the orientation of PIP and DIP rotation axes would become into approximate errors of $11^{\circ}$ and $9^{\circ}$, respectively. These errors $\left(11^{\circ}\right.$ and $\left.9^{\circ}\right)$ are higher than the values of their repeatability errors (maximum values of $3.68^{\circ}$ and $4.65^{\circ}$ ). This fact lead me to conclude that assuming rotation axis parallel to $\mathrm{F} / \mathrm{E}$ creases is not enough to accurately represent the orientation data for the improvement of existing biomechanical models.

The repeatability of the technique has been improved by using this new set of tracking markers proposed in this section. Lowest reliability seems to correspond to the location of landmarks S1-S2. However, the landmarks used provide the location of the rotation axes on reference systems hardly comparable between subjects, with Z-axes parallel to $\mathrm{F} / \mathrm{E}$ creases. The landmarks used in the previous section require a less number of markers, are widely used in literature and makes easy the comparability of axes location between subjects. Therefore, in the next section, tracking markers similar to those proposed in this section are used, together with landmarks similar to those used in the previous section but with special care in their location repeatability. And using these markers, a study to locate the rotation axes of the IP joints of all the fingers is performed, focusing on analysing their parametric presentation from common anthropometric hand parameters. 


\subsection{In search of a parametric representation of the rotation axes of the interphalangeal joints of the fingers}

In order to locate the rotation axes of the IP joints of the fingers, an experiment for all the fingers has been performed, with special emphasis in analysing their possible parametric presentation from the analysis of correlations with common anthropometric parameters of the hand.

\section{Methods}

\section{Experiment description}

Thirty healthy subjects ( 22 men and 8 women), free of previous hand injuries or pathologies, participated in this experiment, approved by the Ethics Committee of the Universitat Jaume I. All subjects were properly informed and gave their written consent to participate in the experiment. The age of the subjects was controlled to avoid kinematic alterations due to degeneration of the joints because of ageing ( $33.5 \pm 9.3$ years). Subjects were selected to homogenously cover the range of hand sizes representative of the Spanish population (Vergara et al., 2016).

Common anthropometric parameters were measured to each subject (Figure 1.11): hand length $(\mathrm{H} L)$, hand breadth $(H B)$, fingers length $\left(L_{i}\right)$ and the thickness of each joint $\left(J T_{j}\right) . \quad L_{i}$ was measure from the centre of the head of the corresponding metacarpophalangeal joint of each finger.

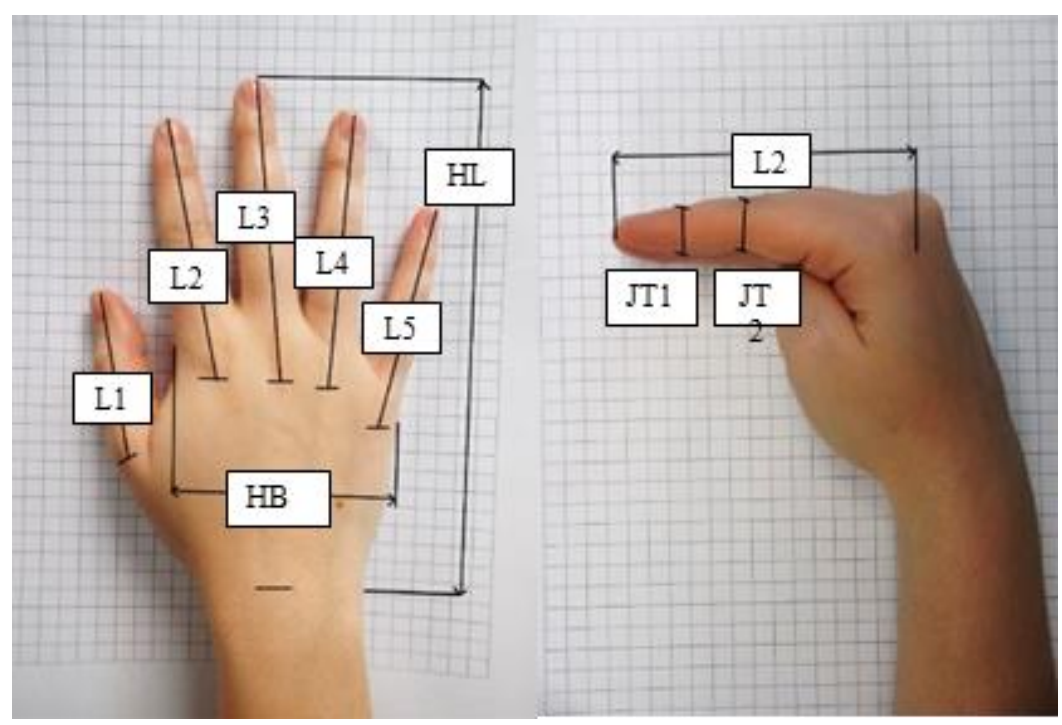

Figure 1.11. Anthropometric parameters measured for each subject

For each digit, the $3 \mathrm{D}$ coordinates of reflective markers were recorded at $100 \mathrm{~Hz}$ using a motion analysis system consisting of 8 infrared cameras (Vicon® Motion Systems Ltd., Oxford, United Kingdom). First, the operator placed the landmarks (one on each joint) and the tracking markers (a base with three markers on each phalange) on the back of the finger (Figure 1.12). 


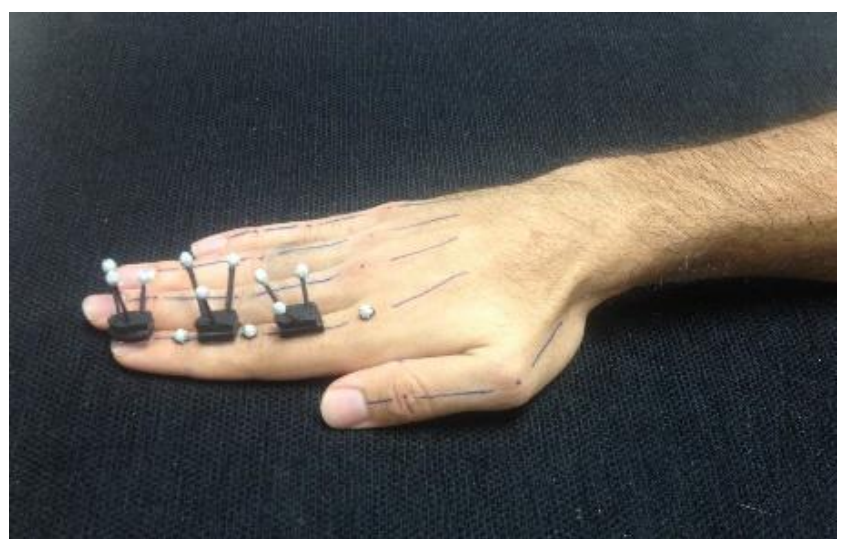

Figure 1.12 Reference posture with landmarks and tracking markers on the index finger

Special attention was paid to the placement of the landmarks: the longitudinal axes of both phalanges connected by the joint were drawn on the back; then, a manual goniometer (Figure 1.13) was placed on the drawn lines at a predetermined angle $\left(50^{\circ}\right.$ for the DIP and $70^{\circ}$ for the PIP joint), and the location for placing the marker was drawn on the back of the joint, as the point defined by the bisector of the angle.

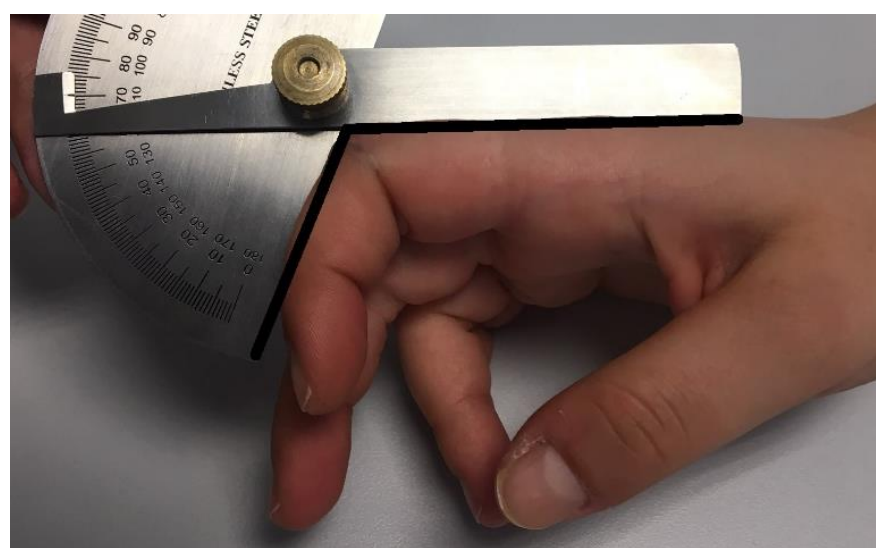

Figure 1.13 Manual goniometer used to drawn lines to locate markers

Secondly, the subject was seated in front of a table, with the elbow at table height and the arm resting on it in a relaxed position, and the static reference posture was recorded (the forearm and hand laying on the table, keeping the fingers close together, Figure 1.12) with all the markers (tracking and reference ones) attached to the finger. After removing the landmarks, a sequence of three F/E movements of the IP joints was recorded, each $\mathrm{F} / \mathrm{E}$ movement consisting of: starting from the fully extended finger (Figure 1.14, left.) and keeping the proximal phalange extended (static MCP joint), the subject was asked to flex the IP joints at a moderate speed until achieving their maximum flexion range (Figure 1.14, right), and afterwards to extend the IP joints until returning to the initial position (Figure 1.14, left). The whole process was repeated for all digits, 
including the thumb. The recorded $3 \mathrm{D}$ coordinates were filtered with a $2^{\text {nd }}$ order Butterworth low pass filter with a cut-off frequency of $10 \mathrm{~Hz}$.

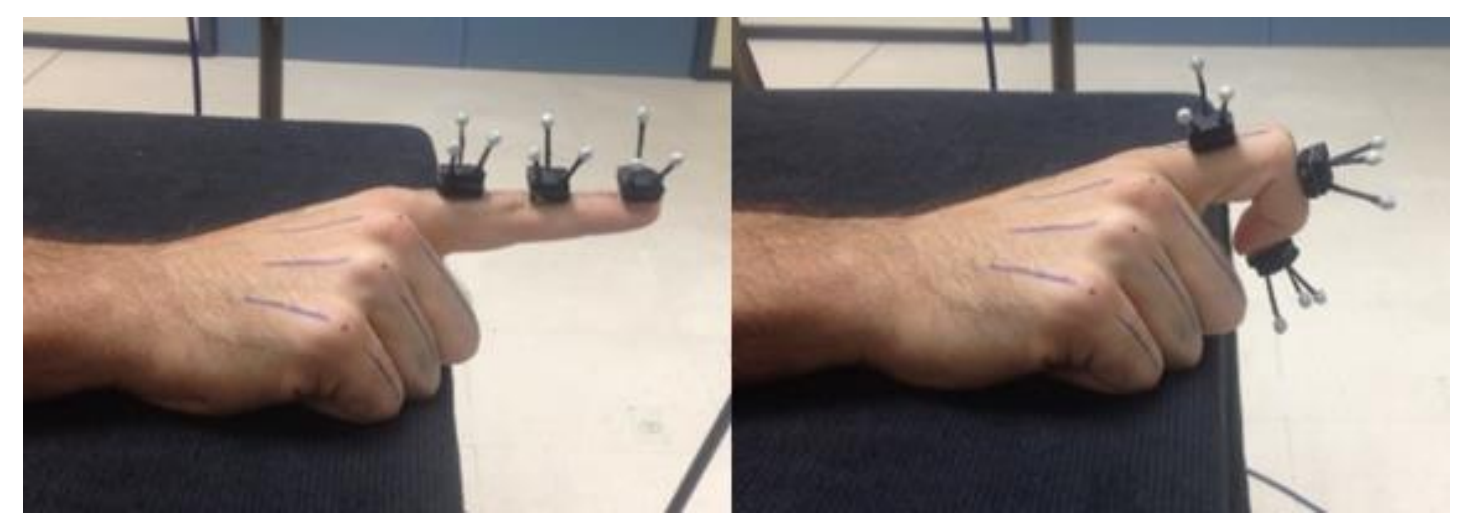

Figure 1.14. Movements recorded. (Left) Initial (and final) posture of the F/E movement for the index finger. (Right) Maximum flexion posture of the F/E movement for the index finger.

\section{Coordinate systems}

For each finger joint, the CS of the proximal and distal segments were defined from the landmarks in the reference posture. Both coordinate systems were defined coincident, with origin on the back of the joint (centre of the joint landmark, displaced in palmar direction a distance equal to the radius of the marker, i.e. intended to be on the skin). The Y-axis was mapped to the longitudinal axis of the finger, pointing in proximal direction, by a least squares adjustment of the three landmarks in the static reference posture. The $\mathrm{Z}$-axis was defined perpendicular to the $\mathrm{Y}$-axis, and parallel to the plane of the table where the hand rested during the static reference posture, pointing radial direction. And the $X$ axis was defined perpendicular to the Z- and Y-axes, pointing in the palmar direction.

In the case of the thumb, the $\mathrm{Z}$-axis was defined as the normal vector to the plane formed by the four landmarks (one on each joint: IP, MCP and CMC and another on the nail), pointing in thumb abduction direction. The $\mathrm{Y}$-axis corresponded to the longitudinal axis of the segment, by means of least squares adjustment of the four landmarks, pointing in proximal direction. And the $\mathrm{X}$-axis was defined perpendicular to the $\mathrm{Z}$ - and $\mathrm{Y}$-axes, pointing in the palmar direction. In this way, the $\mathrm{XY}, \mathrm{YZ}$ and $\mathrm{XZ}$ planes correspond to the sagittal, frontal and transverse planes, respectively, of each digit (Figure 1.15). 


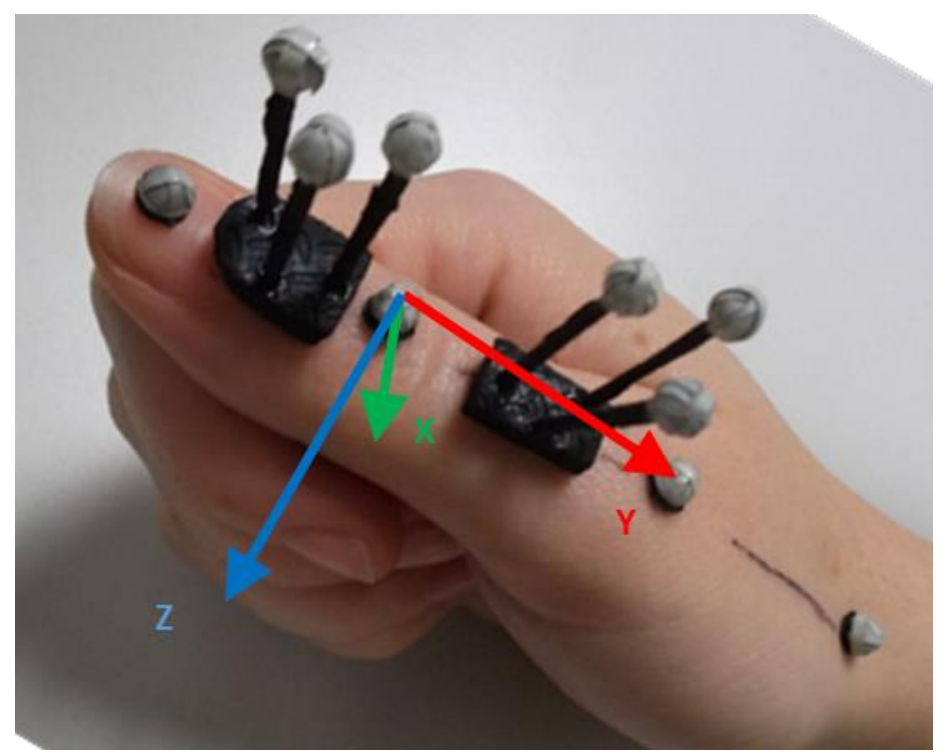

Figure 1.15 Axes definition for the IP joint of the thumb

\section{Axes location}

In each joint, the location of the F/E axis with respect to the proximal segment was described by 4 parameters as in the previous sections: coordinates of the intersection of the axis with the sagittal plane ( $T_{x}$ and $T_{y}$ ); and the inclination angles with respect to the frontal and transversal planes ( $\alpha_{f}$ and $\alpha_{t}$ ) (Appendix I, Figure A.2).

To obtain these 4 parameters, the dynamic sequence of F/E movements and the reference posture were used. For computational efficiency, only 75 frames of each dynamic record were considered, equidistant along the three F/E cycles. For each frame, the segment transformation matrices were obtained from the tracking markers (Söderkvist and Wedin, 1993). The parameters were calculated within the evolutionary optimisation approach (Hansen and Kern, 2004) analogously to the method explained in the previous sections (Section 1.3 and 1.4), by minimizing the mean across frames of the RMSE at each frame $k$ between the elements of the model transformation matrix (M_model $\mathrm{k}_{\mathrm{k}}$, matching the mathematical model proposed) and the experimental transformation matrix (M_experimental ${ }_{k}$, calculated from the tracking markers) (Cerveri et al., 2008).

\section{Data analysis}

First, a statistical description of the measured anthropometric parameters (mean, standard deviation (SD) and percentiles 5, 25, 50, 75 and 95) was performed, in order to check the representativeness of the hand sizes considered.

Secondly, the average values and SD of the 4 location parameters of the rotation axis of each joint $\left(T_{x}, T_{y}, \alpha_{f}\right.$ and $\left.\alpha_{t}\right)$ were calculated, in order to provide global values of the location of the rotation axes and their variability within the sample. 
Then, a more detailed analysis of the variability of the location parameters was carried out. Firstly, the variability attributable to the differences in hand sizes was studied. To do so, Pearson correlations were calculated for each of the 2 coordinate parameters $\left(\mathrm{T}_{\mathrm{x}}, \mathrm{T}_{\mathrm{y}}\right)$ of the different joints with the different anthropometric parameters. For those parameters with significant correlations, a linear model (without considering the constant) was proposed for their estimation (parameterisation). Secondly, to search groups or patterns due to the variability attributable to anatomical differences, one hierarchical cluster analysis on the inclination parameters $\left(\alpha_{f}, \alpha_{t}\right)$ was performed. The Ward method was considered for clustering, which minimises the total intra-group variance, and the Euclidean distance was used as a measure of dissimilarity. The elements were grouped when the highest distance between the clustered groups was found. Box-plot for the inclination parameters for the different groups and frequency graphs regarding the number of subjects, finger joint type, mean and SD of the inclination parameters are also shown, in order to check differences in inclination parameters between groups.

\section{Results}

Table 1.5 shows the descriptive statistics of the anthropometric parameters measured to the sample of subjects considered in the experiment, where the homogeneous distribution of sizes can be appreciated.

Table 1.5 Anthropometric parameters of the sample considered in the experiment. Acronyms used for the parameters are defined in Figure 1.

\begin{tabular}{|c|c|c|c|c|c|c|c|c|}
\hline & \multirow{2}{*}{ Parameter } & \multirow{2}{*}{$\begin{array}{l}\text { Mean } \\
(\mathrm{mm})\end{array}$} & \multirow{2}{*}{$\begin{array}{c}\mathrm{SD} \\
(\mathrm{mm})\end{array}$} & \multicolumn{5}{|c|}{ Percentiles $(\mathrm{mm})$} \\
\hline & & & & 5 & 25 & 50 & 75 & 95 \\
\hline & HL & 178.3 & 13.9 & 155.5 & 163.5 & 179.5 & 190.25 & 198.0 \\
\hline & $\mathrm{HB}$ & 82.0 & 5.9 & 70.1 & 77.8 & 82.5 & 86.5 & 90.5 \\
\hline \multirow{2}{*}{ Thumb } & $\mathrm{L} 1$ & 68.0 & 6.8 & 56.6 & 64.8 & 68.0 & 72.3 & 83.1 \\
\hline & JT1 & 15.3 & 1.2 & 13.4 & 14.3 & 15.0 & 16.4 & 17.5 \\
\hline \multirow{3}{*}{ Index } & L2 & 101.0 & 6.9 & 89.1 & 94.0 & 100.5 & 106.5 & 111.5 \\
\hline & JT1 & 10.9 & 0.9 & 9.8 & 10.1 & 10.9 & 11.6 & 12.8 \\
\hline & JT2 & 15.2 & 1.1 & 13.5 & 14.3 & 15.1 & 16.3 & 16.9 \\
\hline \multirow{3}{*}{ Middle } & L3 & 110.0 & 6.9 & 99.2 & 105.0 & 110.0 & 116.3 & 121.0 \\
\hline & JT1 & 11.5 & 0.9 & 10.1 & 10.7 & 11.2 & 12.2 & 13.0 \\
\hline & JT2 & 15.4 & 1.2 & 13.7 & 14.4 & 15.4 & 16.2 & 17.4 \\
\hline \multirow{3}{*}{ Ring } & L4 & 105.0 & 6.8 & 94.7 & 99.8 & 104.5 & 111.0 & 115.9 \\
\hline & JT1 & 10.5 & 0.8 & 9.4 & 9.8 & 10.5 & 11.2 & 11.9 \\
\hline & JT2 & 14.1 & 0.9 & 12.7 & 13.6 & 14.0 & 14.8 & 15.7 \\
\hline \multirow{3}{*}{ Little } & L5 & 86.0 & 7.4 & 77.1 & 80.0 & 84.0 & 91.3 & 103.9 \\
\hline & JT1 & 9.3 & 0.8 & 7.8 & 8.8 & 9.4 & 9.8 & 10.6 \\
\hline & JT2 & 12.6 & 1.1 & 10.8 & 12.0 & 12.6 & 13.4 & 14.8 \\
\hline
\end{tabular}


Optimisations took about an hour for each analysis performed with maximum optimisation error of 0.01 . The mean values and SD of the location parameters of the rotation axes obtained for the different joints are shown in Table 1.6. Globally, the SDs are of the same order of magnitude in DIP and PIP joints, less than $1.8 \mathrm{~mm}$ for the coordinate parameters, and less than $9.8^{\circ}$ for the inclination parameters; being the SD of the inclination angles with the transverse plane $\left(\alpha_{t}\right)$ about half value of the frontal plane (maximum values of $4.7^{\circ}$ versus $9.8^{\circ}$ ).

Table 1.6 Mean (SD) values of the location parameters of the rotation axes

\begin{tabular}{lccccc|cccc}
\hline & \multicolumn{4}{c}{ Distal interphalangeal joint } & \multicolumn{3}{c}{ Proximal interphalangeal joint } \\
\cline { 2 - 10 } & Thumb & Index & Middle & Ring & Little & Index & Middle & Ring & Little \\
\hline$T_{x}$ & 7.4 & 4.69 & 7.3 & 4.5 & 4.8 & 6.7 & 7.2 & 7.1 & 6.3 \\
$(\mathrm{~mm})$ & $(1.4)$ & $(0.6)$ & $(0.9)$ & $(0.5)$ & $(1.0)$ & $(1.0)$ & $(0.9)$ & $(0.9)$ & $(0.7)$ \\
$T_{y}$ & -0.1 & 0.5 & 0.0 & 0.2 & 0.3 & 0.0 & 0.0 & 0.2 & 0.2 \\
$(\mathrm{~mm})$ & $(1.4)$ & $(1.3)$ & $(1.6)$ & $(1.3)$ & $(1.3)$ & $(1.8)$ & $(1.6)$ & $(1.1)$ & $(1.1)$ \\
$\alpha_{t}\left(^{\circ}\right)$ & -5.8 & -1.3 & 1.0 & -1.9 & -2.3 & -1.0 & 1.0 & 3.6 & 2.1 \\
& $(3.6)$ & $(4.3)$ & $(4.0)$ & $(4.2)$ & $(4.7)$ & $(3.3)$ & $(4.0)$ & $(3.0)$ & $(4.2)$ \\
$\alpha_{f}\left(^{\circ}\right)$ & -11.6 & -10.7 & 1.2 & -1.2 & -7.4 & 0.1 & 1.2 & 1.1 & -10.0 \\
& $(9.8)$ & $(7.4)$ & $(7.8)$ & $(8.3)$ & $(8.1)$ & $(6.7)$ & $(7.8)$ & $(6.1)$ & $(8.8)$ \\
\hline
\end{tabular}

Pearson correlation analysis of the coordinate parameters of the rotation axes with the different measured anthropometric parameters only shows significant correlations for the $\mathrm{T}_{\mathrm{x}}$ coordinate (Table 1.7), the thickness of the joint being the parameter that presents the greatest number of significant correlations.

Table 1.7 Pearson correlations identified for the $T_{x}$ coordinate. Correlations with significance level of 0.01 and 0.05 have been coloured in dark and light, respectively.

\begin{tabular}{lccccc|ccccc}
\hline & \multicolumn{3}{l}{ Distal interphalangeal joint } & & \multicolumn{3}{c}{ Proximal interphalangeal joint } \\
\cline { 2 - 10 } & Thumb & Index & Middle & Ring & Little & Index & Middle & Ring & Little \\
\hline$H L$ & 0.253 & 0.384 & 0.497 & 0.109 & -0.057 & 0.542 & 0.058 & 0.251 & 0.181 \\
$H B$ & 0.028 & 0.464 & 0.463 & 0.138 & 0.060 & 0.616 & 0.237 & 0.204 & 0.052 \\
$L_{i}$ & 0.262 & 0.433 & 0.495 & 0.183 & 0.016 & 0.637 & 0.157 & 0.281 & 0.215 \\
$T J_{j}$ & 0.186 & 0.398 & 0.514 & 0.181 & 0.250 & 0.541 & 0.388 & 0.425 & 0.103 \\
\hline
\end{tabular}

Table 1.8 The Tx coordinate was parameterised considering a proportionality with respect to the thickness of each joint (Equation 2). Table 1.8 shows the values of the parameterisation coefficients for each of the finger joints.

$$
T_{x}=\beta \cdot G A
$$


Table 1.8 Parameterisation coefficients for the $T_{x}$ coordinate

\begin{tabular}{cccccc|cccc}
\hline & \multicolumn{4}{c|}{ Distal interphalangeal joint } & \multicolumn{4}{c}{ Proximal interphalangeal joint } \\
\cline { 2 - 10 } & Thumb & Index & Middle & Ring & Little & Index & Middle & Ring & Little \\
\hline$\beta$ & 0.49 & 0.43 & 0.46 & 0.43 & 0.52 & 0.44 & 0.47 & 0.50 & 0.50 \\
\hline
\end{tabular}

Figure 1.16 shows the dendrogram resulting from the hierarchical cluster analysis performed on the inclination angles with the transverse and frontal planes. The dendrogram allowed identifying 3 groups with different inclination values in the DIP and PIP joints (cutting distance of 70).

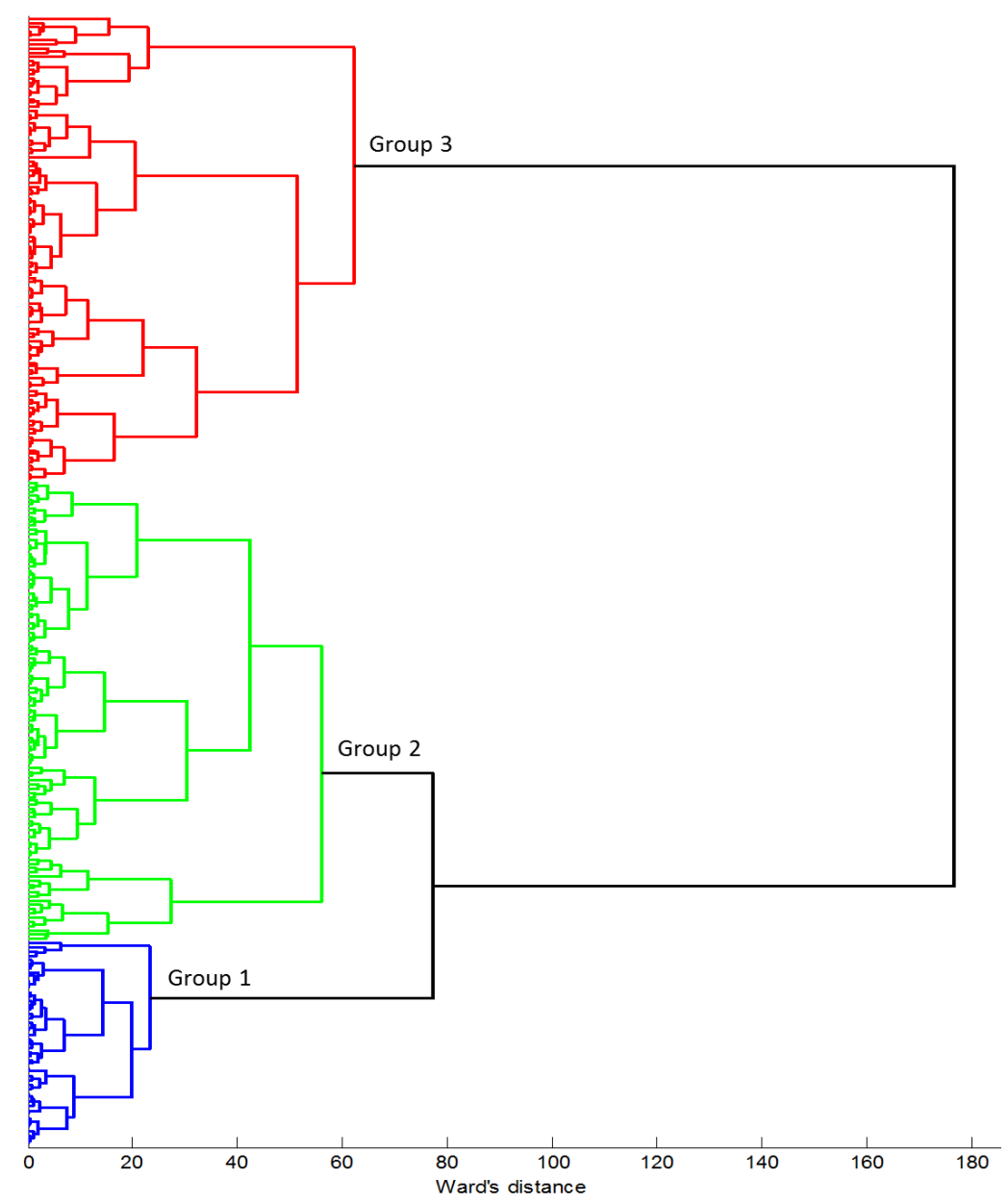

Figure 1.16 Dendrogram from the hierarchical analysis performed.

Table 1.9 shows the finger joint type and number of subjects classified in each group as well as the average and SD values of $\alpha_{\mathrm{f}}$ and $\alpha_{\mathrm{t}}$ for the different groups identified. Figure 1.17 shows the box plots corresponding to the inclination parameters for the different groups identified.

Figure 1.18 presents frequency graphs of finger joint type and number of subject classified in each group. These figures allowed identifying the differences between 
groups, the differences in the inclination angles with the frontal plane being higher than with the transversal plane. Groups obtained contain different subjects and finger joint type, without any predominance between them; i.e. groups are not formed according to different subjects or by finger joint type.

Table 1.9 Number of cases of each finger joint, number of subjects with any digit in that group, mean and $S D$ values of the inclination angles with the frontal and transversal planes $\left(\alpha_{f}, \alpha_{t}\right)$ of the rotation axes in each group resulting from the hierarchical analyses

\begin{tabular}{|c|c|c|c|c|}
\hline & & Group 1 & Group 2 & Group 3 \\
\hline \multicolumn{2}{|c|}{$\mathrm{N}^{\circ}$ of cases } & 49 & 110 & 111 \\
\hline Thumb & IP & 2 & 6 & 22 \\
\hline \multirow{2}{*}{ Index } & DIP & 2 & 6 & 22 \\
\hline & PIP & 8 & 18 & 4 \\
\hline \multirow{2}{*}{ Medium } & DIP & 7 & 6 & 17 \\
\hline & PIP & 4 & 22 & 4 \\
\hline \multirow{2}{*}{ Ring } & DIP & 3 & 20 & 7 \\
\hline & PIP & 11 & 18 & 1 \\
\hline \multirow{2}{*}{ Pinkie } & DIP & 4 & 10 & 16 \\
\hline & PIP & 8 & 4 & 18 \\
\hline \multicolumn{2}{|c|}{ N Subjects } & 26 & 26 & 29 \\
\hline \multirow{2}{*}{$\alpha_{\mathrm{f}}$} & Mean & -5.12 & 3.62 & -14.21 \\
\hline & SD & 2.52 & 4.68 & 5.42 \\
\hline \multirow{2}{*}{$\alpha_{\mathrm{t}}$} & Mean & 3.15 & -0.24 & -2.29 \\
\hline & SD & 3.00 & 4.27 & 4.59 \\
\hline
\end{tabular}

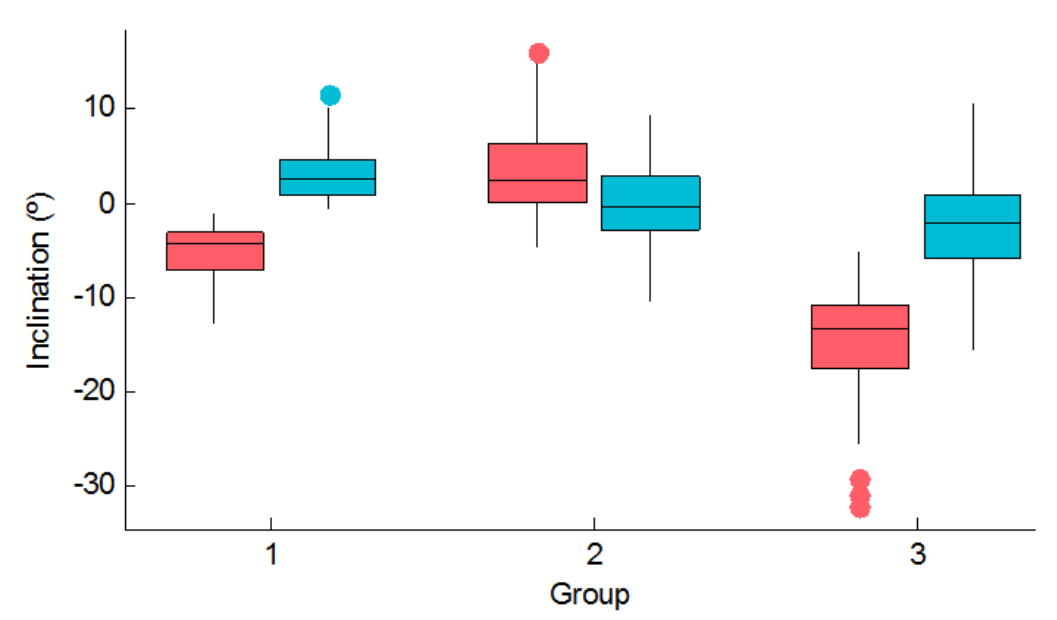

\section{Inclination parameter}

$$
\begin{aligned}
& -\alpha_{f} \\
& -\alpha_{t}
\end{aligned}
$$

Figure 1.17 Median, percentiles 25 and 75 and whiskers (those values that are within 1.5 times the interquartile range) of the each group identified in the dendrogram differentiating per inclination angles with the frontal and transverse planes $\left(\alpha_{f}, \alpha_{t}\right)$ 

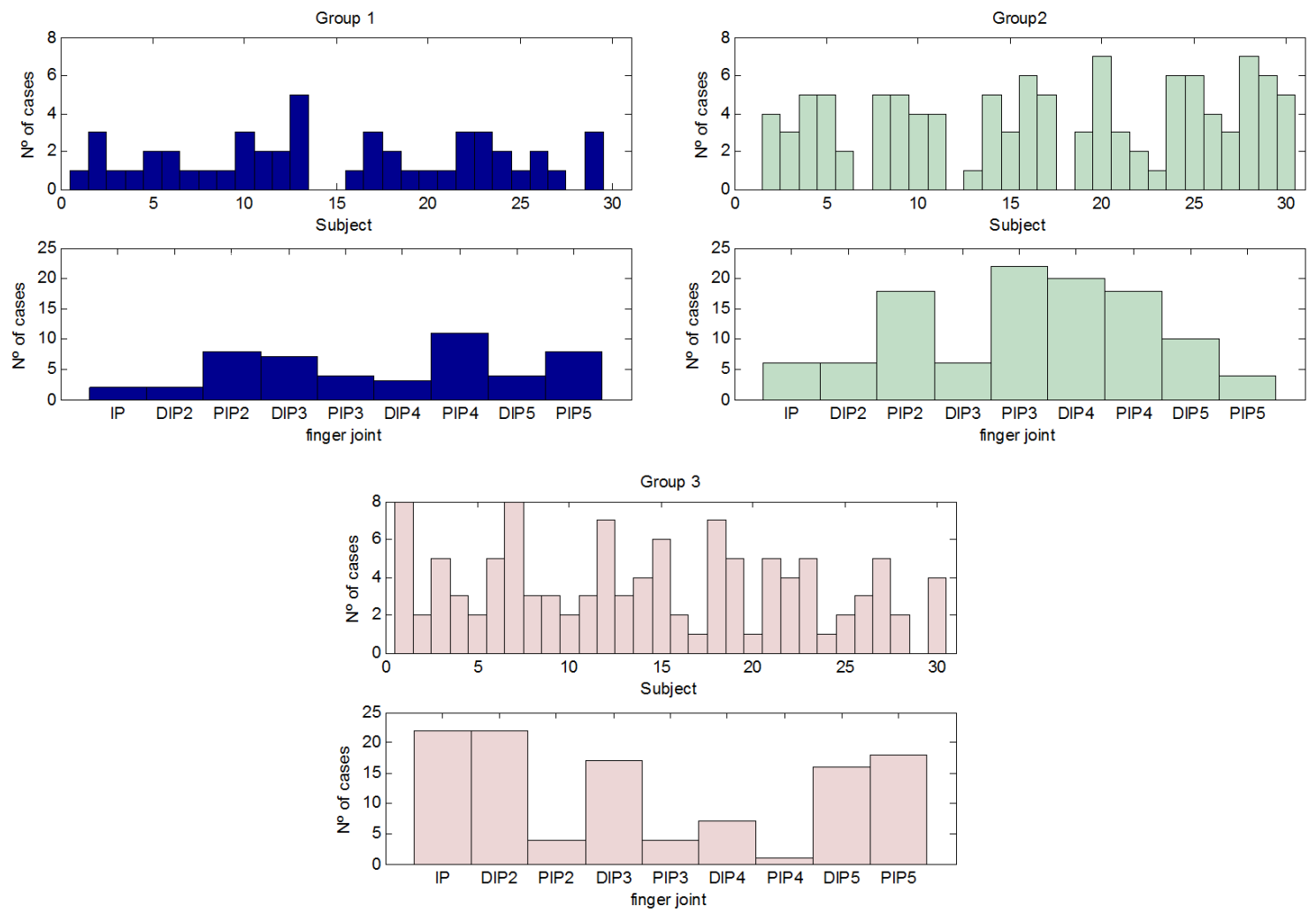

Figure 1.18 Frequency graphs (number of subjects and finger joint type) of the each group identified in the dendrogram

\section{Discussion}

The in vivo technique used allowed locating the rotation axes of the IP joints of the digits in a sample consisting of 30 healthy subjects with hand sizes representative of the Spanish population. The SD values across subjects for the location parameters of the rotation axes are of the same order of magnitude in both joints, distal and proximal. These SD values are lower than $1.8 \mathrm{~mm}$ for the coordinate parameters, and lower than $9.8^{\circ}$ for the inclination parameters, the SD values of the inclinations with the transverse plane being about half of the frontal plane $\left(4.7^{\circ}\right.$ versus $\left.9.8^{\circ}\right)$. The maximum SD value observed for the coordinate parameters is much lower than the intra-subject repeatability error reported in a previous work (Cerveri et al., 2008), $1.6 \mathrm{~mm}$ versus $5 \mathrm{~mm}$, while the maximum observed SD value for the inclination angles is somewhat higher than the repeatability error in the orientation reported in that work (Cerveri et al., 2008), 9.8 versus $6^{\circ}$, which seems to be a reasonable value considering the expected intrinsic variability of each subject (greater number of subjects analyzed, 30 versus 10 subjects).

The study of the differences due to the hand size as a possible source of variability has allowed me to identify an effect of the size in the $\mathrm{T}_{\mathrm{x}}$ coordinate of the axis location, which was expected. The depth at which the rotation axis lies is between $43 \%$ and $52 \%$ of the joint thickness. The values of the $\mathrm{T}_{\mathrm{y}}$ coordinate can be considered practically null, given the mean and SD values obtained, which indicate that the longitudinal location of the axis corresponds to the points used to place the markers. Therefore, in order to obtain 
a scalable model, these positions, in parametric form, could be obtained from anthropometric data of the population.

The results from the hierarchical analysis carried out have allowed deepening into the study of the variability observed in the orientation parameters of the axes. Apart from the inherent error of the technique used ( $6^{\circ}$ reported in a previous work (Cerveri et al., 2008)), the hierarchical analysis seems to suggest that part of this variability may be due to anatomical variations between subjects. Three different groups were clearly distinguished. No subject predominates in any of the obtained groups that would mean that there would be different types of subjects, with different inclinations (but similar in all joints of the same subject). No finger joints (IP, DIP or PIP) predominates in any of the groups that would mean that each joint would have a different configuration of inclinations (but similar for all the subjects). Nevertheless, the different groups contain different subjects and finger joint types, which reinforces the hypothesis introduced in a previous work (Santos and Valero-Cuevas, 2006) that the anatomical variability between subjects can be undertaken considering a finite number of biomechanical models types. It seems to be true, especially in terms of the inclination angles of the axes. Thus, after segmentation into groups, the SD values are reduced (maximum values of $5.42^{\circ}$ and $4.59^{\circ}$ for the frontal and transversal planes, respectively).

The mean values obtained for the inclination angles with the frontal and transversal planes $\left(\alpha_{f}\right.$ and $\alpha_{t}$ ) are lower than $11^{\circ}$ and $4^{\circ}$, respectively. However, similarly to the previous sections, the precision of the technique used is not enough (maximum SD value of $9.8^{\circ}$ ) to accurately represent the orientation data for the improvement of existing biomechanical models. Therefore, the results show that precision is a limitation for measuring the small mean orientation angles observed and other more accurate and invasive techniques must be considered to measure the position and orientation of the rotation axes, as the use of MRI. On the other hand, a robust and novel mathematical model to obtain the orientation and position of the axes rotation has been validated with acceptable computational times.

\subsection{Conclusion}

Summing up, I presented a robust mathematical method to obtain the orientation and position of the axes of rotation. The method has been implemented and used for locating the rotation axes in joints with 1 and $2 \mathrm{DoF}$, by using reflective markers on the skin. From the different studies, I may conclude that:

- The kinematics of the MCP joint can be described accurately with a model consisting of two non-orthogonal and non-intersecting rotation axes that should be taken into account when implementing biomechanical models.

- Considering the IP rotation axes parallel to the F/E creases is not a good assumption 
- The center of the rotation axes of the IP joints are approximately on the saggittal plane, at approximately null longitudinal distance from the joint centers and at a depth from dorsal surface than can be obtained from the thickness of the joints.

- Anatomical variability between subjects has been observed in the inclination of the IP rotation axes, which seem to be addressed using a finite number of biomechanical type models.

- More accurate techniques are needed for obtaining reliable data for the improvement of the existing biomechanical models, since the inclination angles are of the same order of magnitude as the errors.

Further studies are needed. In this sense, I want to continue investigating this topic but using more accurate techniques for obtaining the position of the bone segments connected in each joint, as MRI, avoiding the error introduced by the skin displacement.

However, in our research group we do not have the necessary equipment. Therefore, alternatives have been sought through collaboration with other research groups. Therefore, following this line of research will be possible thanks to the collaboration with a research group in Chicago (https://www.sralab.org). In this investigation, we would investigate which of the different models proposed for the MCP joint in the literature fits best to the experimental kinematics of the joint: the NINO model as presented here, the tilted abduction axis model (Brand and Hollister, 1999), adding a third supinationpronation hinge (Berme et al., 1977), or the NINO model but considering the F/E axis attached to the distal segment and the Ab/Ad axis attached to the proximal segment. However, we should also analyse which model provides best estimation of muscles forces during the performance of ADL when implemented into biomechanical models of the hand. 



\section{CHAPTER 2}

Contributions on hand kinematic reduction (I): an application to static power and precision grasps postures 

This chapter corresponds exactly to the paper published in the Applied Ergonomics journal, 2016, that presents a novel method of kinematics dimensional reduction for all joints of the hand, and explores its use for the analysis of power and precision cylindrical grasps, more oriented towards ergonomic evaluation.

The paper is titled: 'Using kinematic reduction for studying grasping postures. An application to power and precision grasp of cylinders'.

\subsection{Abstract \& keywords}

Using principal component and factorial analyses is proposed for reducing hand kinematics dimensionality in ergonomics studies. This method allows a comprehensive study of hand posture without losing accuracy and allowing velocity and acceleration analysis. It has been applied to study the effect of diameter and weight on the grasping posture of cylinders with precision and power grasps. The original sixteen degrees of freedom were reduced to five, which were identified as digit arching, closeness, palmar arching, finger adduction and thumb opposition. Both cylinder diameter and weight significantly affected precision grasping posture: diameter affects closeness, palmar arching and opposition, while weight affects digit arching, palmar arching and closeness. Power-grasping posture is mainly affected by the cylinder diameter, through digit arching, closeness and opposition. The grasping posture is largely affected by the subject factor and this effect cannot be attributed only to the hand size.

Keywords: hand posture, principal components analysis, cylindrical objects

\section{HIGHLIGHTS}

- Reducing hand kinematics with PCA is proposed to study grasping in ergonomics

- Kinematics of power and precision grasps of cylinders is reduced to 5 factors

- Factors: digit arch, closeness, palmar arch, finger abduction and thumb opposition

- Diameter affects power and precision grasps, weight only affects precision grasp

- Hand size is not enough to explain subject's effect on grasping posture.

\subsection{Introduction}

The human hand is a complex and useful mechanical system that allows us to perform many activities of daily living, work, and recreation. Hand posture determines the strength required to complete a given task (Domalain et al., 2008; Shivers et al., 2002; Watanabe et al., 2005). Hand posture also affects loads and excursions of tendons, and stresses on adjacent tissues such as synovial membranes and nerves (An et al., 1983; Lee 
et al., 2008), which is associated with the risk of developing work-related musculoskeletal disorders (WMSD) (Laoopugsin and Laoopugsin, 2012; Wells et al., 1994). Traditionally, ergonomic interventions to prevent WMSD on upper limb focus on registering shoulder and wrist postures, although recent works have also shown interest in registering all hand joints with more detail (Baker et al., 2007a, 2007b; Lee and Jung, 2015b; Wang et al., $2015,2014)$.

Hand posture analysis is hindered by the intrinsic kinematic complexity of the hand; using all joint angles might be cumbersome for describing hand shape, and focusing only on specific parameters might limit the results (Bae, 2011; Supuk et al., 2005). Observation-based assessments are more used by occupational safety and health practitioners due to its affordability (David, 2005). In this sense, some recent studies have used video recording and posture classification to describe hand posture (Hwang et al., 2010; Vergara et al., 2014; Wang et al., 2014, 2015). However these observation-based techniques have problems of hiding, are very time-consuming and are less reliable than the methods that register joint angles directly (David, 2005), named direct methods. Among these methods, instrumented gloves and videogrammetry have been used for ergonomic applications (Baker et al., 2007b, 2007a; Endo et al., 2007; Sánchez-Margallo et al., 2014; Yun, 1993). Direct methods also allow obtaining velocities and accelerations of movements, which are critical for the analysis of WMSD (Juul-Kristensen et al., 2001; Marras and Schoenmarklin, 1993). However the results provided with so many degrees of freedom (DoF) are difficult to interpret.

A recent study proposed two metrics to describe hand shape registered by direct methods in a more comprehensive way than using the angles of all DoF (Bae, 2011): openness indicates the positions of finger-tips based on metacarpophalangeal (MCP) joint angles, while flatness indicates the extent to which each finger is flat or curved, based on the proximal interphalangeal (PIP) joint angles. These metrics were employed to test object size and shape effect on hand shaping during grasping. Limitations are apparent, as both metrics are related only to finger MCP and PIP flexion.

Although hand motion has many DoF, not all the joint movements are independent, because of mechanical and neural coupling. Mechanical coupling is due to connections between tendons and multidigit insertions of extrinsic finger muscles (el-Badawi et al., 1995; Tubiana and Valentin, 1964; von Schroeder et al., 1990), and neural coupling comes from the innervation of multiple spinal motor neuron pools from a single cortical motor neuron (McKiernan et al., 1998; Santello et al., 2013; Schieber et al., 2001). The coordinated movements between various joints resulting from these couplings are referred to as kinematic synergies (Bernshteĭn, 1967).

Based on principal component analysis (PCA), Santello and collaborators found support for the existence of static postural synergies, so that the hand shape can be predicted using a reduced set of variables, or postural synergies (Santello et al., 2002, 1998; Santello and Soechting, 1998). PCA is a statistical procedure that uses an orthogonal transformation to transform a set of correlated variables into a smaller set of 
linearly uncorrelated variables called principal components (PCs). In a recent work (Thakur et al., 2008), 17 subjects were asked to perform an unconstrained haptic exploration task over 50 different objects, identifying nine PCs, i.e., synergies, that were similar across subjects and across manipulations of different objects and accounted for more than $90 \%$ of the variance in the hand postures registered throughout all tasks. These synergies were suggested to represent basic building blocks underlying natural hand motions and may be used to represent hand posture and movements, reducing the dimensionality of the results.

Furthermore, these synergies may be used to measure hand postures also in ergonomics studies in order to improve the design of handles and other parameters of the products that affect the way they are grasped and manipulated. Previous studies have shown that object size and shape cause different grasp execution (Cuijpers et al., 2004; Domalain et al., 2008; Meulenbroek et al., 2001; Santello and Soechting, 1998): the hand adapts its aperture to the object size and shape of the object trying to avoid collisions, especially the fingers; this adaptation is not uniform, but increases dramatically during the last phase of grasp execution; thick objects (envelop diameter $>4 \mathrm{~cm}$ ) tend to be grasped with all digits, while only the thumb and the index and middle fingers are used to grasp thin objects. There are fewer studies that have addressed object weight effect on hand posture. Weir et al. (1991) found a significant, but small effect on thumb and index finger motion of the weight object during prehension of a metallic dowel. A significant influence of object size and weight on grip force during manipulation has been found (Jordan et al., 2005; Kinoshita et al., 1997; Vigouroux et al., 2011a) and, consequently, hand kinematics might be modified by the central nervous system to apply grip force in a more efficient way. More knowledge is required about the whole hand posture while grasping objects of different weights (Lee and Jung, 2015b, 2014). Finally, hand posture is expected to be dependent on the subject. One personal factor that has been repeatedly studied is the relationship between hand size (mainly hand length) and object size (Seo and Armstrong, 2008), however the way the central nervous system adapts the musculoskeletal configuration to the grasping of objects may be different for different people. Actually, in a previous work (Mora et al., 2012), the hand size was postulated to take into account the subject effect into an artificial neural network aimed to predict hand posture, with poor results, indicating that the subject effect would not be reduced to hand size.

In this work we propose to use kinematic reduction as a rational generalized method for studying the grasping posture in ergonomics studies. In particular, we applied PCA to reduce the hand kinematics while grasping cylinders, and studied the effect of the cylinder diameter and weight on the grasping posture for precision and power grasps. We also verify whether hand size is able to account for subject posture variability for these grasps. 


\subsection{Material and methods}

\section{Kinematic reduction of DoF using Principal Component Analysis}

The method proposed for the kinematic reduction is to perform a PCA based on eigenvalue decomposition of a data correlation matrix (Daffertshofer et al., 2004; Hair et al., 2009) on all the hand joint angles registered. The sample size to apply PCA should be 100 observations or larger (Hair et al., 2009); as a general rule at least 5 (recommended 10) times as many observations as the number of variables (angles registered) to be analysed. The criterion recommended to extract the PCs is the latent root criterion in which all eigenvalues $>1$, so that each PC accounts for the variance of at least one of the original variables. This method is more reliable when the number of variables is between 20 and 50 (Hair et al., 2009). Prior to computation of the PCs, the joint angles should be rescaled to unit variance (Daffertshofer et al., 2004) to prevent the first modes from reflecting the joint angles with the largest amplitudes (flexion of MCP joints are expected to vary more than abduction of these joints). Communalities can be used as reliability indicators of the PC extraction, as they show how much of the variance in each of the original variables is explained by the extracted factors. The interpretation of the PCs in terms of the original variables is always useful to understand how the movement of the joints is coordinated. In order to achieve simpler and more meaningful solutions, the Varimax rotation can be used to simplify the interpretation of the PCs (Hair et al., 2009), so that each PC represents mainly a small number of the original joint angles. To calculate the new variables that substitute the original ones, factorial analysis with PCA and subsequent regression method for computing normalized factor scores (mean $=0, S D=$ $1)$ can be applied. These factors or reduced kinematic variables $(R K V s)$ represent the same PCs obtained and can be interpreted from their correlations with the original variables.

\section{Application to grasp of cylinders: Experiment to collect data}

Six right-handed subjects participated in two experiments (approved by the University Ethics Committee) performed simultaneously. Subjects grasped paper covered cylinders of different diameters in Experiment I, and of different weights in Experiment II (Table 2.1). All subjects gave their informed consent to participate in the experiments. 
Table 2.1 Descriptive data of subjects participating in the experiments, and cylinders used.

\begin{tabular}{|c|c|c|c|c|c|c|c|c|}
\hline Subject & \multicolumn{2}{|l|}{ Sex } & \multicolumn{2}{|c|}{$\begin{array}{l}\text { Age } \\
\text { (years) }\end{array}$} & \multicolumn{2}{|l|}{$\begin{array}{l}\mathrm{HL} \\
(\mathrm{mm})\end{array}$} & \multicolumn{2}{|l|}{$\begin{array}{l}\mathrm{HB} \\
(\mathrm{mm})\end{array}$} \\
\hline 1 & \multicolumn{2}{|c|}{ Female } & \multicolumn{2}{|l|}{37} & \multicolumn{2}{|c|}{163.5} & \multicolumn{2}{|l|}{69.5} \\
\hline 2 & \multicolumn{2}{|c|}{ Female } & \multicolumn{2}{|l|}{22} & \multicolumn{2}{|l|}{170.0} & \multicolumn{2}{|l|}{73.0} \\
\hline 3 & \multicolumn{2}{|c|}{ Female } & \multicolumn{2}{|l|}{42} & \multicolumn{2}{|l|}{173.0} & \multicolumn{2}{|l|}{72.5} \\
\hline 4 & \multicolumn{2}{|l|}{ Male } & \multicolumn{2}{|l|}{45} & \multicolumn{2}{|c|}{186.0} & \multicolumn{2}{|l|}{88.0} \\
\hline 5 & \multicolumn{2}{|l|}{ Male } & \multicolumn{2}{|l|}{30} & \multicolumn{2}{|l|}{173.0} & \multicolumn{2}{|l|}{81.0} \\
\hline 6 & \multicolumn{2}{|l|}{ Male } & \multicolumn{2}{|l|}{39} & \multicolumn{2}{|l|}{193.0} & \multicolumn{2}{|l|}{89.0} \\
\hline & \multicolumn{4}{|c|}{ Experiment I } & \multicolumn{4}{|c|}{ Experiment II } \\
\hline Cylinder Id & 1 & 2 & 3 & 4 & 5 & 2 & 6 & 7 \\
\hline Diameter $(\mathrm{mm})$ & 35 & 50 & 65 & 90 & 50 & 50 & 50 & 50 \\
\hline Height (mm) & 200 & 200 & 200 & 200 & 200 & 200 & 200 & 200 \\
\hline Weight (g) & 469 & 469 & 469 & 469 & 193 & 469 & 780 & 1117 \\
\hline
\end{tabular}

Note. HL: hand length (from the proximal palmar crease to the tip of the third digit), HB: hand breath (at the metacarpal heads).

Each subject was seated by a table, with the right arm lying on the table in a relaxed posture and the hand placed about $15 \mathrm{~cm}$ away from the cylinder to be grasped. The subject was asked to grasp each cylinder and move it forward about $15 \mathrm{~cm}$ while keeping it in a vertical upright position, and then return the hand to the initial location. Each cylinder was grasped with a prismatic precision grasp involving all fingers and thumb tips, and a cylindrical power grasp (Figure 2.1). Each subject repeated both grasps on each cylinder, until completing 3 consecutive repetitions of each combination of grasp type and cylinder (after three previous and non-recorded training trials) in a single session. The order of the seven cylinders was set at random for each subject.

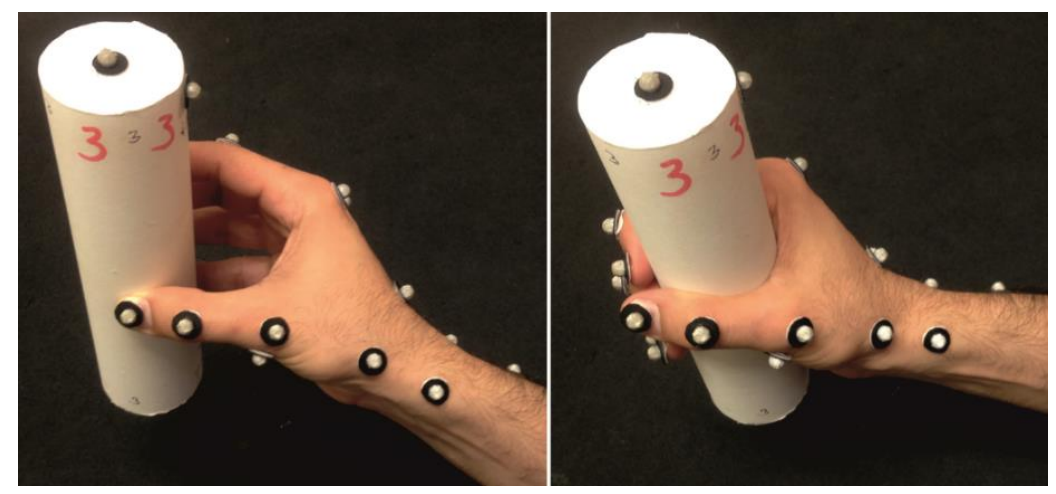

Figure 2.1 Types of grasps: left, all fingers and thumb prismatic precision grasp; right, cylindrical power grasp.

The hand posture and the cylinder position, and orientation were recorded using a Vicon ${ }^{\circledR}$ motion-tracking system composed of 8 Bonita ${ }^{\circledR}$ infrared cameras. The 3D 
positions of 32 reflective markers ( 3 on the object and 29 on the hand) were recorded (Figure 2.2), and the 23 joint angles defining the hand posture were obtained using the method described in a previous work (Sancho-Bru et al., 2014): flexion/extension (F/E) and abduction/adduction (Ab/Ad) at the carpometacarpal (CMC) joint of the thumb and all the MCP joints of the thumb and fingers; and F/E at the interphalangeal (IP) joint of the thumb, all PIP and distal interphalangeal (DIP) joints and at the CMC joints of the ring and little fingers. Flexion rotations and ulnar deviations were considered as positive at all joints.
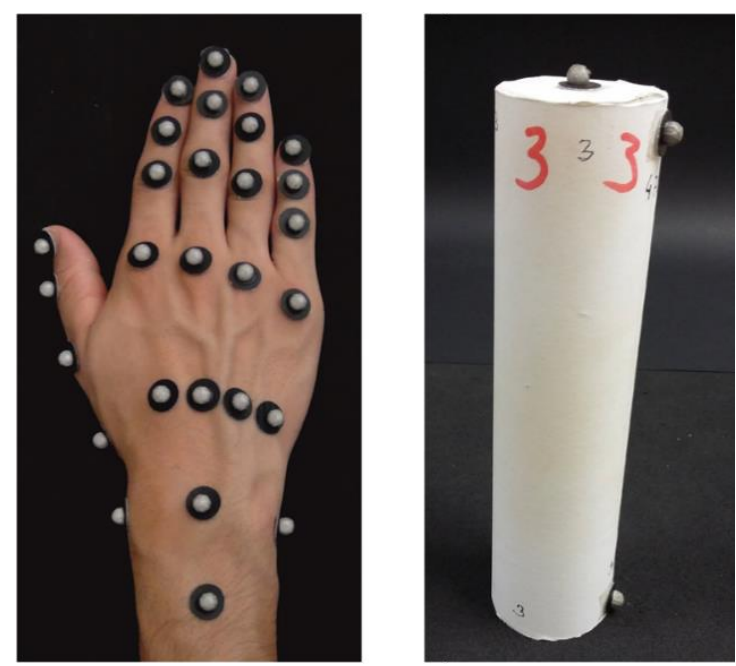

Figure 2.2 Detail of the location of the reflective markers used on the hand and on the cylinder.

The grasping postures used for the subsequent statistical analysis were obtained by setting a trigger at the highest marker of the object translation, ensuring that the subject's hand was grasping it securely.

\section{Application to grasp of cylinders: Statistical analyses}

The following statistical analyses were performed using the SPSS® Statistics software:

Kinematic reduction: the method described in section "Kinematic reduction of DoF using Principal Component Analysis" was applied to the 23 joint angles registered in both experiments together, in order to extract the PCs, named PC. The number of postures registered included in the analysis was 242 ( 7 cylinders $x 2$ grasps x 6 subjects $\times 3$ repetitions), enough to perform the analysis. Varimax rotation was used to simplify interpretation and the reduced kinematic variables $(R K V s)$ were calculated.

Cylinder diameter and weight effect analysis: as an application for ergonomics, the global influence of the diameter and weight was analysed by means of two MANOVAs on the RKVs as dependent variables, and with diameter (weight, for the second analysis), grasp type, subject, and all their second-order interactions as independent variables (factors). The specific effect on each $R K V$ was analysed by means of ANOVAs on the 
$R K V s$ as dependent variables, and with the factors that resulted statistically significant in the MANOVAs. The mean values of the $R K V s$ were plotted for each grasp type against the diameter and weight to identify potential trends.

Subject/Hand size effect verification: as the factor subject was significant in the MANOVAs and ANOVAs performed in (ii), as an application for ergonomics, additional analyses were performed to check the approximation of substituting the subject effect by hand size, represented by $H B$ (hand breadth), $H L$ (hand length) or $H B \cdot H L$. Mean values of the $R K V s$ were analysed to identify potential trends when changing hand size. Furthermore, for each experiment, the variance explained by hand size was compared to the variability due to the subject. This was accomplished by comparing the variances explained in two sets of ANOVAs: one set conducted on each $R K V$ as dependent variable, and with the factors subject, grasp type and diameter (or weight); and another set conducted on the same $R K V$ as dependent variable, but with $H B \cdot H L$ as a covariable, and grasp type, and diameter (or weight) as factors. Box-and-whisker plots were also used to show differences in the RKVs among subjects. Finally, as it was checked that subject effect was greater than hand size effect, a hierarchical clustering analysis was performed for each grasp type to identify similarities in grasping postures between subjects. The data were collapsed to have only a single value for each of the $R K V s$ (mean value) for each subject, for each of the two grasp types considered. The hierarchical analyses consisted of agglomerative clustering with centroid linkage criterion, and Euclidean distance metric.

\subsection{Results}

\section{Kinematic reduction}

The communalities observed in the PCA were high (mean 0.82, SD 0.13), which is a reliability indicator of $P C$ extraction. Five PCs were extracted, which accounted for $82 \%$ of the total variance, the first two being responsible for $52 \%$ of this variance. Table 2.2 shows the correlations of these PCs with the original variables and Figure 2.3 represents graphically the first four PCs. The PCs are visualized using the hand kinematical model developed in Opensim by the ARMS lab of the Rehabilitation Institute of Chicago (Buffi et al., 2013; Holzbaur et al., 2005). PC $_{1}$ represents DIP and PIP flexion of fingers and thumb. $\mathrm{PC}_{2}$ shows $\mathrm{MCP}$ flexion of fingers. $\mathrm{PC}_{3}$ combines the palmar arching (ring and little $\mathrm{CMC}$ flexion) with thumb $\mathrm{CMC}$ adduction. $\mathrm{PC}_{4}$ represents ulnar deviation of index, middle and ring MCP joints, accompanied by some palmar arching and little MCP adduction. Finally, $\mathrm{PC}_{5}$ shows thumb MCP adduction with some palmar arching. 


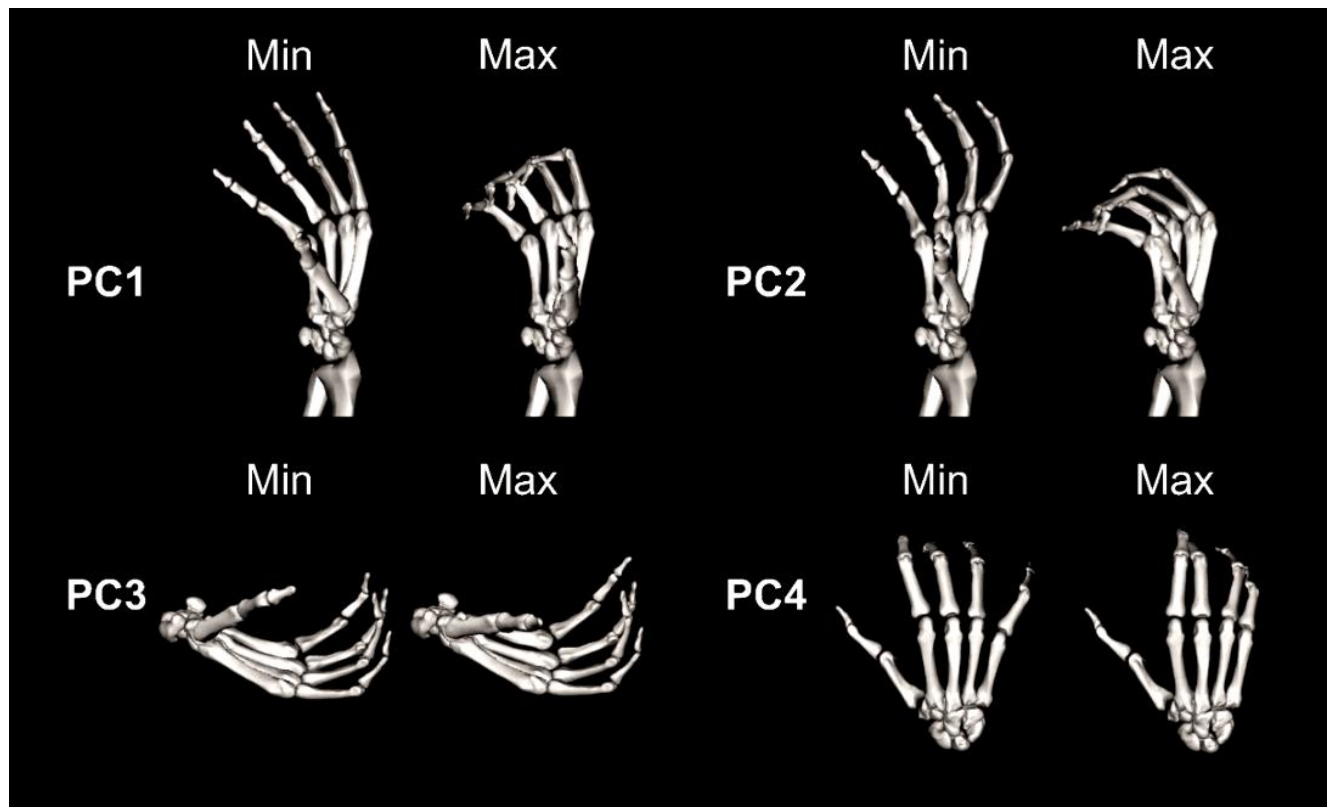

Figure 2.3 Mean extreme postures representing the first four PCs obtained after the kinematical reduction throughout both experiments I and II altogether.

Table 2.2 Rotated component matrix for the 5 PCs extracted, showing the correlations between each of the original variables and the estimated PCs. To simplify the interpretation of results, correlations smaller than 0.3 have been suppressed and those greater than 0.6 have been marked in bold

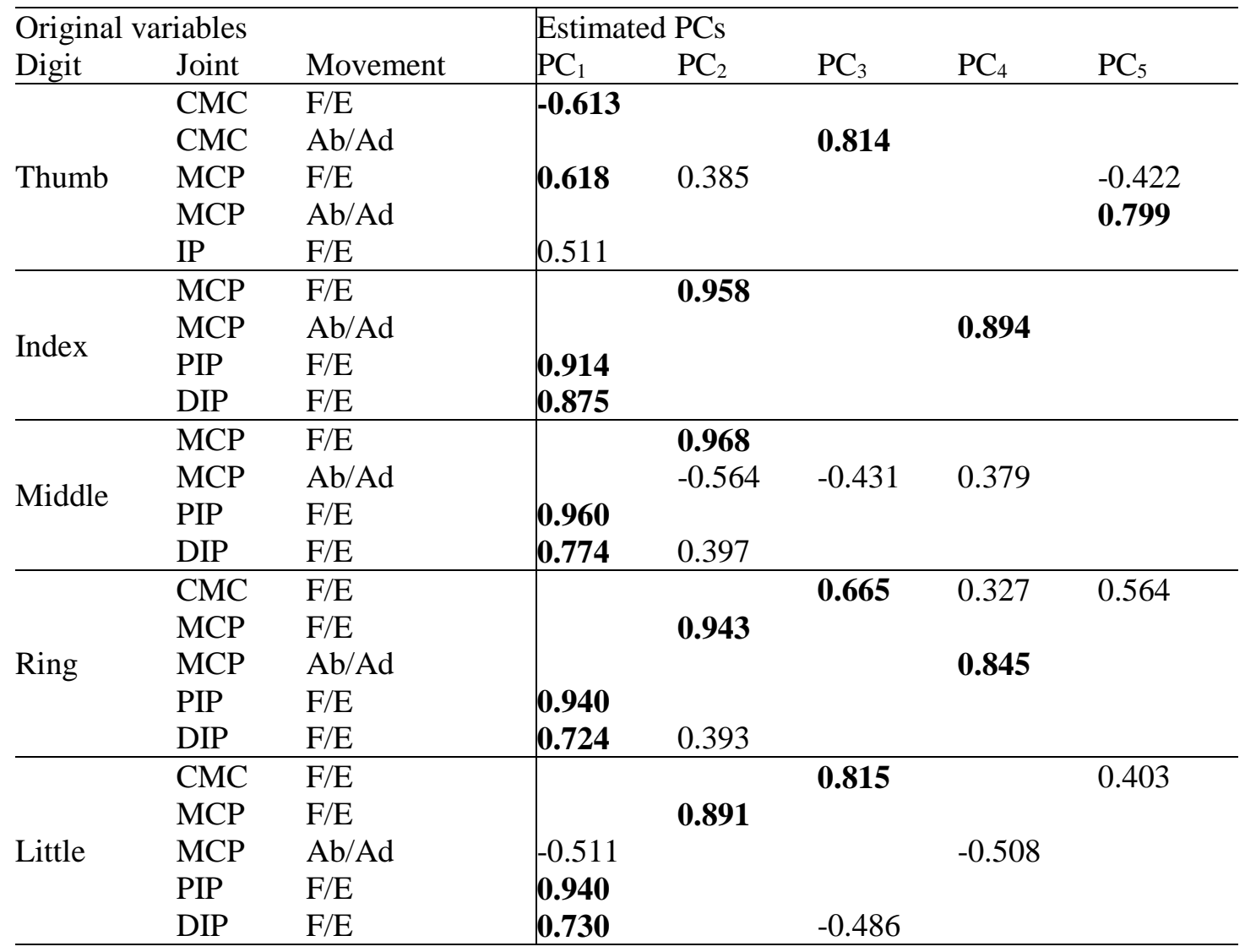

Kinematic and muscular characterisation of the hand during ADL 


\section{Cylinder diameter and weight effect}

All factors were found to significantly affect the $R K V s \quad(\mathrm{p}<0.001)$ in both MANOVAs performed (Table 2.3). All univariate models were significant $(\mathrm{p}<0.001)$, and explained more than $88 \%$ of the variance in the $R K V s$. In Experiment I (diameter effect), all the factors significantly affected all the $R K V s(\mathrm{p}<.05)$, the only exception being grasp type $x$ diameter on $R K V_{5}$. Analogously, in Experiment II (weight effect), subject, grasp type, and the interaction grasp type $x$ subject were found to significantly affect all $R K V s(\mathrm{p}<.05)$, while weight affected all $R K V s$ except $R K V_{4}$, the interaction grasp type $x$ weight affected all $R K V$ s except $R K V_{5}$, and the interaction subject $x$ weight only significantly affected $R K V_{2}, R K V_{4}$, and $R K V_{5}$. Note that the variance explained by factor subject in both experiments is high in all $R K V s$, except in $R K V_{l}$, whose variance was basically explained by factor grasp type. In Experiment I, however, the factor diameter explained more variance than subject. And the variance explained by diameter in Experiment I was higher than that explained by weight in Experiment II.

Table 2.3 Results of the ANOVAs on the RKVs in experiments I and II.

\begin{tabular}{l|lll|lll}
\hline Dependent & \multicolumn{3}{|c|}{ Experiment I } & \multicolumn{3}{c}{ Experiment II } \\
\cline { 2 - 7 } variable & Source & MSV & Sig. & Source & MSV & Sig. \\
\hline$R K V_{1}$ & & 75.865 & 0.000 & & 128.257 & 0.000 \\
$R K V_{2}$ & & 6.318 & 0.000 & & 1.592 & 0.000 \\
$R K V_{3}$ & grasp type & 3.610 & 0.000 & grasp type & 7.659 & 0.000 \\
$R K V_{4}$ & & 0.487 & 0.004 & & 1.050 & 0.000 \\
$R K V_{5}$ & & 5.743 & 0.000 & & 9.976 & 0.000 \\
\hline$R K V_{1}$ & & 2.216 & 0.000 & & 2.670 & 0.000 \\
$R K V_{2}$ & & 11.703 & 0.000 & & 12.219 & 0.000 \\
$R K V_{3}$ & subject & 17.320 & 0.000 & subject & 22.377 & 0.000 \\
$R K V_{4}$ & & 26.707 & 0.000 & & 21.207 & 0.000 \\
$R K V_{5}$ & & 15.394 & 0.000 & & 14.958 & 0.000 \\
\hline$R K V_{1}$ & & 2.790 & 0.000 & & 0.242 & 0.000 \\
$R K V_{2}$ & & 21.837 & 0.000 & & 0.749 & 0.000 \\
$R K V_{3}$ & diameter & 4.818 & 0.000 & weight & 1.137 & 0.000 \\
$R K V_{4}$ & & 1.415 & 0.000 & & 0.040 & 0.325 \\
$R K V_{5}$ & & 4.675 & 0.000 & & 0.279 & 0.008 \\
\hline$R K V_{1}$ & & 5.030 & 0.000 & & 0.268 & 0.000 \\
$R K V_{2}$ & & 1.985 & 0.000 & & 0.598 & 0.000 \\
$R K V_{3}$ & grasp type $x$ & 2.669 & 0.000 & grasp type $x$ & 0.386 & 0.000 \\
$R K V_{4}$ & diameter & 0.192 & 0.019 & & 0.114 & 0.023 \\
$R K V_{5}$ & & 0.422 & 0.061 & & 0.062 & 0.430 \\
\hline$R K V_{1}$ & & 0.127 & 0.000 & & 0.024 & 0.053 \\
$R K V_{2}$ & subjectx $x$ & 0.438 & 0.000 & subject $x$ & 0.100 & 0.015 \\
$R K V_{3}$ & diameter & 0.356 & 0.000 & weight & 0.051 & 0.361 \\
$R K V_{4}$ & & 0.267 & 0.000 & & 0.143 & 0.000 \\
$R K V_{5}$ & & 0.879 & 0.000 & & 0.183 & 0.001 \\
\hline
\end{tabular}




\begin{tabular}{l|lll|lll}
\hline Dependent & \multicolumn{3}{|c|}{ Experiment I } & \multicolumn{3}{c}{ Experiment II } \\
\cline { 2 - 7 } variable & Source & MSV & Sig. & Source & MSV & Sig. \\
\hline$R K V_{I}$ & & 1.166 & 0.000 & & 2.005 & 0.000 \\
$R K V_{2}$ & & 1.772 & 0.000 & grasp type $x$ & 5.676 & 0.000 \\
$R K V_{3}$ & grasp type $x$ & 1.267 & 0.000 & subject & 2.751 & 0.000 \\
$R K V_{4}$ & subject & 0.983 & 0.000 & & 6.277 & 0.000 \\
$R K V_{5}$ & & 4.824 & 0.000 & & 6.031 & 0.000 \\
\hline
\end{tabular}

Note. MSV: Mean square variance explained, Sig.: Significance level.

Figure 2.4 shows the mean values of the $R K V$ s plotted against diameter and weight, distinguishing by grasp type. The diameter variation generated greater changes in the $R K V s$ than the weight variation. Moreover, values and trends of the $R K V s$ differed among grasp types when varying the diameter or weight. A general decrease was observed for all $R K V s$ when increasing the diameter, except for $R K V_{5}$ in both grasp types, and for $R K V_{l}$ in the precision grasp. Weight variation did not produce any big changes in the $R K V s$ in the case of the power grasp. An additional ANOVA on $R K V s$ restricted to power grasps (not shown for brevity) revealed no significant differences in $R K V_{2}, R K V_{3}$, and $R K V_{4}$ for the factor weight.
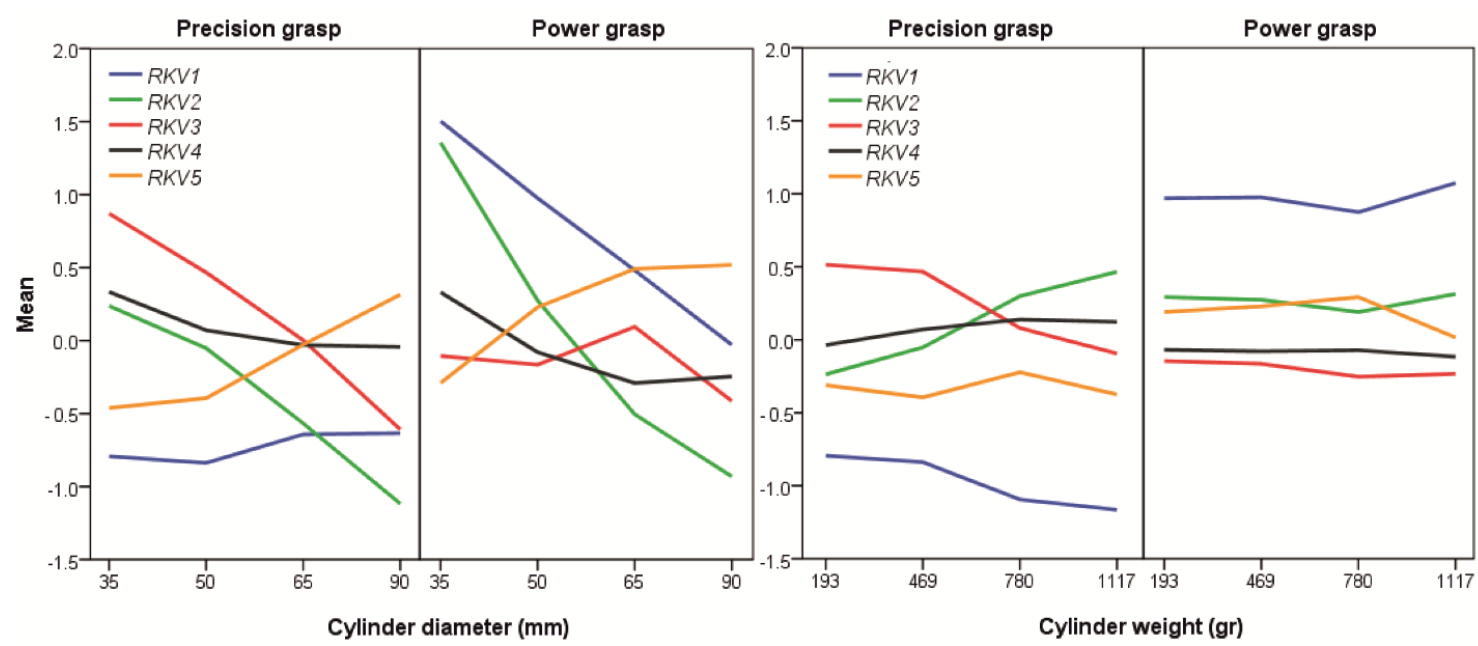

Figure 2.4 Evolution of the RKVs mean values when varying the cylinder diameter (left) and cylinder weight (right) obtained from Experiment I and II, respectively, for both types of grasp.

\section{Subject/Hand size effect}

Results from the ANOVAs in the previous section revealed a significant subject effect on all $R K V s$ in both experiments, subject explaining a high variance in all $R K V s$, except in $R K V_{l}$. Different analyses were performed looking for a relationship between the $R K V s$, and the parameters $H B, H L$, and $H B \cdot H L$, representative of hand size, with unproductive results. As an example, the plots of the mean values of the $R K V s$ against $H B \cdot H L$ were reflected distinguishing by diameter and weight, for the precision grasp (Figure 2.). No clear trend was observed for the $R K V s$ with hand size, except perhaps for 
$R K V_{2}$, which seems to present higher values for higher hand sizes. These results, anyway, must be taken with care, as only 6 hand sizes were used.
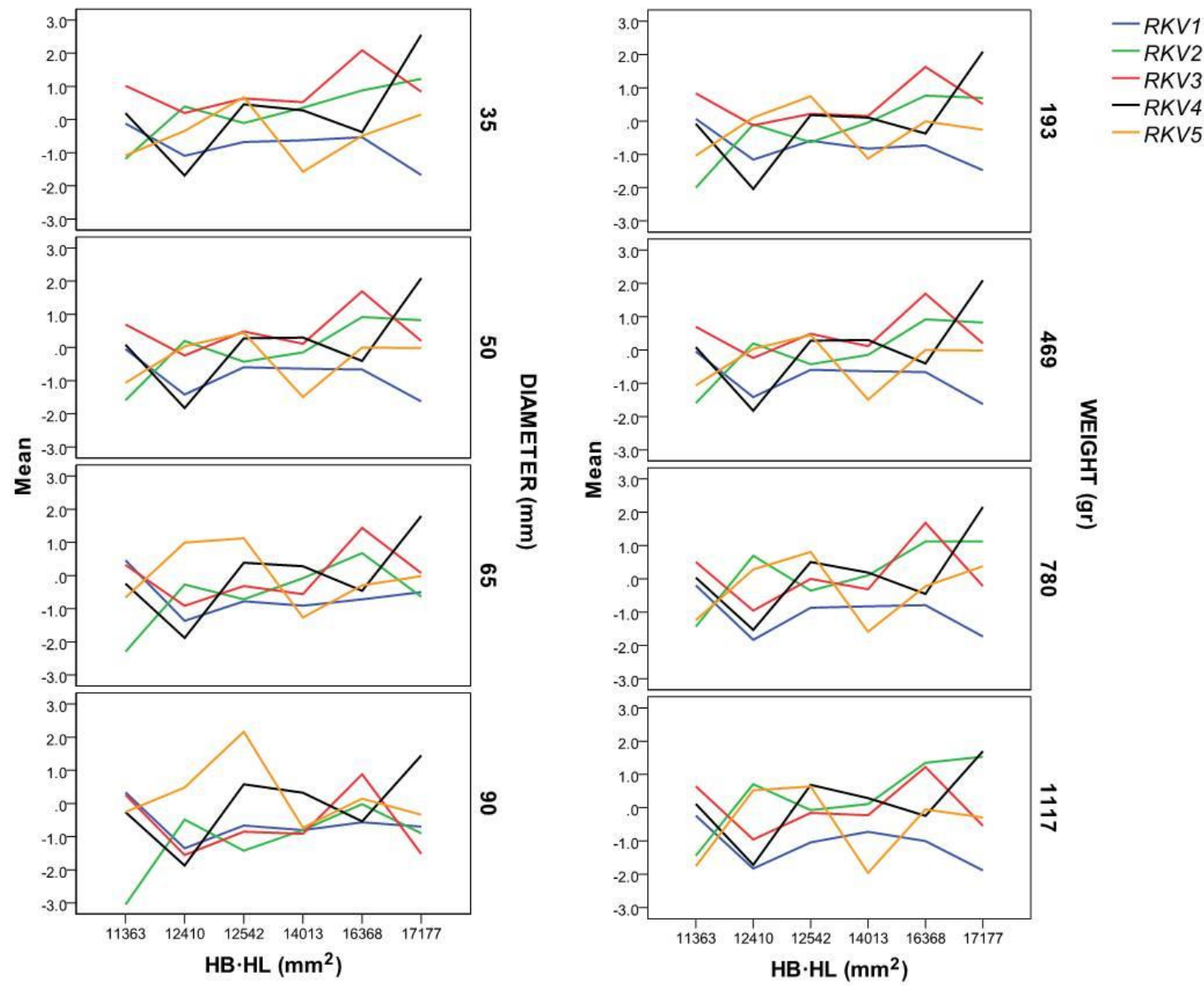

Figure 2.5 Mean values of the RKVs against HB.HL, for precision grasp, distinguishing by cylinder diameter (left) and weight (right).

The variances explained by the two sets of ANOVAs, with factor subject or with $H B \cdot H L$ as a covariable are shown in Table 2.4 , together with the $\mathrm{R}$ squared coefficient of the model (which measures the percentage of variance explained by the model). The variances explained by the univariate models that used $H B \cdot H L$ as a covariable were lower in both experiments than the variances explained by those using the subject factor. Furthermore, in the models with $H B \cdot H L$, the R coefficients are low, especially for $R K V_{3}$, $R K V_{4}$, and $R K V_{5}$ in both experiments, and also for $R K V_{2}$ in Experiment II. 
Table 2.4 Results of the two sets of univariate analyses performed for both experiments on all $R K V$ s to compare the variances explained by the subject and the hand size, represented by $H B \cdot H L$.

\begin{tabular}{|c|c|c|c|c|c|c|c|c|}
\hline \multirow[b]{3}{*}{$\begin{array}{l}\text { Dependent } \\
\text { variable }\end{array}$} & \multicolumn{4}{|c|}{ Experiment I } & \multicolumn{4}{|c|}{ Experiment II } \\
\hline & \multicolumn{2}{|c|}{ Subject ${ }^{\mathrm{a}}$} & \multicolumn{2}{|c|}{$H B \cdot H L^{\mathrm{b}}$} & \multicolumn{2}{|c|}{ Subject ${ }^{\mathrm{c}}$} & \multicolumn{2}{|c|}{$H B \cdot H L^{\mathrm{d}}$} \\
\hline & EV & $\mathrm{R}^{2}$ & EV & $\mathrm{R}^{2}$ & EV & $\mathrm{R}^{2}$ & EV & $\mathrm{R}^{2}$ \\
\hline$\overline{R K V_{l}}$ & 111.1 & 0.906 & 100.4 & 0.820 & 147.7 & 0.925 & 135.4 & 0.849 \\
\hline$R K V_{2}$ & 138.2 & 0.880 & 103.0 & 0.656 & 65.5 & 0.651 & 24.2 & 0.241 \\
\hline$R K V_{3}$ & 114.1 & 0.832 & 28.2 & 0.206 & 126.1 & 0.864 & 16.4 & 0.112 \\
\hline$R K V_{4}$ & 140.7 & 0.903 & 36.9 & 0.237 & 109.1 & 0.863 & 28.4 & 0.225 \\
\hline$R K V_{5}$ & 94.0 & 0.631 & 25.0 & 0.168 & 84.2 & 0.677 & 15.7 & 0.127 \\
\hline
\end{tabular}

Note. EV: Explained variance, $\mathrm{R}^{2}$ : R squared coefficient of the model

Factors: subject, grasp type and diameter.

Covariable: HB.HL. Factors: grasp type and diameter.

Factors: subject, grasp type and weight.

Covariable: HB·HL. Factors: grasp type and weight.

Figure 2.6 shows box-and-whisker plots of the $R K V s$ for each subject and all the data (both experiments together), where each subject is observed to use very different values and ranges of the $R K V s$. Figure 2.7 shows a dendrogram with the results from the hierarchical clustering analyses. Different groupings were obtained for each grasp type. While subjects 1 and 5, and 3 and 6 were found to perform the precision grasp in a similar way, subjects 5 and 6 , and 1 and 4 performed the power grasp similarly.
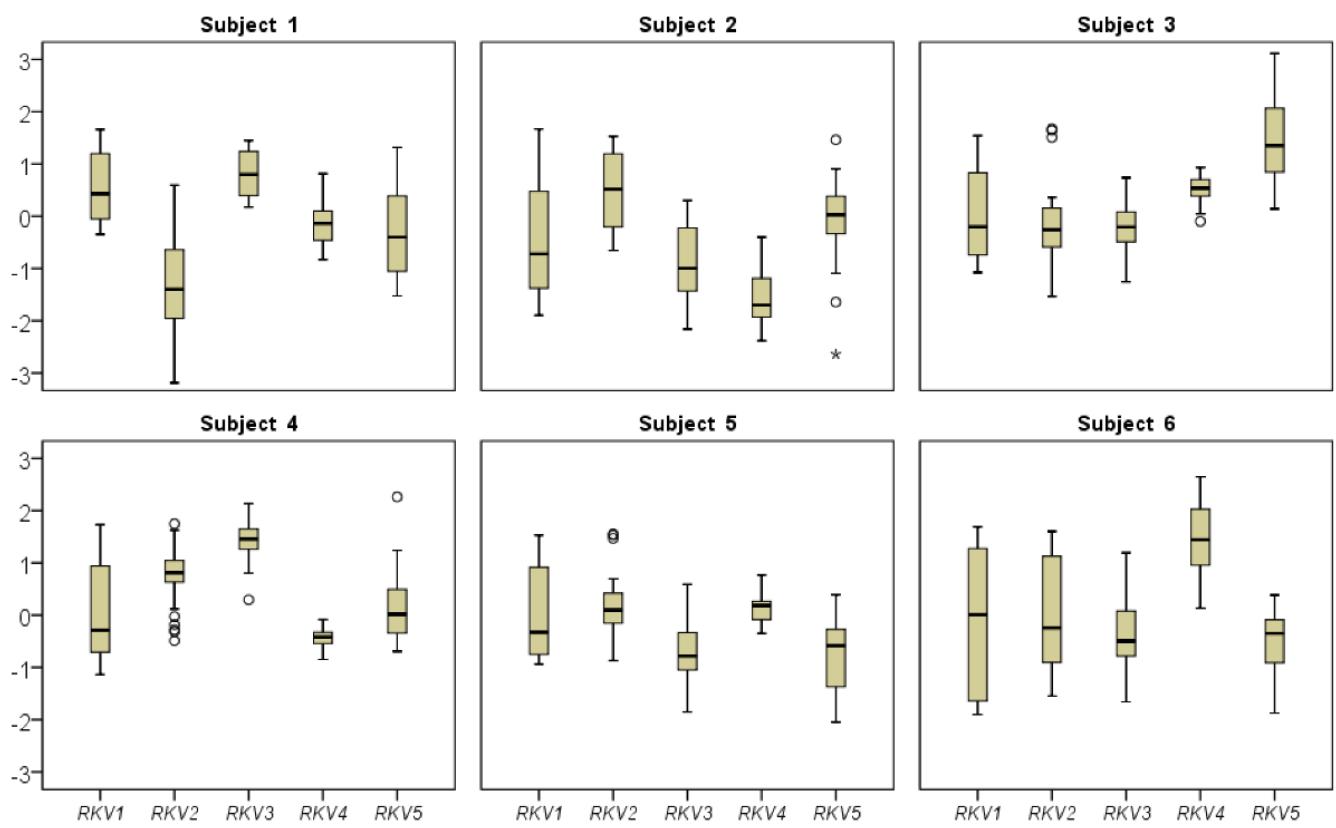

Figure 2.6 Box-and-whisker plots of the RKVs for each subject in experiments I and II altogether 

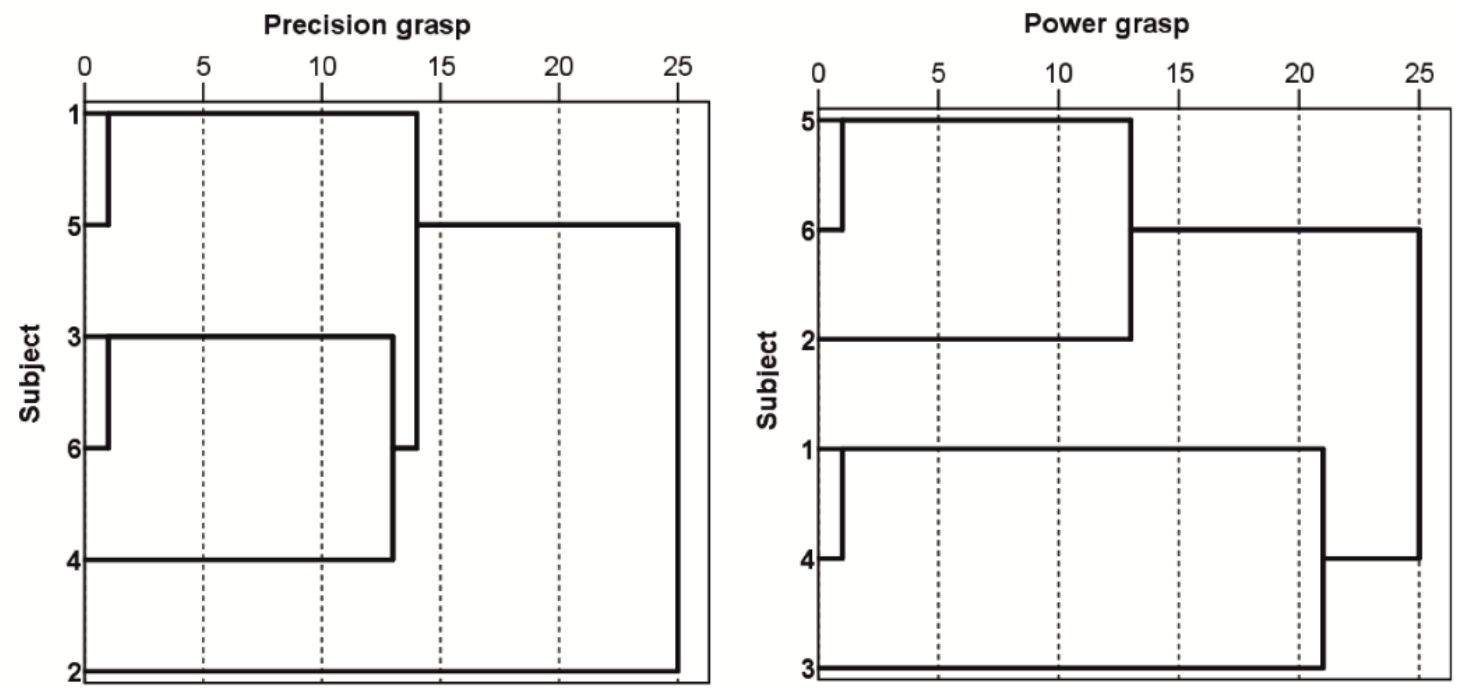

Figure 2.7 Dendrograms resulting from the hierarchical clustering analyses: left, for precision grasp; right, for power grasp. Vertical lines represent clusters, and distances from 0 of these lines represents similarity (the more close to 0 the more similar).

\subsection{Discussion}

Hand posture analysis in ergonomics can benefit from the use of PCA and factorial analysis, as we have shown that the whole hand grasping kinematics is actually low dimensional and can be efficiently described by a small number of reduced variables ( 5 $R K V s$ ) for precision and power grasps of cylinders with all fingers. This new set of variables provide the same information but more easily interpretable: $R K V_{l}$ represents DIP and PIP flexion of fingers and thumb, i.e., the digit arching (opposed to flatness); $R K V_{2}$ represents MCP flexion of fingers, i.e., the closeness (opposed to openness); $R K V_{3}$ represents ring and little $\mathrm{CMC}$ flexion with thumb CMC adduction, i.e., the palmar arching (like holding water with the hands); $R K V_{4}$ represents finger adduction; and finally, $R K V_{5}$ represents thumb MCP adduction with some palmar arching, i.e., opposition.

The first two RKVs, each one associated to the PCs obtained in this same study, match those PCs obtained in previous works on similar grasps (Mason et al., 2001; Santello et al., 1998; Todorov and Ghahramani, 2004). However, the number of PCs obtained in this work is higher than that reported in those works, but much smaller than the number of PCs obtained by Thakur and collaborators (Thakur et al., 2008). One of the main reasons is that the number of DoF measured here and in Thakur's work is higher. In particular, previous works in the literature have not registered the movements at the ring and little CMC joints, and were therefore unable to observe the palmar arching that has been found here, as well as in Thakur's work, as an important factor to represent the grasping posture. Another reason is that previous studies considered the grasping postures on imaginary objects and/or the movements during planning of the grasping, so adapting 
the posture to the real object shape was neglected or limited, as these works focused on investigating hand control and not on studying the posture during grasping. The number of PCs obtained by Thakur and collaborators was higher than in this work because they studied the whole process of manipulating very diverse objects by a high number of subjects to find the basic synergies underlying any natural hand motion, while in this work the objects are limited to cylinders, and the action to holding.

The use of the $R K V s$ to study hand posture is a good compromise between simplicity of posture representation and accuracy. Previous metrics, such as openness and flatness used by Bae (Bae, 2011), are very limited as they do not provide information on palmar arching, thumb motion or finger abduction, which have been shown to be important aspects for characterizing hand posture.

Both the cylinder diameter and weight significantly affect the hand posture for precision and power grasping. However, the differences in variance explained by these factors reveal that diameter has a higher effect than weight, which matches previous results (Weir et al., 1991). Diameter variation significantly affects all $R K V s$, while weight variation affects all $R K V$ s except opposition. Furthermore, both interactions grasp type $x$ diameter and grasp type $x$ weight significantly affect the $R K V s$, which means that the effect of the cylinder attributes was different depending on the grasp type. Furthermore, a different effect of diameter was identified depending on the grasp type considered for all $R K V s$ except for opposition. To grasp wider cylinders using the precision grasp, subjects basically decrease closeness and palmar arching and increase opposition. Conversely, when using the power grasp with wider diameters, subjects mostly decrease digit arching and closeness and increase opposition. These results are coherent with those from previous works (Cuijpers et al., 2004; Domalain et al., 2008; Meulenbroek et al., 2001; Santello and Soechting, 1998), as they show that the hand adapts its aperture to the object size, but provide much more detailed comprehensive information. Different weight effects were also identified depending on the grasp type performed for all $R K V s$ except for finger adduction. In fact, very small changes in the $R K V s$ are observed when varying the weight in the power grasp (significant differences were found only on digit arching and opposition with weight), while the differences in the precision grasp are higher. The increase in weight in the precision grasp was counteracted with lower values for digit arching and palmar arching and an increase for closeness. This agrees with the fact that additional flexion strength requires intrinsic muscle collaboration, which generates flexion on MCP joints and extension on PIP and DIP joints (Brand and Hollister, 1999). In the power grasp, postures do not change so much, as the grasp forces required are far from their limits and the hand posture is conditioned by the cylinder geometry being grasped.

The values of digit arching are always higher for power than for precision grasp and the variance explained by grasp type in both cases for digit arching is very high compared with the other factors, so that this variable may help to distinguish between both grasp types when grasping cylinders. Future works should consider a wider range of 
grasps and object shapes to study whether RKVs can be used as automatic predictors of the type of grasp being used at each instant. This would reduce time in analysing videos of observational techniques with the advantage that velocities and accelerations could be also considered.

A significant effect of the subject factor has been identified on all $R K V s$ when varying cylinder diameter or weight. Moreover, the subject was the factor that explained most of the variance in all $R K V s$ (except for digit arching which depends mainly on the grasp type, as said above) in both experiments. It is obvious that hand size affects hand posture (Edgren et al., 2004), but we wanted to check whether the variance introduced by the subject in our experiments was mostly due to differences in hand anthropometry, or to other factors such as personal preferences or anatomical variations in the intertendinous connections, i.e., we wanted to evaluate the result of substituting the subject effect by the hand size in posture prediction. This hypothesis was discarded, as no relationship was observed between the mean values of the $R K V s$ and hand size (represented by $H B \cdot H L$, $H B$ or $H L$ ), for the different cylinder diameters and weights, with any of the grasp types considered. The low variances explained by the univariate models that used $H B \cdot H L$ as a covariable, unlike the high variances explained by the univariate models that used the subject factor, confirm that the subject effect is complex, and only a small part of it might be explained by looking at hand anthropometry; basically, higher hand sizes seem to require higher closeness, in an effort to adapt the hand to the cylinder being grasped. Although these results have to be taken with care because of the small number of subjects considered, we observed large differences in the overall ranges (mean and confidence interval) of the $R K V s$ used by the different subjects participating in the experiments, which possibly implied the use of different strategies to accomplish the grasp. The hierarchical clustering analyses revealed some similarities in the grasping postures between different pair of subjects for each grasp type, i.e., these pairs of subjects used the same strategy to perform a specific grasp type. Notice that most of the similarities found between pair of subjects occurred for subjects with very different hand sizes, like subjects 1 and 5, 3 and 6, and 1 and 4. Pairs of subjects with similar grasping postures were different for each grasp type, which is consistent with the significant effect observed for the interaction grasp type $x$ subject.

In short, using the kinematic reduction we have been able to show how the cylinder diameter and weight affect the hand posture in a comprehensive way. We have shown that both cylinder diameter and weight significantly affect precision grasping posture (diameter affects closeness, palmar arching and opposition, while weight affects digit arching, palmar arching and closeness), while the power-grasping posture is mainly affected by the cylinder diameter (which affects digit arching, closeness and opposition). In addition, we have seen that the factor digit arching could be used for distinguishing automatically between both grasp types studied. Finally, we have also shown that the subject factor is the one that most affects the hand posture, and that it makes a large contribution arising from factors other than hand size. Further studies involving a large 
varied number of subjects might help to identify the most common strategies for performing each grasp type.

One limitation of our study comes from the range of weights and sizes considered in the experiments, and from the number of subjects. Furthermore, we have to limit the validity of our particular results to holding cylinders, but the method presented here to study the kinematics of hand posture can be useful to study the grasping posture for other objects and tasks.

\subsection{Conclusion}

Hand posture analysis in ergonomics can benefit from the use of PCA and factorial analysis, as the whole hand grasping kinematics is actually low dimensional. The use of the RKVs to study hand posture is a good compromise between simplicity of posture representation and accuracy.

Kinematic reduction has allowed a comprehensive study of the effect of cylinder diameter and weight on the hand posture. Both cylinder diameter and weight significantly affect precision grasping posture: diameter affects closeness, palmar arching and opposition, while weight affects digit arching, palmar arching and closeness. Powergrasping posture is affected by the cylinder diameter, through digit arching, closeness and opposition. Finally, the factor subject has a large effect on the hand posture, with a large contribution arising from factors other than hand size.

A potential use of RKVs as automatic predictors of the type of grasp used at each instant has also been postulated, which would accelerate data processing of observational techniques, with the added value of allowing velocity and acceleration analysis. 


\section{CHAPTER 3}

Contributions on hand kinematic reduction (II): application to activities of daily living using temporal data 

This chapter focuses on the use of the kinematics reduction method explained in the previous chapter to the characterisation of hand kinematics by means of studying the temporal evolution of kinematic patterns applied to a set of representative ADL. I am preparing it to be submitted to the IEEE Transactions on Neural Systems and Rehabilitation Engineering

\subsection{Abstract \& keywords}

PCA method presented in Chapter 2 has been used to reduce the dimensionality of the dataset to a limited number of kinematic patterns underlying a large variety of ADL. The study presented in this chapter involved a large number of subjects ( 22 subjects) and activities (26 simulated ADL). Results on PCs were consistent with previous literature results, showing an important reduction in the number of DoF of the hand: Five kinematic synergies were obtained during the reaching and performance phases of the 26 simulated ADLs, explaining $75 \%$ of the total variance. The three first synergies obtained were very similar to those obtained in Chapter 2: metacarpophalangeal finger joints coordination (closeness), proximal interphalangeal joint coordination (digit arching) and palmar arching, respectively. Therefore, this method allowed me characterizing the hand kinematics in ADL by means of a rational generalised method. In addition, standardised upper limb tasks allowed me comparing the same activity between different subjects in different phases of movement (reaching and manipulation), by means of studying the temporal evolution of kinematic patterns.

Keywords: activities of daily living, hand grasps, hand kinematics, principal component analysis

\subsection{Introduction}

The hand is a complex mechanical system that provides humans with the ability to reach, grasp, and manipulate objects, which are essential to perform activities of daily living (ADL). Reaching precedes grasp and combines the approaching movement of the hand to the object and the finger joint motion in anticipation of the intended grasp (Arbib and A., 1985; Jeannerod and M., 1981). Reaching ends when the hand grasps and stably holds the object. Depending on the ability, force and dexterity required to manipulate the object, a different number of grasps is presented in the literature depending on their purpose (Edwards et al., 2002; Feix et al., 2009; Vergara et al., 2014). Subsequent manipulation is characterised by hand motions that allow the required movements of an object to perform activities. Manipulation can be as simple as moving an object or as complex as simultaneously transporting and handling an object accurately with fingertips (Landsmeer, 1962). Consequently, the ability to reach, grasp and manipulate an object 
involves many neural structures that work in concert in a highly complex way to control intricate hand kinematics (Castiello, 2005).

The study of hand kinematics required for performing ADL in the different involved phases can provide measurable objective data to better understand human movement (e.g. to assess hand function (Tsai et al., 2017)), improve grasping in robotics (Grinyagin et al., 2005; Sanchez-Margallo et al., 2010), or make hand models more realistic, such as three-dimensional modelling for films or computer games (Gustus et al., 2012)), or to even improve rehabilitation and physiotherapy (Chiu et al., 2000; Nathan et al., 2009; Oess et al., 2012). However, the high number of degrees of freedom (DoF) of the hand hinders such analysis, so that the studies of the kinematics used during ADL are mainly limited to the analysis of the ranges of motion of the hand joints (Gates et al., 2016; Gracia-Ibáñez et al., 2017b) and grasping trajectories and velocities (Coupier et al., 2016; Mottet et al., 2017). However, hand kinematics behaviour while performing ADL is not only defined by these parameters, but also by the coordination underlying ADL performance (SangWook Lee et al., 2014).

In Chapter 2, I proposed using kinematic reduction through a principal component analysis (PCA) to make the analysis of the simultaneous movement of all hand joints affordable, based on the fact that these movements are coordinated because of mechanical and neurological couplings. As a result, I showed that using these coordinated movements to address hand characterisation is a good compromise between the simplicity of kinematic representation and accuracy. These coordinated movements are commonly known as kinematic synergies (Bernstein, 1967), and are suggested to represent the basic building blocks underlying natural hand motions that can be used to represent hand movements to, therefore, reduce the dimensionality of kinematics (d'Avella et al., 2003; Prevete et al., 2018; Smeets and Brenner, 2016). PCA has been applied previously to study the human grasp with different purposes (Braido and Zhang, 2004; Jarque-Bou et al., 2016; Jarrassé et al., 2014; Liu et al., 2016; Mason et al., 2001; Patel et al., 2017; Santello et al., 1998; Thakur et al., 2008; Todorov and Ghahramani, 2004), but these studies provided limited knowledge regarding the characterisation of the hand kinematics during ADL. A recent study (Jarque-Bou et al., 2019) provided a set of hand kinematic synergies extracted from the largest database of kinematic hand grasps currently available. 418 individual extracted synergies were grouped into 12 groups of synergies explaining $80 \%$ of the total variance, with the first three groups of synergies explaining $40 \%$ of the variance. Higher-order synergies $\left(4^{\text {th }}\right.$ to $12^{\text {th }}$ synergy groups $)$ showed higher variability, probably due to the high number of subjects (different coordination strategies to perform the same grasps). However, the studies focused on obtaining the synergies used by the hand while performing different grasps, but they did not analyse how the synergies are used for performing the tasks. Main results from these studies can be summarised as: a reduced number of synergies are needed to reproduce the original movements (Mason et al., 2001; Santello et al., 1998); a greater number of DoF requires more synergies (Jarrassé et al., 2014); the synergies are different depending on the tasks or grasps considered, and not all subjects use exactly the same synergies (Todorov and 
Ghahramani, 2004); and hand actions are best represented as sparse combinations of a predefined set of basic synergies, each involving a reduced number of DoF (Prevete et al., 2018).

The studies on hand synergies from literature present other limitations as regards the representativeness of the hand function while performing ADL. Firstly, the number of subjects considered in most works is quite limited (no more than 10). Secondly, studies tend to focus on small sets of activities, which poorly represent the wide range of activities needed in daily living. Lastly, most studies focus on analysing either postural synergies of static grasps, and therefore ignore the reaching and manipulation phases required to perform ADL or very specific and controlled tasks. Regarding the first limitation, the data sample size as well as the number of subjects involved in the study must be high enough to obtain representative results, since the subject was the factor that explained most of the variance in Chapter 2. Third, a selection of a limited set of representative tasks is needed to be chosen, given the wide variety of ADL that can be performed by humans. The selection of representative activities for the functional assessment of upper extremities is generally complicated, and requires the introduction of specific protocols to standardise the task (Reissner et al., 2019). Standardisation of the tasks would help distinguishing between the different task phases (Hebert et al., 2014), and also comparing kinematic patterns of different subjects in order to identify different individual strategies used.

However, defining such set of representative ADLs, susceptible of being standardised, is not straightforward. One possibility would be to select tasks from those considered in the common clinical tests used to track the functional recovery of the upper extremity. These clinical tests consider different variety of ADL, ranging from 7 to 20 . Some focus more on assessing fine motor skills, such as the Jamar Hand Function Test or the Jebsen Hand Function Test (Program, 2006), centre more on measuring the ability to perform the more realistic tasks required in ADL, such as the Sollerman Hand Function Test (SHFT) (Sollerman and Ejeskar, 1995). SHFT is one of the most popular tests that consists of performing 20 representative ADL at the maximum possible pace following operator's instructions, which include whether subjects had to use two hands, or only the dominant one. SHFT score is computed as the sum of scores given to each of the ADL, by taking into account the time to complete the task, the difficulty encountered and the grasp used. However, the resultant score provides limited insight into the hand kinematics.

In this chapter, I propose an approach to use the kinematic reduction method explained in the Chapter 2, as a rational generalised method to characterise hand kinematics in terms of synergies during the performance of a set of 26 representative simulated ADL, based in the SHFT, by studying individually each task and differentiating between reaching and manipulation. 


\subsection{Methods}

\section{Experiment description}

Twenty-two right-handed subjects gave their written informed consent before participating in this study, approved by the ethics committee of our University. Subjects performed 26 simulated ADL), of which 20 were obtained from SHFT. Some ADL from the SHFT were adapted in order to ensure their repeatability, and six additional activities (A10, A15, A19, A24, A25, and A26) were added (Table 3.1), based on the percentage of using the commonest grasps during ADL (Vergara et al., 2014). Figure 3.1 shows the scenario with the objects used in the ADL.

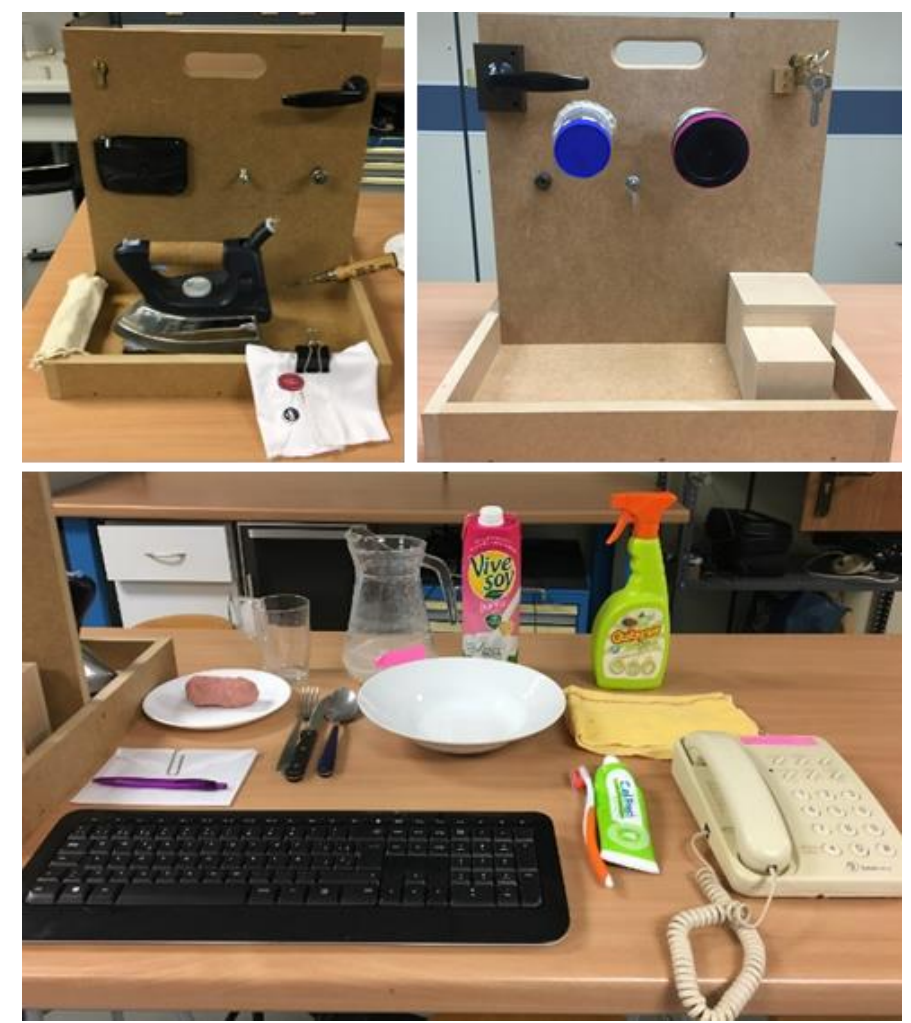

Figure 3.1 Scenario used during the experiment

Each simulated ADL started and ended with the body and arms in the same posture (arms relaxed at the side of the body if people were standing, or arms resting in a relaxed position on the table if they were sitting). Precise instructions were provided for each task, including details such as the angle of rotation of the key (A8), the position of the coin (A1 \& A3), the angle of rotation of the door handle (A9) or the amount of water to be poured (A21). The subjects could practice each task as many times as necessary in advance to become familiar with performing it before recordings. While carrying out each task, the operator marked (or labelled) the time stamp of two specific events: when any part of the hand came into contact with the object and when the contact disappeared to release the object. 
Table 3.1 Description of the ADL performed

\begin{tabular}{cl}
\hline \hline ADLs & \\
\hline A1 & Collecting a coin and putting it into a change purse \\
A2 & Opening and closing a zip \\
A3 & Removing the coin from the change purse and leaving it on the table \\
A4 & Catching and moving two different sized wooden cubes \\
A5 & Lifting and moving an iron from one marked point to another \\
A6 & Taking a screwdriver and turning a screw clockwise $360^{\circ}$ with it \\
A7 & Taking a nut and turning it until completely inserted inside the bolt \\
A8 & Taking a key, placing it in a lock and turning it counter-clockwise $180^{\circ}$ \\
A9 & Turning a door handle 30 \\
A10 & Tying a shoelace \\
A11 & Unscrewing two lids and leaving them on the table \\
A12 & Passing two buttons through their respective buttonhole using both hands \\
A13 & Taking a bandage and putting it on his/her left arm up to the elbow \\
A14 & Taking a knife with the right hand and a fork with the left hand and splitting a piece \\
& of clay (sitting) \\
A15 & Taking a spoon with the right hand and using it 5 times to eat soup (sitting) \\
A16 & Picking up a pen from the table, writing his/her name and putting the pen back on \\
& the table (sitting) \\
A17 & Folding a piece of paper with both hands, placing it into an envelope and leaving it \\
& on the table (sitting) \\
A18 & Taking a clip and putting it on the flap of the envelope (sitting) \\
A19 & Writing with the keypad (sitting) \\
A20 & Picking up the phone, placing it to his/her ear and hanging up the phone (sitting) \\
A21 & Pouring 1L of water from a carton into a jug (sitting) \\
A22 & Pouring water from the jug into the cup up to a marked point (sitting) \\
A23 & Pouring the water from the cup back into the jug (sitting) \\
A24 & Putting toothpaste on the toothbrush \\
A25 & Using a spray over the table 5 times \\
A26 & Cleaning the table with a cloth for 5 seconds \\
\hline \hline
\end{tabular}

The right hand kinematics was recorded $(100 \mathrm{~Hz})$ during the performance of these simulated ADL with an instrumented glove (Cyberglove Systems LLC; San Jose, CA), using a previously validated calibration protocol (Gracia-Ibáñez et al., 2017). Sixteen joint angles recorded were: MCP1 to MCP5, 1 to 5 meaning thumb to little digits flexion, IP1 flexion, PIP2 to PIP5 flexion, flexion and abduction of the thumb CMC1 joint, relative abduction between fingers (index-middle: MCP2-3_A; middle-ring: MCP3-4_A; and ring-little: MCP4-5_A), and palmar arch (P_Arch). A reference posture (hands resting flat on a table with fingers and thumbs close together, and middle fingers aligned with forearms) was recorded before recording the hand kinematics while performing the selected ADL, and was considered zero for all the joint angles according to (Gracia- 
Ibáñez et al., 2017). Joint angles were filtered by a 2nd-order 2-way low-pass Butterworth filter with cut-off frequency of $5 \mathrm{~Hz}$.

\section{Data analysis}

The following statistical analyses were performed using the MATLAB® software:

Kinematic reduction: The movement of each simulated ADL was divided into two phases: reaching and manipulation, defined by the marked events as follows:

- Reaching: from the go signal until touching the object to be grasped

- Manipulation: from touching the object until the contact disappeared to release the object.

For all the ADL and phases to be weighted the same in the analyses, the number of frames of each record (per subject and each ADL) were rescaled to 500 for both the reaching and manipulation phases, with a total of 1000 frames per ADL.

In order to assess the kinematic synergies, a PCA was applied to all frames of both phases altogether of all ADL and subjects. PCA matrix input was composed of the ensemble of 16 joint angle time-profiles (1000 frames) for the 26 ADL and 22 subjects (matrix dimension $16 \times 572,000$ ). This procedure allows computing the temporal scores of the different PCs, representing the time-varying of the PCs and can be interpreted from their correlations with the original variables. The first PCs with eigenvalues higher than 1 were obtained with Varimax rotation (usually applied so that interpretations becomes easier, each involving a reduced number of DoF (Prevete et al., 2018). The normalisation was performed referred to the sample data as reported in the previous Chapter 2. Description of the PCs was performed by means of the rotated component matrix for the PCs extracted and the variance explained in the PCA. The coordination represented by each PC was interpreted (and graphically represented using Opensim) from the elements of the rotated PCs extracted.

The temporal scores of the PCs were calculated and used as reduced kinematic variables (RKV-PCs). Statistics (mean and SD values) of the joint angles across all simulated ADL and subjects (input matrix of the PCA) were also presented in order to properly interpret the values of the RKV-PCs, where a value of zero corresponds to the mean posture of the corresponding joints.

Description of $R K V$-PCs during reaching: Reaching combines the approaching movement of the hand to the object and finger joint motion in anticipation of the intended grasp. The approaching hand movement is determined by the position, orientation and shape of the object to be grasped, as well as by the subject characteristics as hand size and previous experience or preferences, causing that even for the same ADL, there are subjects that use different types of grasps. Therefore, I considered convenient to study the kinematics of the hand during reaching by classifying each simulated ADL performed by 
each subject according to the intended grasp performed in the reaching phase. For such goal, I considered the 9-type classification of the most common grasps used in ADL proposed by Vergara et al (Vergara et\& al., 2014) (Figure 3.2): Cylindrical grasp (Cyl), intermediate power-precision grasp (IntPP), lateral pinch (LatP), Hook grasp (Hook), lumbrical grasp (Lum), nonprehensile grasp $(\mathrm{NonP})$, oblique palmar grasp $(\mathrm{Obl})$, pad-topad pinch $(P p P i n c h)$, and special pinch $(S p P)$.
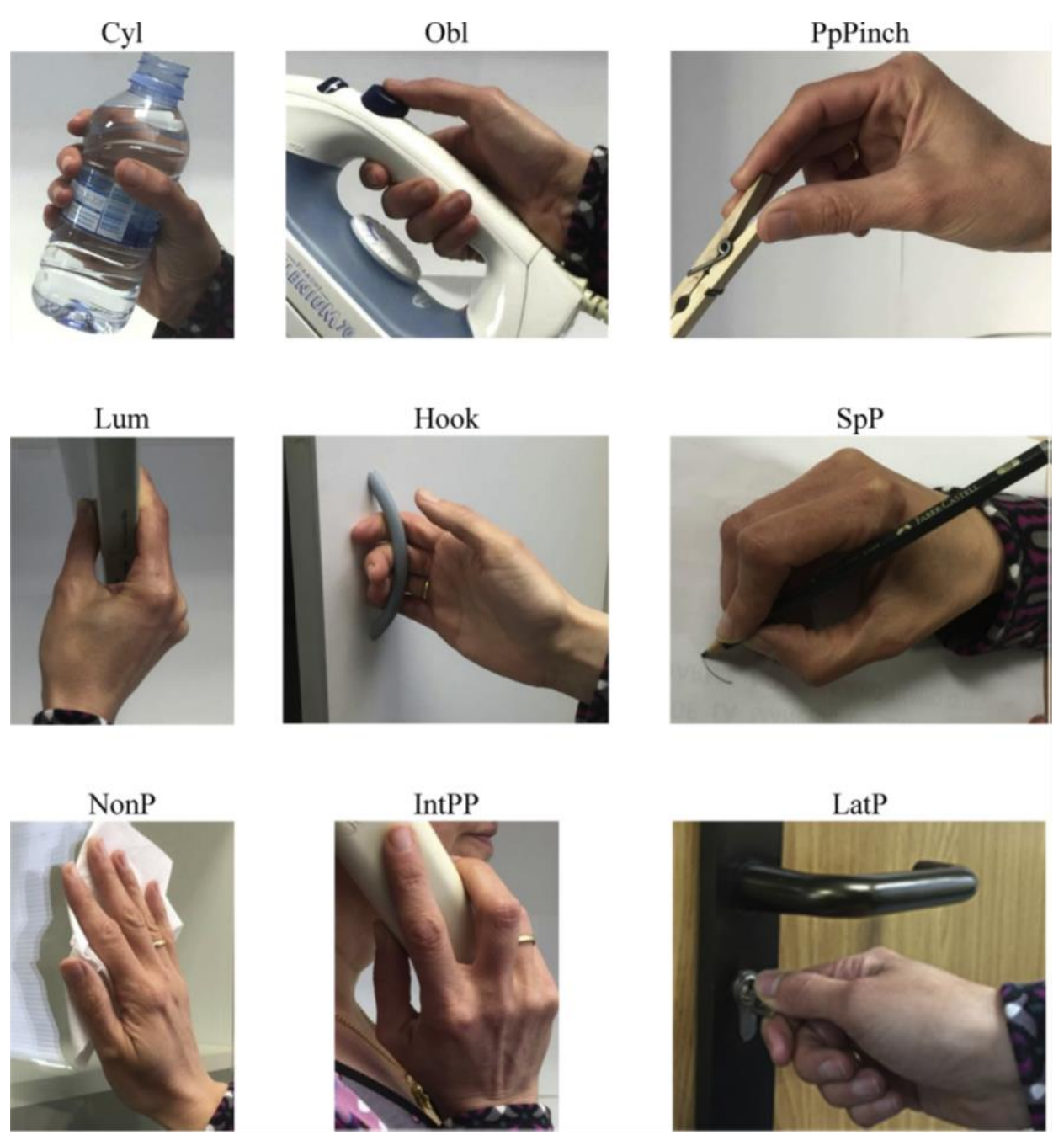

Figure 3.2 The nine different grasps considered in the taxonomy (Gracia-Ibáñez et al., 2018)

This taxonomy was used to classify the intended grasp performed by each subject in each ADL through a visual check of the experimental videos $(22$ subjects $\times 26 \mathrm{ADL}=$ 572 videos). The grasps were identified by looking at the time when the hand grasped the object for the first time, independently of the final grasp used. The frequency of grasps observed per each ADL was presented, and characterisation of hand kinematics was performed through a description of the RKV-PCs, differentiating per type of intended grasp: 
- Mean values across subjects and frames of the RKV-PCs and differences between the 95th and 5th percentiles (range).

- Temporal description of the averaged RKV-PCs and $95 \%$ confidence intervals (CI) across subjects.

Description of RKV-PCs during manipulation: During the manipulation, hand motion is characterised by the required movements of the object for the development of the ADL. Characterisation of hand kinematics during manipulation was performed through description of the RKV-PCs, differentiating per ADL, by means of:

- Mean values across subjects and frames of the RKV-PCs and differences between the 95th and 5th percentiles (range)

- Temporal description of the averaged RKV-PCs and 95\% confidence intervals

(CI) across subjects.

A cluster analysis was performed by using the aforementioned statistics (mean and range values), in order to look for similar requirements during the manipulation in the different ADL. In this case, Hierarchical clustering analysis (Hair et al., 2009), with the Euclidean distance as the distance criterion and Ward's method as the linkage criterion, was applied to group similar ADL. The resulting dendrogram with the ADL organised in branches was used to identify the clusters by observing the distances in each step. When the distance between the clustered groups in a step becomes high in comparison to the previous steps, the elements or clusters grouped are not so close and so the grouping of the previous step may be more appropriate. The resulting groups of ADL were described, and a summary of their statistics of the RKV-PCs (and box plots) was used in order to characterise the kinematics during manipulation in each group of ADL.

\subsection{Results}

The statistics of the postures recorded for each joint are shown in Table 3.2. Zero degrees correspond to the reference posture. Mean posture corresponds to a slightly flexed posture in all joints with exception of the CMC and MCP thumb joints, with fingers and thumb also slightly abducted. In addition, seemed to have displayed ample variation during recordings, with $\mathrm{Ab} / \mathrm{Ad}$ movements being those with less variation, as expected given their narrower range of motion.

Table 3.2 Mean and SD values of joint angles measured across ADL and subjects. F/E corresponds with flexion/extension and Ab/Ad with abduction/adduction movements.

\begin{tabular}{lcc|cc}
\hline \multicolumn{3}{c|}{ Original variables } & \multicolumn{2}{c}{ Statistics } \\
\hline \multirow{2}{*}{ Digit } & Joint & \multirow{2}{*}{ Movement } & Mean (degrees) & SD (degrees) \\
\hline \multirow{2}{*}{ Thumb } & CMC & F/E & -2.51 & 18.33 \\
\cline { 2 - 5 } & MCP & F/E & -3.86 & 9.45 \\
\hline
\end{tabular}


Chapter 3. Contributions on hand kinematic reduction (II):

\begin{tabular}{lcc|cc}
\hline \multicolumn{3}{c}{ Original variables } & \multicolumn{2}{c}{ Statistics } \\
\hline Digit & Joint & Movement & Mean (degrees) & SD (degrees) \\
\hline Thumb-Index & CMC & Ab/Ad & 13.32 & 4.75 \\
\hline Index & MCP & F/E & 21.20 & 17.76 \\
\hline & PIP & F/E & 39.32 & 21.39 \\
\hline Index-Middle & MCP & Ab/Ad & 4.33 & 7.71 \\
\hline \multirow{2}{*}{ Middle } & MCP & F/E & 30.87 & 22.36 \\
\hline Middle-Ring & PIP & F/E & 43.05 & 20.13 \\
\hline \multirow{2}{*}{ Ring } & MCP & Ab/Ad & 6.37 & 5.86 \\
\hline Ring-Little & MCP & F/E & 21.55 & 21.88 \\
\hline \multirow{2}{*}{ Little } & PIP & F/E & 48.89 & 22.84 \\
\hline Palm & MCP & Ab/Ad & 1.12 & 5.05 \\
\hline & MCP & F/E & 22.62 & 23.23 \\
\cline { 2 - 5 } & PIP & F/E & 41.03 & 22.22 \\
\hline
\end{tabular}

\section{Kinematics reduction}

Five PCs were extracted, which accounted for $75 \%$ of the total variance, the first two being responsible for $48 \%$ of this variance. Table 3.3 shows the correlations of these PCs with the original variables, which have been used for their graphical representation (Figure 3.3) by means of the hand kinematic model developed in Opensim by the ARMS lab of the Shirley Ryan AbilityLab (Formerly Rehabilitation Institute of Chicago) (Buffi et al., 2013; Holzbaur et al., 2005).

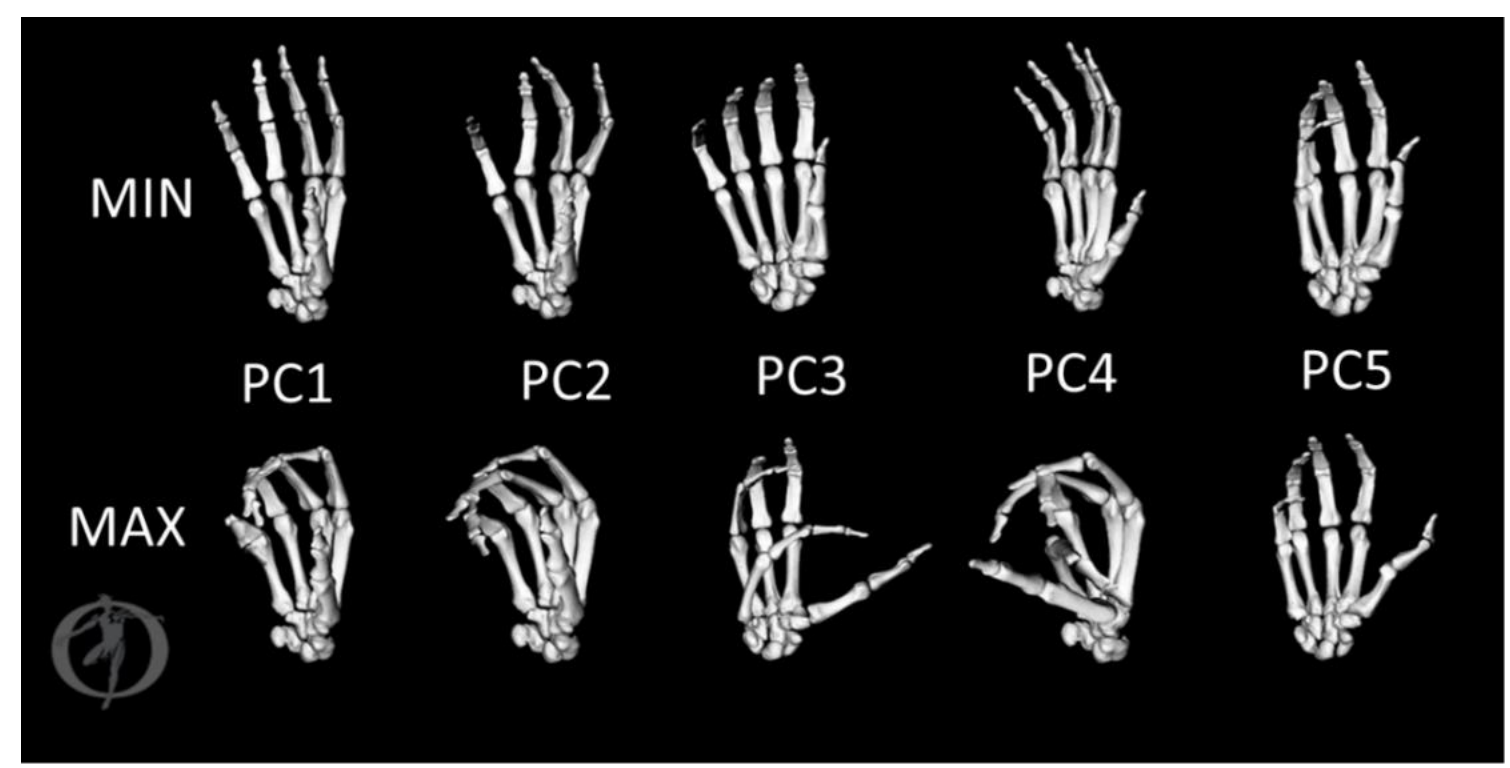

Figure 3.3 Mean extreme postures (MIN and MAX) representing the 6 PCs obtained from the $P C A$, and used later for the kinematical reduction 
Table 3.3 Rotated component matrix for the 5 PCs extracted during reaching and manipulation, showing the correlations between each of the original variables and the estimated PCs. To simplify the interpretation of results, values smaller than 0.1 have been suppressed and those bigger than 0.4 are in bold

\begin{tabular}{|c|c|c|c|c|c|c|c|}
\hline \multicolumn{3}{|c|}{ Original variables } & \multicolumn{5}{|c|}{ Estimated PCs } \\
\hline Digit & Joint & Movement & $\mathrm{PC}_{1}$ & $\mathrm{PC}_{2}$ & $\mathrm{PC}_{3}$ & $\mathrm{PC}_{4}$ & $\mathrm{PC}_{5}$ \\
\hline \multirow{3}{*}{ Thumb } & $\mathrm{CMC}$ & $\mathrm{F} / \mathrm{E}$ & & & 0.83 & 0.25 & -0.17 \\
\hline & $\mathrm{MCP}$ & $\mathrm{F} / \mathrm{E}$ & & -0.24 & -0.24 & -0.12 & -0.69 \\
\hline & IP & $\mathrm{F} / \mathrm{E}$ & & & -0.22 & & $\mathbf{0 . 7 5}$ \\
\hline Thumb-Index & $\mathrm{CMC}$ & $\mathrm{Ab} / \mathrm{Ad}$ & 0.22 & & & 0.86 & \\
\hline \multirow{2}{*}{ Index } & $\mathrm{MCP}$ & $\mathrm{F} / \mathrm{E}$ & 0.30 & 0.78 & & 0.23 & -0.18 \\
\hline & PIP & $\mathrm{F} / \mathrm{E}$ & 0.66 & -0.25 & & 0.11 & 0.20 \\
\hline Index-Middle & $\mathrm{MCP}$ & $\mathrm{Ab} / \mathrm{Ad}$ & & -0.74 & & 0.32 & \\
\hline \multirow{2}{*}{ Middle } & $\mathrm{MCP}$ & $\mathrm{F} / \mathrm{E}$ & 0.39 & 0.81 & & 0.29 & \\
\hline & PIP & $\mathrm{F} / \mathrm{E}$ & 0.94 & & & 0.11 & \\
\hline Middle-Ring & MCP & $\mathrm{Ab} / \mathrm{Ad}$ & & -0.74 & -0.21 & 0.34 & \\
\hline \multirow{2}{*}{ Ring } & $\mathrm{MCP}$ & $\mathrm{F} / \mathrm{E}$ & 0.50 & 0.76 & & 0.23 & \\
\hline & PIP & $\mathrm{F} / \mathrm{E}$ & 0.95 & & & & \\
\hline Ring-Little & $\mathrm{MCP}$ & $\mathrm{Ab} / \mathrm{Ad}$ & -0.44 & -0.46 & & -0.10 & -0.37 \\
\hline \multirow{2}{*}{ Little } & $\mathrm{MCP}$ & $\mathrm{F} / \mathrm{E}$ & 0.59 & 0.59 & & 0.26 & 0.20 \\
\hline & PIP & $\mathrm{F} / \mathrm{E}$ & 0.88 & -0.17 & & & \\
\hline Palm & P_Arch & $\mathrm{F} / \mathrm{E}$ & & & -0.78 & 0.28 & -0.12 \\
\hline \multicolumn{3}{|c|}{ Variance explained (\%) } & 25.6 & 22.9 & 9.2 & 8.8 & 8.5 \\
\hline
\end{tabular}

PC1 shows a coordinated flexion of the PIP joints of fingers, with a slight MCP joint flexion of the fingers and a small abduction/adduction of the MCP of the little finger. PC2 depicts coordinated flexion and adduction of the MCP joints of fingers. PC3 shows coordination between palmar arch extension and the CMC joint flexion of the thumb. PC4 mostly depicts CMC thumb abduction. PC5 shows coordination between the CMC.

\section{Description of RKV-PCs during reaching}

Table 3.4 presents the frequency of the intended grasps performed by the subjects for each ADL during reaching. PpPinch was the most frequent grip (35.1\%) and Hook grasp was the least frequent (3.8\%). In addition, $\mathrm{SpP}$ was not identified in the reaching phase in any case. Note that some ADL, e.g. \#14 (using a knife and a fork), \#15 (eating soup with a spoon), \#16 (writing with a pen) or \#24 (putting toothpaste on the toothbrush) have no clear predominant grasp, being all the grasps observed precision grasps. 
Table 3.4 Frequency of intended grasps used per ADL during the reaching phase

\begin{tabular}{|c|c|c|c|c|c|c|c|c|c|}
\hline ADL & PpPinch & Cyl & Lum & LatP & Obl & IntPP & $\mathrm{SpP}$ & Hook & NonP \\
\hline 1 & 22 & - & - & - & - & - & - & - & - \\
\hline 2 & - & - & - & 22 & - & - & - & - & - \\
\hline 3 & 2 & - & 14 & - & - & - & - & - & 6 \\
\hline 4 & 22 & - & - & - & - & - & - & - & - \\
\hline 5 & - & 22 & - & - & - & - & - & - & - \\
\hline 6 & 1 & - & - & - & - & 21 & - & - & - \\
\hline 7 & 21 & - & 1 & - & - & - & - & - & - \\
\hline 8 & 5 & - & - & 17 & - & - & - & - & - \\
\hline 9 & - & - & - & - & - & - & - & 22 & - \\
\hline 10 & 16 & - & - & 6 & - & - & - & - & - \\
\hline 11 & 22 & - & - & - & - & - & - & - & - \\
\hline 12 & 22 & - & - & - & - & - & - & - & - \\
\hline 13 & 21 & - & - & 1 & - & - & - & - & - \\
\hline 14 & 7 & - & - & 7 & - & 8 & - & - & - \\
\hline 15 & 7 & - & - & 13 & - & 2 & - & - & - \\
\hline 16 & 4 & - & - & 17 & - & 1 & - & - & - \\
\hline 17 & - & - & 8 & - & - & - & - & - & 14 \\
\hline 18 & 22 & - & - & - & - & - & - & - & - \\
\hline 19 & - & - & - & - & - & - & - & - & 22 \\
\hline 20 & - & - & - & - & 3 & 19 & - & - & - \\
\hline 21 & - & 22 & - & - & - & - & - & - & - \\
\hline 22 & - & 1 & - & - & 21 & - & - & - & - \\
\hline 23 & - & - & 18 & 4 & - & - & - & - & - \\
\hline 24 & 7 & - & - & 9 & - & 6 & - & - & - \\
\hline 25 & - & 22 & - & - & - & - & - & - & - \\
\hline 26 & - & - & - & - & - & 3 & - & - & 19 \\
\hline Total $(\%)$ & $35.1 \%$ & $11.7 \%$ & $7.2 \%$ & $16.8 \%$ & $4.2 \%$ & $10.5 \%$ & $0.0 \%$ & $3.8 \%$ & $10.7 \%$ \\
\hline
\end{tabular}

Table 3.5 shows some statistics across subjects and frames of each RKV-PC per intended grasp, such as mean and range (difference between the 95th and 5th percentiles). The results show different mean, median and range values of each RKV-PCs, according to the type of intended grasp. Across grasps, all the RKV-PCs present negative (RKVPC1, RKV-PC2 and RKV-PC4) or zero mean values (RKV-PC3, RKV-PC5). The widest range is observed for the RKV-PC1. 
Table 3.5 Mean and range (difference between $95^{\text {th }}$ percentile and $5^{\text {th }}$ percentile) of each $R K V$ $P C$ during each intended grasp

\begin{tabular}{l|cccccccccc}
\multirow{2}{*}{} & \multicolumn{2}{|c}{ RKV-PC1 } & \multicolumn{2}{c}{ RKV-PC2 } & \multicolumn{2}{c}{ RKV-PC3 } & \multicolumn{2}{c}{ RKV-PC4 } & \multicolumn{2}{c}{ RKV-PC5 } \\
\cline { 2 - 11 } PpPinch & mean & range & mean & range & mean & range & mean & range & mean & range \\
\cline { 2 - 11 } Cyl & -0.18 & 1.19 & -0.23 & 1.16 & -0.03 & 0.61 & -0.09 & 1.07 & -0.09 & 0.95 \\
Lum & -0.88 & 1.09 & -0.47 & 1.40 & 0.10 & 0.76 & 0.07 & 1.81 & 0.25 & 0.80 \\
LatP & -0.88 & 0.99 & 0.00 & 0.81 & 0.01 & 0.66 & -0.15 & 1.66 & -0.33 & 0.98 \\
Obl & 0.11 & 1.80 & 0.06 & 1.08 & 0.06 & 0.65 & -0.48 & 0.82 & 0.08 & 0.97 \\
IntPP & 0.73 & 2.60 & -0.13 & 1.28 & 0.21 & 0.92 & -0.71 & 1.20 & -0.04 & 0.98 \\
Hook & 0.24 & 2.00 & -0.33 & 1.15 & 0.00 & 0.72 & -0.46 & 0.98 & 0.08 & 0.86 \\
NonP & 0.13 & 1.41 & -0.04 & 0.99 & -0.20 & 0.46 & -0.39 & 0.66 & 0.04 & 0.63 \\
\hline All & -1.08 & 0.61 & -0.21 & 0.60 & 0.22 & 0.55 & -0.63 & 0.77 & 0.02 & 0.47 \\
\hline
\end{tabular}

For the eight intended grasps identified, the temporal evolution of the mean value of each RKV-PC with the 95\% confidence interval are shown in Figure 3.4. The curve profiles were similar for some RKV-PC between different grasps (but with differences in the average and peak values), but presented clear differences in other cases.

RKV-PC1 shows the highest positive mean and range values for the $O b l$ grasp, with the highest negative values are found for grasps NonP, Cyl and Lum. From the temporal evolution, RKV-PC1 presents similar profiles along the reaching movement for all grasp types (ascending value) i.e. when opening the hand required in the pre-shaping phase, the PIP joints are flexed. The Hook grasp presents the main difference, in which the ascending profile occurs at the end of the phase.

For all the grasps, RKV-PC2 showed almost no movement in the first half of the reaching phase, i.e. no movement is required for the MCP joints. The $\mathrm{Cyl}, \mathrm{Obl}$ and Hook grasps firstly decrease in the second half of the movement followed by an increase until the end of the phase; i.e. during the opening of the hand required in the pre-shaping phase for these grasps MCP joints are first extended and then flexed. Contrarily, Lum and LatP showed only a slightly increase which means only a slight flexion of the MCP joints while PpPinch, IntPP and NonP needed a slightly decrease along the phase; i.e. these grasps required slightly extended MCP joints. Note that RKV-PC2 shows the widest range value for the $C y l$ grasp

RKV-PC3 profiles present quite dispersion but almost no differences during any of the grasps, i.e. with mean and range values similar between grasps, with the exception of $\mathrm{Obl}$ grasp that presents the widest range and mean values, needed to flex the palm to grasp the object while the thumb extends. It shows slight homogeneity between grasps (wide IC), except in PpPinch for which almost no changes can be seen.

RKV-PC4 has the highest negative mean and median value for the NonP while the highest positive mean and median and range values for the Cyl and Lum grasps. RKV- 
PC4 profiles present a slight ascending value throughout movement for all grasps, except for the Hook grasps which presents a constant value; i.e. in the reaching phase a thumb $\mathrm{CMC}$ abduction is required, except for the Hook grasp in which CMC joint remains invariable.

RKV-PC5 shows the highest negative mean and median values for the Lum grasp while the highest positive values for the $C y l$ grasp. RKV-PC5 profiles presents visually similar and slightly increasing profiles for all the grasps, except for the Lum grasp with a slightly lowering value throughout the reaching movement, i.e. for this grasp, coordination between CMC flexion and IP extension of the thumb is needed.
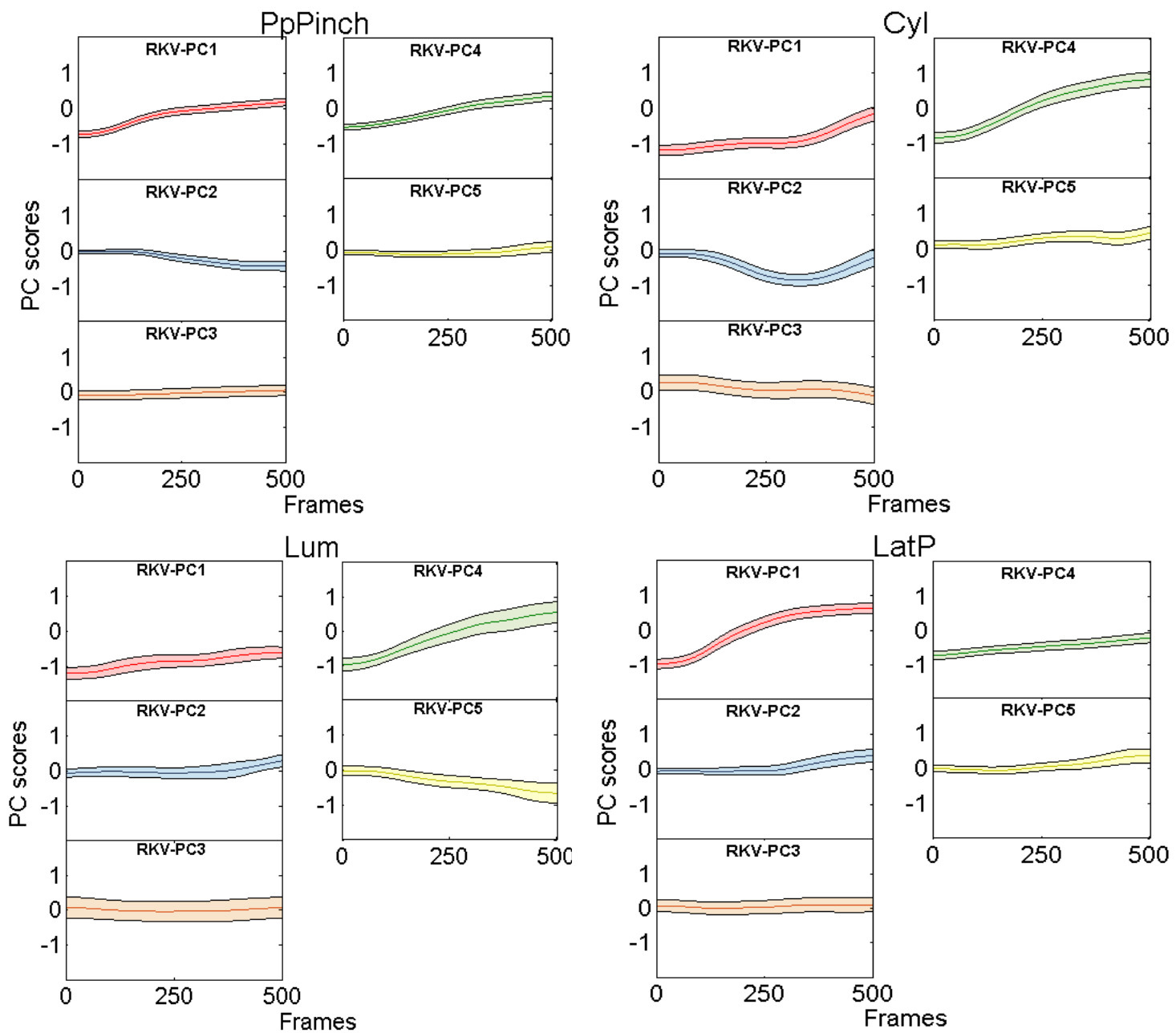

Kinematic and muscular characterisation of the hand during ADL 

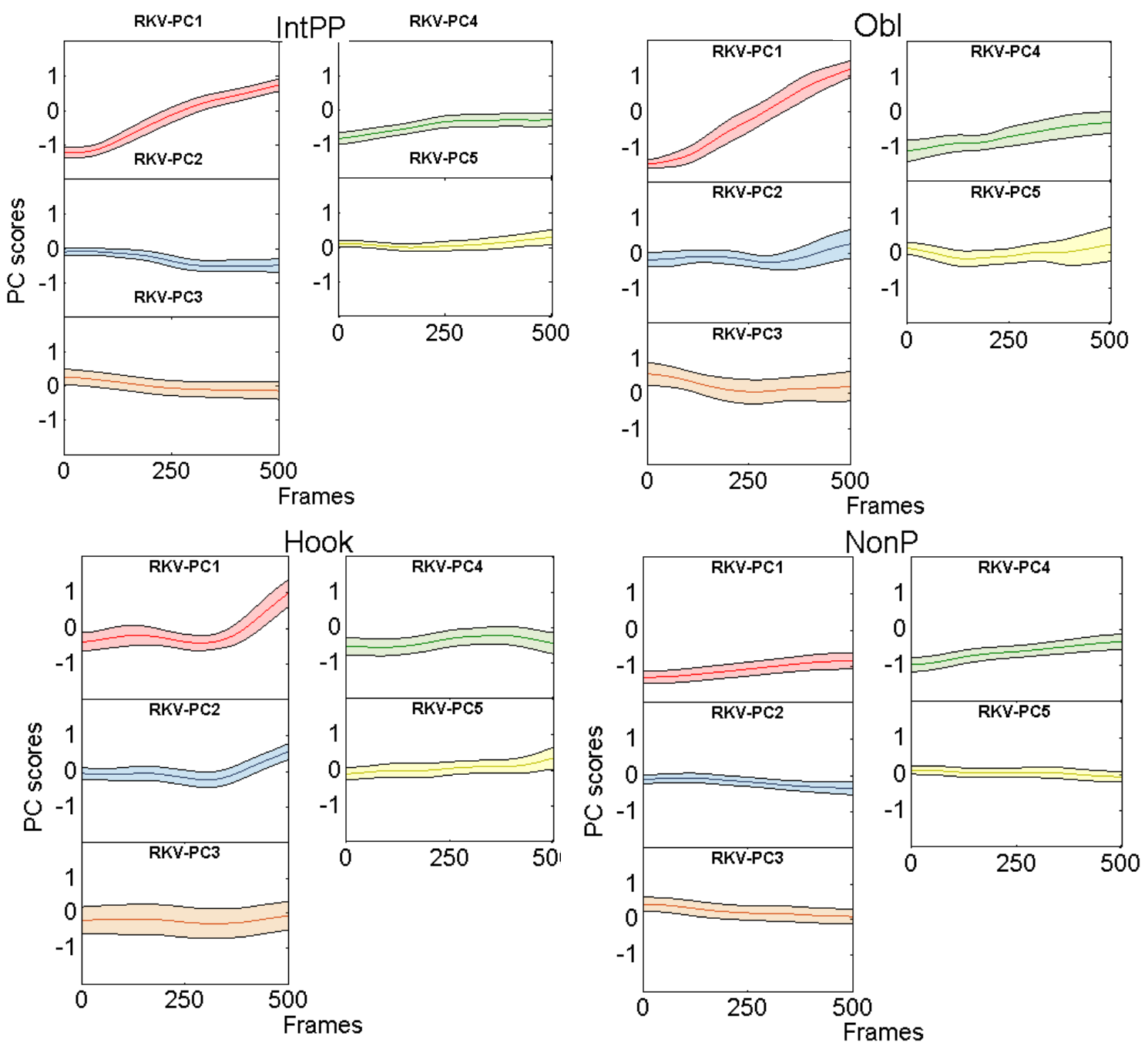

Figure 3.4 Temporal evolution of the averaged RKV-PCs and $95 \%$ CI across subjects, differentiating per grasp

\section{Description of RKV-PCs during manipulation}

Table 3.6 shows some statistics of each RKV-PC per ADL, such as mean and difference between the 95th and 5th percentiles (range). Temporal evolution of the mean value of each RKV-PC for each ADL together with their 95\% confidence interval is shown in Appendix II, Figure A.5. 
Table 3.6 Mean and difference between $95^{\text {th }}$ percentile and $5^{\text {th }}$ percentile (range) of each $R K V$ $P C$ during each ADL performed

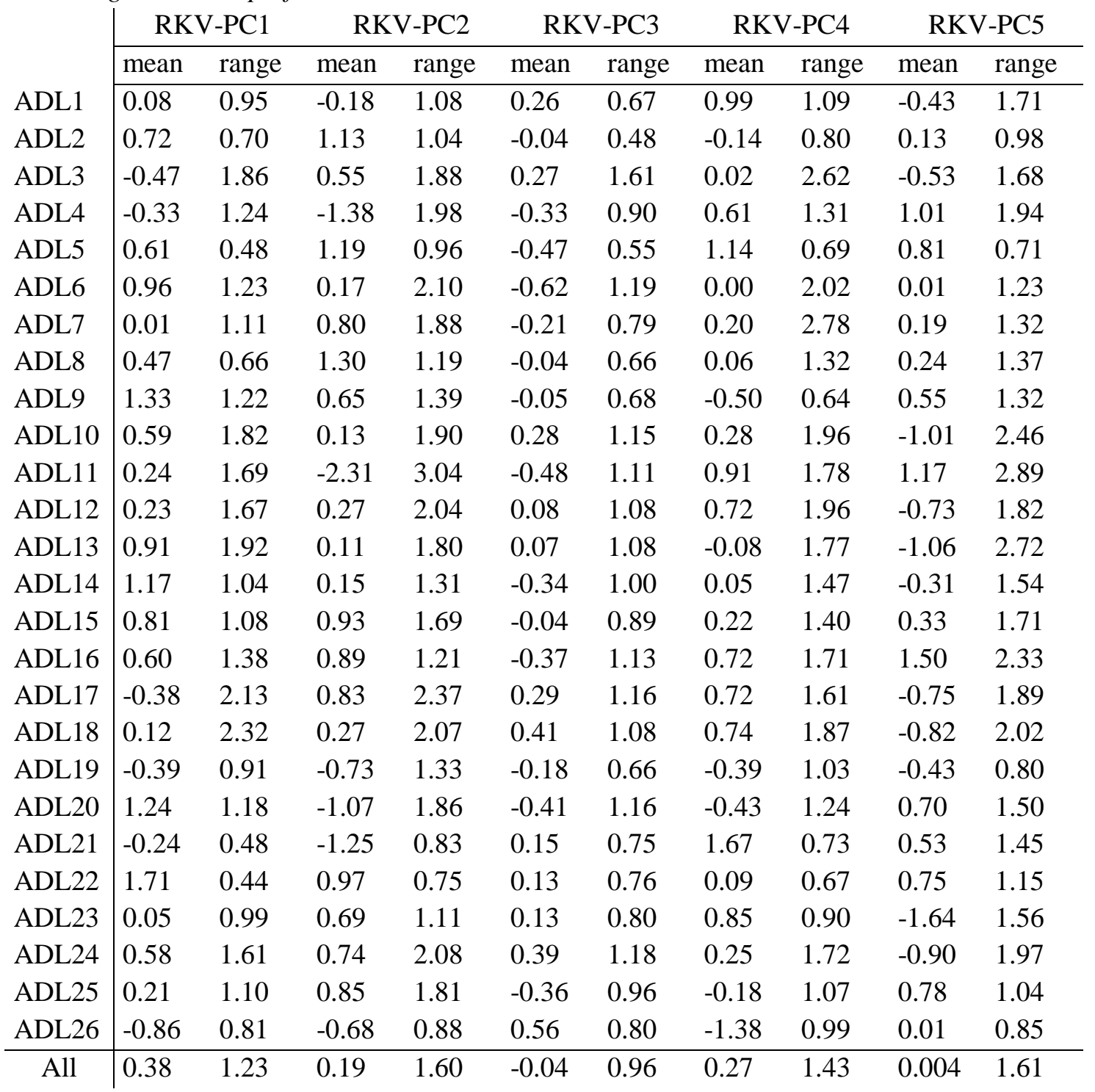

The resulting dendrogram with the ADL organised in branches according to their similarity of mean and range values of the RKV-PCs is displayed in Figure 3.5. Six clusters or groups of ADLs have been identified. Table 3.7 shows the description of these groups: ADLs grouped, intended grasps in the reaching phase, and average values across ADLs of mean and range of each RKV-PC. 

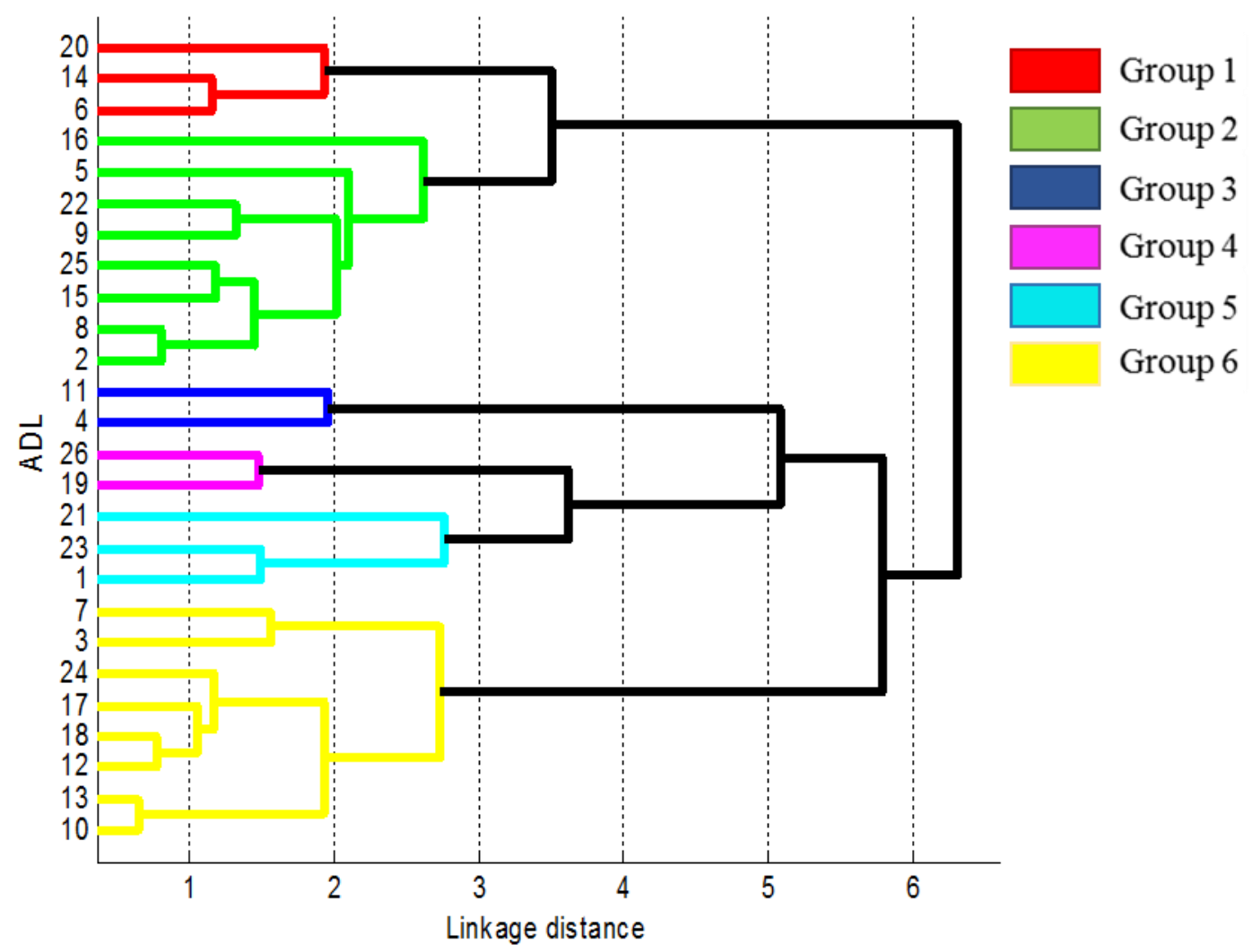

Figure 3.5 Clusters obtained

Table 3.7 Description of the groups obtained in the cluster analysis: ADLs grouped, intended grasps in the reaching phase, and average values of mean and range of each $R K V-P C$ in the manipulation phase

\begin{tabular}{c|c|c|c|c|c|c|c}
\multicolumn{2}{c|}{ Group1 } & Group2 & Group3 & Group4 & Group5 & Group6 \\
\hline \multicolumn{2}{c|}{ ADLs } & $6,14,20$ & $\begin{array}{c}2,5,8,9,15 \\
16,22,25\end{array}$ & 4,11 & 19,26 & $1,21,23$ & $\begin{array}{c}3,7,10,12, \\
13,17,18,24\end{array}$ \\
\hline \multicolumn{2}{c}{$\begin{array}{c}\text { Intended } \\
\text { grasps }\end{array}$} & IntPP & $\begin{array}{c}\text { LatP, Cyl, } \\
\text { Hook, Obl }\end{array}$ & PpPinch & NonP & $\begin{array}{c}\text { PpPinch } \\
\text { Cyl, Lum }\end{array}$ & $\begin{array}{c}\text { Lum, PpPinch } \\
\text { NonP, LatP }\end{array}$ \\
\hline RKV- & mean & 1.126 & 0.807 & -0.048 & -0.629 & -0.036 & 0.199 \\
PC1 & range & 1.151 & 0.883 & 1.462 & 0.862 & 0.807 & 1.805 \\
\hline RKV- & mean & -0.251 & 0.987 & -1.847 & -0.706 & -0.275 & 0.465 \\
PC2 & range & 1.755 & 1.255 & 2.514 & 1.107 & 1.005 & 2.001 \\
\hline RKV- & mean & -0.457 & -0.157 & -0.406 & 0.192 & 0.182 & 0.197 \\
PC3 & range & 1.103 & 0.766 & 1.007 & 0.733 & 0.741 & 1.143 \\
\hline RKV- & mean & -0.127 & 0.176 & 0.759 & -0.888 & 1.17 & 0.356 \\
PC4 & range & 1.575 & 1.038 & 1.545 & 1.011 & 0.907 & 2.036 \\
\hline RKV- & mean & 0.133 & 0.636 & 1.089 & -0.206 & -0.515 & -0.702 \\
PC5 & range & 1.422 & 1.326 & 2.418 & 0.822 & 1.574 & 1.986 \\
\hline
\end{tabular}

Kinematic and muscular characterisation of the hand during ADL 
The average values of mean and range of each RKV-PC per group show clear differences between groups identified. These values are represented in two box-plots (Figure 3.6), one for the average values of the mean and another one for the average values of the range. Boxes represent median and percentiles 25 and 75 and whiskers represent values that are within 1.5 times the interquartile range.
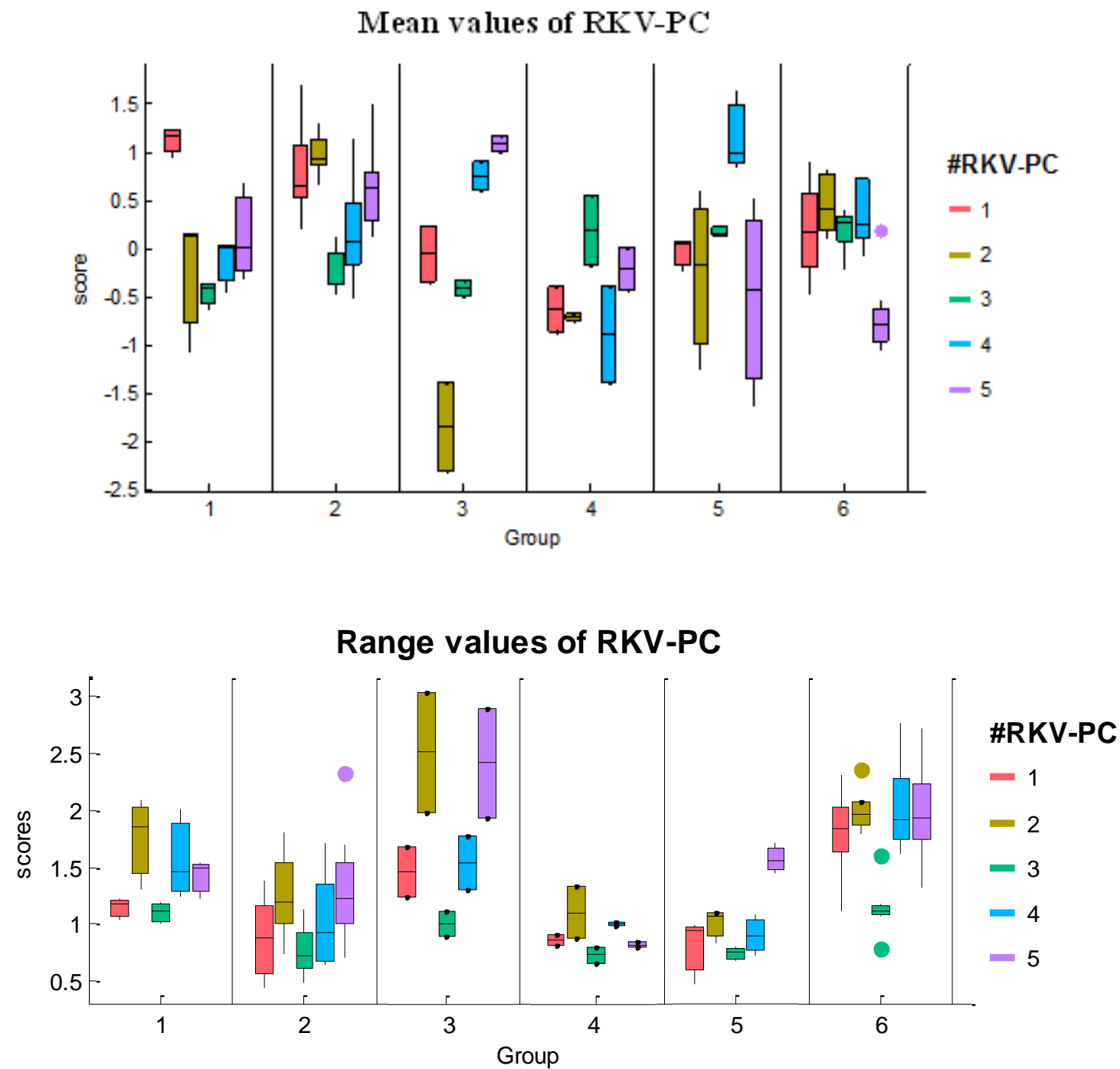

Figure 3.6 Box plots of the statistics shown in Table 3.6 (mean and range values of the RKV-PCs, differentiating per each group obtained in the dendrogram). Boxes represent median and percentiles 25 and 75 and whiskers represent values that are within 1.5 times the interquartile range

Some clear differences are observed between groups: Group 1 brings together the activities \#6, \#14, and \#20 (using a screwdriver, using knife and fork and picking up the phone). This group has the highest positive mean value for the RKV-PC1 while the highest negative mean value is shown for the RKV-PC3. RKV-PC2 and RKV-PC4 present the widest range values. Group 2 gathers activities \#2, \#5, \#8, \#9, \#15, \#16, \#22 and \#25, (using a zipper, moving the iron; opening a lock with a key, turning the door handle; 
eating with spoon, writing with a pen, pouring water from a jug and using a spray). This group has the highest positive mean value for RKV-PC1 and RKV-PC2 (similar values). Group 3 includes activities \#4 and \#11 (moving wooden cubes and unscrewing lids with a hand). This group has all the negative mean values, and the highest goes to RKV-PC4. Contrarily, Group 4 comprises activities \#19 and \#26 (writing using a keypad and cleaning the table with a cloth) and has the highest positive mean value for RKV-PC4, while the highest negative mean value is shown for RKV-PC5. The range values are narrow for all the RKV-PCs, except for RKV-PC5. Group 5 combines activities \#1, \#21, and \#23 (putting a coin into a change purse, pouring water from a jug and from a glass). This group has high positive values for RKV-PC4 and RKV-PC5, while the highest negative value is shown for RKV-PC2. This group also presents the widest range of values for RKV-PC2 and RKV-PC5. Finally, Group 6 includes activities \#3, \#7, \#10, \#12, $\# 13$, \#17, \#18, and \#24 (removing a coin from the change purse, inserting a nut inside a bolt, tying a shoelace, passing buttons, putting a bandage on the arm, folding a piece of paper and placing it inside an envelope, using a clip, and putting toothpaste on a toothbrush). This group presents similar values for all the RKV-PCs, except for RKVPC5 with a high negative value. Note that Groups 5 and 6 have the widest range values for all the RKV-PCs.

\subsection{Discussion}

In this work, I characterised the functional kinematics patterns of the hand while simulating ADL. The study was performed according to standardised actions based on SHFT, and these tasks reflect the accurate representativeness of hand functions in day-today life.

The PCA allowed reducing the dimensionality of the dataset to a limited number of kinematic patterns underlying a large variety of hand movements and explaining most (over $75 \%$ ) of the dataset variability. These results can be considered as a further experimental evidence of the modular organisation of the control strategy of the central nervous system, of the biomechanical connections between digits and of the functional organisation of multi-tendon finger muscles (Lang and Schieber, 2004; Santello et al., 2013). This set of new variables may reduce the $16 \mathrm{DoF}$ to 5, providing almost the same information but in a more easily interpretable way: RKV1 and RKV2 measure a coordinated flexion of the PIP joints of fingers (digit arch), and a coordinated flexion and adduction of the MCP joints of fingers (closeness), respectively. RKV3 measures a coordination between the palmar arch and the CMC joint of the thumb (i.e. the palmar arch). RKV4 and RKV5 mostly measures the coordination of the thumb joints: a CMC thumb abduction (thumb opposition), and a coordination between extension of CMC and flexion of IP of the thumb (thumb arch), respectively.

The first two PCs found (digit arch and closeness) explain almost the 50\% of variance, whereas each of the three remaining PCs explains only about 8\%-9\% each. As proposed by Santello (Santello et al., 1998), the lower-order synergies (digit arch and closeness) define the gross motion of the hand, while the higher-order synergies (palmar 
arch, thumb opposition and thumb arch) are required to improve or refine the control of the hand by a fine adaptation to the shape of the object and the task to be performed.

Some of the synergies obtained in this study are similar to those ones found in the previous Chapter 2 (digit arch, closeness and palmar arch) as well as to those ones found in the literature (Jarque-Bou et al., 2019; Jarrassé et al., 2014; Mason et al., 2001; Santello et al., 1998), especially the two first synergies (digit arch and closeness). The third synergy (palmar arch) has not been described in most of the previous studies, since it includes the P_Arch, which is not usually recorded and that has a small range of motion. It has been reported although in a recent study (Jarque-Bou et al., 2019) as the second synergy that explained more variance, since they used the same PCA normalisation performed in this chapter. The fourth and fifth synergies mainly represents the thumb joints coordination, which is also frequently described in literature (Jarrassé et al., 2014). However, in this work, the variance explained by these synergies is higher than that reported in literature. These results are similar to those of a recent study (Jarque-Bou et al., 2019), that reported the thumb opposition as the third synergy found. These results confirm and reinforce the importance of the thumb during the performance of ADL-

To summarise, differences in the PCs found with those from other studies may be due to different sources: 1) the PCA normalisation performed here allows comparing at the same level joints with different range of motion (i.e., the variance in joints with small range of movement, such as finger abduction/adduction or palmar arch, has been equalled to the variance in joints with greater ranges, such as finger flexion/extension). 2) Anatomical angles are not defined in the same way in all works (even in some cases raw data are directly used), and when measured with gloves (as in this case), required nonlinear correction to obtain specific anatomical angles (Eccarius et al., 2012) that is not performed in many cases. 3) Most studies considered only static postures or simple movements, in comparison to the complex movements (including reaching and manipulation) considered here. 4) The higher the number of DoF and/or subjects and/or the number and variability of activities performed, the higher the number of PCs that are required to explain variance (Liu et al., 2016).

Studying hand kinematics by the temporal evolution of the extracted synergies provided me with a good compromise between the simplicity of kinematic representation and accuracy. The RKV-PCs used to characterise the hand kinematics during simulated ADL distinguished between reaching and manipulation by analysing the temporal evolution of these new variables in these task performance phases. Therefore, this method enabled me to identify different functional patterns according to the intended grasp and ADL performed.

In the reaching phase, hand movement is determined by the distance of the object from the hand and by the shape of the object to be grasped, so that hand kinematics is expected to be dependent on the type of grasp to be performed. Therefore, the temporal evolution of RKV-PCs allowed me identifying the kinematic patterns required during the reaching phase to shape the hand accordingly to the intended type of grasp. 
PpPinch is achieved by controlling the closeness, digit arch and thumb opposition jointly (decrease of closeness, and increase of digit arch and thumb opposition) to get the opening of the hand in the pre-shaping phase. $C y l$ is shaped by controlling the digit arch and thumb opposition jointly (both increase), and controlling the closeness separately (a first decrease followed by a posterior increase until the hand touches the object to be grasped). In this way, the hand controls the opening depending on the object size. LatP, IntPP and $\mathrm{Obl}$ are characterised by the same profiles for almost every of the RKV-PCs: they are achieved by controlling jointly the digit arch and thumb opposition, but the closeness is controlled separately. LatP and $O b l$ require to increase them at the end of the reaching phase to close the hand, while IntPP requires opening of the hand during this phase. Lum is mostly achieved by controlling the thumb opposition and thumb arch, i.e. controlling the thumb during the pre-shaping phase. Hook is shaped by controlling the closeness and digit arch, i.e. controlling digit movements during the pre-shaping phase. NonP is characterised by almost no movement of any RKV-PC.

This sort of analysis allows characterizing the kinematics of the hand in terms of synergies. The different synergies found could be used to improve the control of current prostheses during reaching, considering the different behaviours between grasps observed. Table 3.8 summarises those synergies that need to be controlled per grasp.

Table 3.8 RKV-PC control needed per grasp in the reaching phase. The movement direction required by each $R K V-P C$ is marked with +/-. "+" means a positive direction of the movement; "- "means a negative direction of the movement. When both directions are needed, it is denoted as "+/- ". "="denotes that a fixed posture is needed without movement

\begin{tabular}{|c|c|c|c|c|c|}
\hline Grasp & $\begin{array}{l}\text { RKV-PC1 } \\
\text { (digit arch) }\end{array}$ & $\begin{array}{l}\text { RKV-PC2 } \\
\text { (closeness) }\end{array}$ & $\begin{array}{c}\text { RKV-PC3 } \\
\text { (palmar arch) }\end{array}$ & $\begin{array}{l}\text { RKV-PC4 } \\
\text { (thumb } \\
\text { opposition) }\end{array}$ & $\begin{array}{c}\text { RKV-PC5 } \\
\text { (thumb } \\
\text { arch) }\end{array}$ \\
\hline$C y l$ & + & $+/-$ & $=$ & + & $=$ \\
\hline PpPinch & + & - & $=$ & + & $=$ \\
\hline Lum & $=$ & $=$ & $=$ & + & - \\
\hline LatP & + & + & $=$ & + & $=$ \\
\hline $\operatorname{Int} P P$ & + & - & $=$ & + & $=$ \\
\hline$O b l$ & + & + & $-*$ & + & $=$ \\
\hline Hook & + & + & $=$ & $=$ & $=$ \\
\hline NonP & $=$ & $=$ & $=$ & $=$ & $=$ \\
\hline
\end{tabular}

*Little movement required

These results suggest that during reaching the most used synergies are the closeness, digit arch and thumb opposition with different control patterns per grasp while thumb arch and palmar arch are almost fixed and therefore, they don't need to be controlled, with the exception of the thumb arch for the Lum grasp. Note that the palmar arch is the same for all the grasps, with the exception of $\mathrm{Obl}$ where it is observed a little variation in the mean posture to reach this grasp. Although that variation could be greater with other 
sizes/shapes of the grasped object, it seems that its usefulness is better observed during manipulation.

In the manipulation phase, hand kinematics is characterised by specific movements, highly dependent on the specific tasks. In some cases, the task will require more movements of the fingers (e.g. fingers move while turning a nut), in others it will be necessary to maintain an exact configuration of the hand (e.g. fingers are fixed when pouring water). In order to understand the kinematics of this phase in a global way, I used parameters of mean postures and dispersion (mean and range between the 95th and 5th percentiles) of the RKV-PCs to classify the ADL in groups with similar requirements. Through cluster analysis I found 6 groups of ADL.

Group 1 is defined by three ADL: using a screwdriver, using knife and fork and picking up the phone. These ADLs are characterised by using IntPP grasp to manipulate objects with an elongated shape. The hand kinematics of this group is characterised mostly by a positive digit arch and negative palmar arch. In addition, closeness and thumb opposition present the widest ranges of movement.

Group 2 is defined by eight ADL: using a zip, moving an iron, opening a lock with a key, turning a door handle, eating with spoon, writing with a pen, pouring water from a jug and using a spray. These ADLs are characterised by a positive digit arch and closeness, corresponding to grasps Cyl, Obl, Hook and LatP. This group is composed of different ADL that need grasps for which the flexion of fingers is necessary.

Group 3 is defined by two ADL: moving wooden cubes and unscrewing lids with the hand. These ADL are characterised by a negative closeness and a positive thumb arch corresponding to PpPinch grasp.

Group 4 is defined by two ADL: writing using a keypad and cleaning the table with a cloth. These ADL are characterised by the NonP grasp. This group is characterised mostly by negative thumb opposition with wide thumb arch ranges.

Group 5 is defined by three ADL: putting a coin into a change purse, pouring water from a jug and pouring water from a glass. These ADL are characterised by positive thumb opposition, corresponding to grasps Cyl and Lum. This group is characterised mostly by positive thumb opposition and thumb arch, and negative closeness, with wide ranges for closeness and thumb arch.

Finally, Group 6 is defined by eight ADL: removing a coin from the change purse, inserting a nut inside a bolt, tying a shoelace, passing buttons through buttonholes, putting a bandage on an arm, folding a piece of paper and placing it into an envelope, using a clip, and putting toothpaste on a toothbrush. These ADL are more complex, and involve not only one grasp type and can, thus, be done in more than one way. These ADLs are mainly characterised by a negative thumb arch with large ranges of motion of digit arch, closeness, thumb opposition and thumb arch.

Different kinematics behaviours have been observed when comparing both phases, reaching and manipulation. Comparing mean values between phases, I see that during 
reaching negative mean values are needed, i.e. less digit arch, closeness and thumb opposition (Table 3.5), while during manipulation positive mean values are required, i.e. more digit arch, closeness, and thumb opposition (Table 3.6). Palmar arch and thumb arch presented similar mean values (about zero) in both phases, but with more range of movement during manipulation. During reaching, thumb arch and palmar arch are kept almost unchanged, while during manipulation all synergies need to be modulated for all tasks. This comparison has been possible thanks to a PC extraction using the data of both phases altogether.

The results obtained have shown that hand kinematics during reaching in day-today life can be characterised by studying a reduced set of RKV-PCs. E.g., during reaching mostly three RKV-PCs (digit arch, closeness and thumb opposition) need to be controlled during all the representative set of ADL performed. During manipulation, ADL have been clustered in six groups with similar mean and range values for the RKV-PCs, some of them also related to the initial intended grasp.

The obtained groups of ADL are quite homogeneous in kinematic demands. Rehabilitation can benefit from these groups: assessing which is the movement affected, the necessary action for rehabilitation may be planned. Furthermore, one representative ADL could be selected per group to consider quantitative parameters to evaluate hand kinematics, finding different patterns that could simplify the current rehabilitation protocols. In this sense, temporal evolution of the reduced kinematic variables is provided for a wide sample of healthy subjects during reaching per intended grasp, and during manipulation per ADL. These profiles may be used to obtain quantitative normative patterns of kinematics that will illuminate the demand required for common tasks, providing baselines for evaluating clinical populations

The results described for kinematic hand synergies can lead to applications in prosthetics and possibly in industrial manipulation. Robotic hands that reproduce hand movements by modulating the main postural hand synergies were recently presented (Matrone et al., 2012, 2010). The results obtained in this study (using standardised and representative ADL, and differentiating between reaching and manipulation phases) can strongly improve usability of these prostheses. These models can lead to prostheses with higher functional adaptability that better interact with the environment in real life conditions. Including reach-to-grasp and manipulation phases into the models can as well improve the prostheses, making them more similar to real hands.

\subsection{Conclusion}

The kinematic analysis of the hand while performing complex and various ADL can benefit from the PCA method (presented in Chapter 2), as the whole hand kinematics during such tasks has been found to be actually low dimensional, so that it can be efficiently described by only five reduced kinematic variables: digit arch, closeness, palmar arch, thumb opposition, and thumb arch. 
Kinematic reduction has allowed a comprehensive study of the hand movement during reaching and manipulation phases. Reaching requires modulation of the closeness, digit arch and thumb opposition synergies, with different control patterns per grasp, while thumb arch and palmar arch are kept almost unchanged. On the contrary, all synergies need to be modulated during manipulation for all tasks. Also, kinematic reduction has allowed grouping the ADL according to similar kinematic requirements, which may benefit the selection of tasks for rehabilitation and for hand function assessment.

The temporal evolution of the reduced kinematic variables is provided for a wide sample of healthy subjects during reaching per intended grasp and during manipulation per ADL. This scenario may help to improve the control of hand prostheses and to quantify the hand function assessment.

Finally, it is noteworthy that the used PCA method offers two key features compared to other studies:

- PCA normalisation performed allowed comparing at the same level joints with different range of motion.

- Varimax rotation performed on PCA allowed obtaining more sparse synergies, according to most recent findings (Prevete et al., 2018). 



\section{CHAPTER 4}

Characterisation of the electromyography of the hand in activities of daily living: state of art 

This chapter corresponds to a state of art that of the research studies that recorded EMG of hand and forearm muscles, organised in two sections: muscle activity in different activities and dimensional reduction of EMG of the hand.

\subsection{Abstract \& keywords}

In this chapter, I present a review of the works in which forearm and hand EMG has been recorded and analysed. The literature review consisted of examining research studies that recorded EMG of hand and forearm muscles regarding the muscles activation of the hand and forearm muscles in ADL's, and regarding the dimensional reduction technique for analysing the muscular action of the hand.

I conducted a systematic literature search on Scopus and PubMed databases during January 2018 to April 2019: The search was restricted to papers published in English and containing the terms ("Electromyography" AND "muscles") AND ("thumb" OR "finger" OR "hand" OR "forearm") in the title, abstract, or keywords. Then, a refined search was performed and a manual screening was made to remove duplicates and reject no relevant articles.

At the end, 21 articles related to muscle activity during different ADL's were selected, and 22 articles related to dimensional reduction of EMG of the hand were identified. In total, 43 articles were selected for inclusion in the current review (including 2 review papers). Finally, the selected articles are discussed and the most important gaps to be addressed in the next chapters are identified.

Keywords Activities of daily living, Dimensional reduction, Electromyography, Forearm muscles, Myoelectric prostheses, Rehabilitation.

\subsection{Introduction}

Performance of activities of daily living (ADL) is critical to ensure a full and autonomous life (Vergara et al., 2015). In this sense, the International Classification of Functioning, Disability and Health (ICF) of the World Health Organisation (WHO) ('WHO | International Classification of Functioning, Disability and Health (ICF)', 2001) established the ability to carry out ADL as the main factor for classifying the degree of disability. The ability of the hands to grasp and manipulate is fundamental for the performance of ADL (Vergara et al., 2014). Therefore, keeping the functionality of the whole hand is critical to ensure a full and autonomous life, not only in ADL but also in working life (Bullock et al., 2013). This ability of the hand is achieved thanks to a complex musculoskeletal system, with 25 degrees of freedom (DoF) that are controlled by approximately 38 muscles located in the forearm and hand (Yu et al., 2004). These muscles can be divided into two groups: extrinsic and intrinsic muscles. The extrinsic muscles are located in the anterior and posterior compartments of the forearm whereas 
intrinsic muscles are located within the hand itself. Grossly, the extrinsic muscles are considered to control crude movements of the hand and produce forceful grip, while the intrinsic muscles would be responsible for the fine motor functions of the hand (Brand and Hollister, 1999; Kapandji A.I., 1996; Lee and Jung, 2015a). However, the specific role of the different muscles of the hand in ADL is already unknown due to the complexity of the muscle system (Oatis, 2009). This information is key for determining the impact on the functionality when a given muscle is compromised because of an accident or a pathology.

The measurement and interpretation of the hand kinematics and the associated muscle activation signals is cumbersome but of high importance to deepening the knowledge of the role of the muscles in ADL (Lee and Jung, 2015a). This knowledge is not only important to rate disability, but it is also of utmost importance for improving rehabilitation processes (Dietz and Schrafl-Altermatt, 2016; Lum et al., 2009) or for helping in decision making during surgical planning, among others (Elkwood et al., 2017). Another important application field is in the control of hand prostheses (Parker et al., 2006; Scheme and Englehart, 2011). Myoelectric hand prostheses use the electrical action potential of the residual muscles in the limb emitted during muscular contractions. These emissions are measured on the skin surface, picked up by electrodes, and are amplified to be used as control signals for the functional elements of the prosthesis. Therefore, deepening the knowledge of the role of the forearm muscles in ADL may help in the selection of the muscles to control these type of prostheses.

Electromyography (EMG) emerged as a diagnostic procedure to assess the health of muscles and the nerve cells that control them (motor neurons). The electrodes receive the electrical signals transmitted by the motor neurons that cause muscle contraction. However, these EMG signals acquired from muscles require advanced methods for detection, decomposition, processing, and classification (Chowdhury et al., 2013; Khokhar et al., 2010; Reaz et al., 2006) that a specialist interprets. In order to acquire these signals there are two basic types of electrodes: surface and intramuscular (indwelling (also known as needle) or fine wire electrodes (Fw-EMG)). Surface electrodes are placed on the skin directly over the muscles whereas intramuscular electrodes are inserted through the skin directly into the muscle (Kamen and Gabriel, 2010). The general advantage of all surface electrodes is that they are non-invasive and easy to apply. Their use, however, is limited to superficial muscles that are large enough to support electrode mounting on the skin surface, and cross-talk is particularly problematic for smaller muscles within a complex mechanical arrangement, such as the forearm (Mogk and Keir, 2003). On the other hand, indwelling electrodes need significantly more training for the proficient use versus surface electrodes. Although they are ideal for recording the activity of deep muscles, correct placement requires a detailed knowledge of musculoskeletal anatomy. Furthermore, the invasiveness of inserting a needle into the muscles, as well as the associated pain, is a major disadvantage of intramuscular electrodes (Kamen and Gabriel, 2010). 
EMG has been incorporated as a diagnostic technique for the detection of pathologies that affect nervous and muscular structures, and for the spatial location of the injury's origin. The examination with needle EMG allows evaluating motor unit action potentials (MUAPs). The MUAPs morphology (duration, amplitude, and number of phases) and recruitment pattern are the key element for diagnosing pathologies using needle EMG. MUAPs are analysed per muscle and the results compared with the normally expected for that particular muscle. For this reason, due to the need of a normal pattern, MUAPs evaluation are not useful for deepening the knowledge of the role of the muscles in ADL. Otherwise, parameters such as time-domain, time-frequency domain or intensity of muscle activation could be more useful for studying tasks. EMG data for these purposes are commonly normalised to a reference value to avoid variability arising from electrode placement, participants, or even day of the experiment. The most popular method is to normalise EMG data to the maximum voluntary contraction (MVC) of the muscle of interest (Konrad, 2005), which besides of making data comparable, also informs about how active muscles are relative to their maximum capabilities. Surface EMG is applied in many fields such as motor control of human movement, myoelectric control of prosthetic and orthotic devices, and rehabilitation (Castellini et al., 2009; Hogrel, 2005; Kumar et al., 2013; Rojas-Martínez et al., 2012). Some studies have performed EMG analyses for intrinsic and/or extrinsic hand muscles in specific situations:

- $\quad$ During grasping objects (Almeida et al., 2013; Birdwell et al., 2013; Bonnefoy et al., 2009; Cooney et al., 1985; Danion and Galléa, 2004; Duque et al., 1995; Hoozemans and Van Dieën, 2005; Johanson et al., 2001; Kamavuako et al., 2009; Kerkhof et al., 2016; Linderman et al., 2009; Maier and Hepp-Reymond, 1995; Park, 2013),

- $\quad$ During working postures (Cifrek et al., 2009; Di Domizio and Keir, 2010; Hägg and Milerad, 1997; Kao et al., 2015; Sako et al., 2017; Straker et al., 2009; Szeto and Lin, 2011; Taib et al., 2016; Van Galen et al., 2002)

- $\quad$ For the design and improvement of sports tools, as well as for the study of the role of muscles in the sports performance (Alizadehkhaiyat and Frostick, 2015; Chow et al., 1999; Hatch et al., 2006; Marta et al., 2012; Rota et al., 2014; Sorbie et al., 2016).

The concept of synergy has been used, in the field of control of myoelectric hand prostheses, in an attempt to simplify the study of the complex kinematics and muscular action of the hand (Santello et al., 2013). There are some studies describing muscle patterns or muscular synergies during some postures (Weiss and Flanders, 2004), grasps (Scano et al., 2018; Zariffa et al., 2012) or hand movements (Weiss and Flanders, 2004; Winges et al., 2013), and during particular actions (D'Andola et al., 2013; Ertan, 2009; Ertan et al., 2003; Ricci et al., 2015; VencesBrito et al., 2011). In these works, different activation patterns have been obtained, revealing coordination between some intrinsic and extrinsic hand muscles. Thus, EMG patterns have been studied as a way to control signals (Geethanjali, 2016). However, the usability of myoelectric prostheses is still challenged 
because of issues such as the effect of electrode location or changes in EMG patterns over time, which can cause long training processes (Johnson and Mansfield, 2014). A small number of studies have investigated the existence of hand muscle synergies in ADLs, which could help in the selection of muscles to control myoelectric prosthesis.

In this chapter, I present a review of the works in which EMG has been used to record the muscular activity of hand and forearm muscles during ADL, which may help to identify the role of these muscles in ADLs. In addition, I have also focused on works studying EMG patterns or muscular synergies between the muscles of the hand and forearm in order to simplify the study of muscular action of the hand. The contents are organised in two sections:

- Muscles activation in different activities

- Hand muscle synergies (dimensional reduction of EMG)

4.3. Methodology

The literature review consisted of examining research studies that recorded EMG of hand and forearm muscles regarding the muscles activation of the hand and forearm muscles in ADL's, and the dimensional reduction of the muscular action of the hand .

For this review, I conducted a systematic literature search on Scopus and PubMed databases during January 2018 to April 2019. Figure 4.1 shows the flowchart followed. The search was restricted to papers published in English and containing the terms ("Electromyography" AND "muscles") AND ("thumb" OR "finger" OR "hand" OR "forearm") in the title, abstract, or keywords. Then, a refined search was conducted including different keywords in the title, abstract, or keywords (see Figure 4.1). Finally, a manual screening was made to remove duplicates and reject no relevant articles.

After the manual screening, 21 articles related to muscle activity during different ADL's were selected (see Table 4.1), and 22 articles related to dimensional reduction of EMG of the hand were identified (see Table 4.2). In total, 43 articles were selected for inclusion in the current review (including 2 reviews). In the following sections, the selected articles are discussed. 


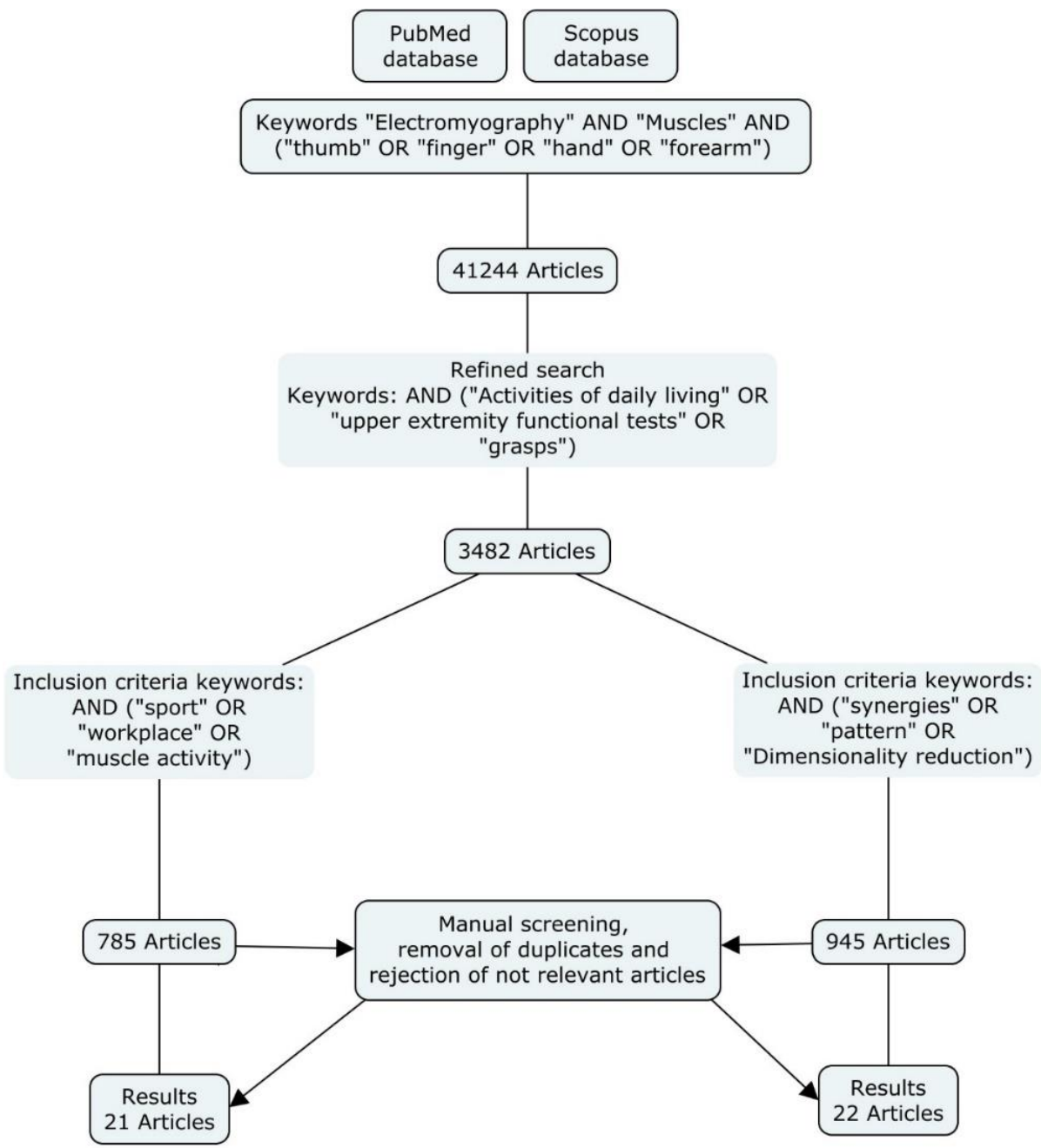

Figure 4.1 Methodology followed for the literature research.

\subsection{Muscles activation in different activities}

This section includes a review of studies that have characterised hand and forearm muscle activity while performing specific activities such as grasps, ADL, working activities and sports. Table 4.1 summarises the most relevant information of the 21 papers related to muscle activity during different ADL found in the literature.

Several studies have analysed hand and forearm muscles (extrinsic and intrinsic) activation during some types of grasps. Regarding extrinsic muscles, they found that in power grasps both flexors and extensors groups of muscles (extrinsic muscles) were activated, although the fatigue of the extensor part was higher (Hägg and Milerad, 1997). Regarding the intrinsic muscles, they found that intrinsic muscles during precision grasps play a major role in finely graded force generation since in finely movements, less stabilisation and counterforce to the long flexor action are needed (Maier and HeppReymond, 1995).

There are many works that studied specifically the thumb muscle activation through EMG performing different grasps (Birdwell et al., 2013; Cooney et al., 1985; Danion and 
Galléa, 2004; Johanson et al., 2001; Kaufman et al., 1999; Kerkhof et al., 2016), especially during the opposition movement, due to its great importance in precision grasps. In general, these studies found a necessity of a cooperation of thumb muscles to accomplish the tasks performed (Kerkhof et al., 2016), with the exception of the long extensor and flexor muscles of the thumb (EPL, FPL), that were able to be activated separately from the other muscles (Birdwell et al., 2013). Another work (Johanson et al., 2001) studied and demonstrated the importance of the opposition of the thumb during stable and unstable lateral grasps. They observed that instability affects some thumb muscles with greater activation of Abductor Policis Longus (APL) and EPL in the unstable tasks. Similarly, Kaufman et al. (Kaufman et al., 1999) recorded the EMG activity of 7 thumb muscles and their contribution at the carpometacarpal (CMC) joint during voluntary isometric contractions. They found that:

- Thumb CMC flexion is supported by Flexor Policis Brevis (FPB), Abductor Policis Brevis (APB), thumb Adductor (ADD) and FPL.

- $\quad$ CMC extension by APB, APL and EPL.

- $\quad$ CMC abduction by FPB, APB, APL and EPL;

- $\mathrm{CMC}$ adduction by FPB, APB, EPL and FPL.

- The Opponens Policis (OPP) was active in all motions.

However, the works in the literature focused on small sets of very controlled and simple activities (few grasps or simple finger movements). Additionally, they also focused on very specific muscles or only on specific fingers or joints, especially for the thumb role.

EMG has also been used to study the effect of different kind of work activities on the forearm muscles, evaluating the influence of different factors on the fatigue during repetitive tasks (Szeto and Lin, 2011; Taib et al., 2016; Van Galen et al., 2002) as typing, keying, writing, reading, mousing tasks, and on pulling and pushing tasks (Di Domizio and Keir, 2010; Kao et al., 2015). These works have focused on evaluating and comparing different forearm and hand positions. However, the relationship between force production and sEMG is not well understood: there are factors that influence the forces generated and, therefore, prevent the direct quantification of muscle force from EMG signals, like variations in the location of the recording electrodes, cross talk, the involvement of synergistic muscles, muscles properties, tendons, ligaments, etc. Consequently, the EMGforce relationships differ for each muscle and for each situation (Disselhorst-Klug et al., 2009). Many works in the literature focused on studying the muscle activation in writing activities of both intrinsic and extrinsic muscles (Almeida et al., 2013; Linderman et al., 2009; Park, 2013). One of these works (Almeida et al., 2013) compared two different typewriting and the results suggested that the major function of the Extensor Carpi Radialis (ECR) muscle as a stabiliser of the wrist joint is kept during handwriting, and it is suggested that the increased use of extrinsic muscles could result in a diminished role of intrinsic hand muscles. In these works, the authors showed that EMG of hand and arm muscles may be converted into handwriting patterns. However, the results of these works 
focused on specific activities and in many cases with a low number of subjects and activities, lacking representativeness in the ADL.

EMG has also been used for the design and improvement of sports tools, as well as for the study of the role of muscles in the sports performance. Some works have studied the regions that are activated, making possible the main movement, in sports as golf (Marta et al., 2012) and tennis (Alizadehkhaiyat and Frostick, 2015; Chow et al., 1999; Hatch et al., 2006; Rota et al., 2014). Other studies have focused on checking the effect of different features of sports equipment, such as the size of the handle of the racket (Hatch et al., 2006) or of a golf club (Sorbie et al., 2016). Some authors (Alizadehkhaiyat and Frostick, 2015; Marta et al., 2012) observed that there is a considerable diversity in the protocol design used for sEMG recording. For example, most of the studies did not specify the electrode placement, so it is not clear which locations were used to acquire the EMG data, resulting in difficulty in comparing values.

However, there are few EMG analyses of upper extremities that examine muscle function during daily tasks, although with little variability and with a limited number of tasks (no more than 10). (Jakobi et al., 2008; Kern et al., 2001; Peters et al., 2018). A wide variety of clinical tests (such as Jebsen Taylor Hand Function test (JTHF) (Program, 2006), Chedoke Arm and Hand Activity Inventory (CAHAI) (Barreca et al., 2004), or Sollerman Hand Function test (SHFT) (Brogardh et al., 2007) are often used to evaluate and track functional recovery of the upper-extremity simulating ADL. In these cases, EMG recordings may provide a window into the central nervous system to evaluate muscle recruitment and coordination. In this sense, Peters and collaborators (Peters et al., 2018) evaluated the recruitment and coordination between some upper-limb muscles during some of these clinical tests (JTHF, CAHAI and Block and box test (BBT)). Specifically, they recorded by means of sEMG eight upper-extremity muscles (Anterior and Posterior Deltoid (AD and PD), Biceps Branchii (BB), Triceps lateral head (TriB), Brachioradialis (Br), ECR, Flexor Carpi Ulnaris (FCU), and Extensor Digitorum (EDC)), evaluating which muscles were used to execute each task and if activation and cocontraction levels were similar across tasks. As results, they found that co-contraction levels were similar across tests and EDC was found to have the greatest activation levels across all tasks, denoting the muscle importance for common tasks. However, this study has several limitations: they evaluated a small set of forearm muscles (only four forearm and fingers muscles), and hand kinematics was not recorded.

Summing up, most works found in the literature present gaps, requiring further investigation: they are focused on small sets of very controlled and simple activities. There is no work characterizing the EMG activity of all hand muscles while developing representative actions, either by developing all possible grasp types required in ADL, or by developing a representative and conveniently standardised ADL set. Furthermore, the lack of a methodology and a standardised protocol hinders the comparison of EMG results between tasks and subjects. 
Table 4.1 Summary of the studies included in the systematic literature review (I).

\begin{tabular}{|c|c|c|c|}
\hline Study & Relevant information & Description of the task & Observations about muscles role \\
\hline \multirow{4}{*}{$\begin{array}{l}\text { (Cooney et } \\
\text { al., 1985) }\end{array}$} & 8 healthy subjects & \multirow{4}{*}{$\begin{array}{c}\text { Isometric } \mathrm{F} / \mathrm{E} \text { and } \\
\mathrm{Abd} / \mathrm{Ad} \text { thumb } \\
\text { movements, } \\
\text { pinch and power grasps }\end{array}$} & \multirow{4}{*}{$\begin{array}{l}\text { Extensor muscles (EPL, EPB, and APL) were primary and contributed nearly equally to the } \\
\text { extension. In flexion, only the FPL was primary } \\
\text { The ADD and APB are primary in adduction but the EPL (adduction) and OPP (abduction) } \\
\text { contribute significantly } \\
\text { Three muscles appear to be primary in pinch and power grasp: the ADD, OPP, and FPL }\end{array}$} \\
\hline & Fw-EMG & & \\
\hline & $\begin{array}{l}\text { Extrinsic muscles: } \\
\text { FPL, APL, EPL, EPB }\end{array}$ & & \\
\hline & $\frac{\text { Intrinsic muscles: }}{\mathrm{ADD}, \mathrm{APB}, \mathrm{OPP}}$ & & \\
\hline \multirow{4}{*}{$\begin{array}{l}\text { (Kilbreath } \\
\text { and } \\
\text { Gandevia, } \\
\text { 1994) }\end{array}$} & 7 healthy subjects & \multirow{4}{*}{$\begin{array}{l}\text { Dynamic movements: } \\
\text { Lift a weight by flexion } \\
\text { of one digit }\end{array}$} & \multirow{4}{*}{$\begin{array}{l}\text { There is a coactivation of other deep digital flexor muscles and this coactivation increases wher } \\
\text { digit flexes at a greater velocity or through a larger angle. }\end{array}$} \\
\hline & needle EMG & & \\
\hline & $\frac{\text { Extrinsic muscles: }}{\text { FPL, FDP }}$ & & \\
\hline & $\frac{\text { Intrinsic muscles: }}{\text { None }}$ & & \\
\hline \multirow{4}{*}{$\begin{array}{l}\text { (Maier and } \\
\text { Hepp- } \\
\text { Reymond, } \\
\text { 1995) }\end{array}$} & 6 healthy subjects & \multirow{4}{*}{$\begin{array}{l}\text { Isometric forces with } \\
\text { thumb and index finger }\end{array}$} & \multirow{4}{*}{$\begin{array}{l}\text { The intrinsic muscles (FDI, FPI, and FLUM) and the long flexors (FDP, FDS) of the index finger, } \\
\text { as well as two intrinsic muscles of the thumb (ADD FPB), increase their activity according to the } \\
\text { load. } \\
\text { The other thenar muscles (OPP, APB) and the extrinsic muscles of the thumb (FPL, EPL, EPB, and } \\
\text { APL) become active only at higher loads and may serve to stabilise joints. } \\
\text { The long extensors of the index finger (EDC, EI) were classified as antagonistic, and only act to } \\
\text { balance the applied load and maintain joint equilibrium. } \\
\text { The intrinsic muscles play a major role in finely graded force generation since less stabilisation and } \\
\text { counterforce to the long flexor action are needed, thus releasing the intrinsic muscles for precise } \\
\text { force regulation. }\end{array}$} \\
\hline & needle EMG & & \\
\hline & $\begin{array}{l}\text { Extrinsic muscles } \\
\text { FDP, FDS, APB,FPL, EPL } \\
\text { EPB, APL, EDC, EI }\end{array}$ & & \\
\hline & $\begin{array}{l}\text { Intrinsic muscles: } \\
\text { FDI, FPI, FPB, FLUM } \\
\text { ADD,OPP }\end{array}$ & & \\
\hline \multirow{4}{*}{$\begin{array}{l}\text { (Hägg and } \\
\text { Milerad, } \\
\text { 1997) }\end{array}$} & 9 healthy subjects & \multirow{4}{*}{$\begin{array}{l}\text { Gripping simulations } \\
\text { of industrial work }\end{array}$} & \multirow{4}{*}{$\begin{array}{l}\text { Fatigue effects are generally larger on the extensor side although none of the studied regimes was } \\
\text { acceptable from EMG fatigue point of view. }\end{array}$} \\
\hline & sEMG & & \\
\hline & $\begin{array}{c}\text { Extrinsic muscles: } \\
\text { FCU, FDS, ECR Longus, ECR } \\
\text { Brevis, EDC } \\
\end{array}$ & & \\
\hline & $\frac{\text { Intrinsic muscles: }}{\text { None }}$ & & \\
\hline
\end{tabular}




\begin{tabular}{|c|c|c|c|}
\hline Study & Relevant information & Description of the task & Observations about muscles role \\
\hline \multirow{4}{*}{$\begin{array}{l}\text { (Chow et } \\
\text { al., 1999) }\end{array}$} & $\begin{array}{l}7 \text { healthy and skilled tennis } \\
\text { subjects }\end{array}$ & \multirow{4}{*}{ Tennis volley } & \multirow{4}{*}{$\begin{array}{l}\text { In general, the ECR was more active than the FCR during the volley, suggesting the presence of } \\
\text { wrist extension and abduction. } \\
\text { The co-contraction of the wrist flexors and extensors might help to stabilise the wrist joint. }\end{array}$} \\
\hline & sEMG & & \\
\hline & $\frac{\text { Extrinsic muscles: }}{\text { FCR, ECR }}$ & & \\
\hline & $\frac{\text { Intrinsic muscles: }}{\text { None }}$ & & \\
\hline \multirow{4}{*}{$\begin{array}{l}\text { (Kaufman } \\
\text { et al., } \\
1999)\end{array}$} & 5 healthy subjects & \multirow{4}{*}{$\begin{array}{l}\text { Isometric thumb } \\
\text { motions in } \mathrm{F} / \mathrm{E} \text { and } \\
\mathrm{Abd} / \mathrm{Ad}\end{array}$} & \multirow{4}{*}{$\begin{array}{l}\text { The FPB was most active in the range from flexion to abduction with about } 50 \% \text { activity or less in } \\
\text { extension and adduction. } \\
\text { The OPP displayed activity in all directions of motion. } \\
\text { The APB displayed maximal activity in abduction and abduction-flexion directions. } \\
\text { The ADD was active during flexion } \\
\text { The APL was most active in abduction and/or extension. } \\
\text { The EPL showed the higher activity during extension in combination with abduction/adduction } \\
\text { functions. } \\
\text { The FPL was the most active in flexion and/or adduction functions. }\end{array}$} \\
\hline & Fw-EMG & & \\
\hline & $\frac{\text { Extrinsic muscles: }}{\text { APL, FPL, ,EPL }}$ & & \\
\hline & $\begin{array}{c}\text { Intrinsic muscles: } \\
\text { APB, OPP, FPB, ADD }\end{array}$ & & \\
\hline \multirow{4}{*}{$\begin{array}{l}\text { (Johanson } \\
\text { et al., } \\
\text { 2001) }\end{array}$} & 7 healthy subjects & \multirow{4}{*}{$\begin{array}{l}\text { Key and opposition } \\
\text { pinch postures between } \\
\text { stable and unstable } \\
\text { tasks }\end{array}$} & \multirow{4}{*}{$\begin{array}{l}\text { Activation patterns are different between key and opposition pinch posture and between stable and } \\
\text { unstable pinch tasks. } \\
\text { APB and EPL muscles are necessary to accurately direct thumb-tip forces in a functional pinch, not } \\
\text { just to position the thumb, independently of pinch force magnitude. } \\
\text { In all unstable conditions, APB and EPL were among the most activated muscles and could provide } \\
\text { directional accuracy to the task }\end{array}$} \\
\hline & Fw-EMG & & \\
\hline & $\begin{array}{l}\text { Extrinsic muscles: } \\
\text { FPL, EPL, EPB, APL }\end{array}$ & & \\
\hline & $\begin{array}{c}\text { Intrinsic muscles: } \\
\mathrm{APB}, \mathrm{ADD}, \mathrm{FDI}, \mathrm{FPB} \text { OPP }\end{array}$ & & \\
\hline \multirow{4}{*}{$\begin{array}{l}\text { (Van } \\
\text { Galen et } \\
\text { al., 2002) }\end{array}$} & 20 subjects & \multirow{4}{*}{$\begin{array}{l}\text { Fast movements with } \\
\text { an electronic } \\
\text { pen along the surface } \\
\text { of a digitizer }\end{array}$} & \multirow{4}{*}{$\begin{array}{l}\text { For the forearm muscle movers our findings show that the participants reacted with a substantial } \\
\text { increase of static muscle activity, i.e., of antagonistic activation. } \\
\text { For the wrist stabilisation musculature, however, the effect was reversed }\end{array}$} \\
\hline & sEMG & & \\
\hline & $\begin{array}{c}\text { Extrinsic muscles: } \\
\mathrm{BB}, \mathrm{TriB}, \mathrm{FCU}, \mathrm{ECR}\end{array}$ & & \\
\hline & $\frac{\text { Intrinsic muscles: }}{\text { None }}$ & & \\
\hline
\end{tabular}




\begin{tabular}{|c|c|c|c|}
\hline Study & Relevant information & Description of the task & Observations about muscles role \\
\hline \multirow{4}{*}{$\begin{array}{l}\text { (Danion } \\
\text { and Galléa, } \\
\text { 2004) }\end{array}$} & 7 healthy subjects & \multirow{4}{*}{$\begin{array}{l}\text { Constant force } \\
\text { matching task during } \\
\text { precision grasp }\end{array}$} & \multirow{4}{*}{$\begin{array}{l}\text { Muscle co-contraction is not a critical factor for force steadiness during a precision grasp task. } \\
\text { Muscle co-contraction and grip force steadiness depend on grip force magnitude, but grip force } \\
\text { steadiness does not depend on muscle co-contraction. }\end{array}$} \\
\hline & sEMG & & \\
\hline & $\frac{\text { Extrinsic muscles: }}{\text { EPL }}$ & & \\
\hline & $\frac{\text { Intrinsic muscles: }}{\text { FPB }}$ & & \\
\hline \multirow{4}{*}{$\begin{array}{l}\text { (Hatch et } \\
\text { al., 2006) }\end{array}$} & 16 healthy tennis players & \multirow{4}{*}{$\begin{array}{l}\text { Back-hand tennis } \\
\quad \text { stroke }\end{array}$} & \multirow{4}{*}{$\begin{array}{l}\text { There was a progressive increase in ECRL and FCR activity from early acceleration through ball } \\
\text { impact. } \\
\text { There was a progressive increase in EDC activity through the early and late acceleration phases. } \\
\text { At ball impact, all muscle activity tended to peak and then gradually decreased in early follow- } \\
\text { through phase }\end{array}$} \\
\hline & Fw-EMG & & \\
\hline & $\begin{array}{c}\text { Extrinsic muscles: } \\
\text { EDC, ECR Longus, ECR } \\
\text { Brevis, PT, FCR } \\
\end{array}$ & & \\
\hline & $\frac{\text { Intrinsic muscles: }}{\text { None }}$ & & \\
\hline \multirow{3}{*}{$\begin{array}{l}\text { (Ertan, } \\
\text { 2009) }\end{array}$} & $\begin{array}{l}20 \text { healthy subjects } \\
\text { sEMG }\end{array}$ & \multirow{3}{*}{$\begin{array}{l}\text { Dynamic Archery } \\
\text { shooting }\end{array}$} & \multirow{3}{*}{$\begin{array}{l}\text { Elite archers relax their finger flexors so as not to grip the bow-handle and contract extensors to } \\
\text { avoid holding/gripping the handle during the whole shot. } \\
\text { The main difference between the elite and beginner archers was that the elite archers had a greater } \\
\text { activation of the EDC }\end{array}$} \\
\hline & $\frac{\text { Extrinsic muscles }}{\text { EDC, FDS }}$ & & \\
\hline & $\frac{\text { Intrinsic muscles }}{\text { None }}$ & & \\
\hline \multirow{4}{*}{$\begin{array}{l}\text { (Linderma } \\
\text { n et al., } \\
2009)\end{array}$} & 6 healthy subjects & \multirow{4}{*}{$\begin{array}{l}\text { Writing numeric } \\
\text { characters }\end{array}$} & \multirow{4}{*}{$\begin{array}{l}\text { It is feasible to recreate handwriting solely from EMG signals thanks to the existence of muscle } \\
\text { patterns during writing }\end{array}$} \\
\hline & sEMG & & \\
\hline & $\begin{array}{l}\text { Extrinsic muscles: } \\
\text { FCR, EDC, ECU, ECR }\end{array}$ & & \\
\hline & $\frac{\text { Intrinsic muscles: }}{\text { OPP, APB, FDI }}$ & & \\
\hline
\end{tabular}

(




\begin{tabular}{|c|c|c|c|}
\hline Study & Relevant information & Description of the task & Observations about muscles role \\
\hline \multirow{4}{*}{$\begin{array}{l}(\mathrm{Di} \\
\text { Domizio } \\
\text { and Keir, } \\
\text { 2010) }\end{array}$} & 12 healthy subjects & \multirow{4}{*}{$\begin{array}{l}\text { Grips with pull and } \\
\text { push tasks }\end{array}$} & \multirow{4}{*}{$\begin{array}{l}\text { Flexor muscle activity tended to be lower when performing push with grip tasks and pull with grip } \\
\text { tasks than extensor muscle activity. } \\
\text { The highest wrist and finger extensor (ECR, ECU, and EDC) activity was elicited when performing } \\
\text { grip tasks in a pronated posture. } \\
\text { ECU was found to be most sensitive to postural changes }\end{array}$} \\
\hline & sEMG & & \\
\hline & $\begin{array}{l}\text { Extrinsic muscles: } \\
\text { FCR,FCU, FDS, ECR, ECU, } \\
\text { EDC, AD, PD }\end{array}$ & & \\
\hline & $\frac{\frac{\text { Intrinsic muscles: }}{\text { None }}}{}$ & & \\
\hline \multirow{4}{*}{$\begin{array}{l}\text { (Szeto and } \\
\text { Lin, 2011) }\end{array}$} & $\begin{array}{l}17 \text { healthy subjects and } \\
9 \text { symptomatic office workers } \\
\text { (case group) }\end{array}$ & \multirow{4}{*}{$\begin{array}{l}\text { Performing } \\
\text { mouse-clicking tasks } \\
\text { during different speed } \\
\text { and precision } \\
\text { conditions }\end{array}$} & \multirow{4}{*}{$\begin{array}{l}\text { Higher EMG amplitudes in the Control Group over Case Group in mostly the ECU and ECR } \\
\text { muscles and more so in the more stressful condition. } \\
\text { ECR muscle recorded significant group differences in both precision and speed condition analyses, } \\
\text { and FCU in speed condition analysis. }\end{array}$} \\
\hline & sEMG & & \\
\hline & $\begin{array}{l}\text { Extrinsic muscles: } \\
\text { ECR, FCU, ECU, FCR }\end{array}$ & & \\
\hline & $\frac{\text { Intrinsic muscles: }}{\text { None }}$ & & \\
\hline \multirow{4}{*}{$\begin{array}{l}\text { (Marta et } \\
\text { al., 2012) }\end{array}$} & $\begin{array}{l}\text { Review paper about amateurs } \\
\text { and professional golfers }\end{array}$ & \multirow{4}{*}{$\begin{array}{l}\text { Different phases of the } \\
\text { golf swing }\end{array}$} & \multirow{4}{*}{$\begin{array}{l}\text { Higher peak activity in the leading PT during the acceleration phase and just after the impact in } \\
\text { professional golfers compared to amateur players who showed a peak activation in the ECRB } \\
\text { This study also reported considerably higher levels of activity in the ECRB in amateurs during all } \\
\text { swing phases. } \\
\text { Some studies did not specify the electrode placement, so it is not clear which locations were used } \\
\text { to acquire the EMG data, resulting in difficulty in comparing values. }\end{array}$} \\
\hline & sEMG/Fw-EMG & & \\
\hline & $\begin{array}{l}\frac{\text { Extrinsic muscles: }}{\text { ECR Brevis, PT, }} \\
\text { FCR, FCU, }\end{array}$ & & \\
\hline & $\frac{\text { Intrinsic muscles: }}{\text { None }}$ & & \\
\hline \multirow{4}{*}{$\begin{array}{l}\text { (Almeida } \\
\text { et al., } \\
\text { 2013) }\end{array}$} & 24 healthy subjects & \multirow{4}{*}{$\begin{array}{l}\text { Writing a word five } \\
\text { times }\end{array}$} & \multirow{4}{*}{$\begin{array}{l}\text { The major function of ECRB muscle as a stabiliser of the wrist joint is kept during handwriting } \\
\text { tasks and the increased use of extrinsic muscles could result in a diminished role of intrinsic hand } \\
\text { muscles during handwriting }\end{array}$} \\
\hline & sEMG & & \\
\hline & $\frac{\text { Extrinsic muscles }}{\mathrm{Tr}, \mathrm{BB}, \text { ECR Brevis, FDS }}$ & & \\
\hline & $\frac{\frac{\text { Intrinsic muscles: }}{\text { None }}}{}$ & & \\
\hline
\end{tabular}




\begin{tabular}{|c|c|c|c|}
\hline Study & Relevant information & Description of the task & Observations about muscles role \\
\hline \multirow{4}{*}{$\begin{array}{l}\text { (Birdwell } \\
\text { et al., } \\
\text { 2013) }\end{array}$} & 7 healthy subjects & \multirow{4}{*}{$\begin{array}{l}\text { Activating each } \\
\text { specific muscle during } \\
3 \mathrm{~s} \text { of MVC }\end{array}$} & \multirow{4}{*}{$\begin{array}{l}\text { Only two extrinsic thumb muscles, EPL and FPL, were capable of sustaining individual activations } \\
\text { from the other thumb muscles. } \\
\text { Activation of EPB elicited coactivity levels from EPL and APL. }\end{array}$} \\
\hline & Fw-EMG & & \\
\hline & $\begin{array}{l}\text { Extrinsic muscles: } \\
\text { APL, EPB, EPL EDC, FDP, } \\
\text { FDS, FPL }\end{array}$ & & \\
\hline & $\frac{\text { Intrinsic muscles: }}{\text { None }}$ & & \\
\hline \multirow{4}{*}{$\begin{array}{l}\text { (Park, } \\
\text { 2013) }\end{array}$} & 36 healthy subjects & \multirow{4}{*}{$\begin{array}{l}\text { Writing subtests of the } \\
\text { JHFT }\end{array}$} & \multirow{4}{*}{ ECU was the most active muscle during writing in both left and right handers } \\
\hline & sEMG & & \\
\hline & $\begin{array}{l}\text { Extrinsic muscles: } \\
\text { FCU, FCR, ECU, ECR, Upper } \\
\operatorname{Tr}\end{array}$ & & \\
\hline & $\frac{\text { Intrinsic muscles: }}{\text { None }}$ & & \\
\hline \multirow{4}{*}{$\begin{array}{l}\text { (Alizadehk } \\
\text { haiyat and } \\
\text { Frostick, } \\
\text { 2015) }\end{array}$} & $\begin{array}{c}\text { Review paper: } \\
198 \text { healthy (control) } \\
18 \text { Lateral-epicondylitis } \\
\text { patients }\end{array}$ & \multirow{4}{*}{ Different tennis strokes } & \multirow{4}{*}{$\begin{array}{l}\text { Increase in the activity of wrist extensors including ECR Brevis and ECR Longus in multiple } \\
\text { phases of forehand, serve, and backhand strokes with the activity of wrist flexors remaining fairly } \\
\text { constant } \\
\text { Higher EMG activity of ECR during repetitive pre- and post-impact in the presence of unchanged } \\
\text { FCR activity has been suggested to predispose players to injury or delay recovery process. } \\
\text { Finally, an earlier, longer, and greater activation of ECR Brevis during backhand volley at } \\
\text { combined conditions of velocity and racket-head impact locations has been reported in LE patients } \\
\text { compared to non-injured players. } \\
\text { There was a considerable diversity in the protocol design used for EMG recording. }\end{array}$} \\
\hline & sEMG/Fw-EMG & & \\
\hline & $\begin{array}{c}\text { Extrinsic muscles: } \\
\text { FCU, FCR, ECR, ECU, PT }\end{array}$ & & \\
\hline & $\frac{\text { Intrinsic muscles: }}{\text { None }}$ & & \\
\hline \multirow{4}{*}{$\begin{array}{l}\text { (Kerkhof } \\
\text { et al., } \\
2016)\end{array}$} & 10 healthy subjects & \multirow{4}{*}{$\begin{array}{l}\text { Isometric contractions } \\
\text { in a lateral key pinch, a } \\
\text { power grasp, and a jar } \\
\text { twist task }\end{array}$} & \multirow{4}{*}{$\begin{array}{l}\text { Extrinsic thumb muscles were significantly more active than intrinsic muscles in all tasks. } \\
\text { The thumb muscles display a high variability in muscle activity during functional tasks of daily } \\
\text { life. } \\
\text { To produce a substantial amount of force, a co-contraction between the intrinsic and extrinsic thumb } \\
\text { muscles is necessary. }\end{array}$} \\
\hline & Fw-EMG & & \\
\hline & $\begin{array}{c}\text { Extrinsic muscles: } \\
\text { FPL, EPB, EPL, APL }\end{array}$ & & \\
\hline & $\begin{array}{l}\text { Intrinsic muscles: } \\
\text { ADD, APB, FPB OPP }\end{array}$ & & \\
\hline
\end{tabular}




\begin{tabular}{|c|c|c|c|}
\hline Study & Relevant information & Description of the task & Observations about muscles role \\
\hline \multirow{4}{*}{$\begin{array}{l}\text { (Peters et } \\
\text { al., 2018) }\end{array}$} & 20 healthy subjects & \multirow{4}{*}{$\begin{array}{l}\text { Clinical Tests of upper } \\
\text { extremity function }\end{array}$} & \multirow{4}{*}{$\begin{array}{l}\text { Minimal muscle force is required to perform these tests. } \\
\text { Co-contraction levels were similar across tests. } \\
\text { EDC has the greatest activation levels across all tasks. } \\
\text { The results suggest that healthy participants used different strategies to execute the tests }\end{array}$} \\
\hline & sEMG & & \\
\hline & $\begin{array}{l}\text { Extrinsic muscles: } \\
\text { AD, PD, BB, TriB, BB, ECR } \\
\text { Longus, FCU, EDC }\end{array}$ & & \\
\hline & $\frac{\text { Intrinsic muscles: }}{\text { None }}$ & & \\
\hline
\end{tabular}

FLUM - First Lumbrical; FDI - First Dorsal Interosseous; FPI - First Palmar Interosseous; ECU - Extensor Carpi Ulnaris; PT - Pronator Teres; FCR - Flexor Carpi Radialis; FDS - Flexor Digitorum Superficialis; FDP - Flexor digitorum Profundus; 


\subsection{Hand muscle synergies}

This section includes a review of studies that have characterised hand and forearm muscle activity by studying EMG patterns or muscular synergies between the muscles of the hand and forearm in order to simplify the study of muscular action of the hand. Table 4.2 summarises the most relevant information of the 22 papers related to hand muscle synergies selected.

The human hand has a complex biomechanical structure, controlled by a neural structure that is not completely understood to date. In the analysis of the biomechanical and behavioural aspects of the hand, one of the most striking aspects is the high redundancy of its structure, seemingly having many more muscles than are actually required. Synergies are thought to be used by the nervous system to simplify the control of these numerous muscles by actuating them in task-relevant subgroups. There are works for and against muscle synergies (Tresch and Jarc, 2009). Many researchers seek to detect and describe such simplifying functional muscle groups, and how to interpret them to reveal the underlying control strategy used by the brain to coordinate muscles. (Santello et al., 2013; Weiss and Flanders, 2004). Others point out the importance of the ability of the brain to break and dissolve such patterns of neural synchrony. This might happen to enable flexible and individuated control of hand muscles (Kutch et al., 2008; Marc H Schieber et al., 2009; Valero-Cuevas et al., 2009), by indicating that muscles are recruited flexibly in accordance with their mechanical action, rather than in fixed groupings. In both cases, EMG of hand muscle activity has been extensively used to infer control strategies underlying the complex coordination of muscle activity within and across digits and as a tool to study the spatial and temporal coordination of multiple muscles. In fact, this technique has been used to examine these organisation of muscle synergies in healthy and neurologically impaired individuals (Jo et al., 2016; Marc H Schieber et al., 2009). In addition, several studies have examined the covariations in EMG amplitudes across muscle pairs (Maier and Hepp-Reymond, 1995) and among multiple muscles (ValeroCuevas, 2000; Valero-Cuevas et al., 1998) related to hand function.

Previous studies reinforce the idea of hand muscles synergies, and their results about features of hand muscles synergies can be summarised as: muscles synergy occurs primarily across muscles with similar mechanical features (Johnston et al., 2009); the coactivity of some muscles are a way to adapt the limb to different environmental conditions (Gribble et al., 2003; Milner and Cloutier, 1993); and the whole set of hand and forearm muscles may be approximated with relatively few muscle synergies adequately scaled and timed (D'Avella et al., 2008; d'Avella and Lacquaniti, 2013; Klein Breteler et al., 2007; Martelloni et al., 2009; Smeets and Brenner, 2016; Weiss and Flanders, 2004).

The basic approach of these works include four steps. Firstly, measuring EMGs from a large number of muscles during a complex behaviour (or more than one behaviour). Secondly, using a computational analysis, such as non-negative matrix factorisation, to identify a set of synergies from the recorded EMGs. Thirdly, evaluating 
whether the observed EMGs can be well described as the combination of these synergies. And fourthly, relating the identified muscle synergies to task relevant variables (Tresch and Jarc, 2009). In the literature, different types of synergies are described: synchronous synergies and time-varying synergies. A synchronous synergy is a vector of weighting coefficients that specify the relative involvement (strength of membership) of each muscle in the group. In contrast, a time-varying synergy is a collection of EMG bursts in various muscles.

There are some works describing muscle patterns or muscular synergies during some specific postures or grasps (Castellini and Van Der Smagt, 2013) or during the whole-hand grasping performance (Scano et al., 2018; Weiss and Flanders, 2004). Some synergies during specific tasks are also described such as during finger spelling (Klein Breteler et al., 2007; Weiss and Flanders, 2004), and even the presence of a preparatory muscle activation response when a fall occurs (Burkhart and Andrews, 2013). Weiss and Flanders (Weiss and Flanders, 2004) recorded EMG activity of 6 hand and forearm muscles (APB, FPB, FDI, EDC, ADM, and FDS) in four subjects while they held the hand statically, shaping around 26 grasped objects and forming the 26 letter shapes of a manual alphabet. They found that a single muscle may be a member of more than one muscle synergy (d'Avella et al., 2003; Weiss and Flanders, 2004). Klein Breteler et al (Klein Breteler et al., 2007) expanded the synergy analysis from static synergies to timevarying synergies to explore the timing of muscle activations during finger spelling using a manual alphabet. They recorded FDI, APB, FPB, ADM, FDS, and EDC and concluded that four time-varying synergies could account for $80 \%$ of the temporal EMG patterns observed, with the first two synergies accounting for about $60 \%$. In addition, they showed that the first component showed a consistent pattern, the first and second component waveforms showed similarities across subjects and higher order components were much more variable across subject. The first component was a pattern where the EDC and the thumb muscles (APB and FPB) were active early and the other muscles were active later. Recently, Scano and collaborators (Scano et al., 2018) extracted muscle synergies from 20 hand grasps with an array of 8 equally spaced electrodes on the forearm, two electrodes on finger flexors and extensors, and other two on BB and TriB. The synergies they found were characterised by two temporal activation patterns: a strong co-activation corresponding to the grasp/hold phase, and two minor co-activating patterns related to hand opening (visible in the pre-shaping and release phase).

Synergistic finger patterns has also been described during dynamic free movements of wrist and single fingers (Gazzoni et al., 2014; Hu et al., 2015). Gazzoni et al. (Gazzoni et al., 2014) identified distinct area of sEMG activity on the forearm for different fingers during hand and finger movements. In the same way, Hu et al (Hu et al., 2015) revealed distinct activation patterns during individual finger extensions, especially for the index and middle fingers. Nevertheless, the detailed location of the recording electrodes was not reported in most of the studies, which makes comparison between subjects and activities difficult. 
However, there are few studies assessing muscle patterns during complex tasks in which the manipulation is the most relevant phase such as in ADL (Ricci et al., 2015; Zariffa et al., 2012), or during particular actions such as playing a piano (Winges et al., 2013), archery (Ertan, 2009; Ertan et al., 2003), catching a ball (D'Andola et al., 2013), or while performing a karate punch (VencesBrito et al., 2011). Winges et al (Winges et al., 2013) studied the muscle activation patterns on 10 pianists, suggesting that the amateur pianists use the same balance than professional pianists: Nevertheless, in other works (Ertan, 2009; Ertan et al., 2003) the authors found different patterns between elite and beginner archers, whose main difference was that the elite archers had a greater activation of the ED. In this sense, in a karate punch study (VencesBrito et al., 2011), experts and non-experts karateka presented distinct kinematic and EMG patterns. Regarding a more complex activity such as catching a ball (D'Andola et al., 2013), the authors found that the variation in the muscle patterns was captured by two time-varying muscle synergies, modulated in amplitude and shifted in time according to the ball's arrival height and flight duration. The initial muscular response, captured by the first synergy, allowed the subject's hand to reach the interception zone. The following component of the muscle pattern, captured by the second synergy, guided the hand to the interception. They recorded sEMG data from 16 shoulder and elbow muscles, but only one forearm muscle (Br) in six subjects. Zariffa et al. (Zariffa et al., 2012) characterised what muscles synergies were present while using different types of hand grips (gripping a block, a cylinder, a ball, a key, and rotating a disk 180 degrees) extracted from clinical tests. sEMG data was recorded from FDI, FCU, FCR, FDS, ECR, EDC, EIP, and the thenar eminence muscle group. Two main synergies were found: the first between EDC and EIP, and the second between FDS and FCU. However, they had some limitations due to the crosstalk, the small number of muscles registered and the few variability of the ADLs chosen. Ricci et al (Ricci et al., 2015) recorded data from shoulder and elbow muscles along with FDS, FCU, ECRLB and ECU while subjects poured water. In the transport phase, characterised by weight bearing, handgrip and displacement of the arm in space, a higher activity of almost all muscles was found. Furthermore, they found that ECR seems to play a key role in maintaining optimal wrist posture and function regardless task demand. That stabilisation could be provided by a delicate balance of co-contraction of forearm muscles to keep the hand in the proper posture to grasp or produce handgrip force (Hagert, 2010). However, few forearm muscles were measured and for very specific actions, therefore, further studies should be conducted to evaluate more forearm muscle patterns in a wide range of ADL as well as recording hand kinematics in order to relate muscular and kinematic hand synergies during representative ADL.

Moving on to the assessment of pathologies, as aforementioned, recently, sEMG has been used for the evaluation of patients with neuromuscular disorders by using muscle synergies. Muscle synergies have been investigated in acute, subacute and chronic stroke showing abnormalities compared to healthy people (Cheung et al., 2012; Hesam-Shariati et al., 2017; Hsiao and Cho, 2012; Lee et al., 2013; Roh et al., 2015; Marc H. Schieber et al., 2009), as well as in patients with dystonia (Lunardini et al., 2017) and sclerosis 
(Pellegrino et al., 2018) or after spinal cord injury (Zariffa et al., 2012). The results illustrate that muscle synergy patterns contain rich information in their spatial components and temporal profiles. Comparing pathological synergies of patients to the baseline synergy can reveal deficits in the underlying neuromuscular coordination and control. The analysis of task-specific muscle synergies should offer both researchers and clinicians new insights into the impairments in the neural organisation of motor control. However, in these studies a considerable diversity in the protocol design was used for sEMG recording: it is not clear which locations were used to acquire the sEMG data, resulting in difficulty when comparing values.

Summarizing, EMG has been widely used to find out muscle patterns, although a small number of studies have investigated more deeply the muscular synergies in the hand. There are some gaps that need to be studied in more detail. First, muscular synergies seem to be task-dependent, and a single muscle may be a member of more than one muscle synergy. In the literature, works generally investigated the presence of synergies during some specific hand movements or grasps, but few works have analysed the different coordination and muscular patterns or synergies during the performance of a representative set of ADL. Second, in order to compare results between subjects and tasks, specific representative forearm areas would need to be selected to record sEMG signals; indeed at hand level there is not any specific recommendation to help in this decision. Last, little has been studied about kinematics and muscular synergies of the forearm and hand relationship. Consequently, little is known about the role of the muscles linked to the joint movement of the hand during ADL. 
Table 4.2 Summary of the studies included in the systematic literature review (II)

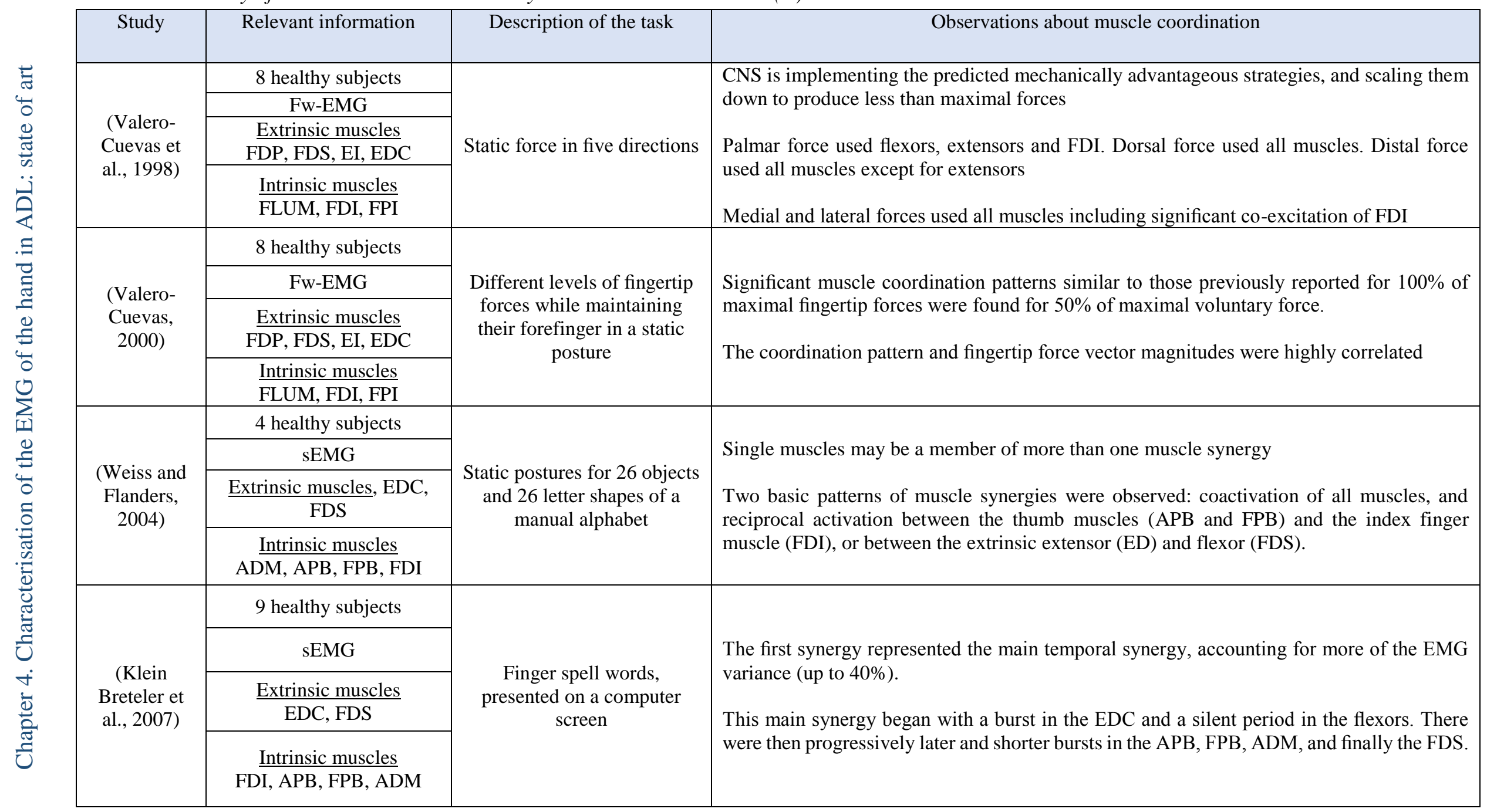




\begin{tabular}{|c|c|c|c|}
\hline Study & Relevant information & Description of the task & Observations about muscle coordination \\
\hline \multirow{4}{*}{$\begin{array}{l}\text { (Martelloni } \\
\text { et al., 2009) }\end{array}$} & 6 healthy subjects & \multirow{4}{*}{$\begin{array}{c}\text { Performing reach-to-grasp } \\
\text { movements for different } \\
\text { objects placed in different } \\
\text { locations }\end{array}$} & \multirow{4}{*}{$\begin{array}{l}\text { Activation of proximal muscles can be statistically different for different grip types } \\
\text { Proximal and distal muscles are simultaneously controlled during reaching and grasping } \\
\text { Patterns of EMG activation in arm muscles can provide a reliable representation of motor } \\
\text { behaviour during reaching and grasping of different objects. }\end{array}$} \\
\hline & sEMG & & \\
\hline & $\begin{array}{c}\frac{\text { Extrinsic muscles }}{\text { TriB, Deltoid, Trapecius, }} \\
\text { FCR, ECR, BB }\end{array}$ & & \\
\hline & $\frac{\text { Intrinsic muscles }}{\text { None }}$ & & \\
\hline \multirow{4}{*}{$\begin{array}{l}\text { (Valero- } \\
\text { Cuevas et } \\
\text { al., 2009) }\end{array}$} & 8 healthy subjects & \multirow{4}{*}{$\begin{array}{l}\text { Vertical fingertip force } \\
\text { vectors of prescribed } \\
\text { constant or time-varying } \\
\text { magnitudes }\end{array}$} & \multirow{4}{*}{$\begin{array}{l}\text { Evidence for preferential control of task-relevant parameters that strongly suggest the use of } \\
\text { a neural control strategy compatible with the principle of minimal intervention. } \\
\text { Only one synergy accounting }>40 \% \text { of the variance with positive correlation among all } \\
\text { muscles (coactivation) } \\
\text { There was no dimensionality reduction because each of the seven principal components } \\
\text { explains a nontrivial amount of variance }\end{array}$} \\
\hline & Fw-EMG & & \\
\hline & $\frac{\text { Extrinsic muscles }}{\text { EDC, EI, FDP, FDS }}$ & & \\
\hline & $\frac{\text { Intrinsic muscles }}{\text { FDI, FPI,FLUM }}$ & & \\
\hline \multirow{4}{*}{$\begin{array}{l}\text { (Marc H. } \\
\text { Schieber et } \\
\text { al., 2009) }\end{array}$} & 10 stroke subjects & \multirow{4}{*}{$\begin{array}{l}\text { Cyclical F/E or Ab/Ad } \\
\text { movements of each digit }\end{array}$} & \multirow{4}{*}{$\begin{array}{l}\text { FDI in the control hand was active only when the index finger was abducting. } \\
\text { FDI in the affected hand was active as well during movement of the thumb or the ring finger. } \\
\text { These inappropriate contractions of FDI in the affected hand would cause the index finger } \\
\text { to move when the subject attempted to move only the thumb or the ring finger. } \\
\text { Muscle synergies of the stroke-affected arm were strikingly similar to those of the unaffected } \\
\text { arm despite marked differences in motor performance between the arms. } \\
\text { In subjects with severe motor impairment, there was much less resemblance between the } \\
\text { synergies of the two arms. }\end{array}$} \\
\hline & sEMG & & \\
\hline & $\frac{\text { Extrinsic muscles }}{\text { None }}$ & & \\
\hline & $\frac{\text { Intrinsic muscles }}{\mathrm{APB}, \mathrm{FDI}, \mathrm{ADM}}$ & & \\
\hline
\end{tabular}




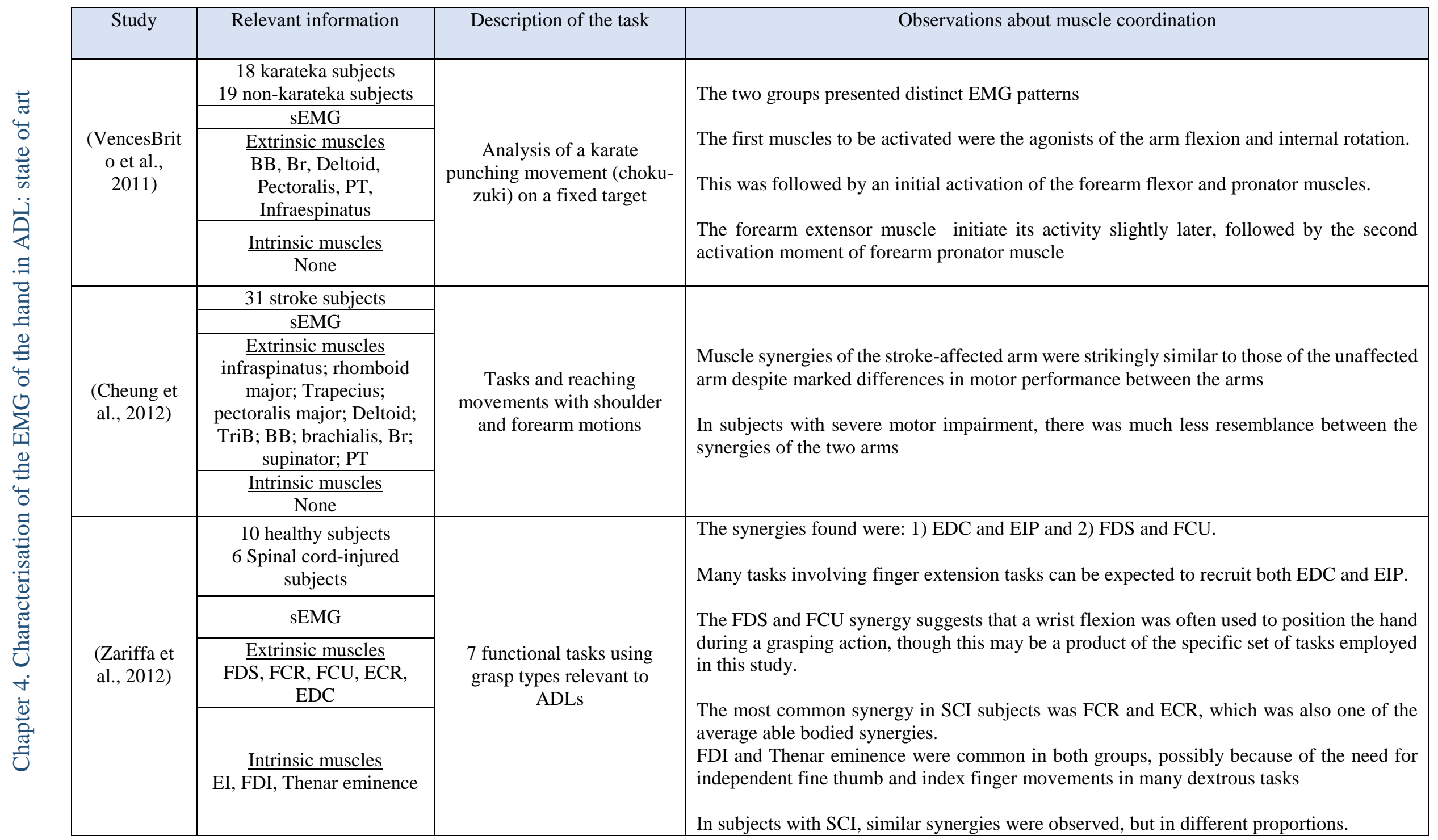




\begin{tabular}{|c|c|c|c|}
\hline Study & Relevant information & Description of the task & Observations about muscle coordination \\
\hline \multirow{4}{*}{$\begin{array}{l}\text { (Burkhart } \\
\text { and } \\
\text { Andrews, } \\
\text { 2013) }\end{array}$} & 20 healthy subjects & \multirow{4}{*}{$\begin{array}{l}\text { Impacts occurred to the hand } \\
\text { from two heights }\end{array}$} & \multirow{4}{*}{$\begin{array}{l}\text { Individuals are capable of selecting an upper extremity posture that allows them to minimise } \\
\text { the effects of an impact and it has confirmed the presence of a preparatory muscle activation } \\
\text { response }\end{array}$} \\
\hline & sEMG & & \\
\hline & $\begin{array}{l}\mathrm{BB}, \underset{\mathrm{Extrinsic} \mathrm{muscles}}{\mathrm{Br}, \text { Anconaeus, FCR, }} \\
\text { ECR }\end{array}$ & & \\
\hline & $\frac{\text { Intrinsic muscles }}{\text { None }}$ & & \\
\hline \multirow{4}{*}{$\begin{array}{l}\text { (Castellini } \\
\text { and Van Der } \\
\text { Smagt, } \\
\text { 2013) }\end{array}$} & 6 healthy subjects & \multirow{4}{*}{$\begin{array}{l}\text { Five static grasps: flat grasp, } \\
\text { pinch grip, tripodal grip, } \\
\text { small power grasp and large } \\
\text { power grasp }\end{array}$} & \multirow{4}{*}{$\begin{array}{l}\text { Three main synergies were found: uniform activation, activation of the dorsal muscles near } \\
\text { the radius and activation of the flexors near the radius. }\end{array}$} \\
\hline & sEMG & & \\
\hline & $\begin{array}{l}\text { Extrinsic muscles } \\
\text { Two bands surrounding } \\
\text { the forearm }\end{array}$ & & \\
\hline & $\frac{\text { Intrinsic muscles }}{\text { None }}$ & & \\
\hline \multirow{4}{*}{$\begin{array}{l}\text { (D’Andola } \\
\text { et al., 2013) }\end{array}$} & 6 healthy subjects & \multirow{4}{*}{$\begin{array}{l}\text { Dynamic movement } \\
\text { catching a ball }\end{array}$} & \multirow{4}{*}{$\begin{array}{l}\text { Two time-varying muscle synergies. } \\
\text { First synergy showed a coordination of elbow flexors, shoulder flexors and shoulder } \\
\text { elevators with shorter bursts in the elbow flexors than in the other muscles in most cases. } \\
\text { The second synergy showed a higher level of co-activation of the entire set of muscles. } \\
\text { Elbow extensors, shoulder extensors and adductors were strongly recruited with a burst } \\
\text { peaking before the end of the synergy, while other muscles were recruited later and showed } \\
\text { a ramped activation }\end{array}$} \\
\hline & sEMG & & \\
\hline & $\begin{array}{l}\text { Extrinsic muscles } \\
\text { BB, Br, TriB, Deltoid, } \\
\text { Pectoralis, Trapecius, PT, } \\
\text { Infraspinatus }\end{array}$ & & \\
\hline & $\frac{\text { Intrinsic muscles }}{\text { None }}$ & & \\
\hline
\end{tabular}




\begin{tabular}{|c|c|c|c|}
\hline Study & Relevant information & Description of the task & Observations about muscle coordination \\
\hline $\begin{array}{l}\text { (Lee et al., } \\
\text { 2013) }\end{array}$ & $\begin{array}{c}4 \text { healthy subjects } \\
14 \text { subjects with chronic } \\
\text { hemiparesi } \\
\text { sEMG } \\
\text { Extrinsic muscles, FDS, } \\
\text { EDC, FCR, FCU,ECR, } \\
\text { ECU } \\
\begin{array}{c}\text { Intrinsic muscles } \\
\text { Thenar muscles, FDI, } \\
\text { hypothenar muscles }\end{array}\end{array}$ & $\begin{array}{l}\text { Wrist F/E finger extension, } \\
\text { lateral pinch, power grip, } \\
\text { and tip pinch }\end{array}$ & $\begin{array}{l}\text { The first synergy, containing mainly thenar and FDI activity, was largely active in the three } \\
\text { grip tasks } \\
\text { The second synergy, consisting of EDC, ECR and ECU, was heavily weighted during } \\
\text { finger/wrist extension } \\
\text { The third synergy, involving coactivation of the wrist and finger muscles } \\
\text { The fourth synergy, with FCR, FCU and EDC activity, was employed during wrist flexion } \\
\text { For stroke survivors the composition of these modules were generally similar to those of } \\
\text { subjects with no impairment. }\end{array}$ \\
\hline $\begin{array}{l}\text { (Winges et } \\
\text { al., 2013) }\end{array}$ & $\frac{\text { Extrinsic muscles FDS (2 }}{\text { portions), EDC }}$ & $\begin{array}{l}\text { Piano dynamic movements: } \\
\text { playing } 14 \text { selected pieces } \\
\text { with the right hand at a } \\
\text { uniform tempo }\end{array}$ & $\begin{array}{l}\text { Phasic coactivation was evident between extensor and flexor muscles during piano playing } \\
\text { For the thumb sequence, PC1 first synergy was dominated by bursts of activity in the APB } \\
\text { and the FPB with activity in the four-finger ED muscle. } \\
\text { For the index finger sequence, the central burst of the first synergy included activity in two } \\
\text { to three flexors of the index finger. } \\
\text { Higher PC synergies were variable across subjects }\end{array}$ \\
\hline $\begin{array}{l}\text { (Hu et al., } \\
\text { 2015) }\end{array}$ & $\begin{array}{c}10 \text { healthy subjects } \\
\text { sEMG } \\
\frac{\text { Extrinsic muscles }}{\text { surface grid centred on the }} \\
\text { EDC } \\
\frac{\text { Intrinsic muscles }}{\text { None }}\end{array}$ & $\begin{array}{l}\text { Static and dynamic finger } \\
\text { movements: To extend } \\
\text { MCP joints individually }\end{array}$ & $\begin{array}{l}\text { When the four fingers extended simultaneously, the entire EDC was active. } \\
\text { When individual fingers extended separately distinct regions of the EDC were selectively } \\
\text { activated, with the index finger in the most distal region, the middle finger in the most } \\
\text { proximal region, and the ring and little fingers in between } \\
\text { Index and middle fingers have a greater degree of individuation in comparison with the little } \\
\text { and ring fingers }\end{array}$ \\
\hline
\end{tabular}




\begin{tabular}{|c|c|c|c|}
\hline Study & Relevant information & Description of the task & Observations about muscle coordination \\
\hline $\begin{array}{l}\text { (Ricci et al., } \\
\text { 2015) }\end{array}$ & $\begin{array}{l}\text { sEMG } \\
\text { Extrinsic muscles } \\
\text { Trapecius, Serratus, } \\
\text { Deltoid, Pectoralis, BB, } \\
\text { TriB, FDS, FCU,ECR, } \\
\text { ECU }\end{array}$ & $\begin{array}{c}\text { Pouring water task } \\
\text { belonging to the Elui } \\
\text { Functional Test of the Upper } \\
\text { Extremity }\end{array}$ & $\begin{array}{l}\text { In the Reaching phase, the main movements observed were shoulder flexion and elbow and } \\
\text { wrist extension, accompanied by significant higher activity of S, D and TriB. } \\
\text { The sequence of movements in this phase ended up with the subjects grasping the pitcher, } \\
\text { which could be related to the late coactivation between ECU and FCU. } \\
\text { Transport phase was mainly characterised by higher muscle activity of all muscles, except } \\
\text { for Pectoralis. } \\
\text { There were almost no significant differences in muscle activity within release phase. } \\
\text { ECR is a key muscle for wrist posture and function regardless task demand. } \\
\text { Activation of FCU and ECRLB were identified as the main control strategy performed to } \\
\text { keep optimal grasping }\end{array}$ \\
\hline \multirow{3}{*}{$\begin{array}{l}\text { (Roh et al., } \\
\text { 2015) }\end{array}$} & $\begin{array}{c}6 \text { healthy subjects } \\
16 \text { post-stroke subjects }\end{array}$ & \multirow{3}{*}{$\begin{array}{l}\text { Grasping the MACARM's } \\
\text { gimbaled handle }\end{array}$} & \multirow{3}{*}{$\begin{array}{l}\text { EMG spatial patterns were well explained by task-dependent combinations of only a few } \\
\text { (typically 4) muscle synergies } \\
\text { Elbow-related synergies were conserved across stroke survivors, regardless of impairment } \\
\text { level } \\
\text { Alterations in the shoulder muscle synergies underlying isometric force generation appear } \\
\text { prominently }\end{array}$} \\
\hline & $\frac{\text { sEMG }}{\mathrm{Br}, \begin{array}{c}\text { Extrinsic muscles } \\
\mathrm{BB}, \text { TriB, Deltoid and } \\
\text { pectoralis }\end{array}}$ & & \\
\hline & $\frac{\text { Intrinsic muscles }}{\text { None }}$ & & \\
\hline \multirow{4}{*}{$\begin{array}{l}\text { (Hesam- } \\
\text { Shariati et } \\
\text { al., 2017) }\end{array}$} & 24 post-stroke subjects & \multirow{4}{*}{$\begin{array}{l}\text { 14-day program focused on } \\
\text { the more- affected upper } \\
\text { limb }\end{array}$} & \multirow{4}{*}{$\begin{array}{l}\text { The profile of coordinated muscle activation varied by the level of residual motor-function } \\
\text { in chronic stroke. } \\
\text { The number of synergies used increased (although not significantly) with therapy for patients } \\
\text { with low and moderate motor-function. } \\
\text { The distribution of muscle weightings within synergies changed as a consequence of therapy }\end{array}$} \\
\hline & sEMG & & \\
\hline & $\begin{array}{l}\frac{\text { Extrinsic muscles }}{\text { Trapecius, Deltoid medius, }} \\
\text { BB, ECR, FCR, FDI }\end{array}$ & & \\
\hline & $\frac{\text { Intrinsic muscles }}{\text { None }}$ & & \\
\hline
\end{tabular}




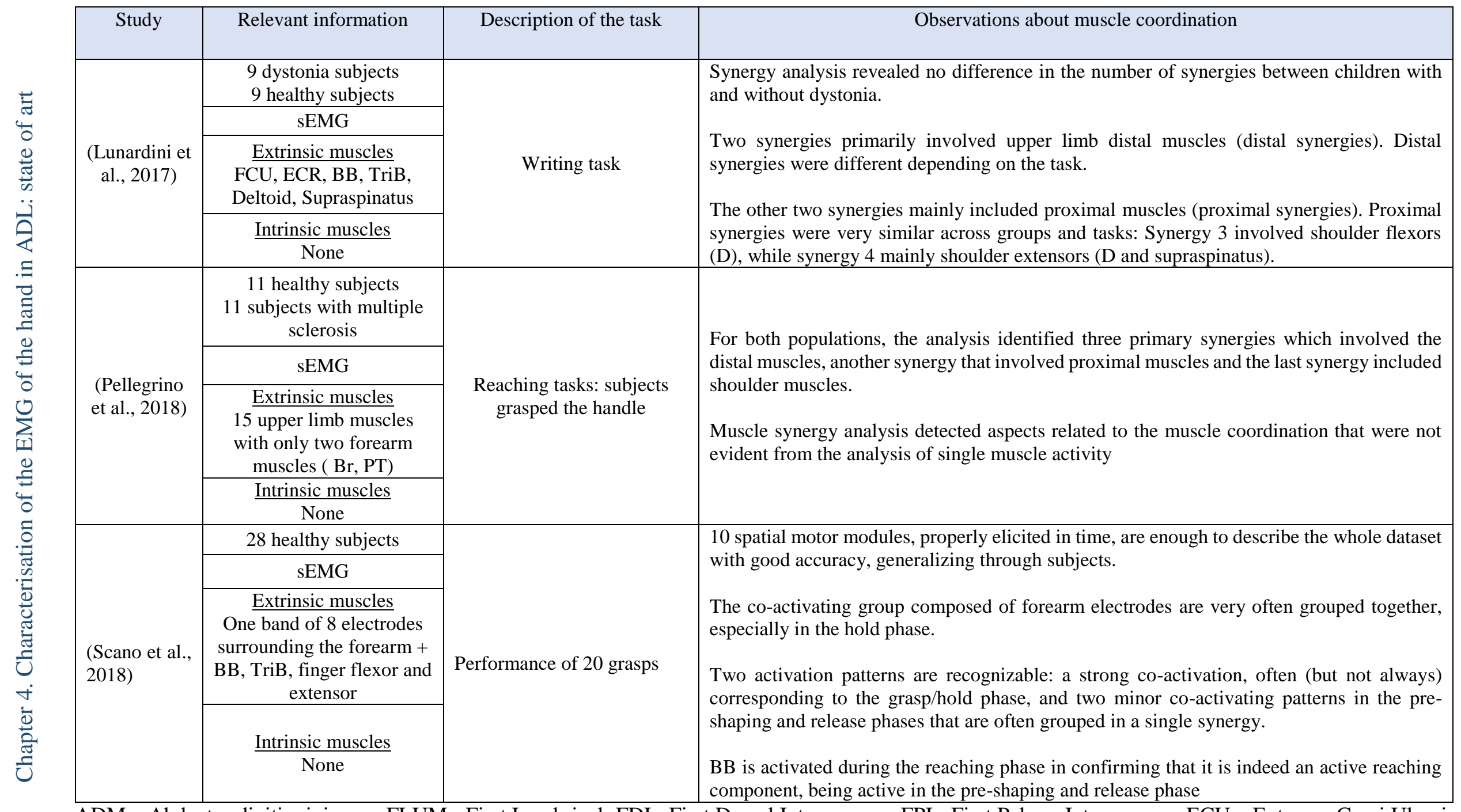

ADM - Abductor digiti minimum; FLUM - First Lumbrical; FDI - First Dorsal Interosseous; FPI - First Palmar Interosseous; ECU - Extensor Carpi Ulnaris; PT - Pronator Teres; FCR - Flexor Carpi Radialis; FDS - Flexor Digitorum Superficialis; FDP - Flexor digitorum Profundus; 


\subsection{Discussion and conclusion}

This literature review found 43 papers that matched the defined search criteria: 21 papers regarding hand and forearm muscles role, and 22 regarding hand muscle synergies.

First, I have analysed the studies focused on the role of specific small sets of forearm/hand muscles during some common tasks and grasps, sport activities and working tasks. Both extrinsic and intrinsic forearm muscles are required to accomplish these tasks, being the extrinsic ones responsible of the gross movements and the intrinsic ones responsible of the fine ones, but also they complement each other. Some specific muscles show high activation level across all the tasks, such as EDC, while others seem to have a specific role, such as ECR as wrist stabiliser. The tasks performed in ADL seem to require moderate co-contraction levels of forearm muscles, needing the cooperation between different groups of muscles and being this cooperation non task-dependent (Peters et al., 2018). Thumb muscles as EPL and EPB are able to activate separately from the other fingers flexors and extensors and their importance role in grasps has been widely demonstrated in the literature.

Second, the muscle synergies reflecting the relationship between muscles provide information in two domains, co-contractions and timing of activation. Therefore, studying muscle synergies can help to a better interpretation about the role of the muscles during different movement/task execution. The idea is consistent with the concept that the central nervous system may embed a modular structure that relies on a limited number of synergies at hand level. The works revised have demonstrated that a small subset of synergies could be generalised across tasks, representing basic building blocks underlying natural human hand motions/actions. Therefore, muscle synergy analysis could be useful as well for comparing different therapies and evaluating the function recovery of subjects regarding ADL performance. It has been hypothesised that patient's functional deficit may be identified by regularly assessing patient's muscle synergy profile, which might be used to track rehabilitation results, and adjust treatments (Safavynia et al., 2011a). Synergies have been suggested to be useful for clinicians to treat more effectively motor dysfunctions by organizing patients into subclasses and tailoring the treatment to the specific patient's deficit (Safavynia et al., 2011a).

However, some important gaps have been also identified, which should be addressed in further studies. One of the main gaps found in the literature is the considerable diversity in the protocol design used to record sEMG from forearm muscles. Most of the studies do not specify the electrode placement, so it is not clear which locations were used to acquire the sEMG data, resulting in difficulty when comparing values or affecting the crosstalk level, which will depend on which longitudinal level of the muscle has been placed. Therefore, it could be useful defining a way to place the electrodes that is comparable across subjects, even though it is not based on muscle identification, and complete, i.e. it covers all muscles involved in hand and wrist movement. This could be achieved by identifying the most representative forearm areas 
for ADL performance in terms of EMG activity. In order to find the minimum number of spots for sEMG recording to characterise the forearm muscular activity during ADL without losing much relevant information, the forearm areas with similar sEMG patterns during ADL performance could be identified.

The second main gap concerns the lack of representativeness of the tasks used for the EMG characterisation. Most studies found in the literature are focused on studying the role of specific muscles during simple tasks (hand postures or free finger movements), or during single activities (such as writing or typing), or during small sets of very controlled activities (few grasps, sport movements...). However, only few studies deal with the analysis of the forearm and hand muscles during ADL, none of them considers a wide representative set of ADL. Therefore, defining a selection of a limited set of representative tasks would improve the current methodology, given the wide variety of ADL that can be performed by humans. Furthermore, standardisation of the tasks would allow comparison between subjects and sessions (important for tracking function recovery). The use of standardised tasks is especially important considering that each different individual may perform the same activity using several different strategies. The standardisation would help the comparison of muscular patterns and the identification of different strategies, distinguishing between the different task phases (Hebert et al., 2014).

In addition, to go further in synergies, simultaneous measurement of hand kinematics is not usually performed, and when measured, is used only to segment the different phases of the movement. Therefore, linked EMG-kinematic datasets, at the hand level, are still lacking. Such synchronised datasets are needed if we want to analyse how hand movements are produced and controlled. This could be helpful in some fields like rehabilitation (to help choosing the most suitable approaches), or prosthetics (to find out a more reliable and natural control of hand prosthetics).

The review performed provides a basis of knowledge about the hand/forearm muscles role, but the lack of a clear methodology introduces some limitations. These methodological inconsistencies add additional difficulty for an effective interpretation of findings and to draw any decisive conclusions. Therefore, although there are more gaps to be addressed in future research, the ones that have been addressed in the next chapters, with the final goal of characterizing the muscular activity of the forearm and hand during ADL, are:

1) To establish representative areas of the forearm for sEMG recording, in order to study and characterise the muscular activity during functional activities.

2) To study the forearm muscles role during the performance of the most used grasps in ADL

3) To establish a database of simultaneous sEMG and kinematics data recorded during the performance of a representative set of realistic and standardised ADLs.

4) To establish relationships between hand kinematics and forearm sEMG during ADL.

Kinematic and muscular characterisation of the hand during ADL 


\section{CHAPTER 5}

Identification of forearm skin zones with similar muscle activation patterns during activities of daily living 

This chapter corresponds exactly to the paper published in the Journal of NeuroEngineering and Rehabilitation, 2018, that presents seven representative forearm skin zones with similar muscle activation patterns in order to determine the minimum number of electrodes required to characterise the muscle activity during simulated ADL without losing any relevant information.

The paper is titled: 'Identification of forearm skin zones with similar muscle activation patterns during activities of daily living'.

\subsection{Abstract \& keywords}

Background A deeper knowledge of the activity of the forearm muscles during activities of daily living (ADL) could help to better understand the role of those muscles and allow clinicians to treat motor dysfunctions more effectively and thus improve patients' ability to perform activities of daily living.

Methods In this work, we recorded sEMG activity from 30 spots distributed over the skin of the whole forearm of six subjects during the performance of 21 representative simulated ADL from the Sollerman Hand Function Test. Functional principal component analysis and hierarchical cluster analysis (HCA) were used to identify forearm spots with similar muscle activation patterns.

Results The best classification of spots with similar activity in simulated ADL consisted in seven muscular-anatomically coherent groups: (1) wrist flexion and ulnar deviation; (2) wrist flexion and radial deviation; (3) digit flexion; (4) thumb extension and abduction/adduction; (5) finger extension; (6) wrist extension and ulnar deviation; and (7) wrist extension and radial deviation.

Conclusion The number of sEMG sensors could be reduced from 30 to 7 without losing any relevant information, using them as representative spots of the muscular activity of the forearm in simulated ADL. This may help to assess muscle function in rehabilitation while also simplifying the complexity of prosthesis control.

Keywords Activities of daily living, Clustering analysis, Electromyography, Electrode placement, Forearm muscles, Functional principal component analysis , Myoelectric prostheses, Rehabilitation, Sollerman Hand Function Test.

\subsection{Introduction}

The forearm and the hand are connected by the wrist, together forming a functional unit in which there are about 30 muscles that work in concert in a highly complex way (Yu et al., 2004), allowing a wide range of activities to be performed, many of them with a high level of precision. When a disease or injury to any part of the hand or forearm take 
place, our manipulation and grip capacities are reduced and, therefore, carrying out the most common activities in our daily life can become a serious problem.

Surface electromyography (sEMG) is a non-invasive approach that allows both structural and functional characterisation of the neuromuscular system, as well as making it possible to quantify variations of this system in different situations. sEMG is applied in many fields such as motor control of human movement, myoelectric control of prosthetic and orthotic devices, and rehabilitation (Castellini et al., 2009; Hogrel, 2005; Kumar et al., 2013; Rojas-Martínez et al., 2012). In rehabilitation, sEMG has been used to monitor the effects of rehabilitation techniques (Hogrel, 2005; Vinstrup et al., 2018), rehabilitation devices (Nam et al., 2017), and therapeutic exercises (Landis et al., 2005). In this line, some studies have proposed the addition of sEMG analysis to clinical assessments to provide quantitative measures of therapy outcomes for people with motor impairment and physical disability in the upper limb, such as stroke (Hesam-Shariati et al., 2017) or hemiplegia (Chae et al., 2002). In those studies, the amplitude of the sEMG signal is used to provide quantitative measures, as patients have a reduced neuromuscular amplitude (Brorsson et al., 2014; Hesam-Shariati et al., 2017; Hogrel, 2005). However, there is no consensus on the muscles or areas of the forearm that must be measured in each case. This fact may lead to the recording of repeated muscle activity information and/or missing information about some muscles.

The central nervous system must control a structure that is in general vastly more complex than necessary to execute any particular task. In this sense, muscular activation patterns or muscular synergies (Johnston et al., 2009; Santello et al., 2013) appeared as a possible way to allow the analysis of muscular control during task execution. Some studies have described muscle patterns or synergies during certain postures (Coscia et al., 2014), grasps (Zariffa et al., 2012) or hand movements (Weiss and Flanders, 2004; Winges et al., 2013), during particular actions (D’Andola et al., 2013; Ertan, 2009; Ertan et al., 2003; Ricci et al., 2015; VencesBrito et al., 2011), and for individually tailored rehabilitation protocols (Cheung et al., 2012). Examining whether muscle synergies change following rehabilitation may provide an assessment of interventions that improve patients' motor function and therefore their ability to perform activities of daily living (ADL). A patient's muscle synergy profile may allow clinicians to treat motor dysfunctions more effectively by organizing patients into subclasses and tailoring the treatment to each patient's specific deficit (Safavynia et al., 2011b).

Myoelectric prostheses are usually controlled with sEMG (Atzori et al., 2013; Castellini and Van Der Smagt, 2009; Farina et al., 2014). However, one quarter to one third of all amputees reject self-powered prostheses (Engdahl et al., 2015) because they feel a non-close-to-natural operation (Zuo and Olson, 2014) that leads to long and discouraging training periods. A deeper knowledge of the activity of the forearm muscles during different functional tasks could help in the development of more intuitively controlled prostheses, capable of replicating the intact hand movements by using sEMG signals from the residual muscles, similarly to when they had their own intact hand. In 
this sense, identification of repeatable patterns of muscle activity (muscular synergies) across multiple muscle sites rather than relying on independent EMG signals has been shown to enable more natural, reliable control of myoelectric prostheses (Daley et al., 2012). However, the electrodes are usually placed on the remaining muscles of the forearm regardless of the muscle's pre-amputation role (Schultz and Kuiken, 2011), favouring a non-close-to-natural operation. To overcome this hindrance, some authors have studied the accuracy of pattern recognition of myoelectric control, by evaluating the number and locations of sEMG channels (Daley et al., 2012; He Huang et al., 2008; Tkach et al., 2012). Daley et al. (Daley et al., 2012) distributed the electrodes around the whole forearm in a grid formation during twelve wrist and hand motions and five different grasps in healthy and amputee subjects. Their results suggest that most of the neural information available could be extracted with a greatly reduced number of electrodes. However, the optimal location of electrodes and their consistency across subjects were not reported, and the tasks used for the analysis were not representative of ADL. Upper limb tasks should be goal-oriented and of a standardised nature to obtain consistent performance (Hebert et al., 2014). Some previous works have evaluated the performance of similar SEMG classification systems by using the NINAPRO database (Baldacchino et al., 2018; Barmpakos et al., 2016; Koch et al., 2017). However, the sEMG data contained in this database was recorded while performing non-goal-oriented actions. Clinical tests, such as the Sollerman Hand Function test (SHFT) (Sollerman and Ejeskar, 1995), are often used to evaluate and track functional recovery of the upper extremity, providing insight into functional performance. These tests typically evaluate this functional performance using tasks simulating ADL.

In this work, we recorded sEMG activity from different areas of the whole forearm skin during the performance of the ADL included in the SHFT, a standardised test for hand function evaluation. The aim was to identify skin zones with similar muscle activation patterns in order to determine the minimum number of electrodes required to characterise the muscle activity during simulated ADL without losing any relevant information.

\subsection{Methods}

\section{Subjects and tasks}

Six able-bodied subjects ( 3 males and 3 females, with average (SD) age of 34.5 (8.2) years) gave their informed written consent before participating in this study, approved by the ethics committee of our University.

Twenty-one simulated ADL were selected, all of them tasks included in the SHFT. Some of the simulated ADL were adapted in order to ensure their repeatability. The activity 14 from the original SHFT was separated in two different activities. In the first one, the piece of paper was folded (A14) and in the second one the folded paper was 
inserted into an envelope (A15). Others were slightly adapted, for example, reducing the number of objects to be manipulated (just one zipper, one coin, one button, etc.) or indicating the direction and the degrees to be turned in each case (Figure 5.1, Table 5.1). Each simulated ADL started and ended with the body and arms in the same posture (arms relaxed at the side of the body, in the case that the person was standing, or arms resting in a relaxed position on the table if they were sitting). Precise instructions were provided for each task by the researcher administering the SHFT, including details such as the angle of rotation of the key (A1), the position of the coin (A2 \& A4), the angle of rotation of the door handle (A18) or the amount of water to be poured (A20). The subjects could practice each task as many times as necessary in advance so as to become familiar with its performance before the sEMG recording.

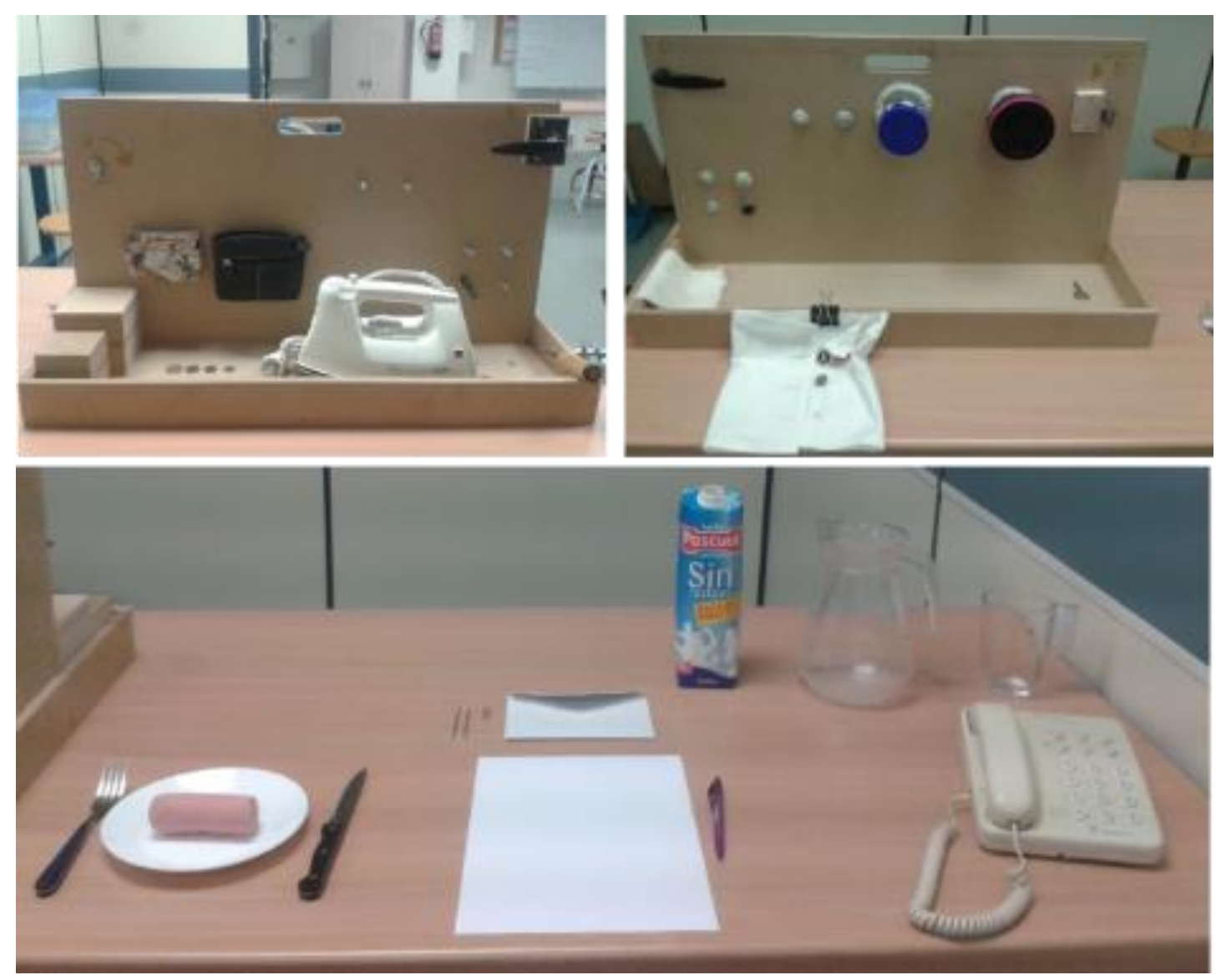

Figure 5.1 Sollerman Hand Function Test configuration 
Table 5.1 Description of the standardised ADL

\begin{tabular}{|c|c|}
\hline ADLs & DESCRIPTION \\
\hline A1 & Take a key, insert it in a lock, turn it counter-clockwise $180^{\circ}$ and leave the key in \\
\hline A2 & Collect a coin and insert it into a change purse \\
\hline A3 & Open and close a zipper \\
\hline A4 & Remove the coin from the change purse and leave it on the table \\
\hline A5 & Catch and move two wooden cubes of different sizes \\
\hline A6 & Lift and move an iron from one marked point to another \\
\hline A7 & Take a screwdriver and turn a screw clockwise $180^{\circ}$ with it \\
\hline A8 & Take a nut and bolt and turn the bolt until it is completely inserted inside the nut \\
\hline A9 & Unscrew a lid and leave it on the table \\
\hline A10 & Pass a button through a buttonhole with the help of both hands \\
\hline A11 & $\begin{array}{l}\text { Take a knife with the right hand and a fork with the left hand and split a piece of clay } \\
\text { (sitting) }\end{array}$ \\
\hline A12 & Take a bandage and put it on your left arm until the elbow \\
\hline A13 & $\begin{array}{l}\text { Pick up a pen from the table, write the Spanish word "SOL" and put the pen back on } \\
\text { the table (sitting) }\end{array}$ \\
\hline A14 & Fold a piece of paper with both hands and insert it into a box \\
\hline A15 & Insert the folded paper (from A14) into an envelope and leave it on the table \\
\hline A16 & Take a clip and put it on the flap of the envelope \\
\hline A17 & Pick up the phone, put it to your ear and hang up the phone \\
\hline A18 & Turn a door handle $30^{\circ}$ \\
\hline A19 & Pour $1 \mathrm{~L}$ of water from a carton into a jug \\
\hline A20 & Pour water from the jug into the glass up to a marked point \\
\hline A21 & Pour the water from the glass back into the jug \\
\hline
\end{tabular}

\section{Electrode placement}

A grid was drawn on the forearm, covering its entire surface, by using five easily identifiable and highly reproducible anatomical landmarks (Figure 5.2, Table 5.2). The grid defined 30 different spots (Figure 5.2) and was drawn with the subject sitting comfortably, the elbow resting on the table, the arm flexed $90^{\circ}$ with respect to the forearm, and the palm of the hand facing the subject. First, three longitudinal lines were drawn joining the anatomical landmarks 1-4, 2-3 and 2-5, and two transverse lines joining landmarks 1-2 and 3-4-5. Each of the longitudinal lines was divided into four equal parts that were used to draw the internal transverse lines of the grid. Transverse lines 1-2 and 4-5 in the cubital region were divided into three equidistant parts, and the same was applied to lines 1-2 and 4-3 in the radial region. These subdivisions were used to draw the corresponding longitudinal lines. Finally, the area formed by landmarks 2-3-5 was divided so that there were three equal spots in the most proximal region (spots 22, 23 and 24), a single spot in the most distal region (spot 7), and two spots in the intermediate 
region (spots 14 and 15), as shown in Figure 5.2. The sensors were placed in the centre of each area and were set out in a longitudinal direction, since most of the muscles of the forearm are quite aligned to it (Yu et al., 2004). Before placing the electrodes, the hair was removed by shaving and the skin was cleaning by using alcohol.

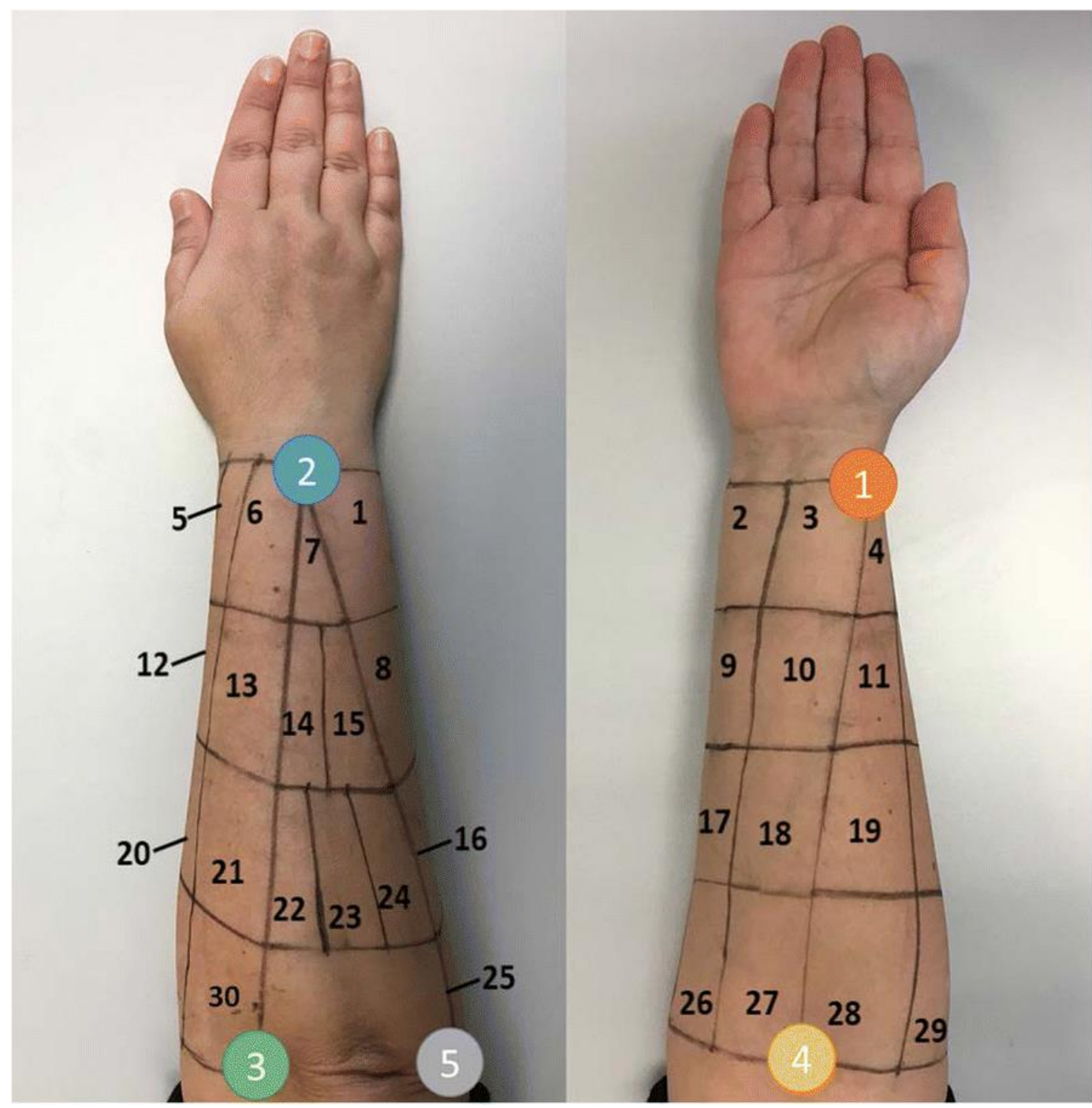

Figure 5.2 Grid with the 30 spots for sEMG recording, and anatomical landmarks used

Table 5.2 Anatomical landmarks

\begin{tabular}{cl}
\hline \hline Number & Landmark \\
\hline 1 & Styloid processes of the radius \\
2 & Ulna head \\
3 & Medial epicondyle of the humerus \\
4 & Center point of the elbow \\
5 & Humeral lateral epicondyle \\
\hline \hline
\end{tabular}

Kinematic and muscular characterisation of the hand during ADL 


\section{Data acquisition}

Muscle activity was recorded with an 8-channel sEMG Biometrics Ltd device, with a sampling frequency of $1000 \mathrm{~Hz}$. Technical information of the electrodes is shown in Figure 5.3. Recording sEMG from the 30 spots of the grid required distributing the measurements over five different sessions. The spots chosen for each session (the same for each subject) were selected to be as widely distributed as possible, so that electrodes were placed in spots in not close to each other. Each simulated ADL was recorded twice within each session. It was also checked that the duration of the same simulated ADL was similar in each session. In order to check the repeatability of the simulated ADLs among sessions, all sessions recorded sEMG from spot 30.

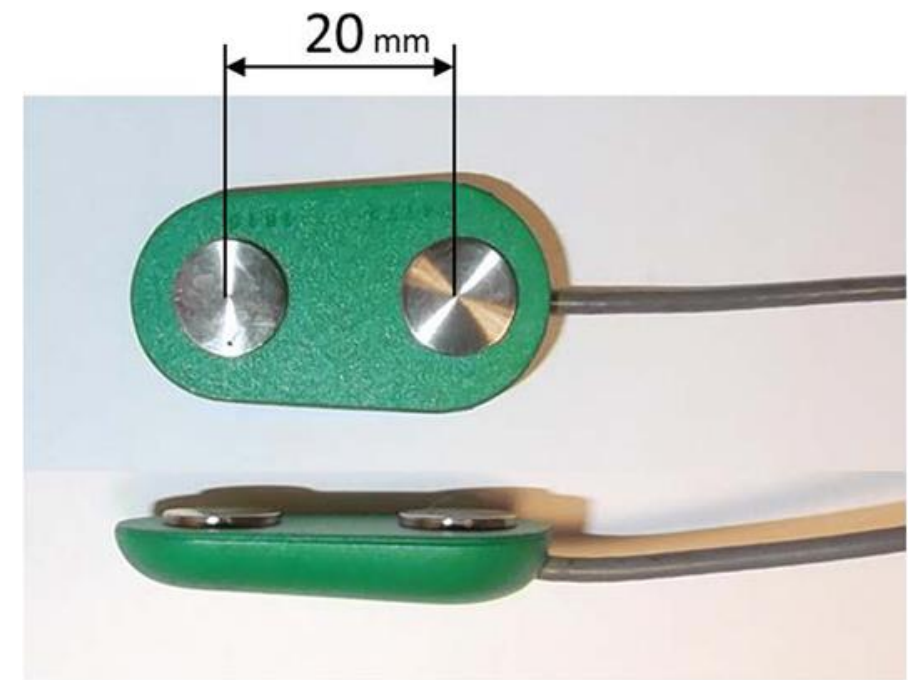

Figure 5.3 sEMG Electrodes (SX230) used: integral dry reusable electrodes with a gain of 1000, bandwidth between $20 \mathrm{~Hz}-460 \mathrm{~Hz}$ and noise less than $5 \mu \mathrm{V}$

The sEMG records were filtered with a 4th-order bandpass filter between 25-500 $\mathrm{Hz}$, rectified, filtered by a 4th-order low pass filter at $8 \mathrm{~Hz}$, and smoothed by Gaussian smoothing. To determine muscle activity, sEMG records were normalised with the maximal values from seven records of maximum voluntary contraction (MVC), measured in each session: flexion and extension of the wrist, flexion and extension of the fingers, pronation of the forearm, ulnar deviation of the wrist, and elbow flexion. MVCs for the different movements were recorded without the use of any external device. In a comfortable posture, the subjects were asked to exert maximum effort (recorded with a dynamometer) without the help of other muscles than those of the forearm and hand. In addition, the beginning and end of the sEMG records were cut to eliminate the first and last moments in which muscle activity did not exceed 5\% in any of the spots. Finally, to make records comparable in duration, all the records were interpolated to 1000 data. 


\section{Data analysis}

i) ADL repeatability: The confidence intervals (CI) of the 10 muscular activity records ( 2 repetitions x 5 sessions) of spot 30 were computed for each simulated ADL (1000 values of CI per ADL x 6 subjects). Statistics per ADL were considered for the analysis of repeatability.

ii) Reduction of temporary muscle activity data: The data from all repetitions at each spot for each simulated ADL were averaged, and used in the subsequent analysis, so that a total of 3780 signals (21 ADL x 6 subjects x 30 spots) of 1000 temporary data were considered. The Principal Component Analysis (PCA) was one of the first methods adapted to functional data. The fundamental idea of this extension is to conserve all the benefits of the PCA as a tool for the reduction of the dimension, conditioning them to functional data. Thus, the Functional Principal Component Analysis (FPCA) (Ullah and Finch, 2013) could provide a basis for creating a new set of variables that incorporate the character and nature of the original functions into a smaller number of new variables. In this case, FPCA was applied to condense the temporary muscle activation data into a smaller number of parameters, in order to make the comparison of temporal patterns feasible. First, for each subject, the signals for the 21 simulated ADL from each spot were concatenated. Subsequently, each of these signals was normalized to 1 using their maximum value, in order to keep only the temporal patterns to be analysed. Then, the data of all the subjects were concatenated. In this way, the 3780 signals were transformed into 30 functions of 126000 data, one function per spot. FPCA was applied then to these 30 functions, extracting the functional principal components (FPCs) that explained at least $90 \%$ of the cumulative variance. Each of the 30 original functions can be expressed therefore as a common mean function plus a linear combination of the FPCs, with specific coefficients for each original function, hereinafter called reduced variables (RVs), as they condense the 126000 data into a small number of coefficients.

iii) Similarity of patterns of muscle activation: Conglomerate or Hierarchical clustering analysis (Hair et al., 2009) is a multivariate technique that allows the classification of elements in groups or clusters, so that each element is very similar to those in its own conglomerate according to some specific selection criteria. In this case, Hierarchical clustering analysis, with the Euclidean distance as the distance criterion and Ward's method as the linkage criterion, was applied to the RVs from the 30 spots to group spots with similar muscle activation patterns. The resulting dendrogram with the spots organized in branches was displayed, and the desired number of clusters was identified by observing the distances in each step. When the distance between the clustered groups in a step becomes high in comparison to the previous steps, the elements or clusters grouped are not so close and so the grouping of the previous step may be more appropriate. The resulting groups of spots with a similar activation pattern were described. Additionally, root mean square (RMS) values of all signals measured at each spot were computed for analysis of representativeness, in order to choose a specific spot as being representative of each group. 


\subsection{Results}

i) ADL repeatability: Statistics of the CI of the muscular activity records at spot 30 for each simulated ADL are shown in Table 5.3 as a percentage of MVC. In general, the results showed a good level of repeatability of the different simulated ADL, with mean CI values of $3.33 \%$ of muscular activity and SD values of $2.22 \%$. The most unfavourable results were for ADL 9, with mean CI of 6\% (SD 4.2\%) of MVC.

Table 5.3 CI Statistics: mean and standard deviation (SD)

\begin{tabular}{ccc}
\hline \hline ADL & mean & SD \\
\hline 1 & $2.6 \%$ & $2.3 \%$ \\
2 & $1.9 \%$ & $1.4 \%$ \\
3 & $1.7 \%$ & $1.4 \%$ \\
4 & $3.6 \%$ & $3.2 \%$ \\
5 & $4.3 \%$ & $2.5 \%$ \\
6 & $5.0 \%$ & $3.1 \%$ \\
7 & $3.9 \%$ & $2.6 \%$ \\
8 & $2.9 \%$ & $2.8 \%$ \\
9 & $6.0 \%$ & $4.2 \%$ \\
10 & $2.7 \%$ & $1.6 \%$ \\
11 & $4.1 \%$ & $2.2 \%$ \\
12 & $3.9 \%$ & $2.7 \%$ \\
13 & $2.9 \%$ & $1.1 \%$ \\
14 & $3.1 \%$ & $1.6 \%$ \\
15 & $3.7 \%$ & $2.5 \%$ \\
16 & $2.1 \%$ & $1.3 \%$ \\
17 & $3.8 \%$ & $2.3 \%$ \\
18 & $2.7 \%$ & $1.5 \%$ \\
19 & $2.2 \%$ & $2.1 \%$ \\
20 & $4.0 \%$ & $2.6 \%$ \\
21 & $2.9 \%$ & $1.6 \%$ \\
\hline \hline
\end{tabular}

ii) Reduction of temporary muscle activity data: 17 FPCs explained $91 \%$ of the total variance. RVs are displayed in Figure 5.4 as a rectangular array of coloured cells defined by the values of the RVs. 


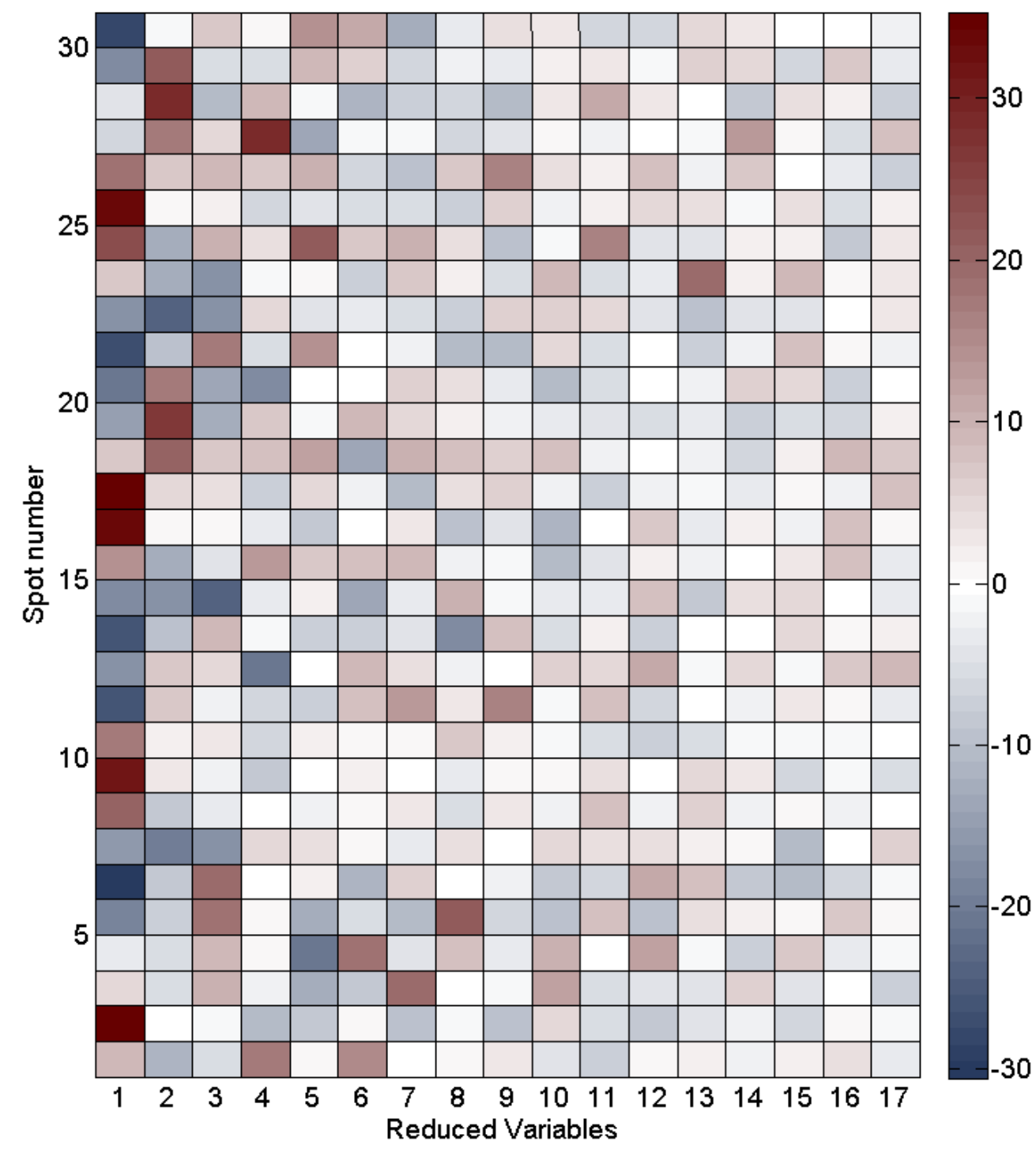

Figure 5.4 Values of the 17 RVs for each of the 30 spots. Positives values are displayed in red and negative values in blue

iii) Similarity of patterns of muscle activation: Figure 5.5 shows the dendrogram obtained from the hierarchical clustering with the distance between grouped elements. The dendrogram shows different possible groupings, depending on the linkage distances. The resulting groups for the case of seven clusters are displayed with different colours in Figure 5.6. 
Chapter 5. Identification of forearm skin zones with similar muscle profiles during ADL153

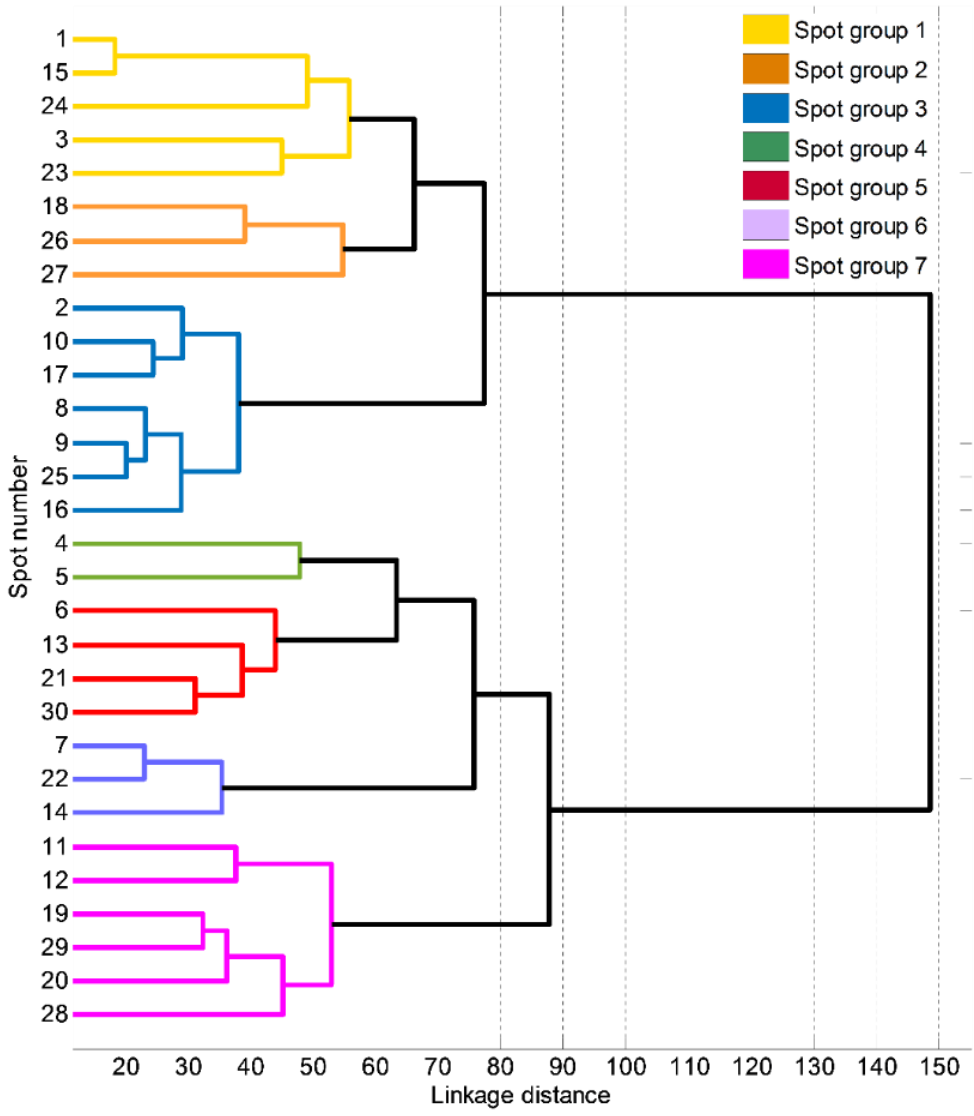

Figure 5.5 Dendrogram obtained from the hierarchical clustering. The seven groups chosen are displayed in different colours

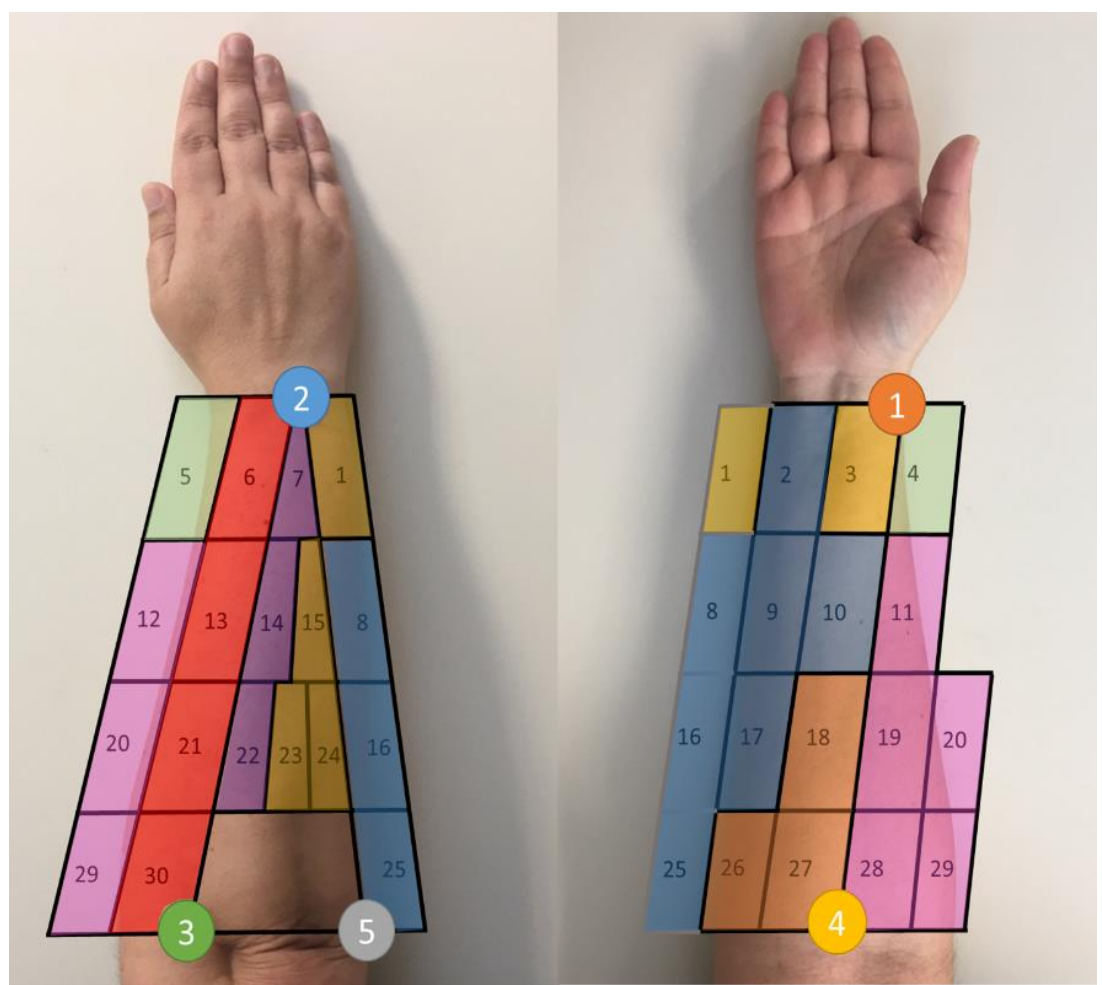

Figure 5.6 Resulting groups of spots with similar activation patterns

Kinematic and muscular characterisation of the hand during ADL 
Figure 5.7 shows the RMS values of the muscular activity measured at each spot, to be considered when choosing a specific spot as representative of a group. Spots 18 and 28 show a low level of RMS values compared to the other spots, reaching less than $5 \%$ of RMS of the muscular activity.

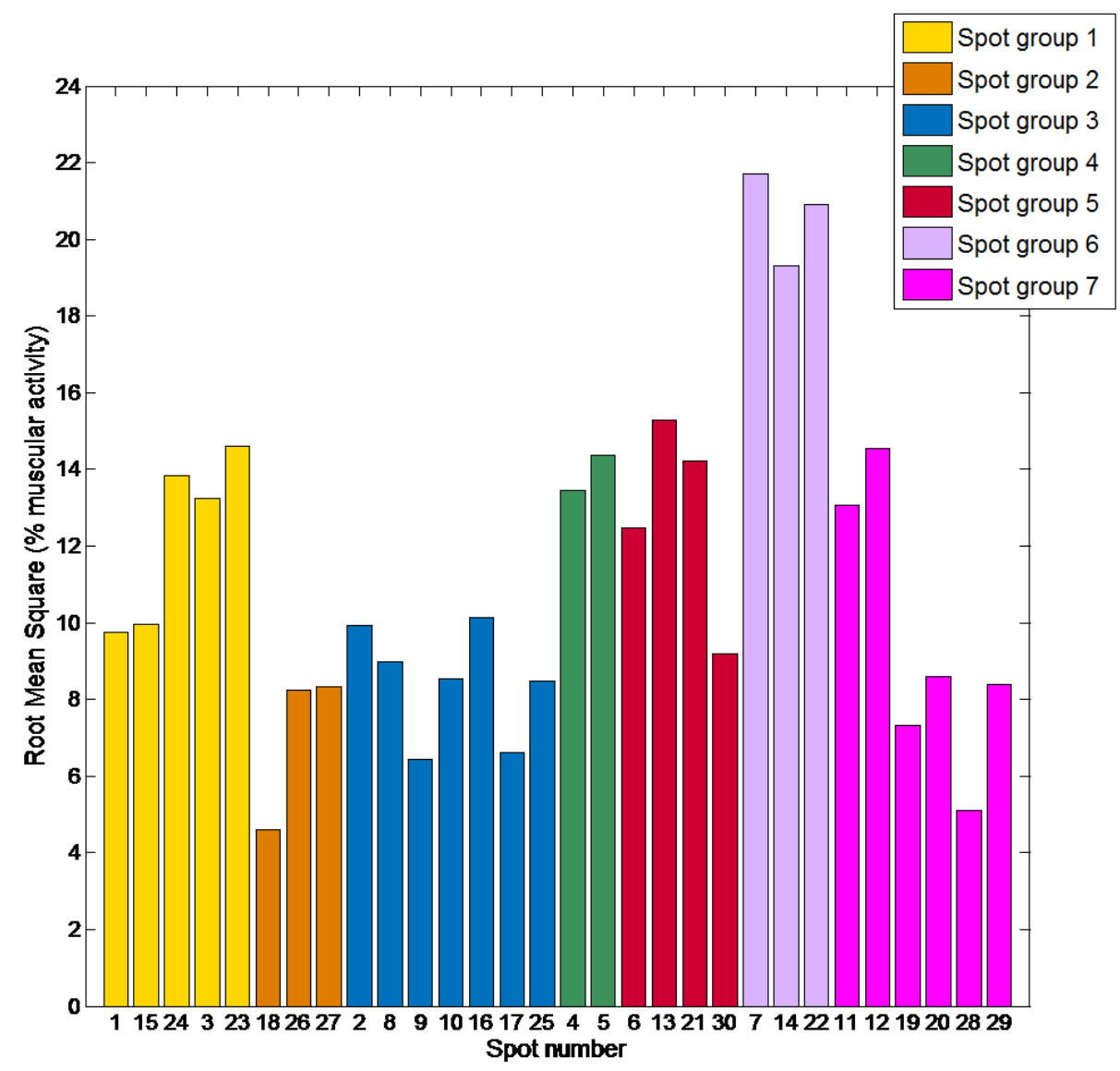

Figure 5.7 RMS of the muscular activity values of each spot. The bars are coloured according to the resulting groups

\subsection{Discussion}

In this work we identified forearm areas with similar muscle activation patterns by means of FPCA and cluster analysis, which could be used to characterize the muscle activity during relevant simulated ADLs. Consequently, one of the main contribution of the proposed approach is the focus on goal-directed actions.

The tasks used in this study were taken from the SHFT. The selection of the tasks was originally based on the percentage use of the most common handgrips during ADL and hence reflects an accurate representativeness of hand function in day-to-day life. Muscle activity on 30 different forearm spots was obtained for each of the 21 representative simulated ADLs by merging sEMG signals recorded in five different sessions This was possible because of the high repeatability observed for the simulated ADLs considered (mean CI values at spot 30 of $3.33 \%$ of MVC, SD 2.22\%), thanks to 
the proposed standardisation. Unscrewing a lid and leaving it on the table (ADL 9) was the least repeatable activity, with a mean CI value of $6 \%$ of MVC.

Seventeen RVs explained $91 \%$ of the total variance. This new set of variables provided the same information but in a more easily interpretable way: each of the 30 original functions of 126000 temporary data was expressed as a common mean function plus a linear combination of 17 FPCs, with specific coefficients (RVs) for each original function. These 17 RVs obtained from the FPCA have been used in a hierarchical cluster analysis to group spots with similar activation patterns.

From the observation of the distances in each step in the hierarchical cluster analysis, seven groups may be established based on the moment in which the distance between the clustered groups in a step becomes high in comparison to the previous steps. Therefore, the number of EMG sensors could be reduced from 30 to 7 without losing any relevant muscle activity information during the performance of simulated ADL. This is very interesting, as there are 20 muscles superimposed on each other in the forearm, thus making it practically impossible to isolate the sEMG signal of each muscle. Protocols of muscular function assessment of the forearm in rehabilitation can benefit from this. The measurement of the amplitude of the sEMG signals from the seven resulting groups may provide a reasonably complete quantitative picture of the patient's rehabilitation outcome. Furthermore, given that the number of available electrodes could be limited and that a smaller number of EMG signals may simplify the assessment, knowing the similarity of the sEMG signals with different levels of hierarchy, as provided with the method used, is also quite interesting. This also applies for prosthesis control, where the number of EMG signals to be used is limited by the complexity of the controller.

When observing the dendrogram obtained from the cluster analysis, different numbers of clusters could be chosen. Two main hierarchy levels can be observed: one involves the flexor muscles of the wrist and digits (spot groups 1 to 3), and the other includes their extensor muscles (spot groups 4 to 7). In the next hierarchy level, flexors bifurcate into wrist flexors (groups 1 and 2) and digit flexors (group 3); it is known that digit flexors also contribute to wrist flexion (Oatis, 2009). And something similar occurs for extensors, which bifurcate into digit extensors (groups 4 and 5) and wrist extensors (groups 6 and 7). Therefore, in the case of using two signals for prosthesis control, it would be logical to consider the two main hierarchy levels for an intuitive control in carrying out ADL, associating the sEMG signals to the performance of flexion and extension movements of the prosthesis. In the case of using four control signals, the next hierarchy level described could be used, differentiating between hand and wrist flexors and extensors. However, the higher the number of signals is, the more difficult it will become to separate them, and using groupings that are different from those resulting from the dendrogram will not be so intuitive.

If we were to divide the classification a step further we would get the seven groups described in the results section: Group 1 is defined by spots 1, 3, 15, 23 and 24. Anatomically, it could be recording mainly the muscle activity of the flexor carpi ulnaris 
(FCU). The FCU is a very powerful muscle that acts as a flexor and ulnar deviator of the wrist (Oatis, 2009), being responsible for stabilizing it during activities such as slicing meat and using a hammer. Group 2 is defined by spots 18,26 , and 27 , and could be recording the muscle activity of the flexor carpi radialis (FCR) and palmaris longus (PL). Both FCR and PL are reported as wrist flexors, and FCR also as a radial deviator (Oatis, 2009). Group 3 is defined by spots 2, 8, 9, 10,16, 17 and 25, and could be recording the muscle activity of the digit flexor muscles: flexor digitorum superficialis (FDS) and profundus (FDP), and flexor pollicis longus (FPL). The FDS and FDP muscles are finger flexors (Basmajian and Luca, 1985), and are located on the same forearm area, but at different depths. FPL is a flexor of all three joints of the thumb, and is the only thumb interphalangeal (IP) joint flexor (Brand and Hollister, 1999). Group 4 is defined by spots 3 and 4, placed next to the thumb. This group could be recording the muscle activity of the abductor pollicis longus (APL), and extensor pollicis longus (EPL) and brevis (EPB). EPB supports the extension of the metacarpophalangeal (MCP) joint of the thumb, APL participates in the abduction and extension of the thumb carpometacarpal (CMC) joint, and EPL extends the three thumb joints, and adducts the thumb CMC joint (Oatis, 2009). Moreover, all these muscles contribute to wrist radial deviation (Oatis, 2009). Group 5 is defined by spots 6,13,21 and 30, and could be recording the muscle activity of the extensor digitorum communis (EDC). The EDC is the primary extensor of the MCP joints of the fingers, although it also contributes to the extension of the proximal (PIP) and distal (DIP) interphalangeal joints of the fingers (Oatis, 2009). Group 6 is defined by spots 7 , 14 and 22, and could be recording the muscle activity of the extensor carpi ulnaris (ECU). ECU has the largest moment arm for ulnar deviation and plays an important role in supporting the distal radioulnar joint (Brand and Hollister, 1999), the joint that enhances the manipulating skills of the hand (Almquist, 1992). Finally, Group 7 is defined by spots $11,12,19,20,28$ and 29, and could be recording the muscle activity of the brachioradialis (BR), pronator teres (PT), extensor carpi radialis brevis (ECRB) and longus (ECRL). The main role of the ECRB and ECRL is wrist extension and radial deviation (Brand and Hollister, 1999). However, some studies suggested that ECRL and ECRB could have pronation and supination elbow moments (Bremer et al., 2006). BR and PT contribute to elbow flexion as well as forearm pronation and supination. Moving forward at the hierarchical level would not make sense, since we would be selecting groups of points where the distance between the spots grouped in the next step is low compared to the previous steps, and the number of sEMG signals to be used is limited.

Therefore, we propose using seven groups of spots for characterizing the muscular activity of the forearm during simulated ADL, in order to substantially reduce the number of spots to be registered, and to maintain muscular-anatomical coherence. The signals from these seven spots would be related to seven different movements: (group 1) wrist flexion and ulnar deviation; (group 2) wrist flexion and radial deviation; (group 3) digit flexion; (group 4) thumb extension and abduction/adduction; (group 5) finger extension; (group 6) wrist extension and ulnar deviation; and (group 7) wrist extension and radial deviation. 
When assessing muscle function in rehabilitation, some spots may be unavailable because of the simultaneous usage of other equipment, such as sensors for kinematics measurement. When choosing the representative spots of each group to be recorded from among those available, the percentage of muscle activity measured (Figure 5.7) should be taken into account. Selecting the spots with the highest percentage of muscle activity may be more reliable, since, at these spots, the muscles recorded could be more superficial or the muscle area recorded could be more centred. In particular, spots with a very low level of muscle activity should be avoided, such as spots 18 and 28 . The greatest muscle activity was observed in the most distal part of the forearm (Figure 5.7). However, more proximal spots could be chosen, depending on the availability, except for group 4, which is composed of two spots placed in the most distal part of the forearm.

FPCA is one of the most popular multivariate analysis techniques for extracting information from functional data, reducing the dimensions of a data set in which there are a large number of interrelated variables, while still holding as much of the total variation as possible (Ullah and Finch, 2013). While FPCA results in dimension reduction, FPCA vector scores can be used for clustering different functions/components using standard clustering methods. Clustering is one of the most frequently used techniques for partitioning a dataset into subgroups that contain instances that are similar to each other while being clearly dissimilar to those of the other groups. In a functional context, clustering helps to identify representative curve patterns and individuals who are very likely to be involved in the same or similar processes. Other methods reported in the literature (Geng et al., 2014) used for task identification in prosthesis control are based on the segmentation of the EMG signals into a series of windows, in which some commonly used time-domain feature sets (such as Mean Absolute Value or Zero Crossings) are extracted and used for motion classification. Our method is similar, but applied to the entire signal for all tasks and subjects, and extracting from the FPCA the features of the signal that holds as much of the total possible variation and using them for muscular classification.

The EMG recordings have been carried out with an 8-channel sEMG device, which required the repetition of the same activities for each subject in five different sessions to allow the measurement of the high number of spots chosen. Although reproducibility error has been checked to be small for the spot 30 between sessions, the use of highdensity surface EMG might be considered in upcoming works.

The current study has been limited to six healthy, able-bodied subjects, and the results could be verified in further studies with a higher number of subjects and including impaired subjects. However, muscular groupings obtained in this study may be used as a first approximation, and may be used as guide for future validation for subjects with hand impairments or amputees.

As future work, studies could be conducted to relate EMG to kinematics during the performance of ADL, by using these seven spots as representative of the muscular activity 
of the forearm in ADL. A further step would be to evaluate kinematics and muscular synergies during specific functional tasks.

\subsection{Conclusions}

This study aimed to identify skin zones with similar muscle activation patterns in order to determine the minimum number of electrodes required to characterize the muscle activity during simulated ADL without losing any relevant information. The results indicate that the number of sEMG sensors could be reduced from 30 to 7 and use them as representative spots of the muscular activity of the forearm in simulated ADL. The simulated ADL performed are included in the SHFT, which uses the most common handgrips in day-to-day life. Hence, the simulated ADL chosen in this study may reflect an accurate representativeness of the hand function. This result may help to assess muscle function in rehabilitation as well as simplify the complexity of prosthesis control. 


\section{CHAPTER 6}

Contribution of forearm muscles to different grasp types 

This chapter merges and deepens the results from different studies, focused on the contribution of forearm muscles to different grasp types with the aim of deepening the knowledge of the role of the forearm muscles during the performance of the grasps most used in ADL. This goal was studied using two different approaches: by means of intramuscular EMG, and using the identified forearm areas of the previous chapter. I am preparing it to be submitted to the IEEE Transactions on Neural Systems and Rehabilitation Engineering.

\subsection{Abstract \& keywords}

The specific role of forearm muscles for the development of activities of daily living (ADL) is still unknown. In this sense, the study of the forearm muscles activity during the most used grasps during ADL would provide very useful information for the functional evaluation of the hand and its rehabilitation as well as for hand prosthetics control.

In this work, forearm muscular activity during grasp performance has been studied from two different approaches: studying the muscular activity of specific forearm muscles recorded by intramuscular EMG and studying the muscular activity of 7 representative spot forearm areas recorded by surface EMG.

Results from both studies allowed me comparing between muscle activities recorded from surface forearm spots and from specific muscles. This allowed me confirming the hypothesis about which muscle information is obtained using the spots defined in Chapter 5. On the other hand, the results allowed me deepening about the role of some of these muscles/spots during grasp performance.

Keywords Electromyography, Electrode placement, Forearm muscles, Myoelectric prostheses, Rehabilitation

\subsection{Introduction}

Hand grasp execution is mainly composed of two stages: the reach-to-object and the grasp itself. The force needed to close the hand around the object and grasp it, is determined by several parameters as grasp stability (the ability to resist external forces), and grasp security (resistance to slippery objects), both of them depending on the configuration of the grasp (Cipriani et al., 2008; Cutkosky, 1989), among other factors.

The ability to grasp of the hand is possible thanks to the action of 32 muscles in the forearm and hand. The specific role of these muscles for the development of activities of daily living (ADL) and others such as sports, is still unknown. In this sense, the study of the muscle activity of the forearm muscles during the common grasps used in ADL would 
provide very useful information for the functional evaluation of the hand and its rehabilitation.

As reviewed in Chapter 4, muscular activity is commonly measured through electromyography (EMG), which consists in recording the electrical activity of the muscle. Two types of EMG can be used: surface (sEMG), where the electrodes are placed on the skin and above the muscle, and intramuscular (iEMG), in which the electrodes are inserted directly into the muscle. A disadvantage of using sEMG is that the recorded sEMG signal is very dependent on the placement of the electrodes on the muscle, and may be affected by adjacent muscles (Kamen and Gabriel, 2010). This is an important problem in the case of the forearm, where there are 20 muscles overlapping on each other (Yu et al., 2004), being practically impossible to isolate the sEMG signal from each of them. In this sense, in the previous chapter I identified forearm areas with similar muscle activation patterns from a set of relevant simulated and standardised ADL, which could be used to characterise the muscle activity. On the contrary, the iEMG allows the study of each specific muscle under interest, no matter if they are small and/or non-superficial muscles, as is the case of some extrinsic muscles of the hand, and even different compartments of the same muscle. However, the insertion of the iEMG electrodes is painful and requires to be carried out by expert personnel, since it is necessary to insert the electrode in the appropriate area and depth without affecting nerves or blood vessels.

Deepening the knowledge of the role of the forearm muscles through EMG recordings would be useful in different areas. Disorders of the upper extremities specifically affect the performance of different muscles, limiting the individual's capacity to perform basic ADL. Fortunately, there are various approaches to restore the functionality of the upper extremity. Robotic devices are already used in clinical practice. Some of these systems use sEMG as an input signal, which provides information about the person's intention to perform particular movement (Maciejasz et al., 2014). The sEMG signals from the contralateral healthy limb have been also used to control movements of the affected one (Li et al., 2006). Therefore, improving the knowledge of the role of forearm muscles during grasps may be useful to provide a more accurate information about intention of the person to perform a particular movement, and thus, improving the current rehabilitation devices. This information may be used also to develop more intuitively controlled hand prostheses, which use the EMG signals from the residual muscles after the amputation.

This chapter presents forearm muscles contribution to grasp performance from two approaches. In a first study (study 1), sEMG is used to analyse the muscle activity of the 7 representative areas in ADL obtained in Chapter 5, during the performance of a set of 7 representative grasps. In a second study (study 2), iEMG is used to analyse the role of 8 extrinsic muscles of the forearm/hand during the performance of the same grasps of the first study. As a result, the role of each muscle with respect to each grasp and the implications on rehabilitation, prosthetics and hand modelling are discussed, linking the forearm areas studied in the study 2 with the extrinsic muscles from the study 1 . 


\subsection{Methods}

\section{Study 1}

\section{Subjects and tasks}

Twenty-two right-handed subjects gave their informed written consent before participating in this study, approved by the ethics committee of our University. Subjects performed 7 representative grasps of ADL (Figure 6.1), based on the grasp taxonomy used in Vergara et al (Vergara et al., 2014): pad-to-pad pinch (PpPinch), cylindrical grasp (Cyl), lumbrical grasp (Lum), lateral pinch (LatP), oblique palmar grasp (Obl), and intermediate power-precision grasp (IntPP).

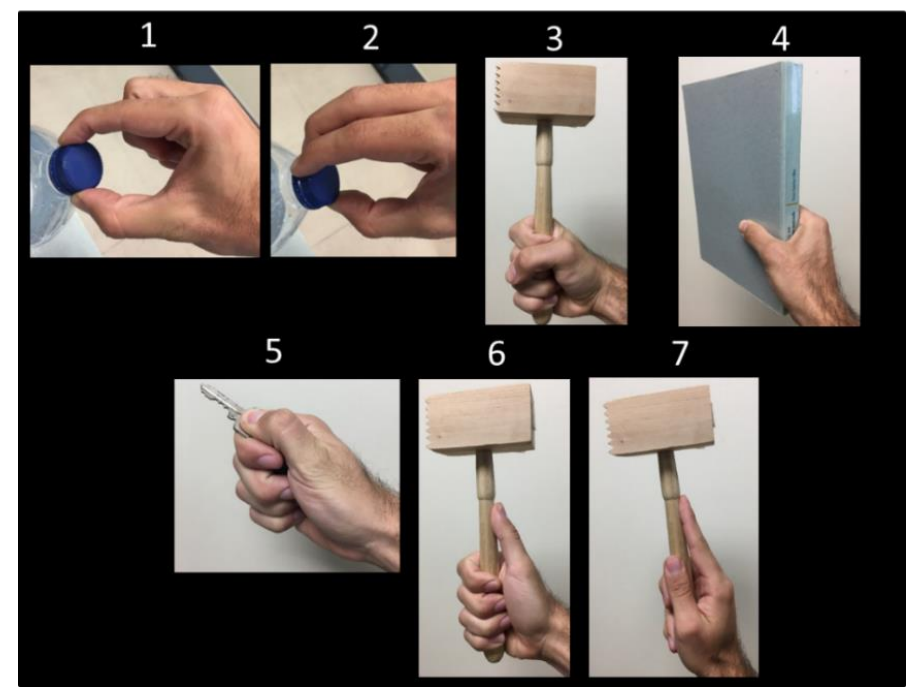

Figure 6.1 Grasps performed: 1. two-fingers PpPinch; 2. three-fingers PpPinch; 3. Cyl; 4. Lum; 5. LatP; 6. Obl, 7. IntPP;

\section{Electrode placement}

A grid was drawn on the forearm, following the same procedure explained in Chapter 5 . The grid was drawn by using 5 anatomical landmarks easily identifiable, while the subject sat comfortably with an elbow resting on a table, arm flexed $90^{\circ}$ compared to the forearm, and the palm of the hand facing the subject. The grid defined 30 different spots covering the entire forearm surface (Figure 6.2). The electrodes were placed in the centre of seven of these spots, based on the spot groups obtained in Chapter 5 (Figure 6.2), and were set out in longitudinal direction. Before placing electrodes, hair was removed by shaving and skin was cleaned with alcohol. 


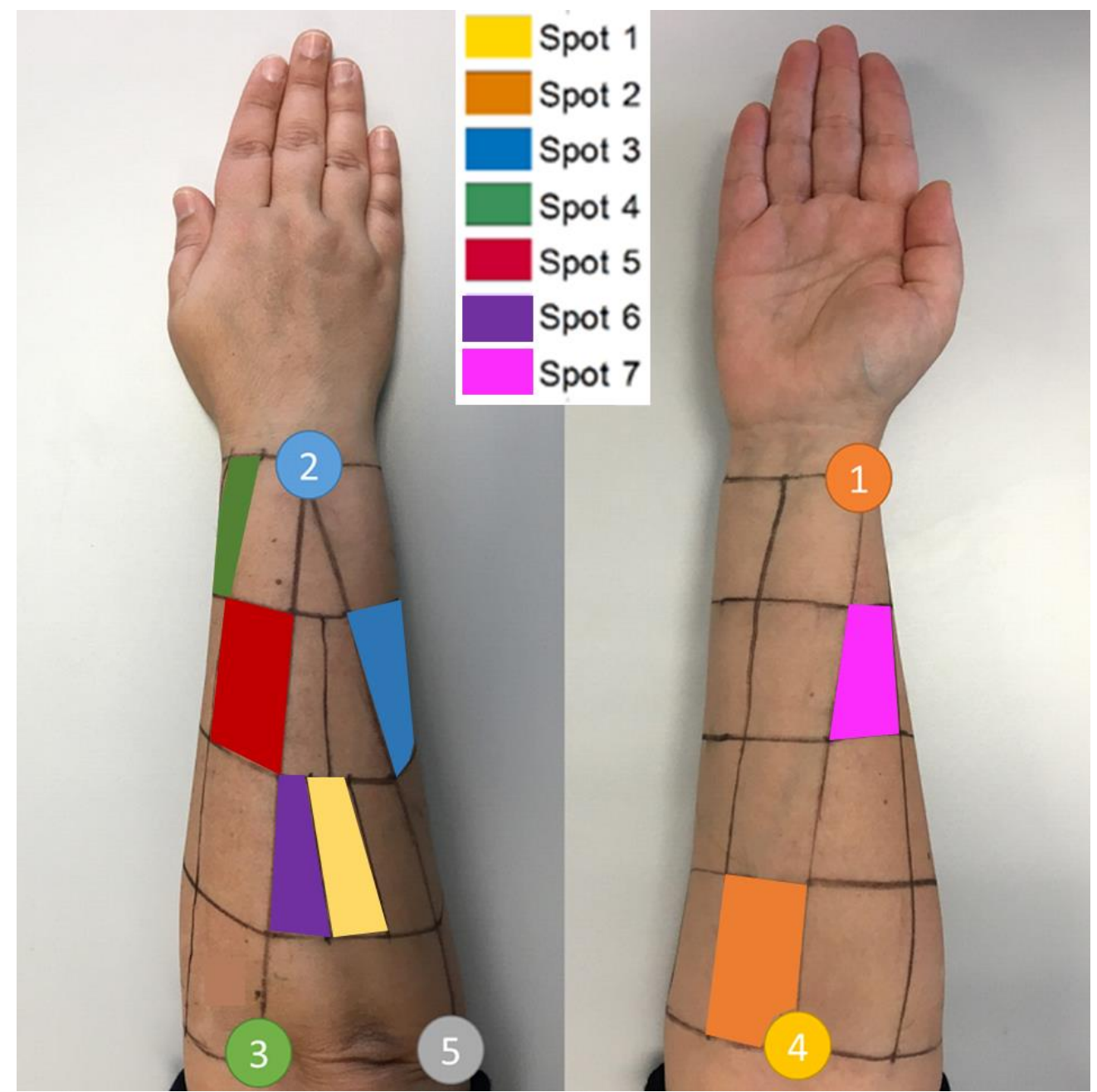

Figure 6.2 Grid and spot areas selected for sEMG recordings. The signals from these seven spots are related to seven different movements, according to Chapter 5: (spot 1) wrist flexion and ulnar deviation; (spot 2) wrist flexion and radial deviation; (spot 3) digit flexion; (spot 4) thumb extension and abduction/adduction; (spot 5) finger extension; (spot 6) wrist extension and ulnar deviation; and (spot 7) wrist extension and radial deviation.

\section{Data acquisition}

Muscle activity was recorded with an 8-channel sEMG Biometrics Ltd device, at a sampling frequency of $1000 \mathrm{~Hz}$. Integral dry reusable sEMG Electrodes (SX230) were used, with a gain of 1000 , a bandwidth between $20 \mathrm{~Hz}-460 \mathrm{~Hz}$ and noise below $5 \mu \mathrm{V}$.

\section{Experiment description}

First, seven records of maximum voluntary contraction (MVC) were measured to each subject for further normalisation of the sEMG signals (same as in Chapter 5): flexion and extension of the wrist, flexion and extension of the fingers, pronation of the forearm, ulnar deviation of the wrist, and elbow flexion. In a comfortable posture, the subjects were asked to exert maximum effort without the help of other muscles than those of the forearm and hand. 
After recording the MVCs, the subjects performed the seven grasps following precise operator's instructions: the subject was asked to hold a dynamometer simulating the grasp to be analysed with the arm aligned with the trunk and forearm flexed $90^{\circ}$ with respect to the arm, but without exerting force on it and then to exert maximum effort while maintaining this posture during three seconds. Afterwards, the subject was asked to progressively increase the effort during 3 seconds until reaching the $50 \%$ of the maximum effort previously recorded with the dynamometer, keep it for 3 seconds, and then gradually decrease it until returning to rest. Each grasp was repeated 3 times consecutively (only the $50 \%$ of the maximum effort), with a 3 minutes break between repetitions to avoid muscle fatigue. The subject was able to practice each grasp as many times as necessary before recording. The duration of each trial was controlled, and those tests that exceeded 10 seconds were discarded.

\section{Data analysis}

The sEMG records were filtered with a 4th-order bandpass filter between 25-500 $\mathrm{Hz}$, rectified, filtered by a fourth-order low pass filter at $8 \mathrm{~Hz}$, and smoothed by Gaussian smoothing. To determine muscle activity, sEMG records were normalised with the maximal values obtained in any of the seven records of MVC measured.

For each record, the average of the sEMG values (during the three seconds in which the $50 \%$ of the maximum effort was performed) was computed for each spot (50V). Then, the $50 \mathrm{~V}$ values of the three repetitions of the same grasp for each spot and subject were averaged (A50V). Finally, the mean across subjects of these A50V values were computed for each spot (mA50V) and grasp. For the interpretation of the results, mA50V values of the seven spots for the different grasps were represented using a polar diagram.

\section{Study 2}

\section{Methods}

\section{Subjects and tasks}

The experiment was conducted at the Shirley Ryan AbilityLab in Chicago, USA. One healthy adult participated after giving his informed consent. The experiment consisted in recording the muscular activity of different extrinsic muscles of the forearm during the performance of maximum efforts with different grasps. While sitting at a table, with the forearm resting on it in a relaxed position, the subject was asked to perform the same grasps of the study 1 (Figure 6.1).

\section{Needle insertion}

iEMG signals were recorded from eight extrinsic muscles easy to locate and covering the control of as many hand joints as possible (Table 6.1): two thumb muscles (FPL, APL), two index finger muscles (FDS2, ECD2), two middle finger muscles (FDS3, 
ECD3), and two wrist muscles (ECU and FCR). For the location of the exact place where the electrode was inserted, an ultrasound equipment was used. This allowed to avoid vessels and nerves, and to determine the zone of contraction of the muscle fibers when requesting a certain muscle by means of a given movement of the joints on which it acts. The external location was marked on the skin, and the depth of insertion was obtained from the image on the ultrasound equipment (Figure 6.3).

Table 6.1 Extrinsic muscles measured and their abbreviations.

\begin{tabular}{cc}
\hline Abbreviation & Muscle name \\
\hline FPL & Flexor pollicis longus \\
APL & Abductor pollicis longus \\
FDS2 & Superficial flexor of the index finger \\
ECD2 & Common extensor of the finger index \\
FDS3 & Superficial flexor of the middle finger \\
EDC3 & Common extensor of the middle finger \\
ECU & Extensor carpi ulnaris \\
FCR & Flexor carpi radialis \\
\hline
\end{tabular}

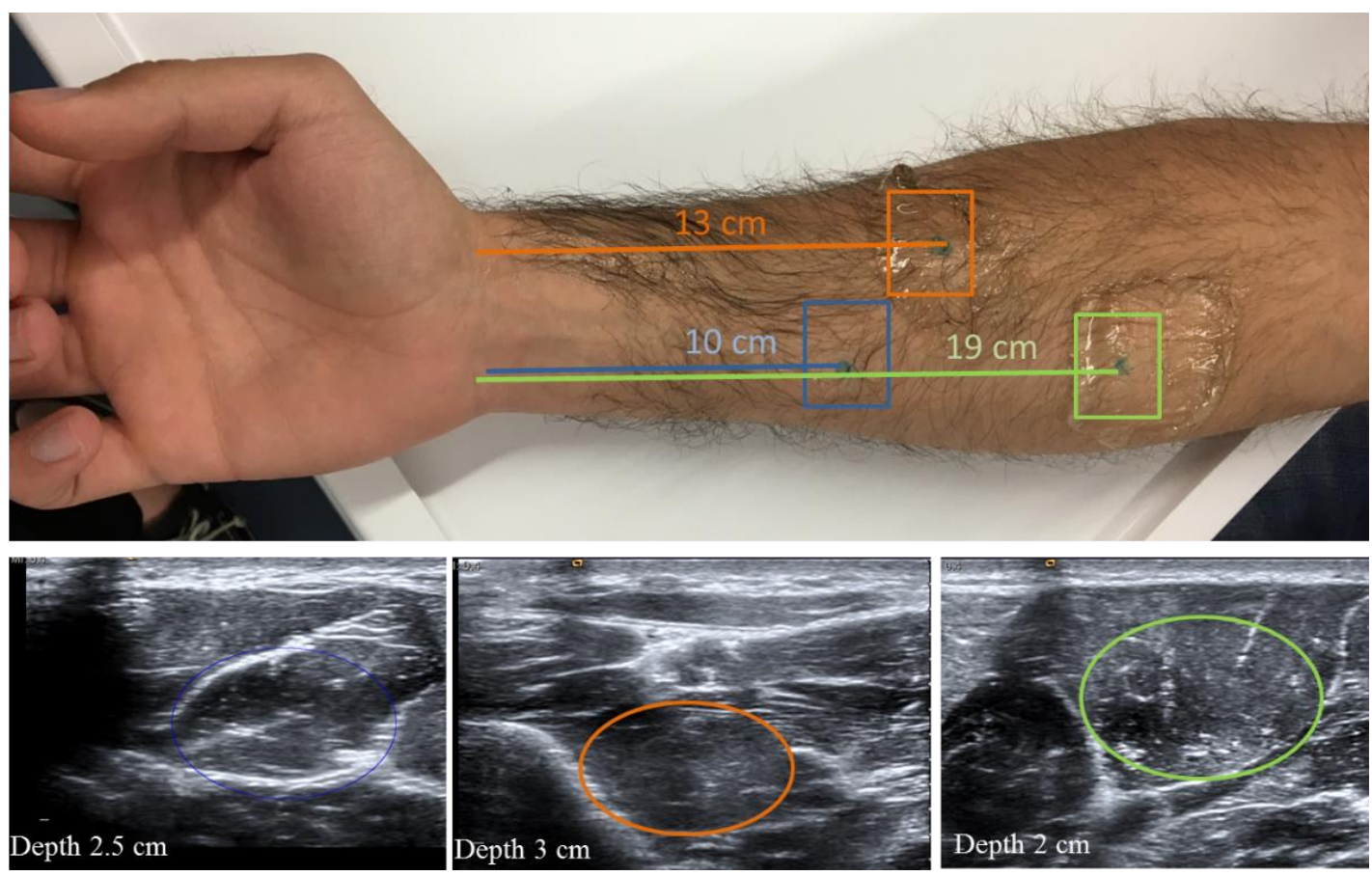

Figure 6.3 (From left to right) Localisation of the FDS, FPL and FCR muscles for the insertion of the electrode, respectively. 


\section{Data acquisition}

iEMG signals were recorded at $4000 \mathrm{~Hz}$ with a Delsys Bagnoli-16 system (Delsys Inc, Boston, MA) with bipolar needle electrodes. The electrodes were inserted through the skin, by means of $27 \mathrm{G}$ hypodermic needles, into the muscles recorded.

\section{Experiment description}

For practical reasons (due to pain and discomfort), the experiment was carried out in two different sessions: in the first one, 2 muscles were recorded (FDS2 and EDC2); in the second one, the activity of the other 6 muscles were recorded (FPL, APL, FCR, FDS3, EDC3 and ECU).

First, seven records of MVC (Table 6.2) were measured in each session for further normalisation of iEMG signals.

Table 6.2 Maximum voluntary contractions (MVC) performed for each muscle.

\begin{tabular}{|c|c|c|}
\hline Muscle & Forearm position & MVC description \\
\hline FPL & $\begin{array}{l}\text { Forearm in supination with } \\
\text { flexion of the distal phalanx of } \\
\text { the thumb }\end{array}$ & $\begin{array}{l}\text { The operator stabilises the metacarpophalangeal } \\
\text { joint (MCP) of the thumb in extension and with the } \\
\text { other hand generates an extension force on the volar } \\
\text { surface of the distal phalanx }\end{array}$ \\
\hline APL & Forearm in neutral position & $\begin{array}{l}\text { The operator stabilises the wrist while exerting an } \\
\text { abduction and flexion pressure on the lateral side of } \\
\text { the MCP joint of the thumb }\end{array}$ \\
\hline FDS & Forearm in supination & $\begin{array}{l}\text { The operator stabilises the wrist while exerting an } \\
\text { extension pressure on the volar aspect of the middle } \\
\text { phalanx of the corresponding finger }\end{array}$ \\
\hline ECD & $\begin{array}{l}\text { Forearm in neutral position } \\
\text { with slightly flexed } \\
\text { interphalangeal joints }\end{array}$ & $\begin{array}{l}\text { The operator stabilises the wrist while exerting a } \\
\text { pressure on the dorsal surface of the proximal IP } \\
\text { joint of the corresponding finger }\end{array}$ \\
\hline $\mathrm{ECU}$ & Forearm in pronation & $\begin{array}{l}\text { The operator holds the forearm while exerting a } \\
\text { pressure of flexion and radial deviation on the bone } \\
\text { of the MCP joint of the little finger }\end{array}$ \\
\hline FCR & Forearm in supination & $\begin{array}{l}\text { The operator holds the forearm while performing an } \\
\text { extension pressure and ulnar deviation on the thenar } \\
\text { eminence }\end{array}$ \\
\hline
\end{tabular}

After recording the MVCs, the subject performed the seven grasps following precise operator's instructions: the subject was asked to hold a specific object for each grasp to be analysed, but without exerting force on it. Then, the subject was asked to progressively increase the effort during 3 seconds until reaching the maximum effort, keep it for 3 seconds, and then gradually decrease it until returning to rest. Each grasp was repeated 2 times in the first session and 3 times in the second one, with a 3 minutes break between repetitions to avoid muscle fatigue. The subject was able to practice each 
grasp as many times as necessary before recording. Duration of each trial was controlled, and those tests that exceeded 10 seconds were discarded.

\section{Data analysis}

The iEMG signals were filtered with a fourth order recursive Butterworth bandpass filter between $25-500 \mathrm{~Hz}$ and with a notch filter between $59-61 \mathrm{~Hz}$. The signals were subsequently rectified and a low pass filter with $8 \mathrm{~Hz}$ cutoff frequency was applied. The signals were smoothed using a Gaussian filter. To determine muscle activity, sEMG records were normalised with the maximal values obtained from the MVC records (Table $6.2)$.

For each record, the maximum muscle activity was obtained as the average of the muscle activity during the three seconds in which the maximum effort was performed. Then, for each spot, the maximum values of the different repetitions of the same grasp were averaged (AMV). For the interpretation of results, AMV of the spots according to each grasp have been represented using a polar diagram. The role of each muscle with respect to each grasp is discussed.

\subsection{Results}

Figure 6.4 shows the mA50V of each spot according to each grasp performed in the study 1. Figure 6.5 shows the AMV of each muscle recorded according to each grasp performed in the study 2 . 


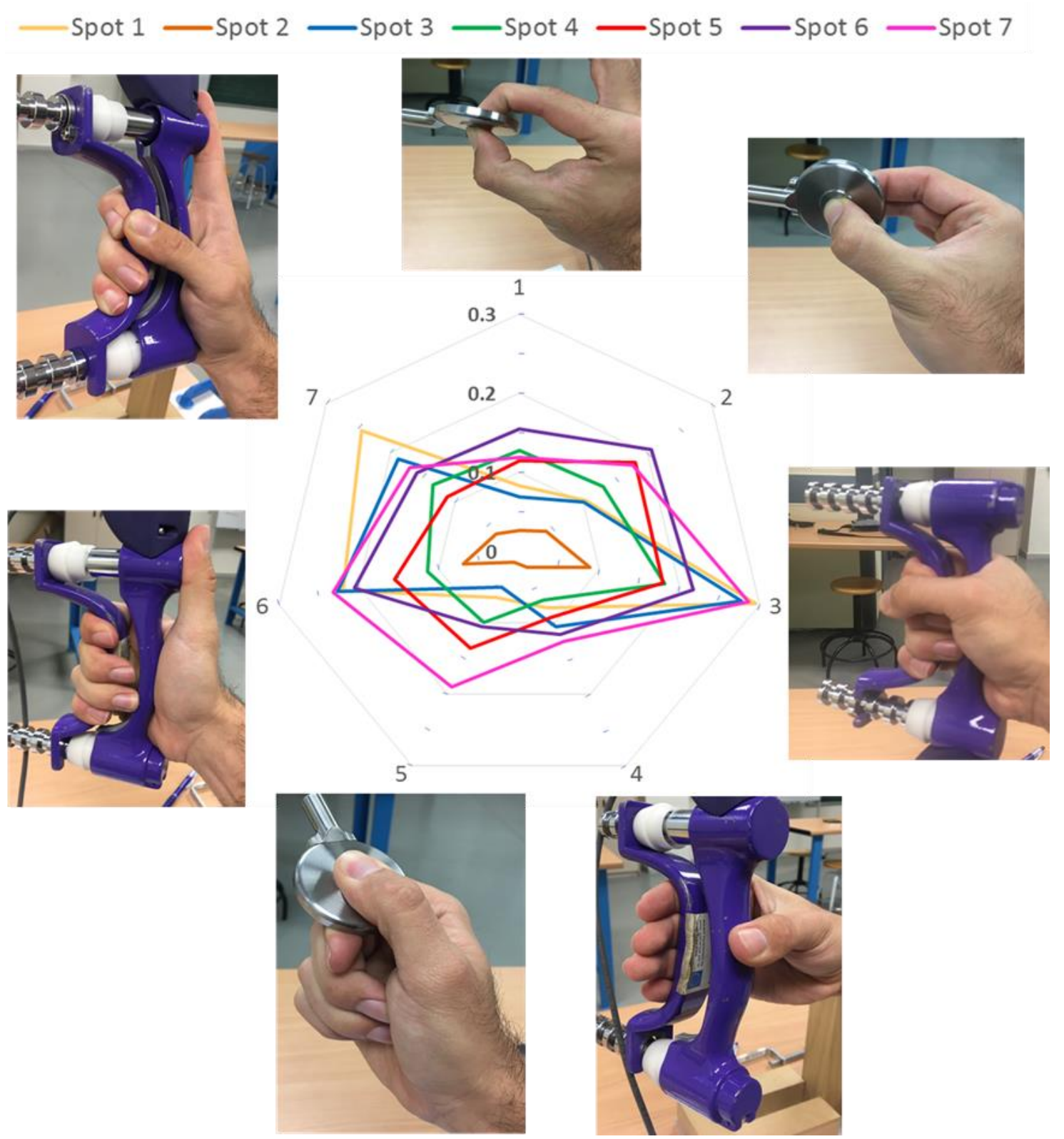

Figure 6.4 mA50V obtained of each spot area for each grasp represented by means of a polar diagram

Kinematic and muscular characterisation of the hand during ADL 


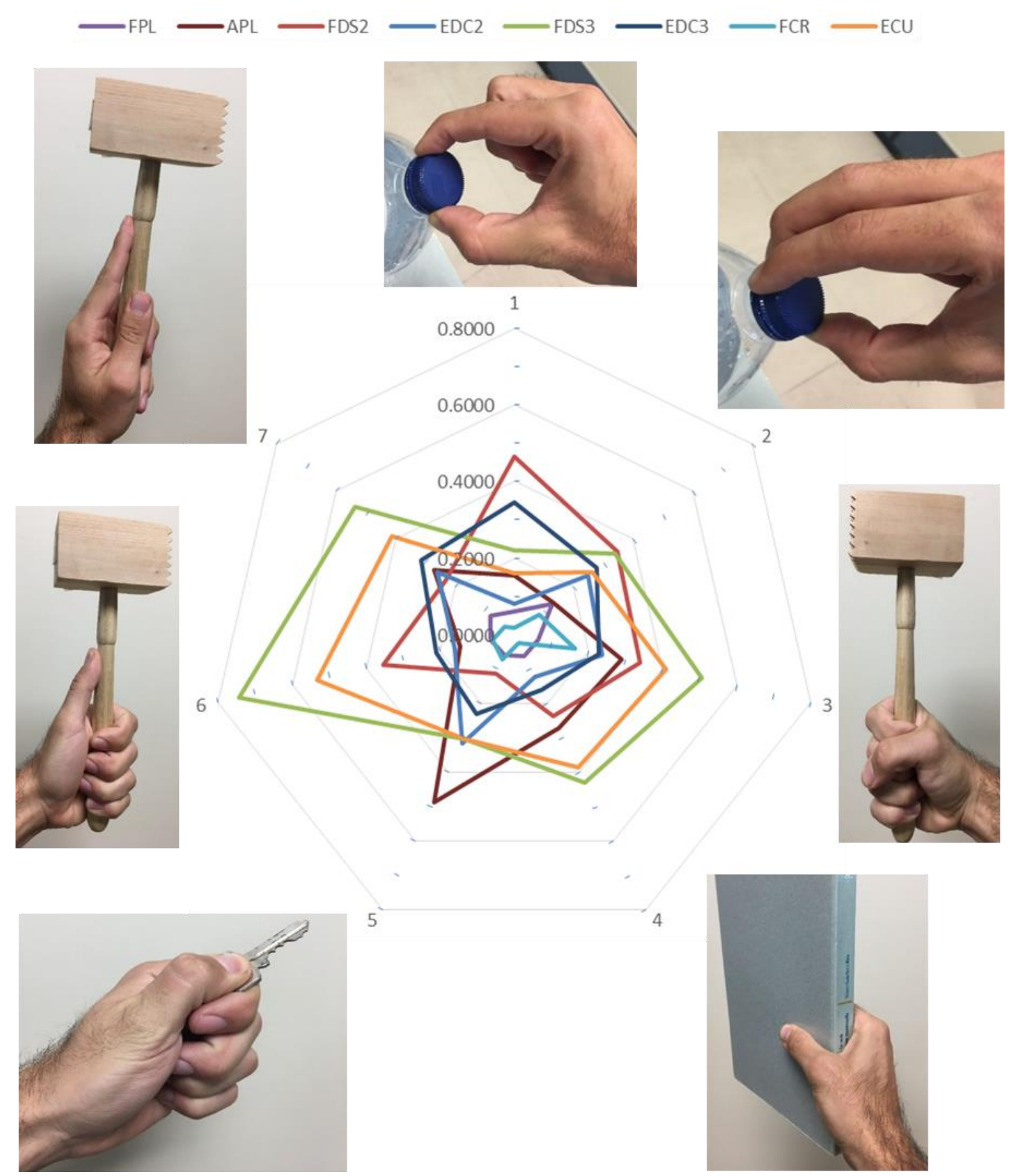

Figure 6.5 AMV obtained of each muscle for each grasp represented by means of a polar diagram

Two-fingers PpPinch grasp presents the highest muscular contribution from the spot 6 (wrist extension and ulnar deviation) but also some activation from spot 4 (thumb muscles), spot 5 (finger extension) and spot 7 (wrist extensor and radial deviation). This grasp also presents the highest muscle activity from the FDS2 and EDC3. This fact contrasts with the low level of the spot 3 , being more logical the results obtained from the iEMG. 
Three-finger PpPinch grasp presents the highest contribution from the spot 5, 6 and 7 , as in the previous grasp, but with less muscle contribution from spot 4 (thumb muscles). This grasp also presents the highest muscle activity from the FDS2 and FDS3. As in the previous grasp, wrist and finger extensors and index finger flexors are required but with less contribution from thumb muscles.

Cyl grasp shows the highest contributions from spot 1 (wrist flexion and ulnar deviation), spot 3 (finger flexors) and spot 7 (wrist extension and radial deviation.). This grasp also presents the highest muscle activity from the FDS3 and ECU.

Lum grasp shows the lowest muscular activity from all spots, reaching maximum values of $15 \%$ with the highest value from the spot group 7 (wrist extensor and deviator). This grasp also presents the highest muscle activity from the FDS3 and ECU.

LatP presents the highest muscle contribution from the spot 7 and spot 5 (finger and wrist extensors) as well as from the APL.

Obl grasp shows highest values from the spot 1, 3 and 7, as in the grasp 3, adding also a high contribution from spot 6 (ulnar deviation). This grasp also presents the highest contribution from the FDS3.

IntPP shows the highest contribution from spot 1 (wrist flexion and ulnar deviation) and some contribution from spot 3 (finger flexors and groups 6 and 7 (ulnar and radial deviation). This grasp also presents the highest muscle activity from the FDS3 and ECU.

\subsection{Discussion}

In this work, forearm muscular activity during grasp performance has been studied from two different approaches: from the muscular activity of 8 specific forearm muscles and from the muscular activity of 7 representative forearm areas.

By comparing both studies, some relationships between recorded areas and muscles can be analysed.

Spot 1 (wrist flexion and ulnar deviation) was proposed in Chapter 5 to be recording mainly the muscle activity of the flexor carpi ulnaris (FCU). It presents the maximum activity during the IntPP grasp. This result is in accordance with literature (Oatis, 2009), in which FCU is responsible for stabilizing the wrist during activities such as slicing meat $(\mathrm{IntPP})$ and using a hammer $(\mathrm{Cyl}$ and $\mathrm{Obl})$. No possible comparison is possible for FCU, as it was not recorded through iEMG in Study 2.

Spot 2 was proposed to be recording the muscle activity of the FCR and palmaris longus (PL). In this case, FCR was recorded through iEMG, but this is not the case for PL. This is the spot area with less muscle activity $(<10 \%)$ throughout all the grasps, with the highest value for the $C y l$ grasp. Accordingly, FCR activity recorded from iEMG do 
not present almost any muscular activity in any of the grasps. This muscle is more activated when simultaneously performing a movement of flexion and radial deviation of the wrist (Oatis, 2009). In this case, the grasps considered do not require the wrist exerting any flexion-radial torque, so that practically no activation higher than $20 \%$ is observed.

Spot 3 was proposed to be recording the muscle activity of the digit flexor muscles: FDS and flexor digitorum profundus (FDP), and FPL. The FDS and FDP muscles are finger flexors (Basmajian and Luca, 1985), and are located on the same forearm area, but at different depths. In this case, only FDS was recorded for its easier location (less depth). FDS presents the maximum activity values in $\mathrm{Cyl}, \mathrm{Obl}$ and $\mathrm{IntPP}$ (grasps 3, 6 and 7). The FDS is one of the flexor muscles of the fingers, together with the FDP, and is the only one that flexes the proximal interphalangeal (PIP) joint of the fingers without flexing the distal interphalangeal (DIP) joint. In addition, it also presents a flexion moment on the metacarpophalangeal (MCP) joint of the fingers. However, this muscle has four separate compartments, one for each finger, although the only finger that has independent muscle fibers is the middle finger, and therefore it is the only one that can present a completely independent activation (Oatis, 2009). Accordingly, the iEMG records for the FDS3 show greater muscular activation in power grasps $(C y l$, IntPP, $O b l)$, while the FDS2 presents greater activation in the precision grasps (PpPinch). Therefore, it seems that spot 3 is recording the muscle activity from finger 3 instead of the muscle activity from the index finger. FPL is a thumb flexor the only one capable of flexing the IP joint of the thumb, although it also participates in the flexion of the other two joints of the thumb (Brand and Hollister, 1999). The grasps studied do not require to exert a flexion movement on the IP joint, so that a maximum activation of $10 \%$ is observed when performing a three-finger PpPinch, which would be the grasp that involves greater flexion movement of the thumb IP joint.

Spot 4 was proposed to be recording muscle activity of the APL, and extensor pollicis longus (EPL) and brevis (EPB). For this spot, APL was recorded. APL participates in the abduction and extension of the thumb carpometacarpal (CMC) joint and contribute to wrist radial deviation (Oatis, 2009). In this case, spot 4 presents maximum activity values in two-finger PpPinch, Cyl and LatP. Accordingly, the iEMG records from APL show higher contribution of this muscle in those grasps in which the thumb is more abducted and extended, reaching values of $50 \%$ of the maximum activity (Cyl and LatP).

Spot 5 (finger extensors) was proposed to be recording mainly the muscle activity of the EDC. It presents the maximum activity in three-finger PpPinch, probably due to the need to counteract the flexor moment required in this grasp. The EDC is the extensor muscle of the MCP joints of the fingers, the extensor of the middle finger being the strongest one. In addition, this muscle also contributes to the extension of the DIP and PIP joints of the fingers, together with the lumbricals and interossei (Oatis, 2009). The iEMG records show that the two extensors measured (EDC2 and EDC3) present average levels of activity although the recorded grasps do not present extension of the fingers. 
This highlights the antagonistic action of these muscles with the flexors of the fingers to stabilise the joints.

Spot 6 (wrist extension and ulnar deviation) was proposed to be mainly recording the muscle activity of the ECU which has the largest moment for ulnar deviation. It presents the maximum activity in three-finger PpPinch, $\mathrm{Cyl}$ and $\mathrm{Obl}$ grasp. The role of the ECU is the extension and ulnar deviation of the wrist, although there are studies that show that the extension time is greater when the forearm is in supination (Oatis, 2009). In addition, this muscle presents the greatest moment of the muscles that deviate the wrist in the ulnar direction. From the grasps studied, the iEMG records show a greater activation of the ECU in those actions that require a fist $(\mathrm{Cyl}, \mathrm{Obl}$, and IntPP, reaching levels of almost $80 \%$ of its maximum). This shows the synergistic functioning of these muscles with the finger flexors. By flexing the fingers forming a fist, wrist is slightly extended, while when we extend the fingers, the wrist is flexed (Oatis, 2009). Therefore, the extensor muscles of the wrist contract with the flexors of the fingers (as seen clearly in the graph of muscles FDS3 and ECU, which have similar values) to counteract the flexion moment exerted on the wrist by the flexors of the fingers.

Finally, Spot 7 was proposed to be recording muscle activity of the brachioradialis (BR), pronator teres (PT), and extensor carpi radialis (ECR) whose main actions are the wrist extension and radial deviation (Brand and Hollister, 1999). Spot 7 presents the maximum effort during $C y l$, and $O b l$ grasps. It is observed that in these grasps, this spot presents a muscular activation similar to spot 1, and therefore it seems that its function is to stabilise the wrist, acting as a synergistic muscle of the FCU. In this case, any of these muscles were recorded through iEMG.

In summary, generally the spots analysed showed similar results according to the activity of the specific muscles that are expected to be underneath (Table 6.3 summarises results). Although for spots 1 and 7 there is no iEMG data from the muscles that are supposed to be underneath, the maximum values found correspond to the grasps in which these muscles perform the greater effort in accordance with the literature. Therefore, matching results from both studies has allowed me comparing between muscle activities recorded form surface forearm spots (recorded with sEMG) and from specific muscles (recorded with iEMG). Thanks to this, firstly I reinforced the hypothesis about which muscles are being recorded by each of the spots previously defined in Chapter 5. Then, it allowed me deepening about the role of some of these muscles/spots during the grasp performance. These results could be used to improve actual robotic devices used in rehabilitation as well as actual prosthetic's control: by defining forearm spots to place the sEMG electrodes to provide a more accurate information about intention of the person to perform a particular movement. In the same way, these forearm spots could be used to increase the muscular capacity of those muscles/spots that contribute most to each grasp, either through specific exercises, or through electro-stimulation. 
Table 6.3. Summary of findings during the different grasps regarding muscles expected to be underneath on each spot and muscles actually recorded.

\begin{tabular}{cccc} 
Spot & Muscles expected & Muscles recorded & Grasps with maximum activity \\
\hline 1 & FCU & - & IntPP, Cyl, Obl \\
2 & FCR, PL & FCR & $C y l$ \\
3 & FDS, FDP, FPL & FDS2, FDS3, FPL & $C y l$, Obl, IntPP \\
4 & APL, EPL,EPB & APL & Cyl, LatP \\
5 & EDC & EDC2, EDC3 & three-finger PpPinch \\
6 & ECU & ECU & three-finger PpPinch, Cyl, Obl \\
7 & Br, PT, FCU & - & $C y l, O b l$ \\
\hline
\end{tabular}

These studies have several limitations. Most obvious limitation is the number of subjects considered. FPL and FCR showed very low muscle activity during the grasps performed and do not should be taken into account. Many forearm muscles have not been measured. Another limitation is the wrist posture: changing wrist posture during the same grasps, may lead to different muscle activity results for the wrist muscles. Therefore, in future works, a study with more muscles, more subjects as well as controlling and measuring wrist posture should be conducted.

\subsection{Conclusion}

I have analysed the contribution of 8 extrinsic muscles and 7 forearm spots during the performance of some types of grasps representative of ADL. Matching results from both studies allowed me comparing between muscle activities recorded form surface forearm spots (recorded with sEMG) and from specific muscles (recorded with iEMG). In general, the spots analysed showed similar results according to the activity of the specific muscles that are expected to be underneath the spots.

Thanks to this, firstly I reinforced the hypothesis about which muscles are being recorded by each of the spots previously defined in Chapter 5. Secondly, it allowed me deepening about the role of some of these muscles/spots during the grasp performance.

The results obtained can help, among other purposes, to choose the most appropriate muscle or spot area for placing the surface electrodes (robotic devices or prosthetics). And also to plan the necessary exercises for increasing the muscular capacity of those muscles/spots that contribute most to the selected grasp, either through specific exercises, or through electro-stimulation. 


\section{CHAPTER 7}

A database of kinematics and EMG of the forearm and hand during ADL 

In the previous chapter, I deepened in the muscles role during the performance of the grasp most used in ADL. However, to know more about how hand movements are controlled, kinematic data are also needed. Additionally, more complex upper limb and standardised activities need to be selected. In this way, this chapter describes a well synchronised dataset of hand kinematics and forearm muscle activity during the performance of a set of 26 representative and standardised ADL.

This chapter corresponds exactly to the paper submitted to be published in Scientific Data, titled: A calibrated database of kinematics and EMG of the forearm and hand during activities of daily living.

\subsection{Abstract \& keywords}

Linking hand kinematics and forearm muscle activity is a challenging and crucial problem for several domains, leading for instance to a better understanding of human hand movements production, improved rehabilitation protocols, prosthetics that better fit human's behaviour, and more realistic 3D biomechanical models. To advance in this relationship between hand kinematics and muscle activity, synchronised and well-defined data are needed. However, currently available datasets are scarce and the presented tasks and data are often limited.

In this paper I present the KIN-MUS UJI Dataset, that contains 572 recordings with anatomical angles and forearm muscle activity of 22 subjects while performing 26 representative activities of daily living, twenty of them extracted from the Sollerman Hand Function Test. This dataset is, to our knowledge, the biggest currently available hand kinematics and muscle activity dataset to focus on goal-oriented actions. Data were recorded using a CyberGlove instrumented glove and surface EMG electrodes, both properly synchronised. Eighteen hand anatomical angles were obtained from the glove sensors using a validated calibration procedure. Surface EMG activity was recorded from seven representative forearm areas (see Chapter 5).

Descriptive analyses are presented in terms of box and whisker graphs for each factor that can affect joint angles and muscle activity. These descriptive analyses verified that the data were not affected by experimental procedures and that were similar to the data acquired under real-life conditions.

Keywords Activities of daily living, Surface Electromyography, Electrode placement, Forearm muscles, Hand kinematics, Myoelectric prostheses, Rehabilitation, Sollerman Hand Function Test. 


\subsection{Introduction}

The hand is a complex functional limb with more than 20 joints controlled by more than 30 hand and forearm muscles that allow a wide range of activities to be performed very precisely. Kinematics and muscles are essential for hand functioning. Knowing how complex hand movements are produced and controlled may be useful for several applications like improving prosthetic control (Sburlea and Müller-Putz, 2018), developing realistic biomechanical hand models (Gustus et al., 2012), or improving hand rehabilitation by more adapted physiotherapy (Chiu et al., 2000; Nathan et al., 2009; Oess et al., 2012).

Synchronised kinematic and electromyographic (EMG) data are needed if we want to analyse how hand movements are produced and controlled. Some works have attempted to link hand kinematics with forearm muscle activity (Hitchcock and Sherwood, 2018; Sburlea and Müller-Putz, 2018; Tagliabue et al., 2015), but have focused on analysing specific muscles to perform very specific, simple and controlled activities, and therefore, lack the representativeness of the activities of daily living (ADL). Datasets with synchronised hand kinematic and EMG activity during the performance of varied and representative ADL are needed.

Furthermore, some booming fields like machine learning could benefit from these linked datasets, since it needs to use datasets with activities as numerous, varied and representative as possible to provide good results (Rajeswaran et al., 2017). Although some hand kinematics datasets (performing different grasps and hand movements) are available in the literature, as well as forearm EMG datasets (usually performing hand gestures or free hand movements), very few datasets exist with simultaneously recorded kinematics and EMG (only Data citations 1-3). Furthermore, these datasets present some weaknesses regarding their usability in prosthetics, neuroscience or clinical evaluation.

Table 7.1 shows an overview of these datasets, with their characteristics and limitations that are briefly summarised afterwards:

- Tasks: Only grasping movement or static finger/hand postures recorded (Data citations 1-3). These tasks lack representativeness of ADL because of the limited variety of activities considered.

- Motion capture system used: Some datasets used motion capture systems with temporal and spatial errors that may limit the use of these devices during ADL. (Data Citation 3).

- Type of kinematic data presented: Some datasets only provide raw kinematic data from the motion capture system (cameras or gloves) (Data Citation 1) instead of offering properly obtained anatomical angles.

- EMG electrodes location: some datasets only provide surface EMG data from an armband surrounding forearm or some few specific muscles, and without indicating the exact location of electrodes (Data citations 1 and 3). 
Table 7.1 Main characteristics of datasets with synchronised hand kinematics and EMG data.

\begin{tabular}{|c|c|c|c|c|c|}
\hline Dataset & Tasks & $\begin{array}{l}\text { Motion } \\
\text { capture } \\
\text { system }\end{array}$ & $\begin{array}{c}\text { Type of } \\
\text { kinematic } \\
\text { data } \\
\end{array}$ & $\begin{array}{l}\text { EMG } \\
\text { system }\end{array}$ & $\begin{array}{l}\text { EMG Electrode } \\
\text { location }\end{array}$ \\
\hline $\begin{array}{c}\text { NINAPRO (Data } \\
\text { Citation 1)(Atzori et } \\
\text { al., 2014) }\end{array}$ & $\begin{array}{l}\text { Static } \\
\text { grasps/ } \\
\text { postures }\end{array}$ & CyberGlove & $\begin{array}{l}\text { Raw data } \\
\text { (22 DoF) }\end{array}$ & $\begin{array}{c}\text { Myo } \\
\text { armband / } \\
\text { sEMG } \\
\text { bipolar } \\
\text { electrodes }\end{array}$ & $\begin{array}{l}\text { Armband located } \\
\text { on the right arm } \\
\text { close to the } \\
\text { elbow, \& } \\
\text { finger flexor, } \\
\text { finger extensor, } \\
\text { triceps and } \\
\text { biceps }\end{array}$ \\
\hline $\begin{array}{l}\text { Dataset for Surface } \\
\text { Electromyographic } \\
\text { (sEMG) signals and } \\
\text { Kinematics of the } \\
\text { Hand for Simultaneous } \\
\text { and Proportional } \\
\text { Finger Movements. } \\
\text { (Data Citation 2) }\end{array}$ & $\begin{array}{c}\text { Free } \\
\text { movements }\end{array}$ & $\begin{array}{l}\text { Reflective } \\
\text { markers }\end{array}$ & $\begin{array}{l}\text { Joint angles } \\
\text { (15 DoF) }\end{array}$ & $\begin{array}{c}\text { sEMG } \\
\text { bipolar } \\
\text { electrodes }\end{array}$ & $\begin{array}{c}8 \text { muscles* } \\
\text { (APL, FCR, } \\
\text { FDS, FDP, EDC, } \\
\text { EI, ECU, ECR) } \\
\text { mostly found by } \\
\text { palpation }\end{array}$ \\
\hline $\begin{array}{l}\text { Grasp representations } \\
\quad \text { (Data Citation } \\
\text { 3)(Bianchi et al., 2013) }\end{array}$ & $\begin{array}{l}\text { Static } \\
\text { grasps }\end{array}$ & $\begin{array}{c}\text { Leap } \\
\text { Motion } \\
\text { optical } \\
\text { tracking } \\
\text { device }\end{array}$ & $\begin{array}{c}\text { Joint angles } \\
\text { (15 DoF) }\end{array}$ & $\begin{array}{c}\text { Myo } \\
\text { armband }\end{array}$ & $\begin{array}{l}\text { Armband located } \\
\text { on the right arm } \\
\text { close to the } \\
\text { elbow }\end{array}$ \\
\hline
\end{tabular}

*APL: abductor pollicis longus; FCR: flexor carpi radialis; FDS: flexor digitorum superficialis; FDP: flexor digitorum profundus; EDC: extensor digitorum communis; EI: extensor indices; ECU: extensor carpi ulnaris; ECR: extensor carpi radialis

Hand movements can be measured from different methods, but most of them fail when capturing kinematics while performing ADL. Goniometers do not allow for the simultaneous measurement of all DoFs. Electromagnetic systems are susceptible to magnetic and electrical interference from metallic objects in the environment. Markerbased optical systems can be used only within the area covered by the cameras, require a substantial amount of time to setup the markers, and markers often become occluded during the recording of tasks. Recently, portable and relatively low-cost devices have become available, as the Leap Motion Controller system. However, these systems lack of accuracy to obtain reliable kinematic data during the performance of ADL (NiechwiejSzwedo et al., 2018). At this point, instrumented gloves seem to be the most effective method for collecting data from all finger joints continuously, without occluding problems, and with no special environmental constraints (Buffi et al., 2014). However, some of the sensors have non-linear relationships with the joint anatomical angles due to their position (that does not measure directly the anatomical angles) or due to the influence of other joint movements (Eccarius et al., 2012). Therefore, calibration procedures are fundamental to obtain reliable angles from the sensors data, as the one described in (Gracia-Ibáñez et al., 2017a), with a mean precision error of 4.45 degrees (global error considering all angles joints). Additionally, as inconvenience, wearing gloves could be lead to make more force than necessary because tactile sensation is lost. 
EMG is commonly used to measure muscular activity, which consists in using electrodes to record the electrical signals transmitted by the motor neurons, which cause muscle contraction. There are two basic types of electrodes: surface (sEMG) and intramuscular (iEMG). iEMG electrodes are ideal for deep muscles, but correct placement requires a thorough knowledge of musculoskeletal anatomy. Furthermore, the invasiveness of inserting a needle into the muscles, as well as the associated pain, is a major disadvantage of their use (Kamen and Gabriel, 2010), especially for the measurement of ADL. On the other hand, the general advantage of sEMG is that it is noninvasive and easy to apply. However, the recorded sEMG signals are very dependent on the placement of the electrodes on the muscle (Kamen and Gabriel, 2010). In this sense, a previous chapter (Chapter 5) identified the most representative forearm areas for ADL performance in EMG activity terms from a set of relevant simulated and standardised ADL, which could be used to characterise the muscle activity during ADLs.

Defining a representative set of ADL is not evident. Clinical tests, like the Sollerman Hand Function test (SHFT) (Sollerman and Ejeskar, 1995), are often used to evaluate and track the upper extremity's functional recovery by performing tasks that simulate ADL, providing insight into functional performance. In this sense, a recent work (Peters et al., 2018) suggests that studying hand kinematics and EMG data while these clinical trials are being carried out can provide a better and necessary understanding of muscle recruitment and coordination for functional recovery. Based on this suggestion, I propose considering the actions used in clinical tests to study how hand movements are produced and controlled while performing ADL. A useful dataset would need kinematic data presented as anatomical angles, muscle activity recorded from forearm spots easily identifiable (with precise sEMG locations) as well as a set of representative standardised ADL, in order to make the sEMG records repeatable and comparable between subjects and activities.

The presented KIN-MUS UJI dataset aims to allow worldwide research groups to study the relationship between hand kinematics and muscle activity required to perform ADL. For such a goal, and taking into account the state of the art, the main characteristics of this dataset are:

- 26 representative ADL, 22 of them from the SHFT, modified for their standardisation,

- $18 \mathrm{DoF}$, including flexions and abductions of the fingers and thumb, and wrist movements, provided as anatomical angles,

- sEMG of 7 spots representative of the muscular activity of the whole forearm, adequately normalised and easily reproducible.

The main contribution of this dataset, compared to others, is the functional activities performed. Furthermore, the kinematic data are standardised, as they are presented as anatomical angles following the ISB sign criteria (Wu et al., 2005). Muscle activity is obtained from seven representative spot areas during ADL. The dataset takes a Matlab data structure (.mat) with kinematic data and sEMG data. These linked data are expected to foster progress in many scientific domains, such as medicine, neuroscience, 
rehabilitation, physiotherapy, prosthetics and computer aided model design, leading for instance to a better understanding of human hand movements, improved rehabilitation protocols, prosthetics that better correspond to human hand behaviour and more realistic $3 \mathrm{D}$ biomechanical models.

\subsection{Methods}

\section{Study participants}

Twenty-two right-handed subjects (12 males, 10 females) participated in the experiment, whose mean age was $35 \pm 9$ years. The criteria used to select subjects were gender parity in the overall data, being aged between 20 and 65 years, and no reported upper limb pathologies. Before the experiments, all the participants gave their written informed consent. All the experiments were run in accordance with the Ethics Committee of the Universitat Jaume I.

\section{Acquisition protocol}

Kinematics acquisition. The kinematic data of the right hand were acquired using a CyberGlove (CyberGlove Systems LLC) instrumented glove (Figure 7.1) connected to a laptop at $100 \mathrm{~Hz}$. This glove has 18 strain gauges that allow the anatomical angles of the underlying joints to be determined. All the experiments were video-recorded so as to be able to check the performance of tasks when subsequently required for data validation. Videos are not included to ensure the subjects' privacy. To correct previous irregularities observed in the wrist sensors, a strap was placed surrounding the wrist (Figure 7.1).

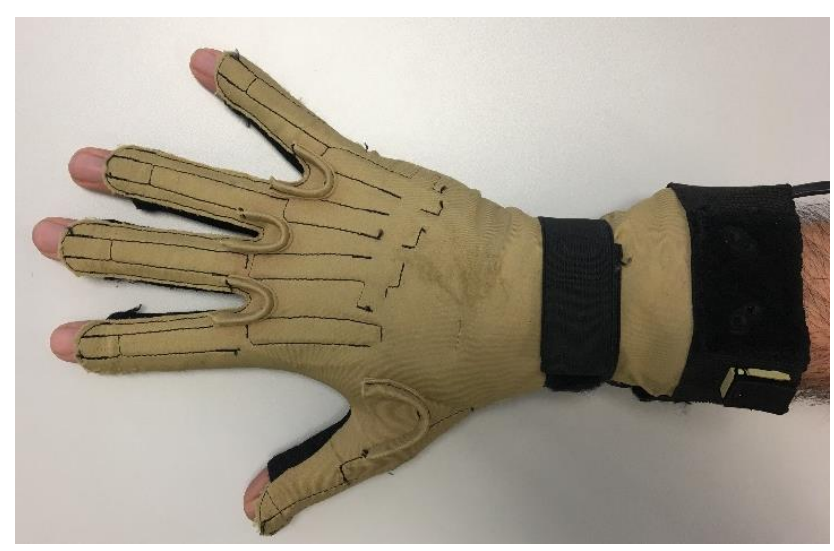

Figure 7.1 Cyberglove I device and the strap used for the wrist sensors

EMG acquisition. Muscle activity was recorded with an 8-channel sEMG Biometrics Ltd device at a sampling frequency of $1000 \mathrm{~Hz}$. Integral dry reusable sEMG Electrodes (SX230) were used, with a gain of 1000, a bandwidth between $20 \mathrm{~Hz}-460 \mathrm{~Hz}$ and noise below $5 \mu \mathrm{V}$ (Figure 7.2). Electrodes were placed in the centre of the seven most representative spot areas of the right forearm (Figure 7.3, A), according to a previous 
work (Jarque-Bou et al., 2018), and were set out in a longitudinal direction. To locate these seven spot areas, a grid defining 30 spots was drawn on the subject's forearm by using five easily identifiable anatomical landmarks (Figure 7.3, B), while the subject sat comfortably with an elbow resting on a table, arm flexed $90^{\circ}$ compared to the forearm, and the palm of the hand facing the subject, as detailed in a previous work (Jarque-Bou et al., 2018). Before placing electrodes, hair was removed by shaving, and skin was cleaned with alcohol.

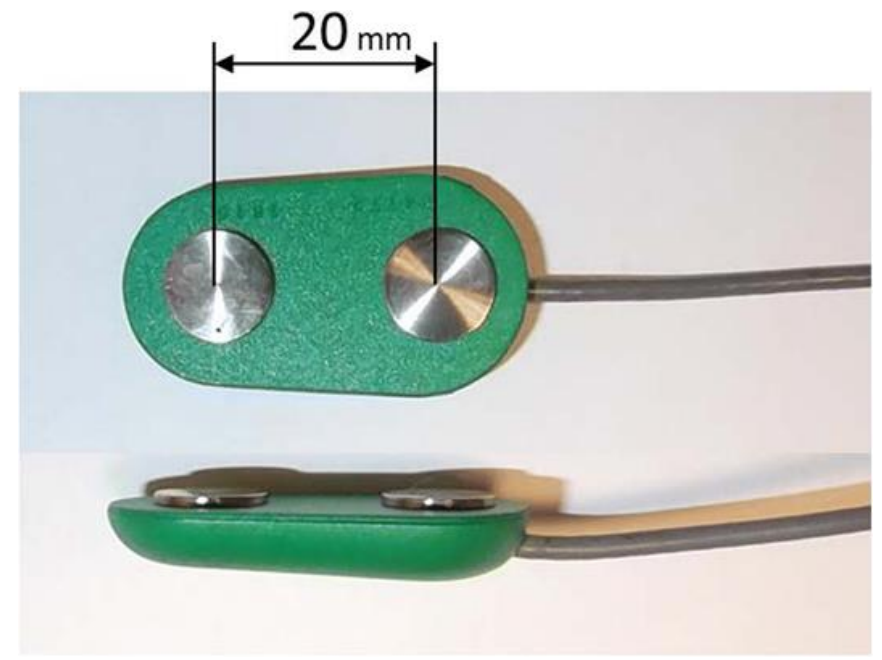

Figure 7.2 sEMG Electrodes (SX230)

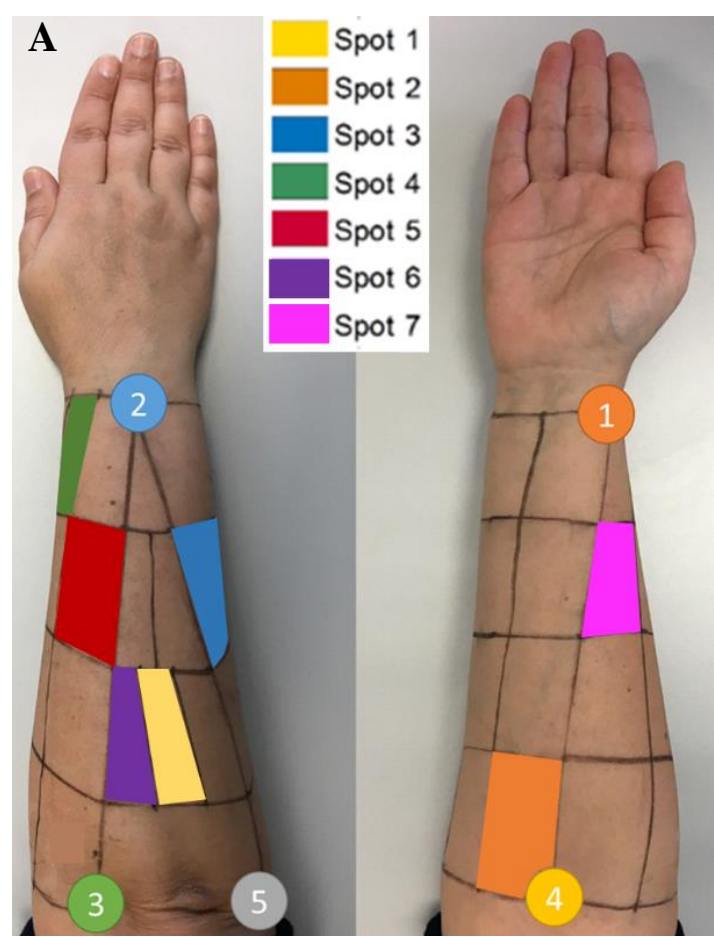

B

\begin{tabular}{ll}
\hline \hline & Landmark \\
\hline 1 & Styloid processes of the radius \\
2 & Ulna head \\
3 & Medial epicondyle of the humerus \\
4 & Centre point of the elbow \\
5 & Humeral lateral epicondyle \\
\hline \hline
\end{tabular}

Figure 7.3 (A) Spot areas selected for EMG recordings. (B) 5 anatomical landmarks used to draw the grid 
Environment \& tasks. The tasks were run in a laboratory, using a typical SHFT scenario. Figure 7.4 shows the scenario with the objects used in ADL. Tasks consisted of 26 simulated ADL, 20 of which are included in SHFT. Some ADL from SHFT were adapted to ensure their repeatability, and six further activities (A10, A15, A19, A24, A25, and A26) were added (Table 7.2), based on the percentage of using the commonest grasps during ADL (Vergara et al., 2014). Table 7.2 provides a description of each performed ADL. Some recordings were performed with the subject standing and others while they sat on a chair (as specified in Table 7.2). The participants were given clear instructions as to how to perform each task, including details like the angle of rotation of the key (A8), the position of the coin (A1 \& A3), the angle of rotation of the door handle (A9) or the amount of water to be poured (A21). Subjects were told to start and end each task in the same posture: arms relaxed on each side of their body, when the subject was standing, or arms resting in a relaxed position on a table when sitting. The subjects could practice each task as many times as necessary in advance to become familiar with its performance before recordings. While carrying out each task, the operator marked (or labelled) the time stamp of two specific events (using the specific EMG/glove software), which were later used to separate different phases or actions: when any part of the hand came into contact with the object and when the hand released the object, to separate reaching/releasing periods from the manipulation ones.
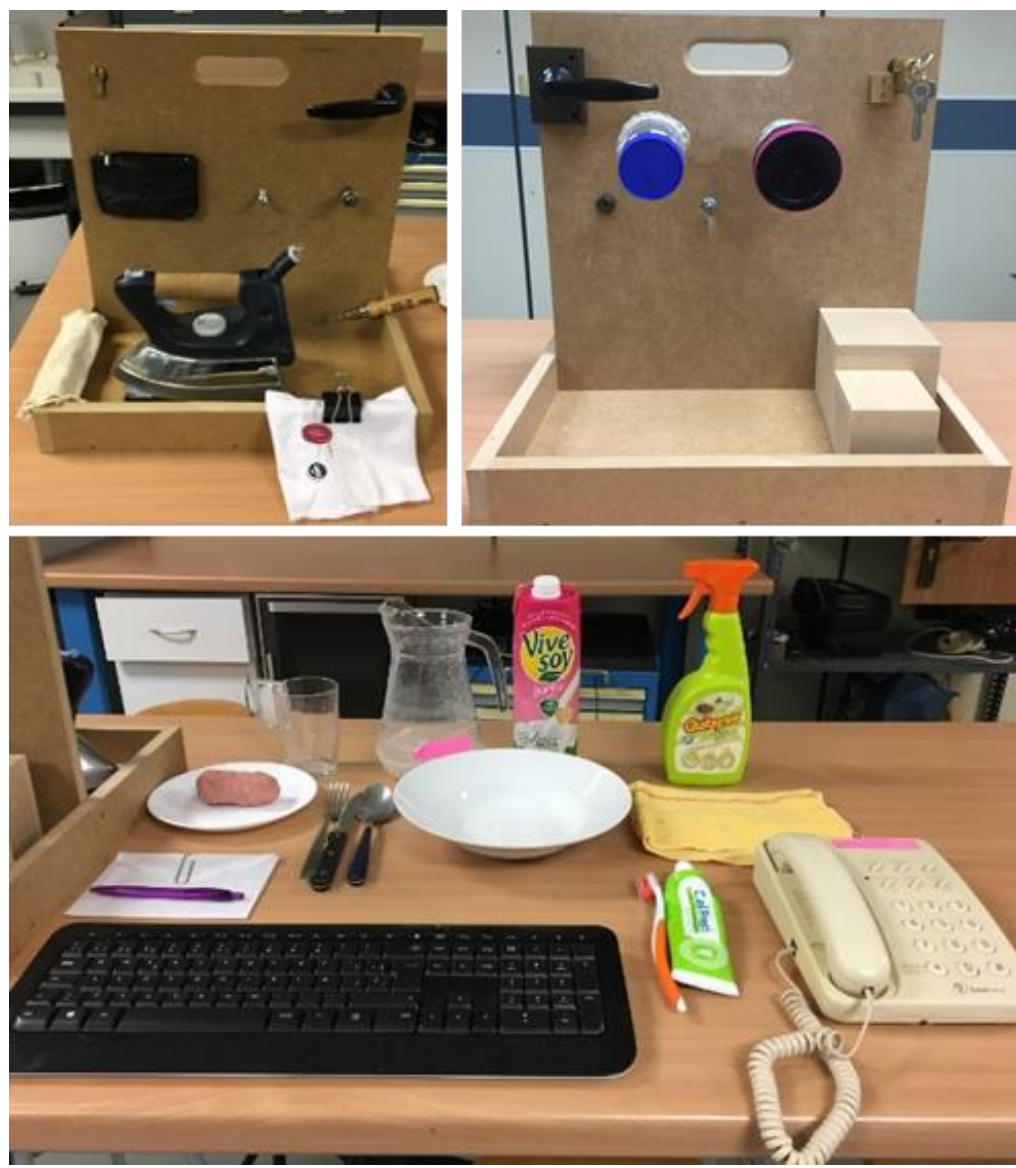

Figure 7.4 Sollerman test scenario

Kinematic and muscular characterisation of the hand during ADL 
Table 7.2 Description of the ADL performed

\begin{tabular}{cl}
\hline \hline ADLs & \multicolumn{1}{c}{ DESCRIPTION } \\
\hline A1 & Collecting a coin and putting it into a change purse \\
A2 & Opening and closing a zip \\
A3 & Removing the coin from the change purse and leaving it on the table \\
A4 & Catching and moving two different sized wooden cubes \\
A5 & Lifting and moving an iron from one marked point to another \\
A6 & Taking a screwdriver and turning a screw clockwise $360^{\circ}$ with it \\
A7 & Taking a nut and turning it until completely inserted inside the bolt \\
A8 & Taking a key, placing it in a lock and turning it counter-clockwise $180^{\circ}$ \\
A9 & Turning a door handle 30 \\
A10 & Tying a shoelace \\
A11 & Unscrewing two lids and leaving them on the table \\
A12 & Passing two buttons through their respective buttonhole using both hands \\
A13 & Taking a bandage and putting it on his/her left arm up to the elbow \\
A14 & Taking a knife with the right hand and a fork with the left hand and splitting a piece \\
& of clay (sitting) \\
A15 & Taking a spoon with the right hand and using it 5 times to eat soup (sitting) \\
A16 & Picking up a pen from the table, writing his/her name and putting the pen back on \\
& the table (sitting) \\
A17 & Folding a piece of paper with both hands, placing it into an envelope and leaving it \\
& on the table (sitting) \\
A18 & Taking a clip and putting it on the flap of the envelope (sitting) \\
A19 & Writing with the keypad (sitting) \\
A20 & Picking up the phone, placing it to his/her ear and hanging up the phone (sitting) \\
A21 & Pouring 1L of water from a carton into a jug (sitting) \\
A22 & Pouring water from the jug into the cup up to a marked point (sitting) \\
A23 & Pouring the water from the cup back into the jug (sitting) \\
A24 & Putting toothpaste on the toothbrush \\
A25 & Using a spray over the table 5 times \\
A26 & Cleaning the table with a cloth for 5 seconds \\
\hline \hline &
\end{tabular}

A reference posture (hands resting flat on a table with fingers and thumbs close together, and middle fingers aligned with forearms) was recorded before recording the hand kinematics during the selected ADL, and was considered zero for all the rotation angles. Seven records of maximum voluntary contraction (MVC) were made: flexion and extension of the wrist, flexion and extension of fingers, pronation of the forearm, ulnar deviation of the wrist, and elbow flexion. By taking a comfortable posture, the subjects were asked to exert maximum effort without the help of other muscles than those of the forearm and hand. The order followed by each subject during recordings was: firstly, the seven MVC were performed by repeating each MVC three consecutive times and resting for 3 minutes between each repetition. Then the reference posture followed by each ADL was recorded in ascending order (from 1 to 26). 


\section{Kinematic signal processing}

Calculating angles. The joint angles rotated from the reference posture were computed by transforming the raw data obtained from the glove sensors according to a non-linear calibration protocol proposed in previous works (Gracia-Ibáñez et al., 2017a). This protocol includes determining gains and also some corrections because of crosscoupling effects for specific anatomical angles. The list of anatomical angles obtained according to the protocol is shown in Figure 7.5:

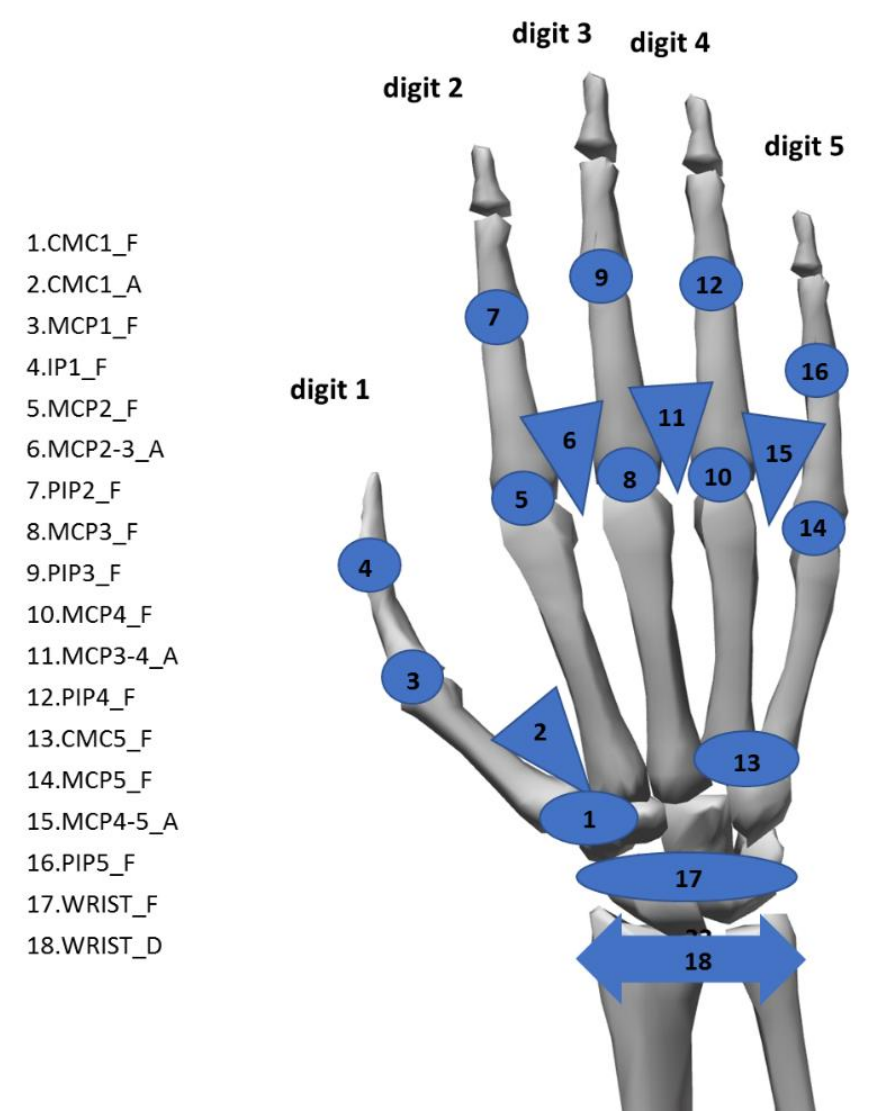

Figure 7.5 List of recorded anatomical angles. Nomenclature:_F for flexion (circles or ellipses), _A for abduction (triangles), _D for deviation (double arrow); 1 to 5, digits. Joints: IP for interphalangeal joint, PIP for proximal interphalangeal joints, MCP for metacarpophalangeal joints, CMC for carpometacarpal joints, CMC5_F for palmar arch.; WRIST for wrist joint.

Filtering. The kinematic data were filtered with a second-order two-way low-pass Butterworth filter with a cut-off frequency of $5 \mathrm{~Hz}$.

\section{EMG signal processing}

Calculating muscle activity. To determine muscle activity, sEMG records were normalised with the maximal values from any records (7 MVCs or 26 ADL) measured for each subject. 
Filtering. The sEMG records were filtered with a fourth-order bandpass filter between $25-500 \mathrm{~Hz}$, rectified, filtered by a fourth-order low-pass filter at $8 \mathrm{~Hz}$, and smoothed by Gaussian smoothing.

\section{Signal synchronisation}

The glove and sEMG records were synchronised by the acquisition software, especially designed for this purpose, to match the initial and final instants of each record.

\section{Data resampling}

The muscle activity recordings were resampled to $100 \mathrm{~Hz}$ to synchronise them with kinematic data.

\section{Data cutting and splitting}

After synchronisation, the initial and final instants of each record (muscle activity and kinematics), during which the hands remained static, were trimmed. Records were then separated into the different phases (reaching, manipulation and release) by using the labelling performed by the operator while recording data. In some specific cases in which labelling data were missing, labelling was performed using the video recordings.

\subsection{Data Records}

\section{Data files}

Data are presented as a single Matlab data structure (.mat file). This structure contains all the recorded kinematic and muscle activity data classified as: ADL, phase (reaching, manipulation or release) and subject. The data produced with the described methods were stored on Zenodo. The fields contained in the structure are those detailed in the following scheme:

- Subject: subject ID;

- ADL: ADL ID, according to Table 7.2;

- Phase: Phase of movement. 1 corresponds to reaching; 2 corresponds to manipulation; and 3 corresponds to releasing.

- Time: Time stamp

- Angles (18 columns): Calibrated anatomical angles in the following order:

$\begin{array}{ll}C M C 1 \_A & \text { Abduction of carpometacarpal 1 } \\ C M C 1 \_F & \text { Flexion of carpometacarpal 1 } \\ M C P 1 \_F & \text { Flexion of metacarpophalangeal } 1 \\ I P 1 \_F & \text { Flexion of interphalangeal } 1 \\ M C P 2-3 \_A & \text { Relative Abduction of metacarpophalangeal } 2 \text { and } 3 \\ M C P 2 \_F & \text { Flexion of metacarpophalangeal } 2 \\ P I P 2 \_F & \text { Flexion of proximal interphalangeal } 2\end{array}$




$\begin{array}{ll}M C P 3 \_F & \text { Flexion of metacarpophalangeal } 3 \\ \text { PIP3_F } & \text { Flexion of proximal interphalangeal } 3 \\ M C P 3-4 \_A & \text { Relative Abduction of metacarpophalangeal } 3 \text { and } 4 \\ M C P 4 \_F & \text { Flexion of metacarpophalangeal 4 } \\ \text { PIP4_F } & \text { Flexion of proximal interphalangeal } 4 \\ \text { CMC5_F } & \text { Palmar Arch } \\ \text { MCP4-5_A } & \text { Relative Abduction of metacarpophalangeal } 4 \text { and } 5 \\ \text { MCP5_F } & \text { Flexion of metacarpophalangeal 5 } \\ \text { PIP5_F } & \text { Flexion of proximal interphalangeal } 5 \\ \text { WRIST_F } & \text { Flexion of wrist } \\ \text { WRIST_A } & \text { Abduction of wrist }\end{array}$

- Muscle activity (7 columns): Normalised signal for the seven representative spot areas (Figure 7.3), ordered from Spot 1 to 7.

\section{Sign criteria}

The sign criteria considered for the kinematics are shown in Table 7.3

Table 7.3 Sign criteria considered

\begin{tabular}{c|l}
\hline PIP(2-5)_F, IP1_F, MCP(1-5)_F & Flexion + / Extension - \\
WRIST_F & Flexion + / Extension - \\
WRIST_A & Radial deviation + / Ulnar deviation - \\
MCP(2-3, 3-4, 4-5)_A & Fingers separated + / Fingers together - \\
P_Arch & Flexion +/Extension - \\
CMC1_F & Flexion +/Extension - (See Figure 7.6) \\
CMC1_A & Abduction +/Adduction -(See Figure 7.6)
\end{tabular}
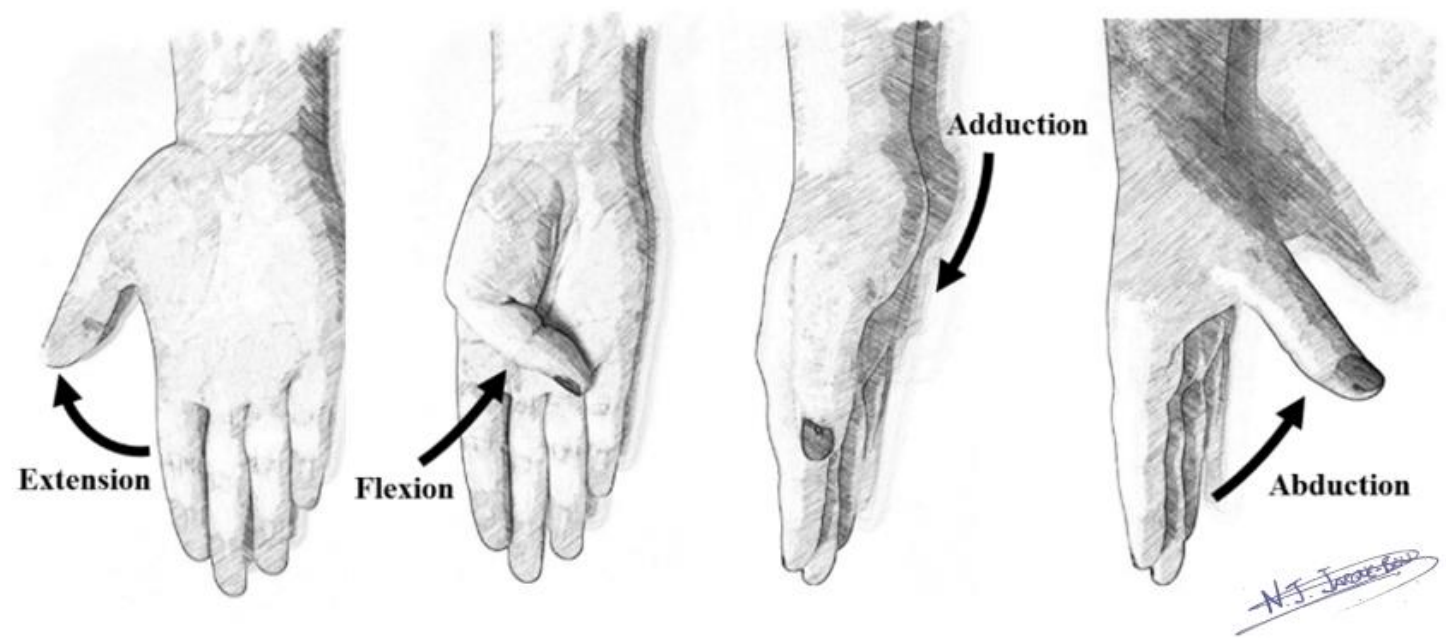

Figure 7.6 Sign criteria for the CMC joint of the thumb 


\subsection{Technical Validation}

\section{Data acquisition}

All the recorded tasks were checked to ensure that the number of labels used to divide them into elementary tasks was correct and that no labels were missing.

In order to avoid any possible unexpected signal values, all the collected data were filtered using a second-order two-way low-pass Butterworth filter with a cut-off frequency of $5 \mathrm{~Hz}$, as explained in previous sections.

\section{Experimental condition effect on hand kinematics}

In order to verify that data were similar to the data produced in real life, the effect of the experimental factors on the range of joint angles was evaluated. The factors that can affect joint angles are joint (as each one corresponds to a specific sensor), phase, subject or activity. The box and whisker graphs for all these factors are shown in Figure 7.7
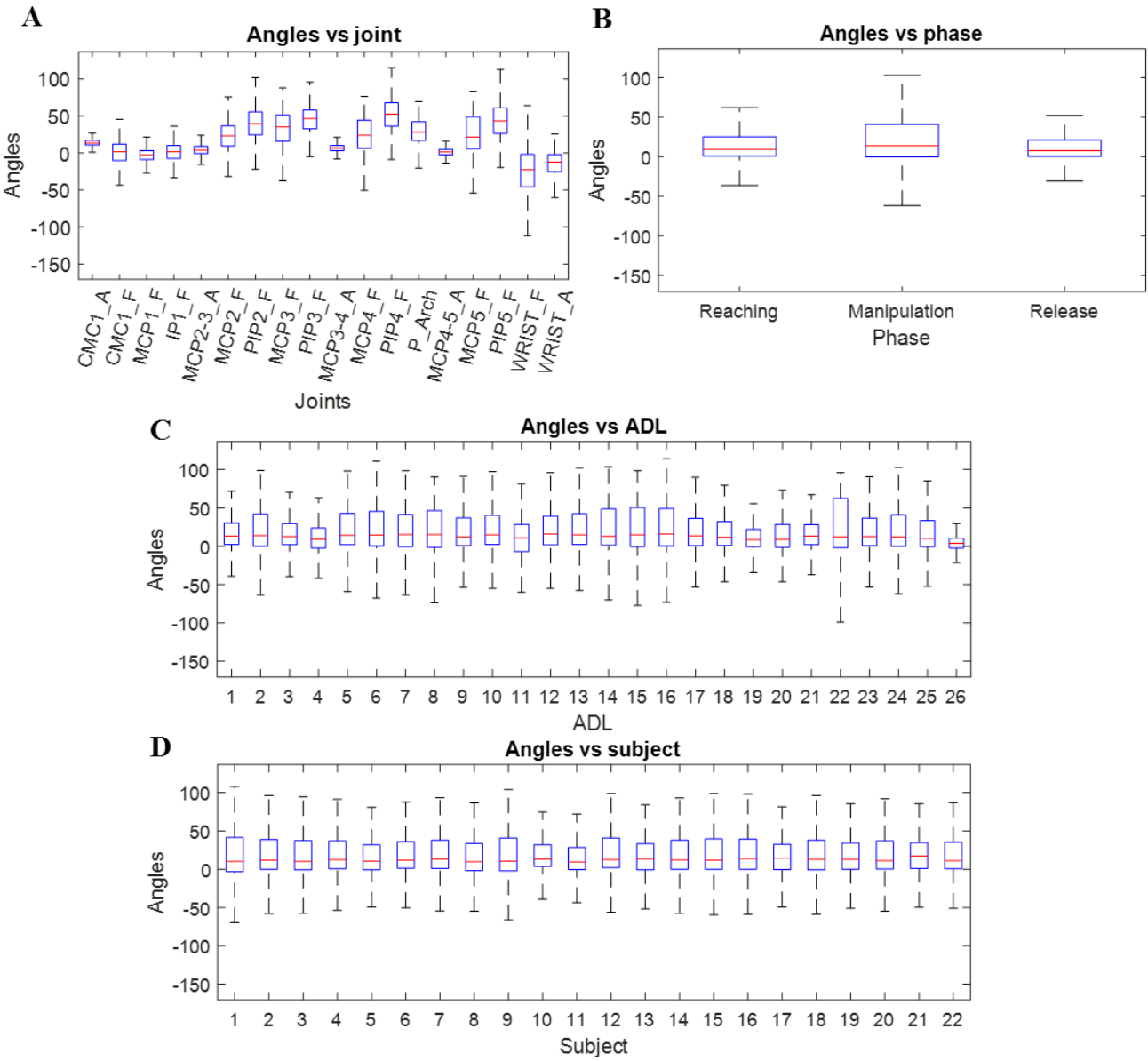

Figure 7.7. Effect of experimental conditions on the hand kinematics. Subplots represent different experimental conditions: joints (subplot A); phase (subplot B); ADL (subplot C); subject (subplot $D)$. The red horizontal central mark in the boxes is the median; the edges of the boxes are the 25 th and 75 th percentiles; whiskers extend to 1.5 times the interquartile range.

Kinematic and muscular characterisation of the hand during ADL 
A wide variability was noticed when considering how angles change in relation to joints. In general, all the joint angles have a normal range of motion (ROM) in accordance with a previous work (Gracia-Ibáñez et al., 2017b). In particular, the flexion of joints PIPs and MCPs presented a positive median with the largest ROM, which agrees with the literature (Lee and Jung, 2015a). The wrist flexion presented a negative median with a large ROM, and wrist deviation obtained a negative median value (ulnar deviation), but with a short ROM. This fact indicates that for most of the time, the wrist works in ulnarextension during ADL, which agrees with previous studies (Dauncey et al., 2017). When considering angles vs. phase, the manipulation phase gave the largest ROM, which seems quite logical: during manipulation, more complex joint movements are required and, therefore, a larger ROM. A passive flexion/extension of joints while manipulating may also contribute. When considering angles vs. ADL, all the activities generally obtained similar median and ROM values. In particular, activity 22 (Pouring water from the jug into the glass) presented the largest ROM, which agrees with the fact that this activity includes the flexion of all the fingers together with the wrist. Activity 26 (Cleaning the table with a cloth for 5 seconds) had the shortest ROM, which also agrees with the fact that this activity does not involve moving almost any hand joint as it only seems to require the elbow movement. When considering angles vs. subjects, the ROM and median values were similar among subjects, which suggests that no subject presented unusual data.

\section{Experimental condition effect on muscle activity}

In order to verify that data were similar to those produced in real life, the effect of the experimental factors on muscle activity was evaluated. The factors that can affect muscle activity are spot number (as each corresponds to a specific location), phase, subject or activity. The box and whisker graphs were plotted for each factor and are shown in Figure 7.8.

When considering muscle activity vs. ADL, minor muscle activity was generally observed in all the ADL. This fact agrees with the fact that minimal muscle force is required to perform ADL (Peters et al., 2018). However, some ADL imply greater muscle activity values than others. This is acceptable if we consider that different ADL involve using distinct muscles, objects and force patterns and, thus, lead to different muscle activity values. In particular, activity 11 (Unscrewing two lids and leaving them on the table) had the highest values, while activity 1 (Collecting a coin and placing it into a change purse) had the lowest values. Some variability was noted when considering muscle activity in relation to the recorded spot. In particular, spots 5 (finger extensors) and 6 (wrist extensors) presented the highest median values, which agrees with the fact that these muscles are the most active ones while performing ADL (Peters et al., 2018). An agreement was also found with the kinematic data as the wrist seemed to work more in extension. When considering muscle activity vs. phase, the reaching and manipulation phases had the highest muscle activity values, which was expected because the release phase is characterised by muscle relaxation. 
When considering muscle activity vs. subjects, some variability was observed among subjects. This is tolerable if we contemplate that some factors can affect muscle activity, such as different subjects being characterised by distinct anatomical characteristics, and the possibility of performing the same hand kinematics with different levels of effort according to the subject's previous experience (Marneweck et al., 2015). These facts highlight the different possibilities that each subject may have to carry out the same activities.
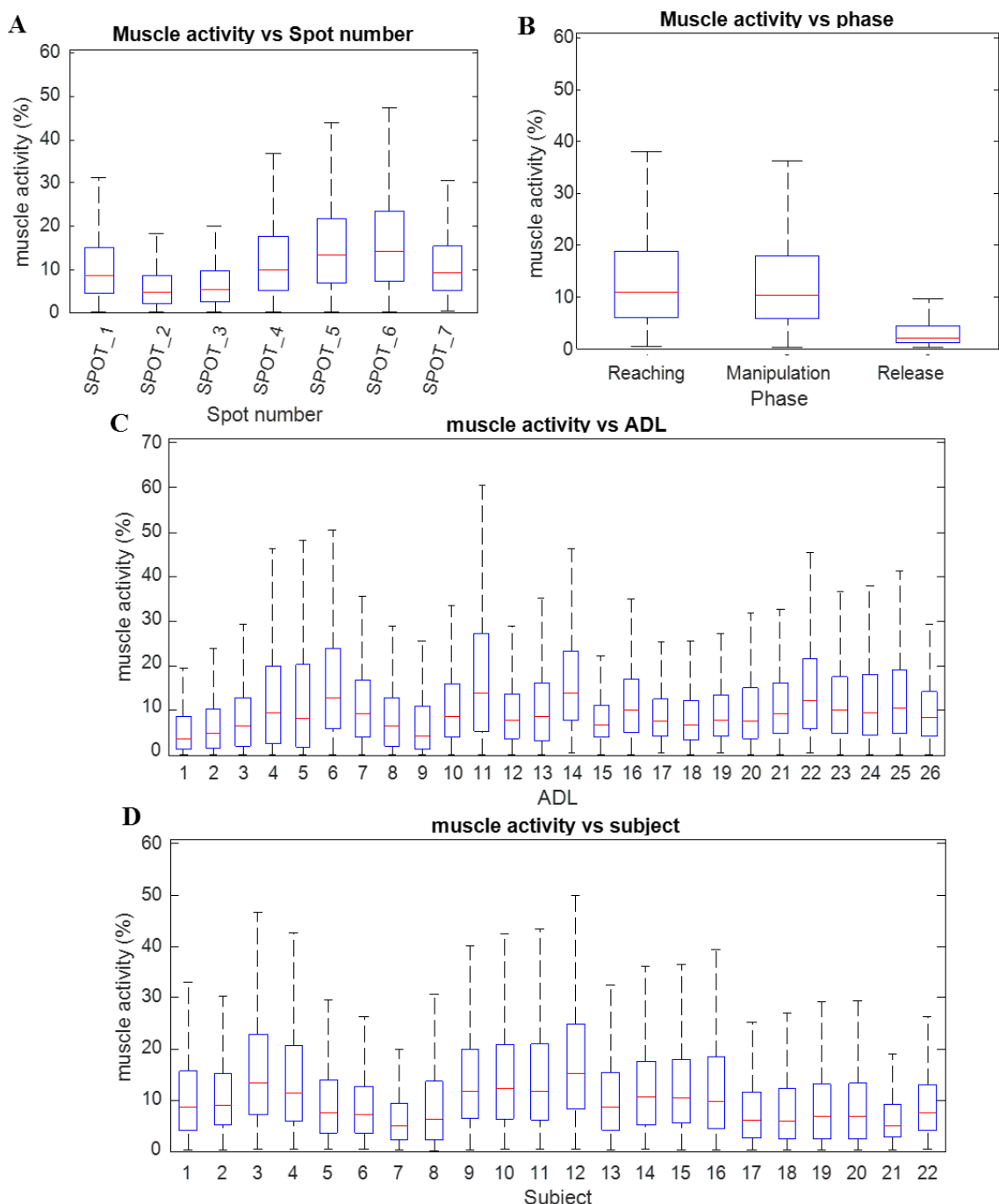

Figure 7.8 Effect of experimental conditions on the muscle activity. Subplots represent different experimental conditions: spots (subplot A); phase (subplot B); ADL (subplot C); subject (subplot $D)$. The red horizontal central mark in the boxes is the median; the edges of the boxes are the 25th and 75th percentiles; the whiskers extend to 1.5 times the interquartile range

In conclusion, the KIN-MUS UJI dataset does not present any visible inappropriate effect that could prevent the database being used to improve current scientific advancements in robotics, rehabilitation, prosthetics, etc. 


\subsection{Usage Notes}

Many factors can affect the amplitude of the signal from sensors, including the acquisition setup, the subject's anatomical characteristics and fatigue, among others.

As wrist sensors do not well fit all hand sizes, an elastic band was used (Figure 7.1) to achieve a better fit. However, sensor WRIST_F may provide more extreme values in extension due to the presence of cables underneath the globe. This effect is observed specially in ADL \#7 and \#11.

For ADL \#25 of subject \#22, all the data were lost. In this case, a Not a Number $(\mathrm{NaN})$ value was presented.

Note that the sEMG records were normalised with the maximal values from any record (MVC and ADL). In particular, the maximum muscle activity on spot 4 was found in most subjects in ADL \#11 (Unscrewing lids), but not during the MVCs records. This may suggest the usefulness of using similar MVC action to this activity in future works.

\subsection{Data citations}

1. Atzori, M., Gijsberts, A., Castellini, C., Caputo, B., Mittaz Hage, A.G., Elsig, S., Giatsidis, G., Bassetto, F. \& Müller, H. Ninaweb http://ninapro.hevs.ch/ (2014)

2. Jimson Ngeo. Dataset for Surface Electromyographic (sEMG) signals and Kinematics of the Hand for Simultaneous and Proportional Finger Movements. https://dynamicbrain.neuroinf.jp/modules/xoonips/detail.php?id=EMG101

3. Sburlea, Andreea I. 2018. "Sburlea and Müller-Putz - Grasp Representations." OSF. November 13. doi:10.17605/OSF.IO/MY5PT. 



\section{CHAPTER 8}

An insight into the relationship between kinematic and muscular activity of the hand during ADL 

This chapter is an introductory study of the relationship between hand kinematics and forearm muscular activity during the performance of ADL, based on the analysis of the data presented in Chapter 7, and following the methodology used in Chapter 3.

\subsection{Abstract \& keywords}

In this chapter, an insight into the relationship between hand kinematics and muscle activity is presented. The analyses presented in this chapter were performed using the database presented in Chapter 7, distinguishing between reaching and manipulation phases, and addressing hand kinematics using the reduced kinematic variables obtained in Chapter 3.

The results showed that hand motor control in day-to-day life can be characterised with a limited set of kinematic and muscular patterns. During reaching different correlations are observed between kinematics and muscle activity, depending on the intended grasp. These correlations could be used to improve prostheses control, by selecting the most suitable muscles spots to control each kinematic synergy. During manipulation, ADL may be clustered into six groups with similar mean and range values for the muscle activity and kinematics. Therefore, ADL could be reduced from 26 ADLs to 9 ADLs, considering one or two ADL per group by using mean and range values as quantitative parameters to evaluate kinematics and muscular activity.

In addition, temporal evolution of the mean muscle activity of each spot and their 95\% confidence interval is provided, considering a wide sample of healthy subjects, during reaching per intended grasp and during manipulation per ADL, which may help improving the control of hand prostheses and quantifying the hand function assessment.

Keywords: Activities of daily living, EMG, Kinematic synergy, Muscle synergy

\subsection{Introduction}

The ability to reach, grasp and manipulate an object involves complex and dynamic relationships between activation of muscles and joint motions. Knowing how the central nervous system (CNS) acts on the redundant human musculoskeletal system is essential for performing activities of daily living (ADL). As seen in previous chapters, CNS coordinates the muscular and kinematic structures using modular control (Johnston et al., 2009; Safavynia et al., 2011b; Santello et al., 2013), allowing a reduction in the dimensionality of the motor control task (synergies).

Establishing a link between kinematics and muscle activation is not straightforward. Muscle activity might not be directly or linearly related to movement kinematics, since 
movements and forces are produced through joint torques (d'Avella and Lacquaniti, 2013). This means that, for example, one can hold two objects of different weight using the same posture, therefore requiring different muscle force demand. Also, one can perform a given activity that may require more or less effort but the same kinematics (e.g. turning a tight vs loose jar lid). In addition, there are also notable differences in the relationship between kinematics and muscle activity depending on the phase of the activity (reaching vs manipulation). During reaching, the only efforts to be counteracted by the muscles are the inertia efforts and the gravity. But during manipulation, additional efforts have to be exerted on the object in order to perform a certain activity that are clearly task dependent (e.g. the muscle forces to hold an object will be dependent on the object's weight). Consequently, the expectable muscle effort variability during reaching is minor when compared to manipulation, although it has also been confirmed that the EMG level in reaching is greater when it is expected to perform an action that requires more effort (such as holding a heavier object) (Tagliabue et al., 2015).

In previous chapters, I observed the existence of hand kinematic synergies. The origin of these synergies may be related, at least partially, to muscular activation, i.e. extrinsic muscles act simultaneously on different joints (e.g. flexor pollicis longus is a flexor of all three joints of the thumb). On the other hand, in Chapter 5, I obtained forearm muscle synergies when I identified spots with similar muscle activation profiles. The source of the correlations found may correspond to muscle coordination and/or to the fact that the same muscle runs beneath different spots.

Tagliabue et al (Tagliabue et al., 2015) suggested that kinematic synergies have (at least in part) their origin not just in muscular activation, but in synergistic muscle activation, i.e. kinematic synergies may result from muscle synergies. However, few studies have attempted studying the relationship between both hand kinematic and muscle synergies (Castellini and Van Der Smagt, 2013; Tagliabue et al., 2015; Weiss and Flanders, 2004). Weiss and Flanders (Weiss and Flanders, 2004) analysed static hand postures (grasping 26 objects and/or forming 26 letter shapes of a manual alphabet) and used multiple regression to map one space synergy into the other. They found that a given muscle may be a member of more than one muscle synergy. Castellini and Van Der Smagt (Castellini and Van Der Smagt, 2013) analysed static grasps and used a distance matrix to compare clustering in the two synergy spaces, kinematic and sEMG spaces (pairwise Euclidean distance). They found that grasps which required similar muscle activations did not necessarily coincide with grasps with similar finger positions. Similarly, Tagliabue et al (Tagliabue et al., 2015) obtained both kinematic and muscular synergies differentiating between reaching/release and manipulation phases. They attempted to relate both spaces, and found that both kinematic and EMG space were linked, i.e. there is a potentially causal relation between kinematic and muscular synergies. However, they focused on the analysis of specific muscles for developing only two different grasping movements (Lateral and Pad-to-pad pinch) in a very controlled environment, so that the results can't be extrapolated to functional activities. Therefore, little is known about the 
contribution of muscle activation and hand kinematics patterns and their relation to the performance of ADL.

In this chapter, an insight into the relationship between hand kinematics and muscle activity is presented. For such goal, I will take into consideration the results from previous chapters:

- As seen in Chapter 3, the whole hand kinematics during ADL is actually low dimensional, and it can be efficiently described by five synergies: digit arch and closeness, responsible of the gross motion, and palmar arch, thumb opposition and thumb arch, needed for the most subtle hand movements.

- In Chapter 3 I also observed the convenience to differentiate between reaching (whose kinematics is mostly influenced by the intended grasp) and manipulation (task dependent): reaching requires modulation of the closeness, digit arch and thumb opposition synergies, with different control patterns per grasp, while thumb arch and palmar arch are kept almost unchanged. On the contrary, all synergies need to be modulated during manipulation for all tasks. Furthermore, kinematic reduction allowed grouping the ADL according to similar kinematic requirements.

- In Chapter 5, functional PCA allowed the identification of six forearm spot areas with similar muscle activation profiles during the performance of ADL, from which six representative spots were selected. These spots were used in Chapter 7 to create a well-synchronised kinematic and muscle activity dataset during the performance of 26 standardised ADL, which contains the kinematic data used in Chapter 3 together with muscle activity of the six representative forearm spots.

Summing up, the insight analyses presented in this chapter were performed using the database presented in Chapter 7, distinguishing between reaching and manipulation phases, and addressing hand kinematics using the reduced kinematic variables obtained in Chapter 3.

Looking for compiling results of all the ADL, during reaching, it is probably best to use the hand configuration to match the shape of the object to be grasped as a possible clustering factor. Therefore, the hand performs a free movement to achieve a given type of grasp, joints kinematics and muscular activity be directly correlated, although the upcoming grasp force has some anticipatory effect on the kinematics and EMG (Tagliabue et al., 2015). However, during manipulation, the EMG should be more linked to the contact forces required to perform the task with the object being manipulated that with the kinematics itself. Therefore, it makes no sense to try to find correlations between kinematics and EMG in the same way as in reaching. Instead, it might be useful also to consider the required force configuration at hand (to apply the required grasp stability). 


\subsection{Methods}

\section{Data source}

Kinematics and muscle activity data from the database presented in Chapter 7 was used. In short, the kinematics data consisted in 16 anatomical hand angles (see Figure 7.5, page 185) of 22 right-handed subjects while performing 26 tasks representative of ADL (description of tasks in Table 7.2, page 184), properly standardised to ensure their repeatability. And the muscle activity data consisted in sEMG signals recorded in six spots representative of the forearm (spot location in Figure 7.3, page 182).

\section{Reduced kinematic variables}

Hand kinematics was addressed by using the reduced kinematic variables (RKVPCs) corresponding to the five synergies (PCs) obtained in Chapter 3 (see Figure 3.3, page 97) from the PCA applied to the 16 original anatomical angles: RKV-PC1 corresponding to digit arch, RKV-PC2 to closeness, RKV-PC3 to palmar arch, RKVPC4 to thumb opposition and RKV-PC5 to thumb arch.

\section{Data analysis}

As in Chapter 3, data was analysed separately for reaching and manipulation phases.

For the reaching phase, the study was performed differentiating by the intended grasp performed (Table 3.4, page 99), according to a 9-type classification of grasps: Cylindrical grasp $(\mathrm{Cyl})$, intermediate power-precision grasp $(\operatorname{Int} P P)$, lateral pinch $(\operatorname{Lat} P)$, Hook grasp (Hook), lumbrical grasp (Lum), non-prehensile grasp (NonP), oblique palmar grasp $(\mathrm{Obl})$, pad-to-pad pinch $(\mathrm{PpPinch})$, and special pinch $(\mathrm{SpP})$. The following analyses were performed on the data during reaching differentiating by grasp:

- Mean values across subjects and frames of the muscle activity of the spots and differences between the 95th and 5th percentiles (range) were computed.

- Temporal evolution of the mean and 95\% confidence interval (CI) across subjects of muscle activity from each spot were plotted and compared to those of the RKVPCs obtained in Chapter 3 (Figure 3.4, page 102).

- Correlation coefficients were computed between the muscle activity from each spot and the RKV-PCs values, considering all the frames of each record.

For the manipulation phase, the study was performed differentiating by ADL. The following analyses were performed on the data during manipulation:

- Mean values across subjects and frames of the muscle activity of the spots and differences between the 95th and 5th percentiles (range) were computed, differentiating per ADL

- Temporal evolution of the mean and 95\% CI across subjects of muscle activity from each spot were plotted, differentiating per ADL. 
Analogously to Chapter 3, a cluster analysis was performed by using the aforementioned statistics (mean and range values) for each ADL of both the muscle activity of each spot and the RKV-PCs (obtained previously in Chapter 3, Table 3.6). The aim was to look for groups of ADL with similar requirements during the manipulation, considering both kinematic and muscular data. In order to make kinematic and muscular data comparable, the input values of the muscle activities were rescaled before the cluster analysis. A linear rescaling was performed to have a mean global muscle activity value equal or equivalent to mean global values of the RKV-PCs, and ranges were checked to be similar. The resulting groups of ADL were described through boxplots of the statistics (mean and range) of the RKV-PCs and muscle activities.

\subsection{Results}

\section{Reaching}

Table 3.52 shows some statistics across subjects and frames of muscle activity from each muscle spot per intended grasp during reaching, such as mean and range (difference between the 95th and 5th percentiles). The results show different mean and range values of muscle activity from each muscle spot, according to the type of intended grasp. $C y l$ presents the largest average values and ranges for most of the spots, while the NonP has the smallest values. Specifically, spot 1 presents the greatest mean values and muscular activation range for $\mathrm{Obl}, \mathrm{Cyl}$, IntPP and Hook. Spot 2 presents very small mean values and ranges for all grasps. Spot 3 also presents small values of muscle activity, showing the greatest values for $\mathrm{Obl}, \mathrm{Cyl}$ and IntPP. Spot 4 presents the greatest values for $C y l$, PpPinch and Obl. Spot 5 and 6 present the greatest values for PpPinch, Cyl and IntPP, although spot 6 has greater values for LatP. Finally, spot 7 presents the greatest values for $C y l$ and $O b l$. Note that, in general, spots 1, 4, 5 and 6 present the greatest mean and range values.

Table 8.1 Mean $(\mu)$ and range $(r)$ (difference between $95^{\text {th }}$ percentile and $5^{\text {th }}$ percentile) of muscle activity from each spot during each intended grasp

\begin{tabular}{|c|c|c|c|c|c|c|c|c|c|c|}
\hline & & PpPinch & Cyl & Lum & LatP & Obl & IntPP & Hook & NonP & All \\
\hline SPOT1 & $\mu$ & 0.14 & 0.18 & 0.09 & 0.13 & 0.24 & 0.19 & 0.16 & 0.09 & 0.15 \\
\hline SPU11 & $\mathrm{r}$ & 0.13 & 0.19 & 0.09 & 0.10 & 0.23 & 0.17 & 0.19 & 0.06 & 0.14 \\
\hline & $\mu$ & 0.08 & 0.07 & 0.06 & 0.06 & 0.07 & 0.08 & 0.07 & 0.06 & 0.07 \\
\hline SPU12 & $\mathrm{r}$ & 0.07 & 0.07 & 0.04 & 0.04 & 0.04 & 0.06 & 0.07 & 0.04 & 0.05 \\
\hline SPOT3 & $\mu$ & 0.08 & 0.11 & 0.07 & 0.07 & 0.11 & 0.10 & 0.08 & 0.09 & 0.09 \\
\hline SPU13 & $\mathrm{r}$ & 0.08 & 0.12 & 0.09 & 0.07 & 0.09 & 0.08 & 0.11 & 0.07 & 0.09 \\
\hline & $\mu$ & 0.18 & 0.24 & 0.12 & 0.13 & 0.18 & 0.15 & 0.17 & 0.14 & 0.16 \\
\hline SPOT4 & $\mathrm{r}$ & 0.17 & 0.23 & 0.11 & 0.12 & 0.11 & 0.12 & 0.19 & 0.11 & 0.15 \\
\hline & $\mu$ & 0.20 & 0.23 & 0.15 & 0.15 & 0.17 & 0.19 & 0.15 & 0.16 & 0.17 \\
\hline SPOT5 & $\mathrm{r}$ & 0.16 & 0.19 & 0.12 & 0.11 & 0.11 & 0.13 & 0.19 & 0.12 & 0.14 \\
\hline SPOT6 & $\mu$ & 0.23 & 0.23 & 0.14 & 0.21 & 0.18 & 0.27 & 0.16 & 0.14 & 0.20 \\
\hline SPU10 & $\mathrm{r}$ & 0.20 & 0.23 & 0.12 & 0.18 & 0.16 & 0.24 & 0.16 & 0.11 & 0.17 \\
\hline & $\mu$ & 0.12 & 0.21 & 0.13 & 0.11 & 0.17 & 0.13 & 0.13 & 0.08 & 0.14 \\
\hline SPOT 7 & $\mathrm{r}$ & 0.10 & 0.19 & 0.10 & 0.08 & 0.13 & 0.10 & 0.18 & 0.05 & 0.12 \\
\hline
\end{tabular}


Figures 8.1 to 8.8 show, for each grasp, the temporal evolutions of the mean across subjects together with their $95 \%$ confidence interval (CI) of the muscle activity from each spot and of the RKV-PCs. The figures show also a matrix with the correlation coefficients between muscle activity and the RKV-PCs (considering all the frames of each record) for each of the intended grasps. In these figures, correlations are observed between kinematic and muscular patterns, differently correlated depending on the intended grasp.

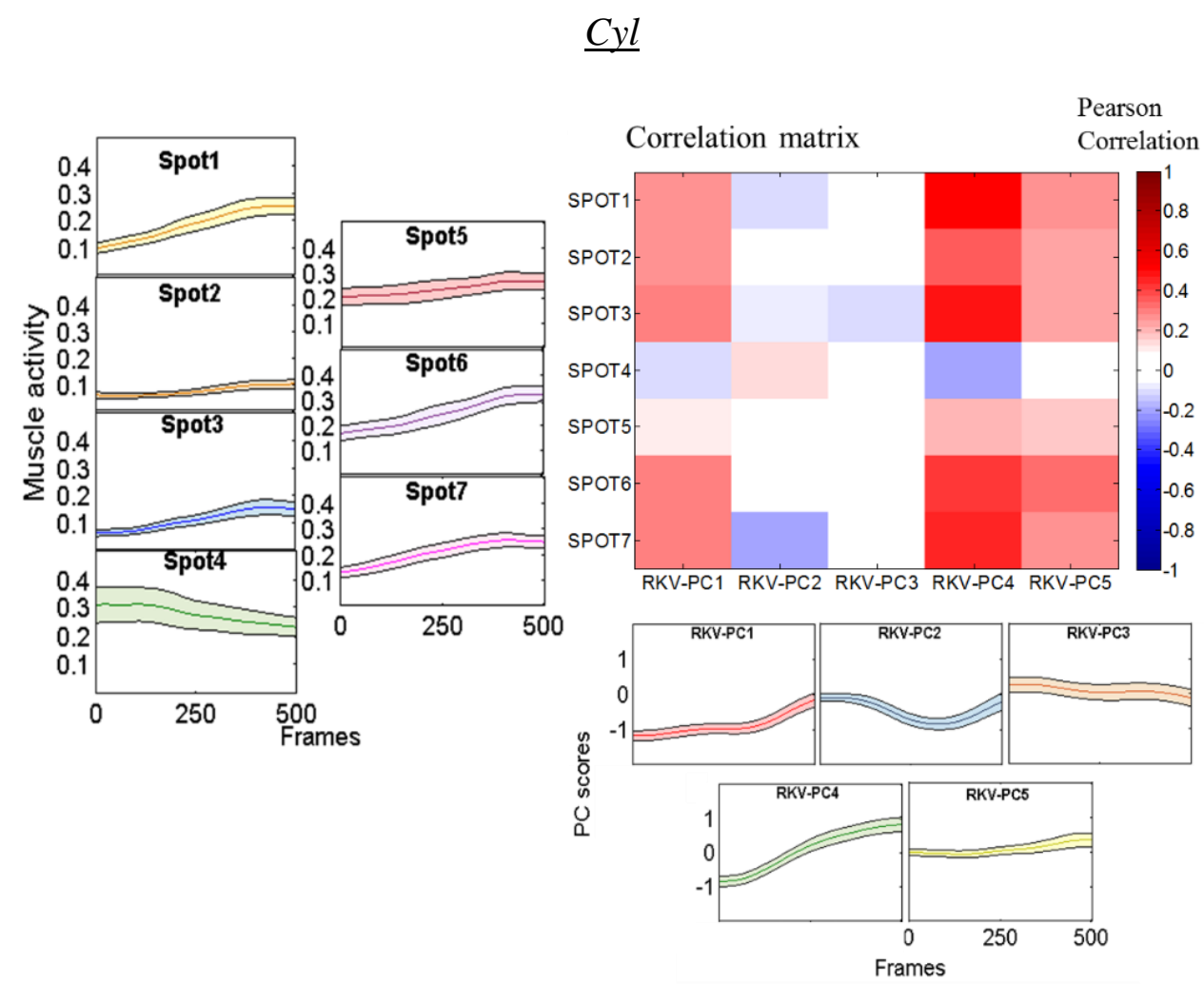

Figure 8.1 Temporal evolution (mean and 95\% CI across subjects) of muscular activity of each of the muscle spots and each RKV-PCs, together with the correlation coefficients between them (considering all the frames of each record) for Cyl grasp during reaching 

and muscular activity of the hand during ADL

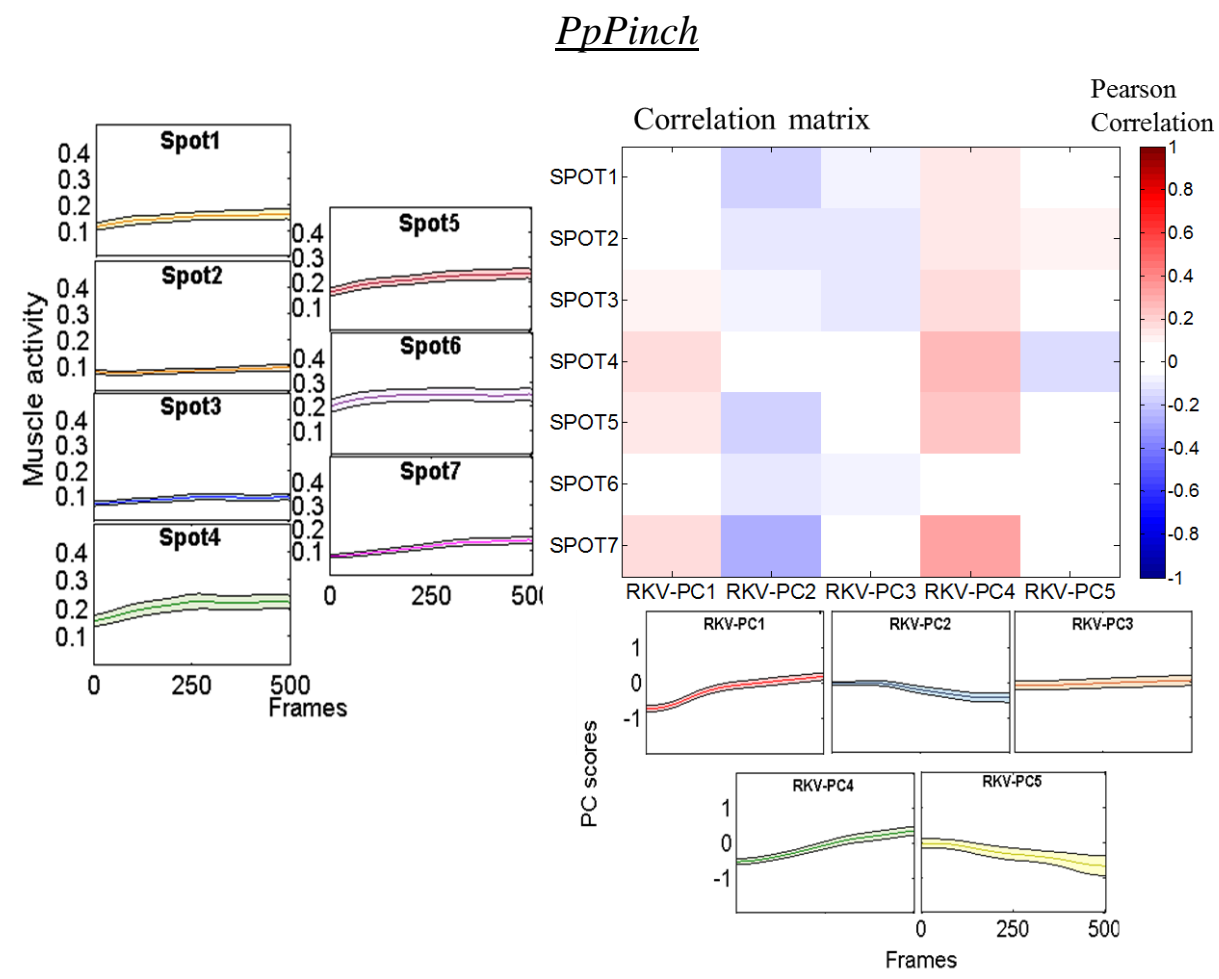

Figure 8.2 Temporal evolution (mean and 95\% CI across subjects) of muscular activity of each of the muscle spots and each RKV-PCs, together with the correlation coefficients between them (considering all the frames of each record) for PpPinch grasp during reaching

\section{$\underline{\text { Lum }}$}
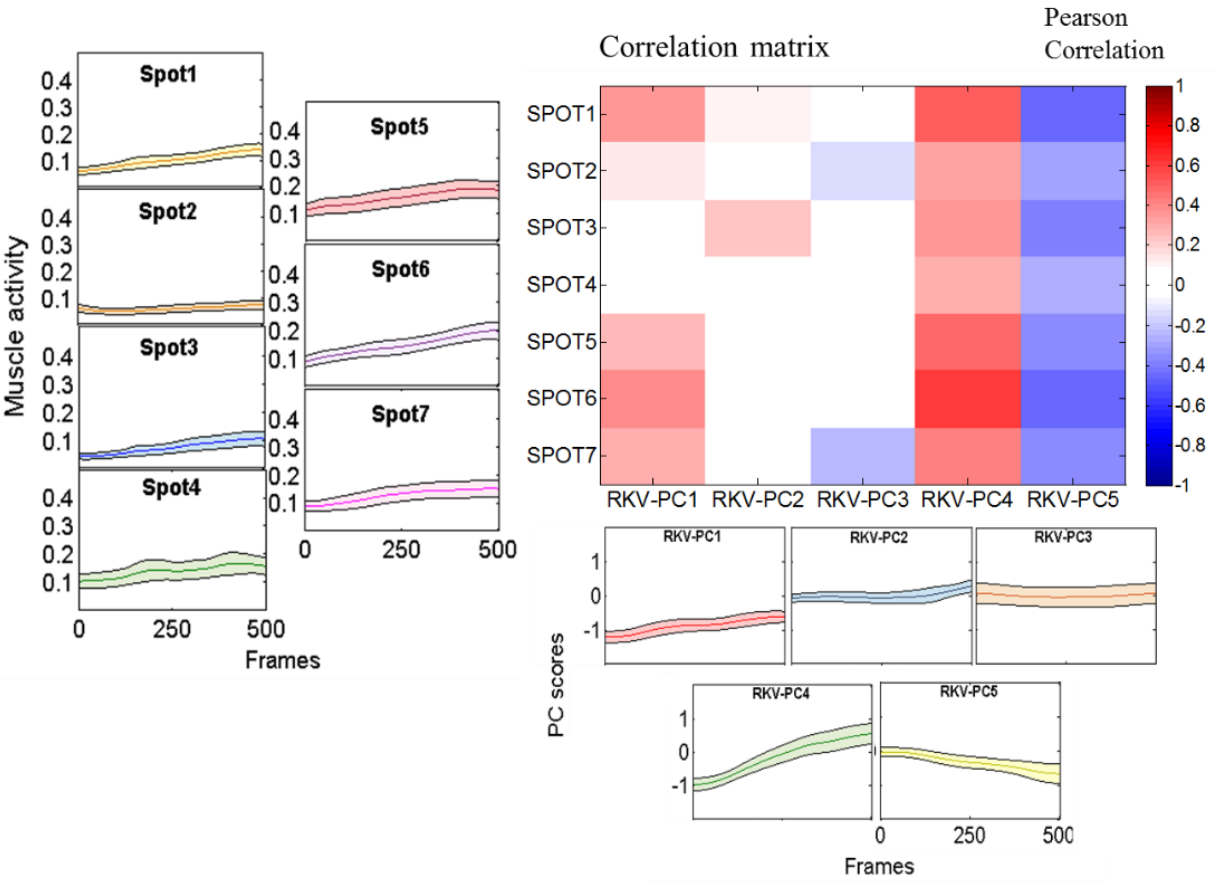

Figure 8.3 Temporal evolution (mean and 95\% CI across subjects) of muscular activity of each of the muscle spots and each RKV-PCs, together with the correlation coefficients between them (considering all the frames of each record) for Lum grasp during reaching 
Chapter 8. An insight into the relationship between kinematic and muscular activity of the hand during ADL

\section{$\underline{\text { LatP }}$}
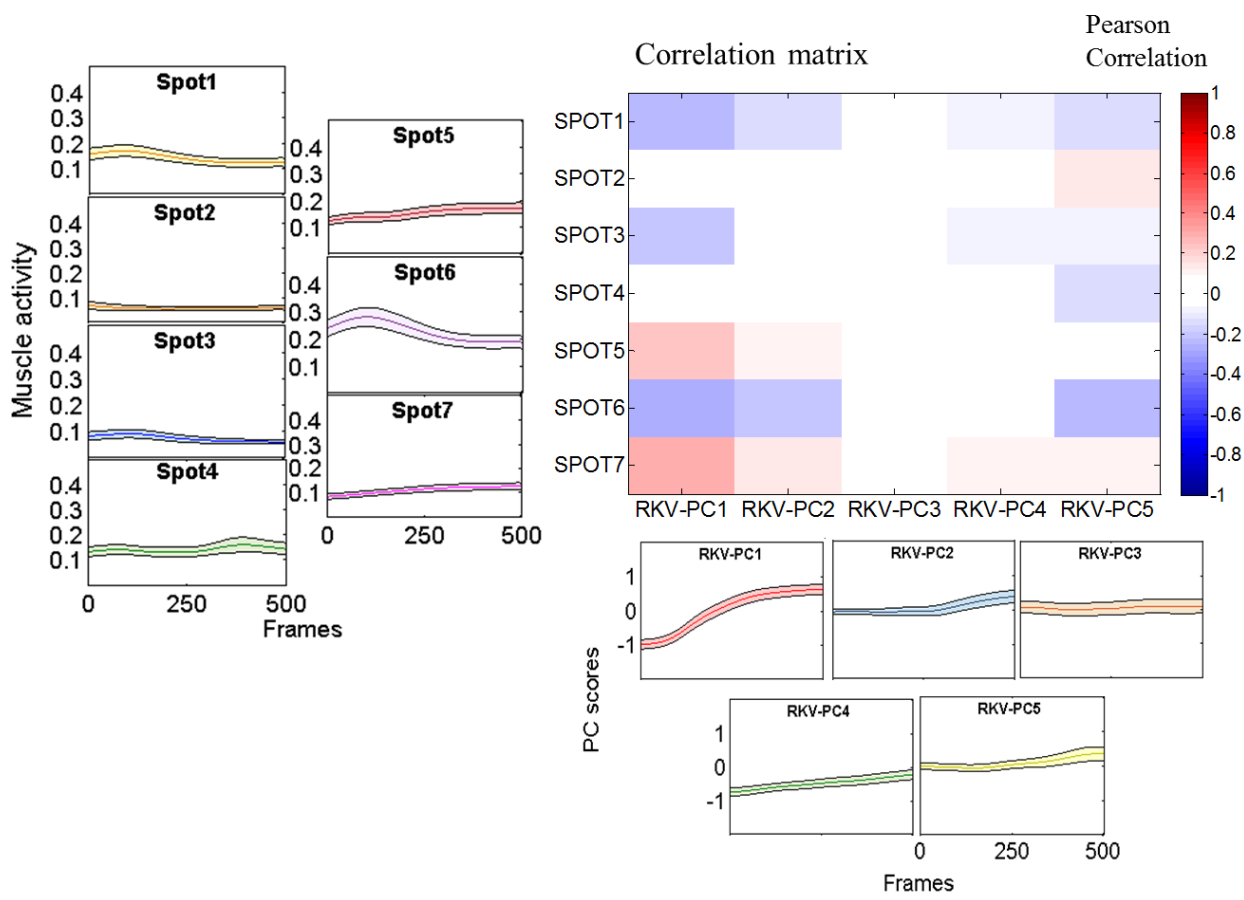

Figure 8.4 Temporal evolution (mean and 95\% CI across subjects) of muscular activity of each of the muscle spots and each RKV-PCs, together with the correlation coefficients between them (considering all the frames of each record) for LatP grasp during reaching

$\underline{\mathrm{Obl}}$

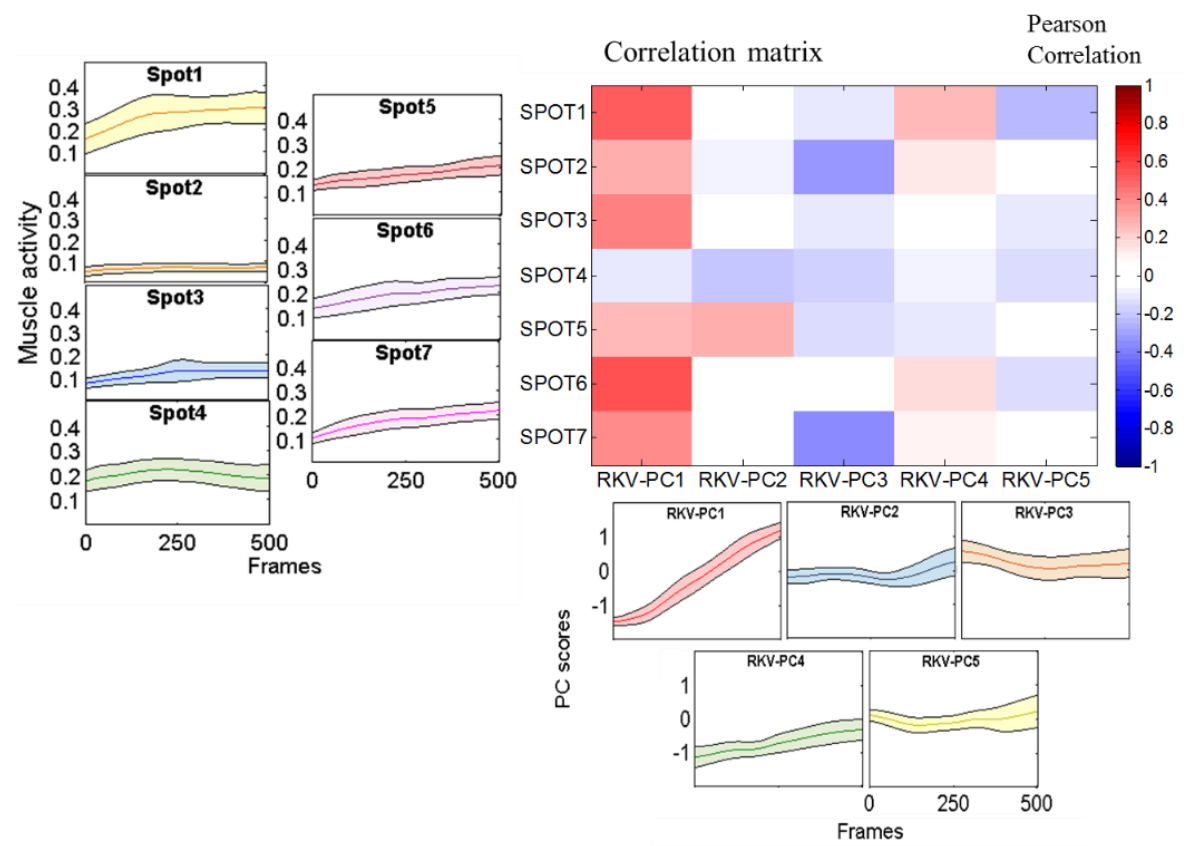

Figure 8.5 Temporal evolution (mean and 95\% CI across subjects) of muscular activity of each of the muscle spots and each RKV-PCs, together with the correlation coefficients between them (considering all the frames of each record) for Obl grasp during reaching 

and muscular activity of the hand during ADL

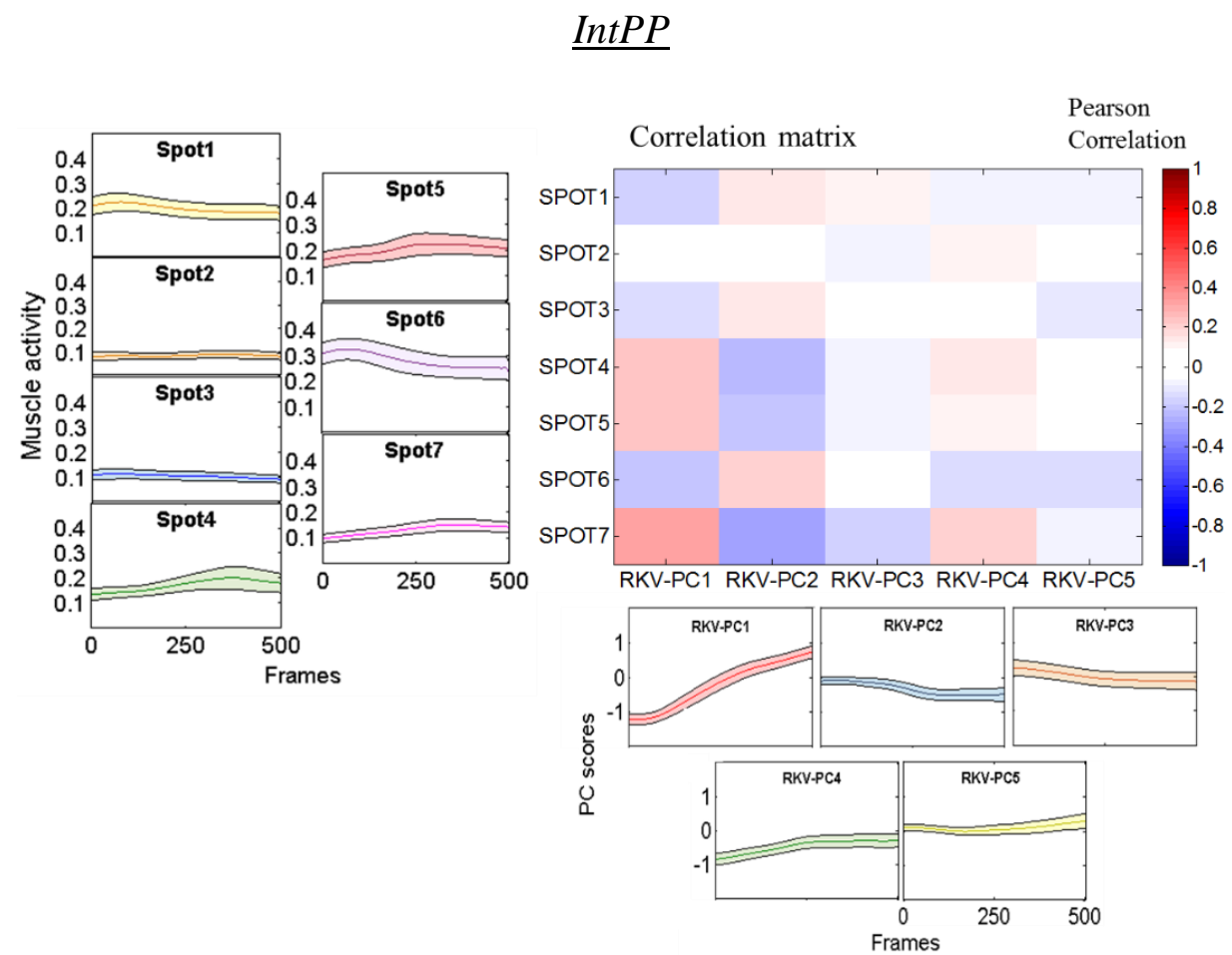

Figure 8.6 Temporal evolution (mean and 95\% CI across subjects) of muscular activity of each of the muscle spots and each RKV-PCs, together with the correlation coefficients between them (considering all the frames of each record) for IntPP grasp during reaching

\section{$\underline{\text { Hook }}$}
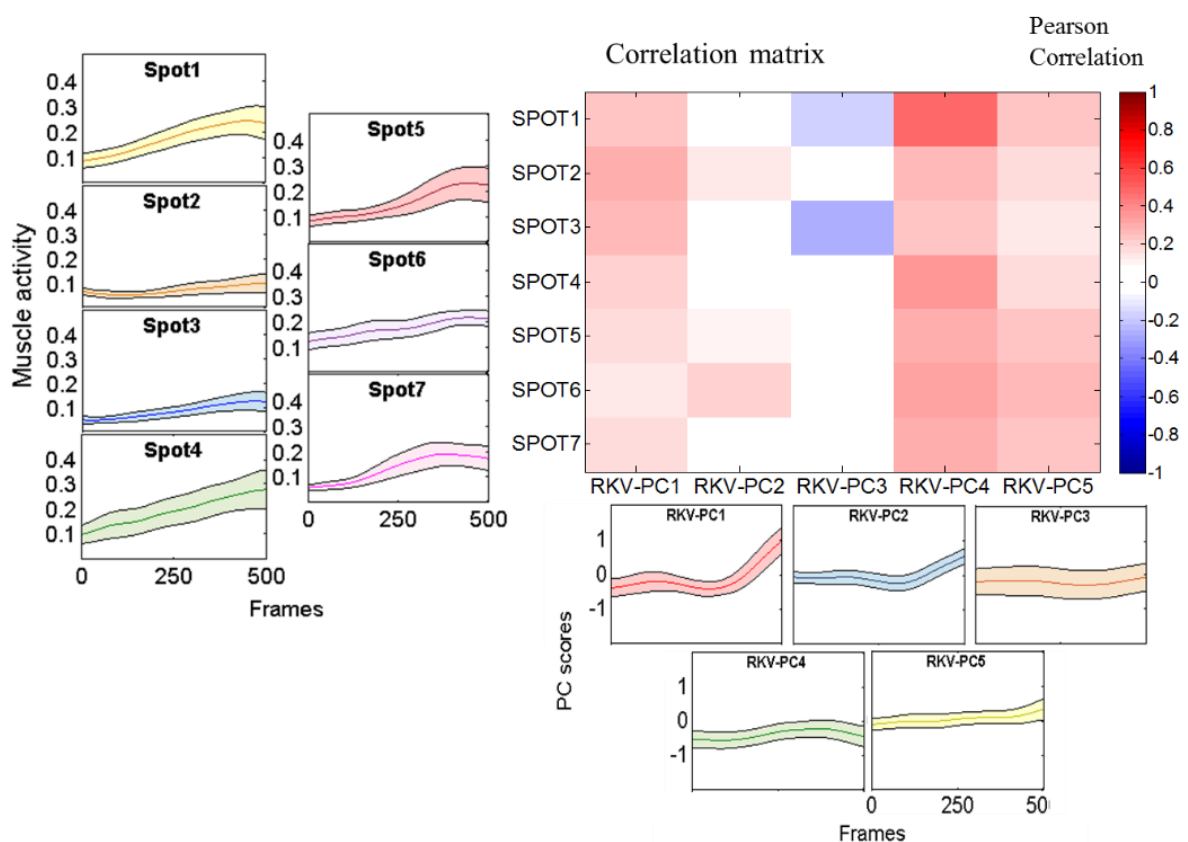

Figure 8.7 Temporal evolution (mean and CI $95 \%$ across subjects) of each of the muscle spots and RKV-PCs, as well as the correlation coefficients between them (considering all the frames of each record) for Hook during reaching 


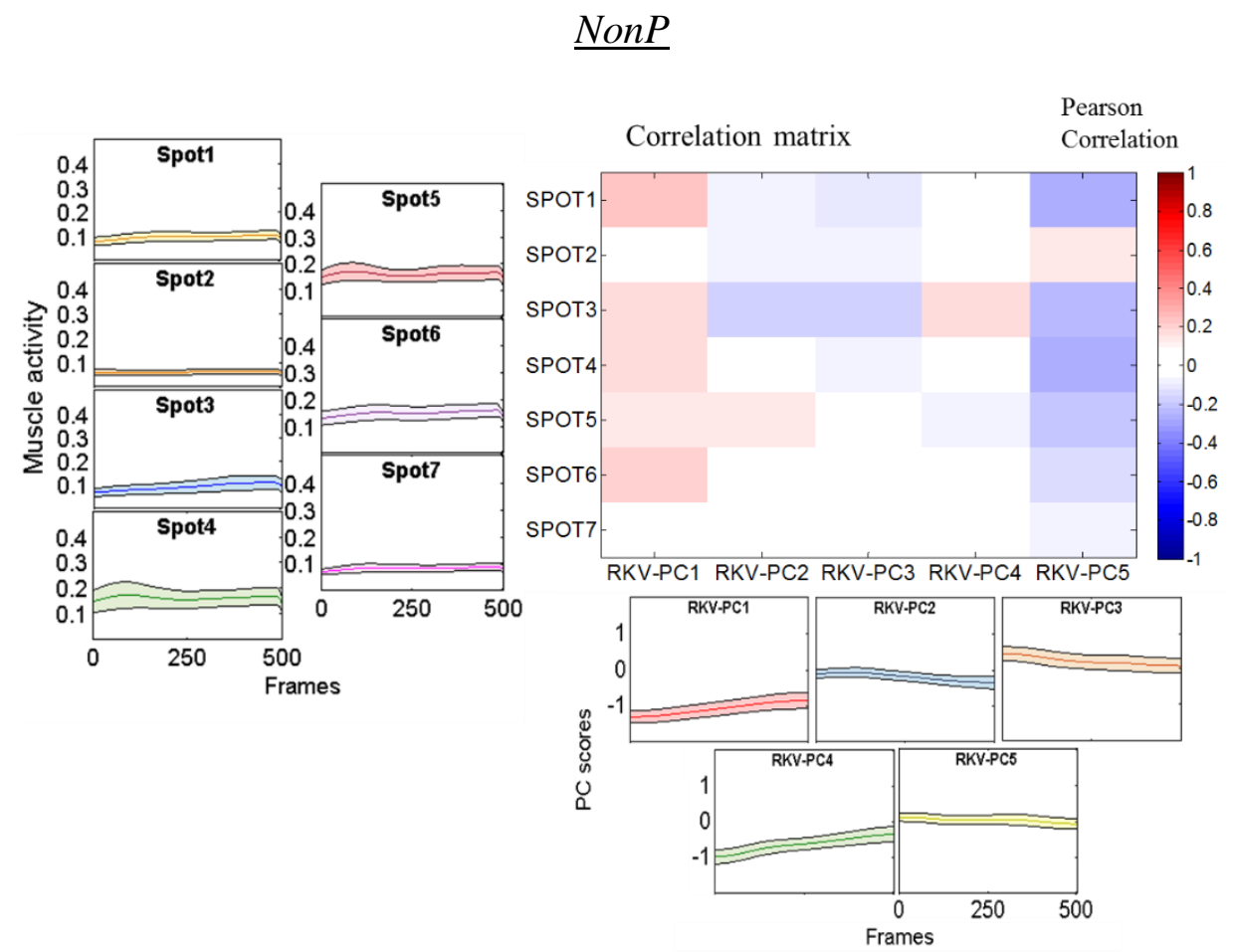

Figure 8.8 Temporal evolution (mean and CI $95 \%$ across subjects) of each of the muscle spots and RKV-PCs, as well as the correlation coefficients between them (considering all the frames of each record) for NonP during reaching.

\section{Manipulation}

Table 3.6 shows some statistics of muscle activity from each muscle spot per ADL across subjects and frames, such as mean and difference between the 95th and 5th percentiles (range). The temporal evolutions of the mean value of muscle activity of each spot per ADL together with their 95\% confidence interval are shown in Appendix III, Figure A.6. During the manipulation, similarly to the reaching phase, spots 1, 4, 5 and 6 are the most activated ones, being spots 4 and 6 the ones with the largest range. Mean values during manipulation are similar to those of reaching. However, a wider range of muscle activity is required during manipulation. 

and muscular activity of the hand during ADL

Table 8.2 Mean $(\mu)$ and difference between $95^{\text {th }}$ percentile and $5^{\text {th }}$ percentile $(r)$ of muscle activity of each spot during each ADL performed

\begin{tabular}{|c|c|c|c|c|c|c|c|c|c|c|c|c|c|c|}
\hline \multirow[b]{3}{*}{ ADL1 } & \multicolumn{2}{|c|}{ SPOT1 } & \multicolumn{2}{|c|}{ SPOT2 } & \multicolumn{2}{|c|}{ SPOT3 } & \multicolumn{2}{|c|}{ SPOT4 } & \multicolumn{2}{|c|}{ SPOT5 } & \multicolumn{2}{|c|}{ SPOT6 } & \multicolumn{2}{|c|}{ SPOT7 } \\
\hline & $\mu$ & $r$ & $\mu$ & $r$ & $\mu$ & $\mathrm{r}$ & $\mu$ & $\mathrm{r}$ & $\mu$ & $r$ & $\mu$ & $\mathrm{r}$ & $\mu$ & $\mathrm{r}$ \\
\hline & 0.09 & 0.13 & & 7 & & & & & & & & & 50 & \\
\hline DL2 & 12 & 16 & 0.07 & 0.07 & 0.04 & 0.04 & 0.10 & 0.14 & 11 & 0.15 & .19 & 0.26 & .10 & 0.10 \\
\hline DL3 & 2 & 16 & 0.08 & 0.12 & 0.11 & 0.23 & & 2 & & 0.26 & 17 & 0.24 & 11 & 14 \\
\hline IDL4 & 20 & .34 & 0.09 & 0.10 & 0.09 & 5 & 0.20 & 0.27 & 23 & 0.30 & 31 & 0.49 & 17 & .23 \\
\hline DL5 & 0.22 & 0.34 & 0.12 & 0.14 & 0.11 & 0.16 & 0.17 & 0.24 & 0.25 & 0.33 & 0.29 & 0.40 & 21 & .27 \\
\hline DL6 & 0.27 & 0.46 & 0.09 & 0. & 0.13 & 0.23 & 0.21 & 0.35 & 0.24 & 0.34 & 0.36 & 0.59 & 0.17 & 0.24 \\
\hline DL7 & 13 & 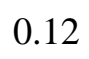 & 0.08 & 7 & 0.06 & 7 & 0.24 & 9 & 0.20 & 0.23 & 0.22 & 0.22 & .12 & 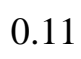 \\
\hline DL8 & 0.13 & 0.17 & 0.07 & 0.12 & 0.06 & 0.08 & 0.14 & 0.24 & 0.13 & 0.19 & 0.21 & 0.30 & 0.12 & 0.17 \\
\hline DL9 & & 7 & 0.08 & 8 & 0.07 & 10 & & 5 & 0.13 & 0.18 & 0.13 & 0.16 & 09 & 13 \\
\hline ADL10 & 0.11 & 0.18 & 0.07 & 0.10 & 0.07 & 0.12 & 0.21 & 0.35 & 0.20 & 0.31 & 0.18 & 0.33 & 0.14 & 0.25 \\
\hline DL11 & 21 & 0.32 & 0.14 & 0.25 & 0.11 & 0.16 & 0.32 & 0.55 & 0.34 & 0.51 & 0.35 & 0.55 & 19 & 0.31 \\
\hline ADL12 & 09 & 0.16 & 0.07 & 0.10 & 0.06 & 0.09 & 0.18 & 0.29 & 0.17 & 0.23 & 0.15 & 0.26 & 0.11 & 0.13 \\
\hline DL13 & 10 & 0.17 & 0.10 & 0.22 & 0.07 & 0.13 & 0.21 & 0.39 & 0.19 & 0.32 & 0.14 & 0.25 & 0.15 & 0.25 \\
\hline ADL14 & & 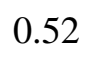 & & & & & & & & & & 0.35 & & \\
\hline ADL15 & .09 & 0.12 & 0.05 & 0.04 & 0.04 & 0.06 & 0.11 & 0.17 & 0.13 & 0.17 & 0.14 & 0.22 & 0.09 & 0.09 \\
\hline DL16 & 13 & 0.13 & 0.06 & 0.07 & 0.09 & 0.11 & 0.22 & 0.25 & 0.19 & 0.20 & 0.20 & 0.21 & .12 & 0.12 \\
\hline ADL17 & 0.09 & 0.12 & 0.05 & 0.07 & 0.06 & 0.10 & 0.14 & 0.25 & 0.15 & 0.21 & 0.15 & 0.21 & 0.11 & 0.15 \\
\hline ADL18 & 0.07 & 0.12 & 0.05 & 0.07 & 0.06 & 0.14 & 0.13 & 0.25 & 0.15 & 0.21 & 0.12 & 0.18 & 0.09 & 0.12 \\
\hline ADL19 & 0.08 & 0.09 & 0.06 & 0.06 & 0.06 & 0.10 & & 0.16 & & 0.19 & 0.17 & 0.16 & 0.09 & 0.07 \\
\hline ADL20 & 0.16 & 0.36 & 0.06 & 0.10 & 0.08 & 0.19 & 0.14 & 0.21 & 0.18 & 0.25 & 0.24 & 0.56 & 0.11 & 0.16 \\
\hline ADL21 & & 0.16 & 0.0 & 0.08 & & 0.08 & & & 0.16 & 0.19 & 0.18 & 0.22 & 0.16 & 0.18 \\
\hline ADL22 & 0.25 & 0.36 & 0.06 & 0.05 & 0.11 & 0.13 & 0.17 & 0.25 & 0.20 & 0.19 & 0.24 & 0.23 & 0.18 & 0.19 \\
\hline ADL23 & 0.14 & 0.16 & 0.06 & 0.11 & 0.08 & 0.09 & 0.15 & 0.18 & 0.21 & 0.24 & 0.21 & 0.24 & 0.17 & 0.22 \\
\hline ADL24 & 0.15 & 0.21 & 0.07 & 0.10 & 0.10 & 0.16 & 0.17 & 0.27 & 0.21 & 0.29 & 0.23 & 0.32 & 0.18 & 0.32 \\
\hline ADL25 & 0.17 & 0.24 & 0.07 & 0.11 & 0.13 & 0.24 & 0.19 & 0.33 & 0.20 & 0.27 & 0.26 & 0.35 & 0.19 & 0.34 \\
\hline ADL26 & 0.12 & 0.16 & 0.07 & 0.08 & 0.15 & 0.20 & 0.18 & 0.24 & 0.11 & 0.14 & 0.15 & 0.25 & 0.08 & 0.08 \\
\hline $\mathrm{ALL}$ & 0.14 & 0.21 & 0.08 & 0.10 & 0.08 & 0.13 & 0.15 & 0.23 & 0.18 & 0.24 & 0.20 & 0.29 & 0.13 & 0.18 \\
\hline
\end{tabular}

Figure 8.9 shows the dendrogram obtained for the cluster analysis with the ADL organised in branches according to their similarity in mean and range values both of the muscle activity of the spots and of the RKVs. Six clusters or groups of ADLs have been identified. The average values of mean and range of each RKV-PC and muscle activity of each spot per group show clear differences between groups identified. These values are represented in four box-plots, two for the mean range values of the muscle activity of each spot (Figure 8.10) and another two for the mean and range values of the RKV-PCs (Figure 8.11), differentiating per each group identified in the dendrogram. 


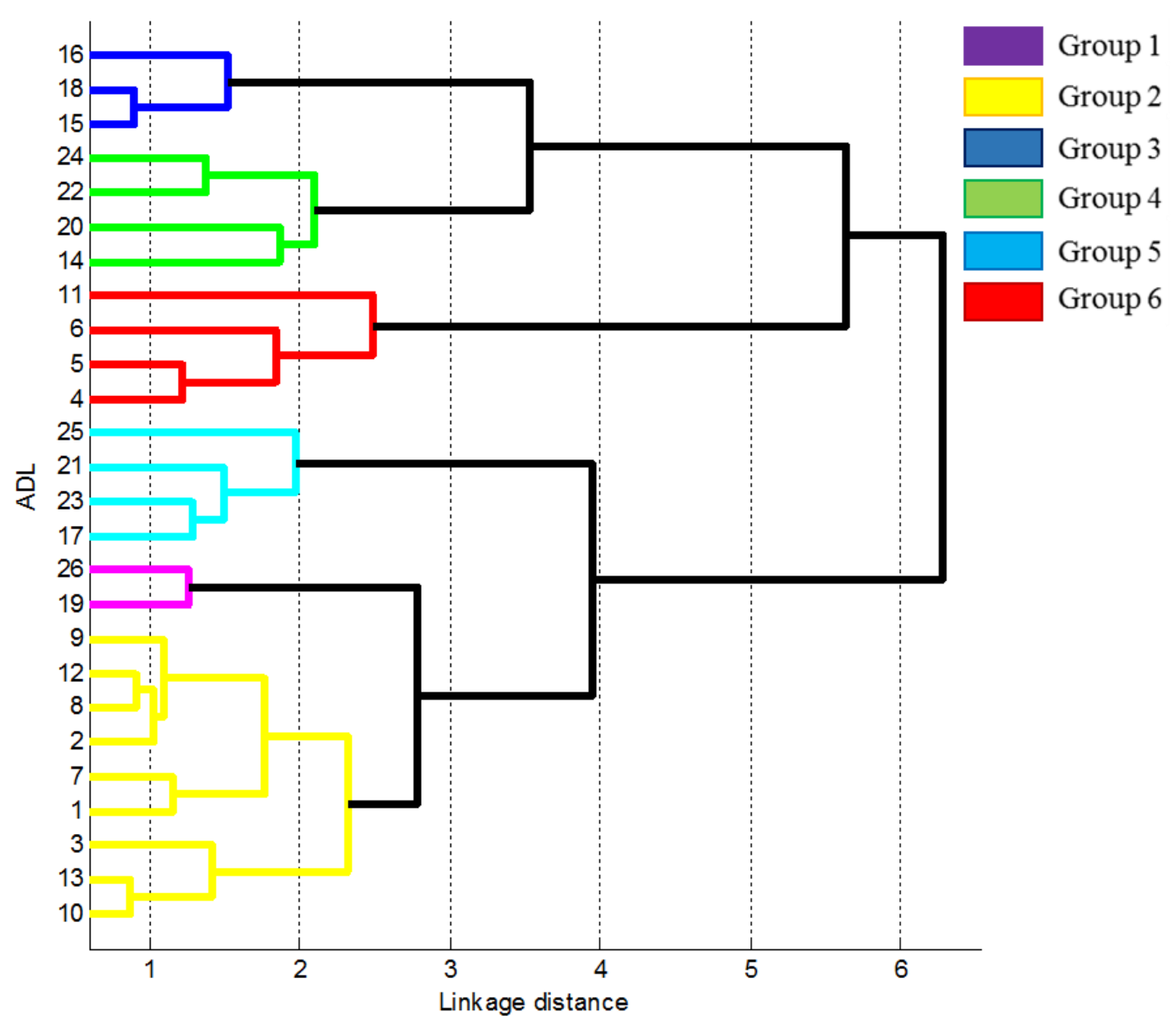

Figure 8.9 Dendrogram classifying ADL according to muscular activity and kinematics (RKVs)

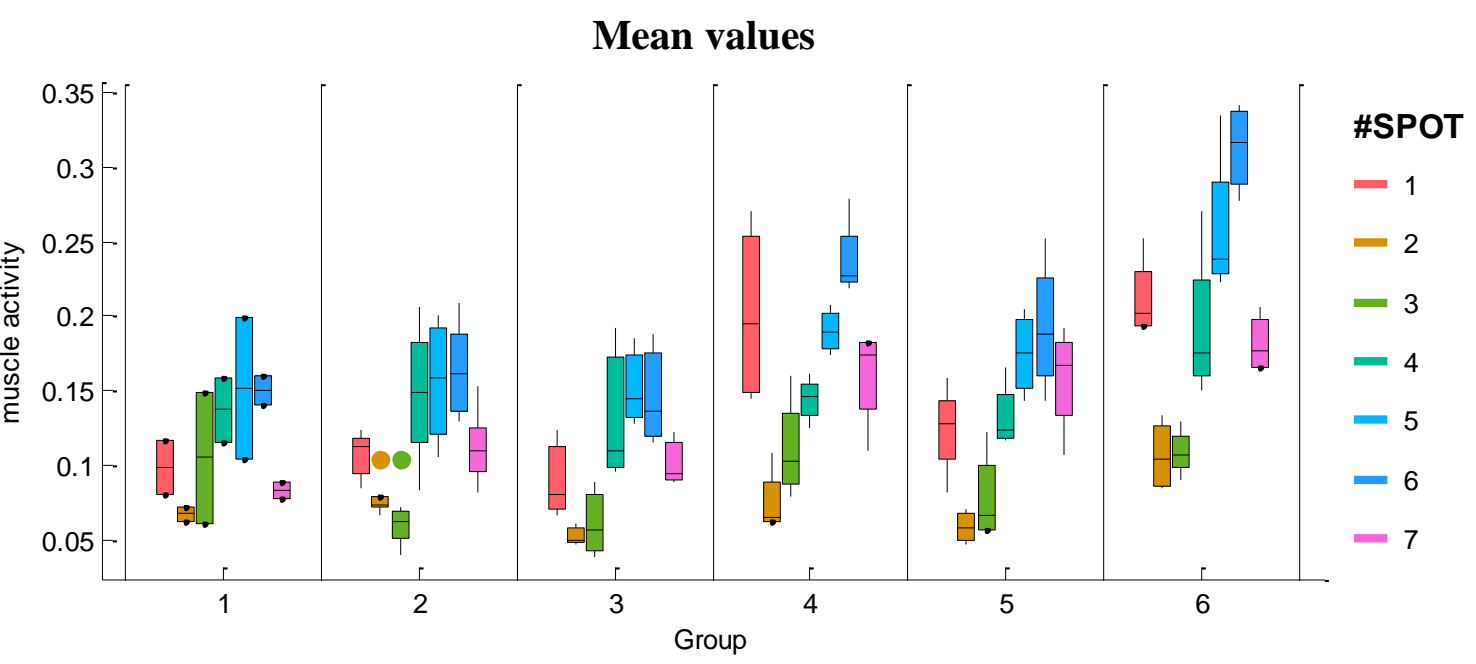

Kinematic and muscular characterisation of the hand during ADL 

and muscular activity of the hand during ADL

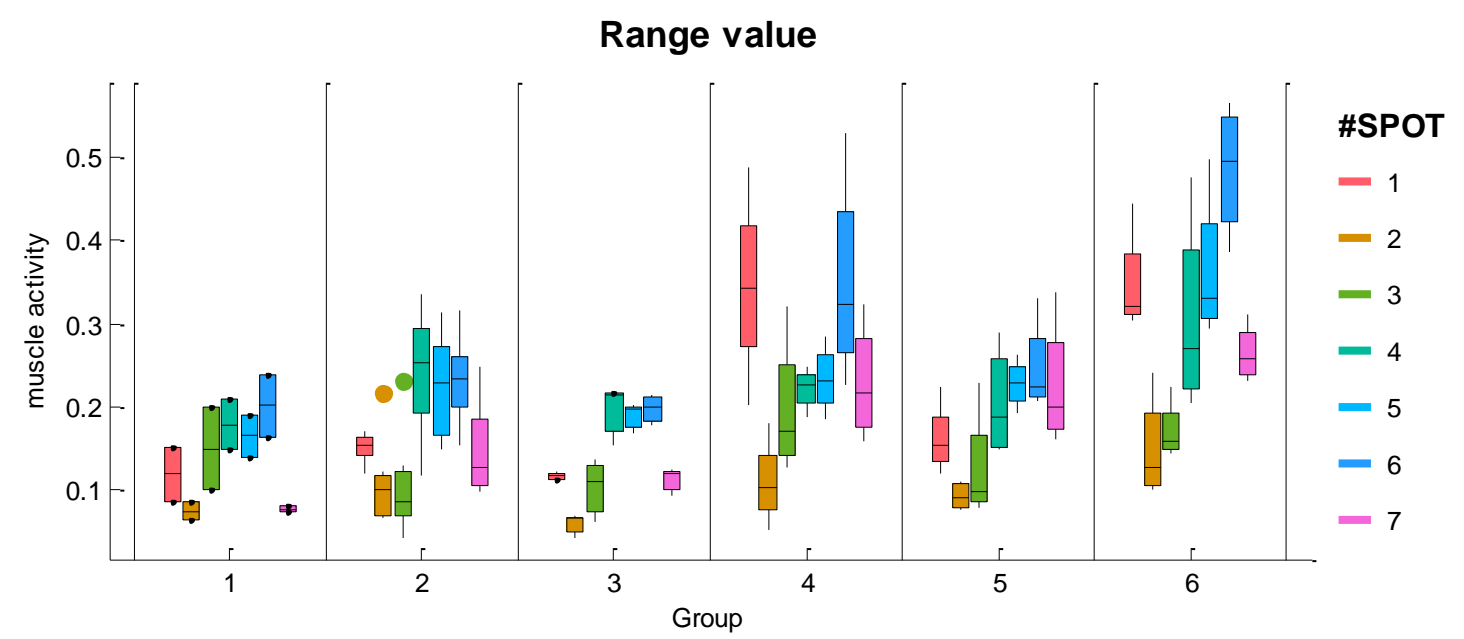

Figure 8.10 Box plots of the statistics shown in Table 8.2 (mean and range values of the muscle activity of each spot, differentiating per each group obtained in the dendrogram. Boxes represent median and percentiles 25 and 75 and whiskers represent values that are within 1.5 times the interquartile range
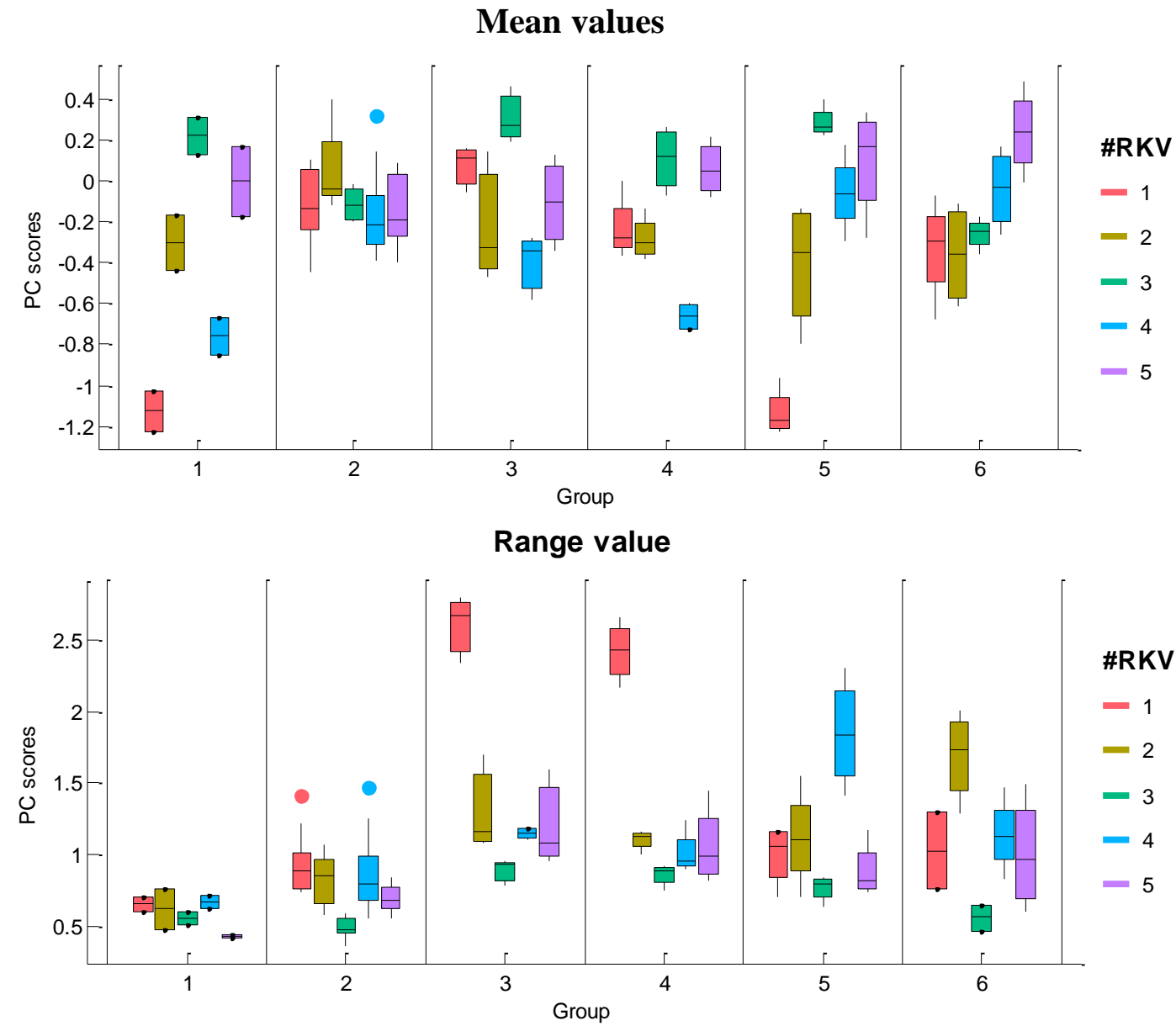

Figure 8.11 Box plots of the statistics shown in Table 3.6 (mean and range values of the RKV$P C s$, differentiating per each group obtained in the dendrogram). Boxes represent median and percentiles 25 and 75 and whiskers represent values that are within 1.5 times the interquartile range

Kinematic and muscular characterisation of the hand during ADL 
Some clear differences are observed between groups. E.g. groups 1, 2 and 3 reach mean small values of muscle activity, corresponding to tasks like \#1 \#15, or \#19 (inserting coin into a purse, eating soup with a spoon or writing with a keypad). On the contrary, groups 4, 5 and 6 reach high mean values of muscle activity, corresponding to tasks like \#5 \#14, or \#22 (e.g. cutting with a knife, lifting and moving an iron or pouring water)

\subsection{Discussion}

In this work, I attempted to link hand kinematics to forearm muscle activity while performing a representative set of ADL, differentiating between reaching and manipulation. Having used the muscle activity recorded in the representative spots extracted in Chapter 5 is equivalent to recording the temporal evolution of the muscle synergies, analogously to the use of RKV-PCs in Chapter 3. This muscular reduction has allowed me a good compromise between simplicity and precision, since it has allowed me to reduce muscle redundancy in the forearm by studying seven representative muscle areas during ADL. Therefore, the use of the temporal evolution of the RKV-PCs and this muscle areas has made it possible to undertake an introductory study of the relationship between both kinematic and muscle synergies.

\section{Reaching}

During the reaching phase, hand movement is determined by the type of grasp to be performed, and muscle activity has to counteract only the inertia efforts and the gravity. Therefore, correlating the temporal evolution of muscle activity and RKV-PCs allowed me identifying the relationship required during reaching to shape the hand accordingly to the intended type of grasp.

Configuring the hand for $C y l$ grasp (Figure 8.1) requires an increase in the muscular activity of the wrist flexors and extensors (spots 1,6 and 7), as well as the flexors and extensors of the fingers (spot 3 and spot 5). Extensors and abductors of the thumb (spot 4) require a great activation although their level is reduced as the hand posture gets closer to the final grasp (i.e. during thumb flexion and adduction). During grasp (results presented in Chapter 6), maximum values of muscle activity were found from wrist flexors and ulnar deviators (spot 1), finger flexors (spot 3) and wrist extensors and radial deviators (spot 7). During the pre-shaping phase, finger extensors (spot 5) and wrist extensors and ulnar deviators (spots 6) also show high activity values, because during this phase they are required to act as antagonistic muscles of wrist and finger flexors in order to control the opening of the hand. This behaviour is also observed in the correlation between spots 1, 3, 6 and 7 and digit arch, thumb opposition and thumb arch, as well as between spot 7 and closeness. 
Configuring the hand for PpPinch grasp (Figure 8.2) requires an increase in the muscle activity of the extensors and abductors of the thumb (spot 4), as well as of the extensors of the wrist and fingers (spots 5, 6 and 7). During grasp (results presented in Chapter 6), maximum values of muscle activity were found from the same spots. Therefore, this type of grasp requires using the same muscles before and during the grasp. In this case, the grasp requirements are also observed in the correlations between spots 4 , 5, 7 and digit arch and thumb opposition, and between spot 4 and thumb arch.

Configuring the hand for Lum grasp (Figure 8.3) requires an increase in muscle activity of most of the spots analysed, but to a greater extent of the thumb extensors and abductors (spot 4), as well as the extensors of fingers (spot 5) and wrist extensor and radial deviator (spot 6). During grasp (results presented in Chapter 6), maximum values of muscle activity were found from wrist extensors and deviators (spots 6 and 7). It seems that the thumb extensors and abductors are more demanded during reach-to-grasp phase, but once the grasp is reached, not great muscle activity is required from them. Conversely, no great activation is required from the flexors of fingers during reach-to-grasp, but they are more demanded during grasp performance. The kinematic requirements to perform this grasp are also observed from the correlation between thumb arch and thumb opposition and spots 1, 3 and 6, as well as between spots 1, 6 and digit arch

Configuring the hand for LatP grasp (Figure 8.4) requires an initial increase of the muscular activity of the wrist flexors and ulnar deviators (spot 1), as well as of the wrist extensors and ulnar deviators (spot 6), as well as a gradual increase of the finger extensors (spot 5). During the grasp (results presented in Chapter 6), maximum values of muscle activity were found from finger extensors (spot 5) and wrist extensors and radial deviators (spot 7). During the pre-shaping phase, wrist flexors and extensors and ulnar deviators are also required, probably to stabilise the wrist during the movement (as antagonistic muscles). The kinematic requirements to perform this grasp are also observed from the correlation between spots 5 and 7 and digit arch and closeness, as well as between spots 4 and 6 and thumb arch.

Configuring the hand for $\mathrm{Obl}$ grasp (Figure 8.5) requires an increase in the muscular activity of the wrist flexors and ulnar deviators (spot 1), as well as wrist extensors and deviators (spot 6 and 7) and fingers extensors (spot 5). It is also evident that activation of the thumb extensors and abductors is necessary. These results agree with those obtained previously in Chapter 6, which showed the greatest values of muscle activity from spots 1, 2, 6 and 7. Finger flexors do not seem to be as necessary during the reach-to-grasp as during the grasp performance, whereas finger extensors are more necessary during reachto-grasp than during grasp performance. The kinematic and muscular requirements to perform this grasp are also observed from the correlation between most of the spots and digit arch, between spot 5 and closeness, as well as between spots 2 and 7 and palmar arch. 
Configuring the hand for IntPP grasp (Figure 8.6) requires an initial increase of the muscular activity of the wrist flexors and ulnar deviators (spot 1), as well as of the wrist extensors and ulnar deviators (spot 6), together with a gradual increase of the finger extensors (spot 5) and of the thumb extensors and abductors (spot4). During the grasp (results presented in Chapter 6), maximum values of muscle activity were found from the wrist flexors and ulnar deviators. However, the finger flexors do not participate during the reach-to-grasp as they do during the grasp performance; i.e. they are not needed during the reach-to-grasp but they are necessary for a firm grasp. Conversely, the thumb muscles seem to be more active during reach-to-grasp than during grasp, where they do not seem to be so important; i.e., they are more involved during the reach-to-grasp but then they are not as important to stabilise the grasp. The wrist and finger extensors are also necessary, both for the necessary extension of the wrist and to maintain the extension of the index finger. The kinematic and muscular requirements to perform this grasp are also observed from the correlation between spots 4, 5 and 7 and digit arch, closeness and thumb opposition.

Configuring the hand for Hook grasp (Figure 8.7) requires an increase in muscle activity of most of the muscle spots, especially the wrist flexors and ulnar deviators (spot 1), thumb extensors and abductors (spot 4) as well as the wrist extensors and ulnar deviators (spot 6) and fingers extensors (spot 5). The kinematic and muscular requirements to perform this grasp are also observed from the correlation between spots 2 and 3 and digit arch; spots 2, 5 and 6 and closeness; spots 1, 4 and 6 and thumb opposition; as well as between spots 1, 5, 6 and 7 and thumb arch.

NonP (Figure 8.8) has practically no muscular activity of any muscle, with very flat slopes and little level of correlation between spots and RKV-PCs. Therefore, NonP requires a minimum muscular activity without any considerable correlation between both muscles and kinematics.

From the correlation matrices and focusing on the prostheses control, different spots could be selected to control the hand kinematic synergies, considering the forearm muscle spot that best matches with the kinematic synergy required for each grasp, thus allowing a more intuitive control of the prosthesis (if any remaining muscle area is available). Table 8.3 summarises the spots suitable to control hand synergies for each grasp. 

and muscular activity of the hand during ADL

Table 8.3. Most suitable spots to be selected for each hand kinematic synergy, depending on each intended grasp

\begin{tabular}{c|ccccc} 
Grasp & Digit arch & Closeness & Palmararch & $\begin{array}{c}\text { Thumb } \\
\text { opposition }\end{array}$ & Thumb arch \\
\hline Cyl & $1,3,6,7$ & 7 & & & \\
PpPinch & $4,5,7$ & & $4,5,7$ & 4 \\
Lum & 1,6 & & $1,3,6$ & $1,3,6$ \\
LatP & 5,7 & 5,7 & & & 4,6 \\
Obl & all & 5 & 2,7 & & \\
IntPP & $4,5,7$ & $4,5,7$ & $4,5,7$ & & $1,5,6,7$ \\
Hook & 2,3 & $2,5,6$ & & $1,4,6$ & \\
\hline
\end{tabular}

Note that the ADLs identified as the same intended grasp may have different configurations (different objects and different hand orientation, and therefore gravity acting differently), and that may affect the results, obtaining inconsistent results. However, in most cases, the results are quite logical, considering the movements of hand and the role of the muscles.

\section{Manipulation}

During the manipulation phase, the muscular activity is not expected to be directly correlated to the joint movement in global terms. Alternatively, in this case I considered that it might be useful identifying groups of activities with similar muscular and kinematics characteristics in order to understand the link between kinematics and muscle activity during this phase in a global way. For such grouping I used parameters of mean values and dispersion (mean and range between the 95th and 5th percentiles) of the RKVPCs and muscle activity of each spot.

From the cluster analysis, six groups of ADL have been identified, with muscle activity and kinematics according to Figures 8.10 and 8.11:

- $\quad$ Group $1 \rightarrow$ ADL \#19 and \#26 (writing with a keypad, or cleaning a table with a cloth) need more muscle activity from fingers and wrist extensors. These activities are mainly characterised by low digit arch and thumb opposition with very low range of motion, and correspond to non-prehensile activities in which no specific grasp is required for their performance.

- Group $2 \rightarrow$ ADLs \#1, \#2, \#3,\#7, \#8,\#9,\#10,\#12, \#13 (inserting coin into a purse, opening and closing a zip, removing the coin from the purse, turning a nut, turning a key, turning a door handle, passing two buttons, tying shoe lice, and putting a bandage) need more muscle activity from fingers and wrist extensors as well as 
from thumb extensors and abductors. These activities are characterised by all the RKV-PCs near to zero with low range of motion, i.e. the hand posture is in a relaxed posture with medium muscle activity of the extensors of the wrist and fingers required for a fine hand dexterity.

- Group $3 \rightarrow$ ADLs \#15, \#16, and \#18 (eating soup with a spoon, writing with a pen, and putting a clip) need more muscle activity from fingers and wrist extensors as well as from thumb extensors and abductors, as the previous group. But in this case they present higher palmar arch values with less thumb opposition and closeness. A large range of motion of digit arch is also observed.

- $\quad$ Group $4 \rightarrow$ ADLs \#14, \#20, \#22 and \#24 (using a knife, picking up the phone, pouring water from jug, and putting toothpaste) need more muscle activity from wrist flexors and radial deviators, and finger and wrist extensors. Ulnar deviations muscles (spots 1 and 6) present large range of variation of muscle activity. These activities are mainly characterised by a low thumb opposition with a large range of motion of the digit arch.

- $\quad$ Group $5 \rightarrow$ ADLs \#17, \#21, \#23 and \#25 (Folding paper and inserting it into an envelope, pouring water from a carton into a jug, pouring water from the cup into the jug, and using a spray) need more muscle activity from fingers and wrist extensors. These activities are mainly characterised by a low digit arch and closeness with a large range of motion of the thumb opposition.

- Group $6 \rightarrow$ ADLs \#4, \#5, \#6, and \#11 (moving cubes, lifting and moving an iron, unscrewing lids) require the high muscle activity from all spots, reporting maximum values for finger and wrist extensors and ulnar deviators. Wrist flexors and ulnar deviators together with finger and wrist extensors present large range variation of muscle activity. It means that the wrist needs to be stabilised to counteract the weight of the objects and own hand (hand palm is facing the table) and/or the force needed during the task. These activities are characterised by high thumb arch and low digit arch, closeness and palmar arch with large motion for closeness.

Considering the muscle activity of each group, in general, a low level of muscle activity is observed during all ADL. This is in accordance with the fact that minimal muscle force is required to perform ADL (Peters et al., 2018). However, some ADL show higher muscle activity values than others. Groups 1, 2 and 3 reach values of only $20 \%$ of muscle activity, thumb extensors and abductors, finger and wrist extensors being the spots with greater activation. These activities correspond to tasks requiring more hand dexterity than force (e.g. writing with a keypad, writing with a pen, or passing two buttons). On the contrary, groups 4, 5 and 6 reach mean values of $35 \%$ of muscle activity, wrist extensor and ulnar deviators being the spots with greater values. These activities correspond to tasks requiring some more force (e.g. cutting with a knife, lifting and moving an iron or pouring water). These results could be used to improve the current control of the 
prostheses, since we may have 6 different kinematics and muscular behaviours to study the way to control the current prostheses during the performance of ADL.

The temporal profiles of kinematics and muscular patterns of the standardised ADLs, shown in Appendixes II and III (Figure A.5 and A.6), can be considered as the normal patterns of muscle activity used by healthy population in order to perform each ADL during manipulation. As an example, Figure 8.12 shows mean and $95 \%$ CI of muscle activity of each spot during ADL \#4 (moving cubes). During this ADL, two peaks in the muscle activity are clearly shown (the first one with greater level of muscle activity), corresponding to the movement of each cube (the first cube was bigger). Wrist extensor/flexors and ulnar deviators (spot 1 and spot 6), as well as finger extensors (spot 5 ) are the most activated ones, reaching values about $50 \%$ of muscle activity for the wrist extensors and ulnar deviators.

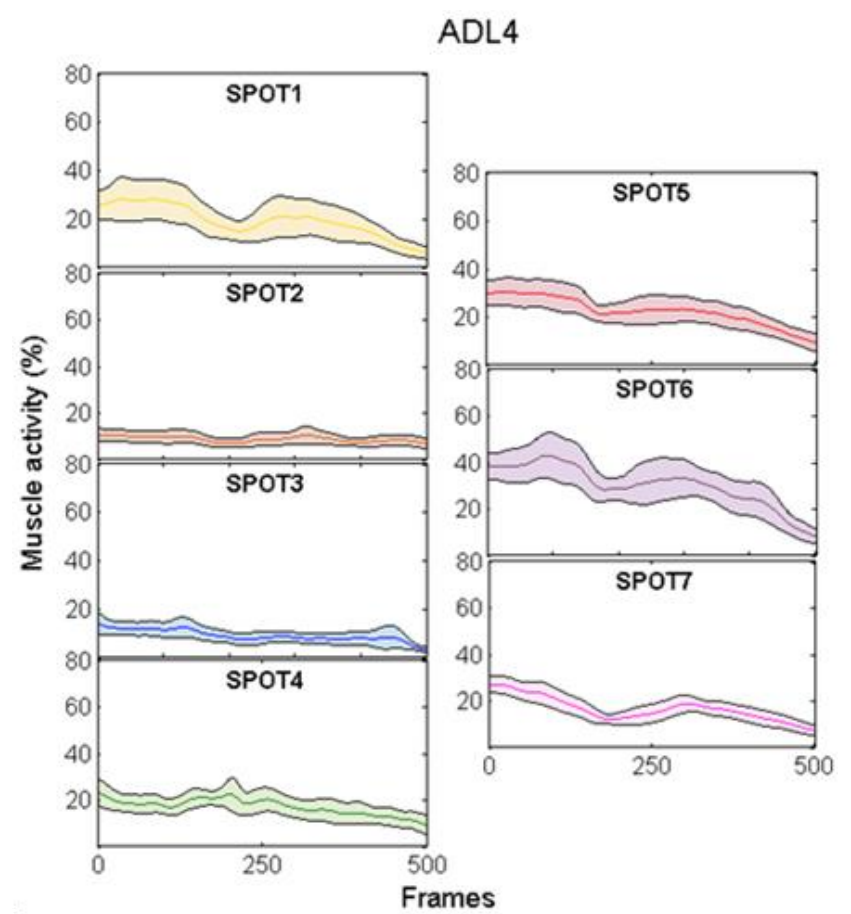

Figure 8.12 Temporal evolution (mean and 95\% CI across subjects) of muscular activity of each of the muscle spots during ADL 4.

\section{Global discussion}

The results have shown that hand motor control in day-to-day life can be characterised with a limited set of kinematic (5 RKV-PCs) and muscular patterns (7 muscle activity spots). During reaching, different correlations are observed between kinematics and muscle activity, depending on the intended grasp. During manipulation, ADL may be clustered into six groups with similar mean and range values for the muscle activity and kinematics.

As seen in Chapter 4 from the literature review, there is a lack of a methodology to make possible the comparison of muscle activity between tasks and subjects. In this 
chapter, I have seen how standardisation of the tasks may allow comparison between subjects and sessions (important for many applications, such as tracking function recovery). Furthermore, the standardisation may help the comparison of muscular patterns and the identification of different strategies, distinguishing between the different phases of the task as proposed by some authors (Hebert et al., 2014). Specifically, the standardisation of the ADL performed here allowed me obtaining muscular patterns for each ADL across subjects, and differentiating and comparing between phases (reaching and manipulation). These patterns could be used as normal patterns in rehabilitation (for tracking function recovery), providing quantitative parameters to evaluate kinematics and muscular activity (e.g. normal ranges of muscle activity for each of the spots studied during the selected ADLs).

Furthermore, the results can help the selection of a small set of representative ADL to be considered to evaluate hand function through the analysis of the kinematics and muscular activity, or to be used to improve current rehabilitation protocols, hand assessment as well as to improve the performance of prosthetics and anthropomorphic hands during ADL. In this sense, from the dendrogram the original 26 ADLs could be reduced to 9 ADLs, selecting one or two ADL per group (depending on the similarity of the tasks within the group). Table 8.4 shows a possible selection of 9 representative ADLs, together with the mean and range values of the RKV-PCs and muscle activation in the spots, which could be used as quantitative parameters to evaluate kinematics and muscular activity.

Table 8.4. ADLs selected as representative from the dendrogram results. Mean and range values across subjects, repetitions and frames for each of the ADL selected are also shown.

\begin{tabular}{|c|c|c|c|c|c|c|c|c|c|c|}
\hline \multicolumn{2}{|c|}{ Group } & 1 & 2 & 2 & 3 & 4 & 4 & 5 & 6 & 6 \\
\hline \multicolumn{2}{|c|}{ ADL \# } & 19 & 3 & 8 & 16 & 14 & 24 & 21 & 4 & 11 \\
\hline \multicolumn{11}{|c|}{ Kinematics } \\
\hline RKV- & mean & -0.39 & -0.47 & 0.47 & 0.6 & 1.17 & 0.58 & -0.24 & -0.33 & 0.24 \\
\hline PC1 & range & 0.91 & 1.86 & 0.66 & 1.38 & 1.04 & 1.61 & 0.48 & 1.24 & 1.69 \\
\hline RKV- & mean & -0.73 & 0.55 & 1.3 & 0.89 & 0.15 & 0.74 & -1.25 & -1.38 & -2.31 \\
\hline PC2 & range & 1.33 & 1.88 & 1.19 & 1.21 & 1.31 & 2.08 & 0.83 & 1.98 & 3.04 \\
\hline RKV- & mean & -0.18 & 0.27 & -0.04 & -0.37 & -0.34 & 0.39 & 0.15 & -0.33 & -0.48 \\
\hline PC3 & range & 0.66 & 1.61 & 0.66 & 1.13 & 1.00 & 1.18 & 0.75 & 0.9 & 1.11 \\
\hline RKV- & mean & -0.39 & 0.02 & 0.06 & 0.72 & 0.05 & 0.25 & 1.67 & 0.61 & 0.91 \\
\hline PC4 & range & 1.03 & 2.62 & 1.32 & 1.71 & 1.47 & 1.72 & 0.73 & 1.31 & 1.78 \\
\hline RKV- & mean & -0.43 & -0.53 & 0.24 & 1.5 & -0.31 & -0.9 & 0.53 & 1.01 & 1.17 \\
\hline PC5 & range & 0.8 & 1.68 & 1.37 & 2.33 & 1.54 & 1.97 & 1.45 & 1.94 & 2.89 \\
\hline \multicolumn{11}{|c|}{ Muscle activity } \\
\hline SPOT & mean & 0.08 & 0.12 & 0.13 & 0.13 & 0.29 & 0.15 & 0.13 & 0.2 & 0.21 \\
\hline 1 & range & 0.09 & 0.16 & 0.17 & 0.13 & 0.52 & 0.21 & 0.16 & 0.34 & 0.32 \\
\hline SPOT & mean & 0.06 & 0.08 & 0.07 & 0.06 & 0.11 & 0.07 & 0.05 & 0.09 & 0.14 \\
\hline 2 & range & 0.06 & 0.12 & 0.12 & 0.07 & 0.18 & 0.1 & 0.08 & 0.1 & 0.25 \\
\hline
\end{tabular}



and muscular activity of the hand during ADL

\begin{tabular}{c|c|c|c|c|c|c|c|c|c|c|}
\hline \multicolumn{2}{c|}{ Group } & 1 & 2 & 2 & 3 & 4 & 4 & 5 & 6 & 6 \\
\hline \multicolumn{2}{c|}{ ADL \# } & 19 & 3 & 8 & 16 & 14 & 24 & 21 & 4 & 11 \\
\hline SPOT & mean & 0.06 & 0.11 & 0.06 & 0.09 & 0.17 & 0.1 & 0.06 & 0.09 & 0.11 \\
3 & range & 0.1 & 0.23 & 0.08 & 0.11 & 0.33 & 0.16 & 0.08 & 0.15 & 0.16 \\
\hline SPOT & mean & 0.13 & 0.17 & 0.14 & 0.22 & 0.19 & 0.17 & 0.13 & 0.2 & 0.32 \\
4 & range & 0.16 & 0.32 & 0.24 & 0.25 & 0.3 & 0.27 & 0.17 & 0.27 & 0.55 \\
\hline SPOT & mean & 0.2 & 0.16 & 0.13 & 0.19 & 0.19 & 0.21 & 0.16 & 0.23 & 0.34 \\
5 & range & 0.19 & 0.26 & 0.19 & 0.2 & 0.22 & 0.29 & 0.19 & 0.3 & 0.51 \\
\hline SPOT & mean & 0.17 & 0.17 & 0.21 & 0.2 & 0.29 & 0.23 & 0.18 & 0.31 & 0.35 \\
6 & range & 0.16 & 0.24 & 0.3 & 0.21 & 0.35 & 0.32 & 0.22 & 0.49 & 0.55 \\
\hline SPOT & mean & 0.09 & 0.11 & 0.12 & 0.12 & 0.17 & 0.18 & 0.16 & 0.17 & 0.19 \\
7 & range & 0.07 & 0.14 & 0.17 & 0.12 & 0.24 & 0.32 & 0.18 & 0.23 & 0.31 \\
\hline
\end{tabular}

\subsection{Conclusion}

Linking hand kinematics and muscular activation while performing complex and various ADL can benefit from reduction methods (presented in Chapter 2 for kinematics, and in Chapter 5 for muscular activation), as the whole hand kinematics and forearm muscle activity during such tasks has been found to be low dimensional, so that it can be efficiently described by only five kinematic synergies and seven forearm muscular spots.

Temporal evolution of the muscle activity of each spot is provided for a wide sample of healthy subjects during reaching per intended grasp and during manipulation per ADL, which may help improving the control of hand prostheses and quantifying the hand function assessment.

ADL standardisation allowed me obtaining muscular patterns for each ADL across subjects, differentiating and comparing between phases (reaching and manipulation). The results have shown that hand motor control in day-to-day life can be characterised with a limited set of kinematic (5 RKV-PCs) and muscular patterns (7 muscle activity spots). During reaching, different correlations are observed between kinematics and muscle activity, depending on the intended grasp. These correlations could be used to improve prostheses control, by selecting the most suitable muscles spots to control each kinematic synergy. During manipulation, ADL may be clustered into six groups with similar mean and range values for the muscle activity and kinematics. Therefore, ADL could be reduced from 26 ADLs to 9 ADLs, considering one or two ADL per group by using mean and range values as quantitative parameters to evaluate kinematics and muscular activity. These patterns could be used as normal patterns in rehabilitation (for tracking function recovery) as well as to consider quantitative parameters to evaluate kinematics and muscular activity (e.g. normal ranges of muscle activity for each of the spots studied during the selected ADLs). 

Conclusions 

The conclusions of this Thesis are aligned with the objectives that motivated the investigation, and collect different results generated throughout the work process. The conclusions have also served to reveal and recognise the limitations of the work carried out, and therefore to propose future lines of research.

This thesis was proposed with the main objective of characterizing the kinematics and muscle activity of the hand during functional activities. For this purpose, some studies focused on contributing to the hand kinematics characterisation and others to forearm muscles characterisation, including the study of the linking between kinematics and muscle activity. Consequently, the conclusions are presented hereunder in two groups: those related to contributions to the kinematic characterisation of the hand and those related to contributions to the knowledge of the role of forearm and hand muscles for developing ADL. These conclusions refer, first, to the methodology developed and employed to respond to the objectives proposed, and secondly, to the aims of the Thesis. These conclusions constitute the closing of a research stage, but some of the conclusions obtained lead to new lines of research. Therefore, this last section includes future lines of research.

\section{A-Contributions to the kinematic characterisation of the hand}

\section{Contributions on improving hand biomechanical models}

In Chapter 1 I presented a robust method to obtain the orientation and position of the axes of rotation. The method was implemented and used for the in vivo location of the rotation axes in joints with 1 and $2 \mathrm{DoF}$, by using reflective markers on the skin. The proposed method allowed me to conclude that:

A.1. The kinematics of the MCP joint can be described accurately with a model consisting of two non-orthogonal and non-intersecting rotation axes.

Other kinematic joint models for the MCP could also be analysed by using the same method, to be compared to the commonly used universal joint: e.g., tilting the ab/ad hinge from that of the universal joint (Brand and Hollister, 1999), or adding a third supination-pronation hinge (Berme et al., 1977). These models should be taken into account when implementing biomechanical models.

$\checkmark \quad$ A.2. Considering the IP rotation axes parallel to the F/E creases is not a good assumption to improve current biomechanical models.

$\checkmark \quad$ A.3. The centers of the rotation axes of the IP joints are approximately on the saggital plane, at approximately null longitudinal distance from the markers attached on the joint centers and at a depth from dorsal surface than can be obtained from the thickness of the joints. 
$\checkmark \quad$ A.4. Anatomical variability between subjects has been observed in the inclination of the IP rotation axes, which seems that can be addressed using a finite number of biomechanical type models.

However, more accurate techniques are needed for obtaining reliable data for the improvement of the existing biomechanical models, since the inclination angles are of the same order of magnitude as the errors.

\section{Contributions on hand kinematics}

PCA method (presented in Chapter 2) allowed the dimensionality of the dataset to be reduced to a small number of kinematic patterns underlying a large variety of representative and standardised ADL. Key features of this PCA method when compared to other studies were: PCA normalisation allowed joints with different range of motion to be compared at the same level. Varimax rotation allowed obtaining more sparse synergies, according to most recent findings (Prevete et al., 2018).

The proposed PCA method was used, first on static postures (Chapter 2), and then using temporal data (Chapter 3). This method allowed me to conclude that:

A.5. The whole hand kinematics is actually low dimensional and can be efficiently described by a small number of reduced variables (5 synergies).

$\checkmark \quad$ A.6. The same first two synergies are found in both chapters (digit arch, closeness), and in addition they are also similar to those ones found in the literature (Santello et al., 1998). All these facts suggest that these coordinated movements (digit arch and closeness) are always required in hand kinematics, independently of the activity performed.

A.7. The third synergy obtained in both studies (palmar arch) included the flexion of the palmar arch, although with significant differences. During power and cylindrical grasps, palmar arch is coordinated with thumb CMC Ab/Ad, whereas

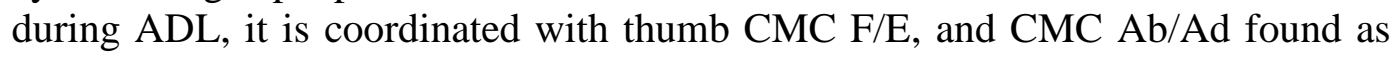
independent synergy.

Palmar arch is not usually recorded because it has a small range of motion, so that it is rarely discussed in literature. It has been reported though in a recent study (Jarque-Bou et al., 2019) as the second synergy that explained more variance, since the authors used the same PCA normalisation performed here. In the grasp postures measured, the opposition of the thumb required was the same, only accommodated in function of a bigger or smaller diameter. In ADL, I have more varied activities, which require greater variability in the opposition of the thumb. That is why the $\mathrm{CMC} \mathrm{Ab} / \mathrm{Ad}$ in $\mathrm{ADL}$ is found independent in a synergy, not coordinated with anyone else.

A.8. Higher-order synergies could improve or refine the control of the hand, and therefore, are more task-dependent. In addition, these higher-order synergies usually involve the thumb movement, suggesting different thumb strategies between tasks and/or subjects. 
Therefore, the use of the temporal evolution of the synergies for characterizing hand kinematics provides a good compromise between simplicity of movement representation and accuracy. The study of the temporal evolution of the synergies allowed me to conclude that:

A.9. Reaching requires modulation of the closeness, digit arch and thumb opposition synergies, with different control patterns per grasp, while thumb arch and palmar arch are kept almost unchanged.

$\checkmark \quad$ A.10. During manipulation, all synergies need to be modulated during all tasks. In addition, kinematic reduction allows grouping the ADL according to similar kinematic requirements, which may benefit the selection of representative tasks for rehabilitation and for hand function assessment.

$\checkmark \quad$ A.11. Furthermore, the temporal evolution of the synergies is provided for a wide sample of healthy subjects during reaching per intended grasp and during manipulation per ADL, which may help improving the control of hand prostheses and quantifying the hand function assessment.

\section{B-Contributions in the knowledge of the role of forearm and hand muscles for developing ADL}

\section{Contributions on forearm muscular characterisation}

I reviewed the state of art about electromyography characterisation of the hand during ADL (Chapter 4): a basis of knowledge about the hand/forearm muscles role and muscle synergy extraction of the upper limb is provided. However, methodological inconsistencies are identified and addressed in the next chapters.

To address one of the gaps, a novel FPCA and clustering method (Chapter 5) is developed to identify forearm areas with similar muscle profiles during ADL. The proposed method allows me to conclude that:

B.1. The muscle activity recorded in the representative forearm areas is similar or equivalent to recording the temporal evolution of forearm muscle synergies during ADL.

$\checkmark \quad$ B.2. The number of sEMG sensors could be reduced from 30 to 7 and use them as representative spots of the muscular activity of the whole forearm in ADL.

B.3. The signals from these seven spots would be related to seven different movements:

- Spot group 1: wrist flexion and ulnar deviation.

- Spot group 2: wrist flexion and radial deviation.

- Spot group 3: finger flexion.

- Spot group 4: thumb extension and abduction/adduction. 
- Spot group 5: finger extension.

- Spot group 6: wrist extension and ulnar deviation.

- Spot group 7: wrist extension and radial deviation.

This result may help to assess muscle function in rehabilitation as well as to simplify the complexity of prostheses control.

In Chapter 6, I analysed the contribution of the 7 forearm spots (one spot for each aforementioned group) and 8 extrinsic muscles during the performance of some types of grasps representative of ADL. Thanks to this, I reinforced the hypothesis about which muscles are being recorded by each of the spots previously defined in Chapter 5 .

B.4. These results allowed me deepening about the role of some of these muscles/spots during the grasp performance:

- Spot 1 presents the maximum activity during the intermediate powerprecision grasp.

- Spot 2 is the spot area with less muscle activity $(<10 \%)$ throughout all the grasps, with the highest value for the cylindrical grasp.

- Spot 3 presents the maximum activity values in cylindrical, oblique palmar and intermediate power-precision grasp.

- Spot 4 presents maximum activity values in two-finger pad-to-pad pinch, cylindrical and lateral pinch.

- Spot 5 presents the maximum activity in three-finger pad-to-pad pinch.

- Spot 6 presents the maximum activity in three-finger pad-to-pad pinch, cylindrical and oblique palmar grasp.

- Finally, Spot 7 presents the maximum effort during cylindrical, and oblique palmar grasps, with muscular activation similar to spot1.

The results obtained can help, among other purposes, to choose the most appropriate muscle or spot area for placing the surface electrodes (robotic devices or prosthetics). And also to plan the necessary exercises for increasing the muscular capacity of those muscles/spots that contribute most to the selected grasp, either through specific exercises, or through electro-stimulation.

\section{Contributions on linking hand kinematics and forearm muscle activity}

In Chapter 7 I presented the KIN-MUS UJI Dataset, containing a total of 572 recordings with synchronised anatomical angles and forearm muscle activity from 22 subjects while performing 26 representative ADL. This dataset is, to our knowledge, the biggest currently available hand kinematics and muscle activity dataset focused on goaloriented actions. The data were recorded using a CyberGlove instrumented glove and surface EMG electrodes, properly synchronised. Eighteen hand anatomical angles were obtained from the glove sensors using a validated calibration procedure. Surface EMG activity was recorded from 7 representative forearm areas (see Chapter 5). Descriptive analyses verified that the data are not affected by experimental procedures and that they 
are similar to data acquired under real-life conditions. From these descriptive analyses I observed that:

B.5. In general, low level of muscle activity are observed during all ADL. This fact is in accordance with the fact that minimal muscle force is required to perform ADL (Peters et al., 2018).

B.6. Muscle activity is very variable among subjects performing the same task, since some factors can affect muscle activity, such as different anatomical characteristics of the subjects, and/or the possibility of performing the same hand kinematics with different levels of effort according to the subject's previous experience (Marneweck et al., 2015).

Finally, with all the results and knowledge gained throughout the thesis, a preliminary study has been made to try to relate the kinematics with muscle activity. From the results, I observed that:

B.7. Hand motor control in day-to-day life can be characterised with a limited set of kinematic and muscular patterns.

B.8. During reaching, different correlations are observed between kinematics and muscle activity, depending on the intended grasp.

$\checkmark \quad$ B.9. During manipulation, ADL can be clustered in six groups with similar mean and range values for the muscle activity and kinematics. Therefore, the 26 ADLs could be reduced to 9 ADLs, considering one or two ADL per group, as the representative tasks to evaluate kinematics and muscular activity.

B.10. Standardisation of the ADL performed here allowed me obtaining muscular patterns across subjects, being able to discern and compare between phases (reaching and manipulation). These patterns could be used as normal patterns in rehabilitation (for tracking function recovery) as well as to consider quantitative parameters to evaluate kinematics and muscular activity (e.g. normal ranges of muscle activity for each of the spots studied during the selected ADLs).

\section{Further studies}

Given the promising results presented, further research will be undertaken in order to widen the extent of the studies. The main and more imminent research work to be undertaken is presented here, thanks to a Spanish project recently accepted from Ministry of Science, Innovation and Universities (PGC2018-095606-B-C21):

- Improvement of existing hand biomechanical models through the consideration of the kinematic and muscular synergies; using more accurate techniques for obtaining the position of the bone segments connected in each joint, as MRI; and considering more complex kinematic joint models for the MCP joints. 
- Deepening in the relationship between hand kinematics and muscle activity by means of developing methods to obtain motor synergies (kinematic and muscular synergies altogether) in order to simplify the problem complexity.

- Proposing quantitative metrics of the kinematics and muscular activity of the upper limb, with special emphasis in quantifying the patterns of muscle contraction and kinematic coordination through the identification of synergies, and studying correlations between them in order to know how the muscular action is modulated during the performance of ADL.

- Elaborating guidelines for using kinematic and dynamic parameters in the objective analysis of loss of hand function for carrying out ADL, as a basis of knowledge in order to improve current assessment tools. 
References 

Alizadehkhaiyat, O., Frostick, S.P., 2015. Electromyographic assessment of forearm muscle function in tennis players with and without Lateral Epicondylitis. J. Electromyogr. Kinesiol. 25, 876-886. https://doi.org/10.1016/j.jelekin.2015.10.013

Almeida, P.H.T.Q. de, Cruz, D.M.C. da, Magna, L.A., Ferrigno, I.S.V., 2013. An electromyographic analysis of two handwriting grasp patterns. J. Electromyogr. Kinesiol. 23, 838-843. https://doi.org/10.1016/j.jelekin.2013.04.004

Almquist, E.E., 1992. Evolution of the distal radioulnar joint. Clin. Orthop. Relat. Res. 5-13.

An, K.N., Ueba, Y., Chao, E.Y., COONEY, W.P., Linscheid, R.L., 1983. Tendon excursion and moment arm of index finger muscles. J. Biomech. 16, 419-425.

Arbib, A., M., 1985. Coordinated control programs for movements of the hand. Hand Funct. Neocortex 111-129.

Atzori, M., Gijsberts, A., Castellini, C., Caputo, B., Hager, A.G.M., Elsig, S., Giatsidis, G., Bassetto, F., Müller, H., 2014. Electromyography data for non-invasive naturally-controlled robotic hand prostheses. Sci. Data 1. https://doi.org/10.1038/sdata.2014.53

Atzori, M., Muller, H., Baechler, M., 2013. Recognition of hand movements in a trans-radial amputated subject by sEMG, in: 2013 IEEE 13th International Conference on Rehabilitation Robotics (ICORR). IEEE, pp. 1-5. https://doi.org/10.1109/ICORR.2013.6650486

Bae, S.C., 2011. Investigation of Hand Posture During Reach and Grasp for Ergonomic Applications. University of Michigan.

Baker, N.A., Cham, R., Cidboy, E.H., Cook, J., Redfern, M.S., 2007a. Kinematics of the fingers and hands during computer keyboard use. Clin. Biomech. 22, 34-43.

Baker, N.A., Cham, R., Hale, E., Cook, J., Redfern, M.S., 2007b. Digit kinematics during typing with standard and ergonomic keyboard configurations. Int. J. Ind. Ergon. 37, 345-355.

Baldacchino, T., Jacobs, W.R., Anderson, S.R., Worden, K., Rowson, J., 2018. Simultaneous Force Regression and Movement Classification of Fingers via Surface EMG within a Unified Bayesian Framework. Front. Bioeng. Biotechnol. 6, 13. https://doi.org/10.3389/fbioe.2018.00013

Barmpakos, D., Strimpakos, N., Karkanis, S.A., Pattichis, C., 2016. Towards a Versatile Surface Electromyography Classification System. Springer, Cham, pp. 33-36. https://doi.org/10.1007/978-3-319-32703-7_7

Barreca, S., (Kelly) Gowland, C., Stratford, P., Huijbregts, M., Griffiths, J., Torresin, W., Dunkley, M., Miller, P., Masters, L., 2004. Development of the Chedoke Arm and Hand Activity Inventory: Theoretical Constructs, Item Generation, and Selection. Top. Stroke Rehabil. 11, 31-42. https://doi.org/10.1310/JU8P-UVK6-68VW-CF3W

Basmajian, J., Luca, C. De, 1985. Muscles alive: their functions revealed by electromyography.

Berme, N., Paul, J.P., Purves, W.K., 1977. A biomechanical analysis of the metacarpo-phalangeal joint. J. Biomech. 10, 409-412. https://doi.org/10.1016/0021-9290(77)90017-3

Bernshteĭn, N.A., 1967. The co-ordination and regulation of movements. Pergamon Press, Oxford.

Bianchi, M., Salaris, P., Bicchi, A., 2013. Synergy-based hand pose sensing: Reconstruction enhancement. Int. J. Rob. Res. 32, 396-406. https://doi.org/10.1177/0278364912474078

Birdwell, J.A., Hargrove, L.J., Kuiken, T.A., Weir, R.F. ff, 2013. Activation of individual extrinsic thumb muscles and compartments of extrinsic finger muscles. J. Neurophysiol. 110, 1385-1392. https://doi.org/10.1152/jn.00748.2012

Bonnefoy, A., Louis, N., Gorce, P., 2009. Muscle activation during a reach-to-grasp movement 
in sitting position: Influence of the distance. J. Electromyogr. Kinesiol. 19, 269-275. https://doi.org/10.1016/j.jelekin.2008.04.010

Braido, P., Zhang, X., 2004. Quantitative analysis of finger motion coordination in hand manipulative and gestic acts. Hum. Mov. Sci. 22, 661-678. https://doi.org/10.1016/j.humov.2003.10.001

Brand, P.W., Hollister, A.M., 1999. Clinical Mechanics of the Hand, 3rd Editio. ed. Mosby Publishing, St. Louis.

Bremer, A.K., Sennwald, G.R., Favre, P., Jacob, H.A.C., 2006. Moment arms of forearm rotators. Clin. Biomech. 21, 683-691. https://doi.org/10.1016/j.clinbiomech.2006.03.002

Brogardh, C., Persson, A.L., Sjolund, B.H., 2007. Intra- and inter-rater reliability of the Sollerman hand function test in patients with chronic stroke. Disabil. Rehabil.

Brorsson, S., Nilsdotter, A., Thorstensson, C., Bremander, A., 2014. Differences in muscle activity during hand-dexterity tasks between women with arthritis and a healthy reference group. BMC Musculoskelet. Disord. 15, 154. https://doi.org/10.1186/1471-2474-15-154

Buffi, J., Sancho-Bru, J.L., Crisco, J.J., Murray, W.M., 2014. Evaluation of Hand Motion Capture Protocol Using Static Computed Tomography Images: Application to an Instrumented Glove. J. Biomech. Eng. 136, 124501. https://doi.org/10.1115/1.4028521

Buffi, J.H., Crisco, J.J., Murray, W.M., 2013. A method for defining carpometacarpal joint kinematics from three-dimensional rotations of the metacarpal bones captured in vivo using computed tomography. J. Biomech. 46, 2104-8. https://doi.org/10.1016/j.jbiomech.2013.05.019

Bullock, I.M., Zheng, J.Z., Rosa, S.D. La, Guertler, C., Dollar, A.M., 2013. Grasp Frequency and Usage in Daily Household and Machine Shop Tasks. IEEE Trans. Haptics 6, 296-308. https://doi.org/10.1109/TOH.2013.6

Burkhart, T.A., Andrews, D.M., 2013. Kinematics, kinetics and muscle activation patterns of the upper extremity during simulated forward falls. J. Electromyogr. Kinesiol. 23, 688-695. https://doi.org/10.1016/j.jelekin.2013.01.015

Casolo, F., Lorenzi, V., 1994. Finger mathematical modelling and rehabilitation BT - (null), in: Schuind, F. (Ed.), Advances in the Biomechanics of the Hand and Wrist,. Plenum Press, pp. 197-223.

Castellini, C., Fiorilla, A.E., Sandini, G., 2009. Multi-subject / daily-life activity EMG-based control of mechanical hands. J. Neuroeng. Rehabil. 6, 41. https://doi.org/10.1186/17430003-6-41

Castellini, C., Van Der Smagt, P., 2013. Evidence of muscle synergies during human grasping. Biol. Cybern. 107, 233-245. https://doi.org/10.1007/s00422-013-0548-4

Castellini, C., Van Der Smagt, P., 2009. Surface EMG in advanced hand prosthetics. Biol. Cybern. 100, 35-47. https://doi.org/10.1007/s00422-008-0278-1

Castiello, U., 2005. The neuroscience of grasping. Nat. Rev. Neurosci. 6, 726-736. https://doi.org/10.1038/nrn1744

Cerveri, P., De Momi, E., Lopomo, N., Baud-Bovy, G., Barros, R.M.L., Ferrigno, G., 2007. Finger kinematic modeling and real-time hand motion estimation. Ann. Biomed. Eng. 35, 1989-2002.

Cerveri, P., De Momi, E., Marchente, M., Baud-Bovy, G., Scifoc, P., Barros, R.M.L., Ferrigno, G., Scifo, P., 2010. Method for the estimation of a double hinge kinematic model for the trapeziometacarpal joint using MR imaging. Comput. Methods Biomech. Biomed. Engin. 13, 387-396. https://doi.org/10.1080/10255840903260818 
Cerveri, P., De Momi, E., Marchente, M., Lopomo, N., Baud-Bovy, G., Barros, R.M.L., Ferrigno, G., 2008. In vivo validation of a realistic kinematic model for the trapezio-metacarpal joint using an optoelectronic system. Ann. Biomed. Eng. 36, 1268-1280. https://doi.org/10.1007/s10439-008-9499-7

Cerveri, P., Pedotti, A., Borghese, N.A., 2001. Combined evolution strategies for dynamic calibration of video-based measurement systems. IEEE Trans. Evol. Comput. 5, 271-282. https://doi.org/10.1109/4235.930315

Chae, J., Yang, G., Park, B.K., Labatia, I., 2002. Muscle Weakness and Cocontraction in Upper Limb Hemiparesis: Relationship to Motor Impairment and Physical Disability. Neurorehabil. Neural Repair 16, 241-248. https://doi.org/10.1177/154596830201600303

Chao, E.Y., Opgrande, J.D., Axmear, F.E., 1976. Three dimensional force analysis of finger joints in selected isometric hand functions. J. Biomech. 9, 387.

Cheung, V.C.K., Turolla, A., Agostini, M., Silvoni, S., Bennis, C., Kasi, P., Paganoni, S., Bonato, P., Bizzi, E., 2012. Muscle synergy patterns as physiological markers of motor cortical damage. Proc. Natl. Acad. Sci. 109, 14652-14656. https://doi.org/10.1073/pnas.1212056109

Chiu, H.Y., Lin, S.C., Su, F.C., Wang, S.T., Hsu, H.Y., 2000. The Use of the Motion Analysis System for Evaluation of Loss of Movement in the Finger. J. Hand Surg. (British Eur. Vol. 25, 195-199.

Chow, J.W., Carlton, L.G., Lim, Y.T., Shim, J.H., Chae, W.S., Kuenster, A.F., 1999. Muscle activation during the tennis volley. Med. Sci. Sports Exerc. 31, 846-54.

Chowdhury, R.H., Reaz, M.B.I., Ali, M.A.B.M., Bakar, A.A.A., Chellappan, K., Chang, T.G., 2013. Surface Electromyography Signal Processing and Classification Techniques. Sensors 13, 12431-12466. https://doi.org/10.3390/s130912431

Cifrek, M., Medved, V., Tonković, S., Ostojić, S., 2009. Surface EMG based muscle fatigue evaluation in biomechanics, Clin. Biomech. 24, 327-340. https://doi.org/10.1016/j.clinbiomech.2009.01.010

Cipriani, C., Zaccone, F., Micera, S., Carrozza, M.C., 2008. On the shared control of an EMGcontrolled prosthetic hand: Analysis of user-prosthesis interaction. IEEE Trans. Robot. 24, 170-184. https://doi.org/10.1109/TRO.2007.910708

Cobos, S., Ferre, M., Sanchez Uran, M.A., Ortego, J., Pena, C., 2008. Efficient human hand kinematics for manipulation tasks, in: IEEE/RSJ International Conference on Intelligent Robots and Systems, 2008. IROS 2008. pp. 2246-2251. https://doi.org/10.1109/IROS.2008.4651053

Cooney, W.P., An, K.-N., Daube, J.R., Askew, L.J., 1985. Electromyographic analysis of the thumb: A study of isometric forces in pinch and grasp. J. Hand Surg. Am. 10, 202-210. https://doi.org/10.1016/S0363-5023(85)80106-4

Coscia, M., Cheung, V.C., Tropea, P., Koenig, A., Monaco, V., Bennis, C., Micera, S., Bonato, P., 2014. The effect of arm weight support on upper limb muscle synergies during reaching movements. J. Neuroeng. Rehabil. 11, 22. https://doi.org/10.1186/1743-0003-11-22

Coupier, J., Hamoudi, S., Telese-Izzi, S., Feipel, V., Rooze, M., Van, S., Jan, S., 2016. A novel method for in-vivo evaluation of finger kinematics including definition of healthy motion patterns. https://doi.org/10.1016/j.clinbiomech.2015.10.002

Cuijpers, R.H., Smeets, J.B.J., Brenner, E., 2004. On the relation between object shape and grasping kinematics. J. Neurophysiol. 91, 2598-606. https://doi.org/10.1152/jn.00644.2003

Cutkosky, M.R., 1989. On grasp choice, grasp models, and the design of hands for manufacturing 
tasks. IEEE Trans. Robot. Autom. 5, 269-279.

D’Andola, M., Cesqui, B., Portone, A., Fernandez, L., Lacquaniti, F., d'Avella, A., 2013. Spatiotemporal characteristics of muscle patterns for ball catching. Front. Comput. Neurosci. 7, 107. https://doi.org/10.3389/fncom.2013.00107

D’Avella, A., Fernandez, L., Portone, A., Lacquaniti, F., 2008. Modulation of phasic and tonic muscle synergies with reaching direction and speed. J. Neurophysiol. 100, 1433-1454. https://doi.org/10.1152/jn.01377.2007

d'Avella, A., Lacquaniti, F., 2013. Control of reaching movements by muscle synergy combinations. Front. Comput. Neurosci. 7, 42. https://doi.org/10.3389/fncom.2013.00042

d'Avella, A., Saltiel, P., Bizzi, E., 2003. Combinations of muscle synergies in the construction of a natural motor behavior. Nat. Neurosci. 6, 300-308. https://doi.org/10.1038/nn1010

Daffertshofer, A., Lamoth, C.J.C., Meijer, O.G., Beek, P.J., 2004. PCA in studying coordination and variability: a tutorial. Clin. Biomech. (Bristol, Avon) 19, 415-28.

Daley, H., Englehart, K., Hargrove, L., Kuruganti, U., 2012. High density electromyography data of normally limbed and transradial amputee subjects for multifunction prosthetic control. J. Electromyogr. Kinesiol. 22, 478-484. https://doi.org/10.1016/j.jelekin.2011.12.012

Danion, F., Galléa, C., 2004. The relation between force magnitude, force steadiness, and muscle co-contraction in the thumb during precision grip. Neurosci. Lett. 368, 176-180. https://doi.org/10.1016/j.neulet.2004.07.006

Dauncey, T., Singh, H.P., Dias, J.J., 2017. Electrogoniometer measurement and directional analysis of wrist angles and movements during the Sollerman hand function test. J. Hand Ther. 30, 328-336. https://doi.org/10.1016/J.JHT.2016.06.011

David, G.C., 2005. Ergonomic methods for assessing exposure to risk factors for work-related musculoskeletal disorders. Occup. Med. (Lond). 55, 190-9.

Di Domizio, J., Keir, P.J., 2010. Forearm posture and grip effects during push and pull tasks. Ergonomics 53, 336-43. https://doi.org/10.1080/00140130903389076

Dietz, V., Schrafl-Altermatt, M., 2016. Control of functional movements in healthy and poststroke subjects: Role of neural interlimb coupling. Clin. Neurophysiol. https://doi.org/10.1016/j.clinph.2016.02.014

Disselhorst-Klug, C., Schmitz-Rode, T., Rau, G., 2009. Surface electromyography and muscle force: Limits in sEMG-force relationship and new approaches for applications. Clin. Biomech. 24, 225-235. https://doi.org/10.1016/j.clinbiomech.2008.08.003

Domalain, M., Vigouroux, L., Danion, F., Sevrez, V., Berton, E., 2008. Effect of object width on precision grip force and finger posture. Ergonomics 51, 1441-1453. https://doi.org/10.1080/00140130802130225

Dragulescu, D., Perdereau, V., Drouin, M., Ungureanu, L., Menyhardt, K., 2007. 3D active workspace of human hand anatomical model. Biomed. Eng. Online 6, 15. https://doi.org/10.1186/1475-925X-6-15

Duque, J., Masset, D., Malchaire, J., 1995. Evaluation of handgrip force from EMG measurements. Appl. Ergon. 26, 61-66. https://doi.org/10.1016/0003-6870(94)00003-H

Eccarius, P., Bour, R., Scheidt, R.A., 2012. Dataglove measurement of joint angles in sign language handshapes. Sign Lang. Linguist. 15, 39-72. https://doi.org/10.1075/sll.15.1.03ecc

Edgren, C.S., Radwin, R.G., Irwin, C.B., 2004. Grip force vectors for varying handle diameters and hand sizes. Hum. Factors 46, 244-51.

Edwards, S., Buckland, D., McCoy-Powlen, J., 2002. Developmental and Functional Hand 
Grasps. All Books Monogr. by WMU Authors.

el-Badawi, M.G., Butt, M.M., al-Zuhair, A.G., Fadel, R.A., 1995. Extensor tendons of the fingers: arrangement and variations--II. Clin. Anat. 8, 391-8. https://doi.org/10.1002/ca.980080604

Elkwood, A.I., Kaufman, M., Schneider, L.F. (Eds.), 2017. Rehabilitative Surgery. Springer International Publishing, Cham. https://doi.org/10.1007/978-3-319-41406-5

Endo, Y., Kanai, S., Kishinami, T., Miyata, N., Kouchi, M., Mochimaru, M., 2007. A computeraided ergonomic assessment and product design system using digital hands, in: Digital Human Modeling. pp. 833-842.

Engdahl, S.M., Christie, B.P., Kelly, B., Davis, A., Chestek, C.A., Gates, D.H., 2015. Surveying the interest of individuals with upper limb loss in novel prosthetic control techniques. J. Neuroeng. Rehabil. 12. https://doi.org/10.1186/s12984-015-0044-2

Ertan, H., 2009. Muscular activation patterns of the bow arm in recurve archery. J. Sci. Med. Sport 12, 357-360. https://doi.org/10.1016/j.jsams.2008.01.003

Ertan, H., Kentel, B., Tümer, S.T., Korkusuz, F., 2003. Activation patterns in forearm muscles during archery shooting. Hum. Mov. Sci. 22, 37-45.

Farina, D., Ning Jiang, N., Rehbaum, H., Holobar, A., Graimann, B., Dietl, H., Aszmann, O.C., 2014. The Extraction of Neural Information from the Surface EMG for the Control of UpperLimb Prostheses: Emerging Avenues and Challenges. IEEE Trans. Neural Syst. Rehabil. Eng. 22, 797-809. https://doi.org/10.1109/TNSRE.2014.2305111

Feix, T., Pawlik, R., Schmiedmayer, H., Romero, J., Kragic, D., 2009. A comprehensive grasp taxonomy, in: Robotics, Science and Systems Conference: Workshop on Understanding the Human Hand for Advancing Robotic Manipulation.

Gates, D.H., Walters, L.S., Cowley, J., Wilken, J.M., Resnik, L., 2016. Range of motion requirements for upper-limb activities of daily living. Am. J. Occup. Ther. 70. https://doi.org/10.5014/ajot.2016.015487

Gazzoni, M., Celadon, N., Mastrapasqua, D., Paleari, M., Margaria, V., Ariano, P., 2014. Quantifying forearm muscle activity during wrist and finger movements by means of multichannel electromyography. PLoS One 9, e109943. https://doi.org/10.1371/journal.pone.0109943

Geethanjali, P., 2016. Myoelectric control of prosthetic hands: State-of-the-art review. Med. Devices Evid. Res. 9, 247-255. https://doi.org/10.2147/MDER.S91102

Geng, Y., Zhang, X., Zhang, Y.-T., Li, G., 2014. A novel channel selection method for multiple motion classification using high-density electromyography. Biomed. Eng. Online 13, 102. https://doi.org/10.1186/1475-925X-13-102

Gracia-Ibáñez, V., Sancho-Bru, J.-L., Vergara, M., 2018. Relevance of grasp types to assess functionality for personal autonomy. J. Hand Ther. 1, 102-110. https://doi.org/https://doi.org/http://dx.doi.org/10.1016/j.jht.2017.02.003

Gracia-Ibáñez, V., Vergara, M., Buffi, J.H., Murray, W.M., Sancho-Bru, J.L., 2017a. Acrosssubject calibration of an instrumented glove to measure hand movement for clinical purposes. C. Comput. Methods Biomech. Biomed. Eng. 20, 587-597. https://doi.org/http://dx.doi.org/10.1080/10255842.2016.1265950

Gracia-Ibáñez, V., Vergara, M., Sancho-Bru, J.L., Mora, M.C., Piqueras, C., 2017b. Functional range of motion of the hand joints in activities of the International Classification of Functioning, Disability and Health. J. Hand Ther. https://doi.org/http://dx.doi.org/10.1016/j.jht.2016.08.001

Gribble, P.L., Mullin, L.I., Cothros, N., Mattar, A., 2003. Role of Cocontraction in Arm 
Movement Accuracy. J. Neurophysiol. 89, 2396-2405. https://doi.org/10.1152/jn.01020.2002

Grinyagin, I. V, Biryukova, E. V, Maier, M.A., 2005. Kinematic and dynamic synergies of human precision-grip movements. J. Neurophysiol. 94, 2284-2294. https://doi.org/10.1152/jn.01310.2004

Gustus, A., Stillfried, G., Visser, J., Jörntell, H., van der Smagt, P., 2012. Human hand modelling: kinematics, dynamics, applications. Biol. Cybern. 106, 741-755. https://doi.org/10.1007/s00422-012-0532-4

Hagert, E., 2010. Proprioception of the Wrist Joint: A Review of Current Concepts and Possible Implications on the Rehabilitation of the Wrist. J. Hand Ther. 23, 2-17. https://doi.org/10.1016/j.jht.2009.09.008

Hägg, G.M., Milerad, E., 1997. Forearm extensor and flexor muscle exertion during simulated gripping work - An electromyographic study. Clin. Biomech. 12, 39-43. https://doi.org/10.1016/S0268-0033(96)00049-6

Hair, J.F.;, Black, Jr, W.C.., Barry, J.B., Anderson E., R., 2009. Multivariate Data Analysis, 7th ed. Prentice Hall.

Hansen, N., Kern, S., 2004. Evaluating the CMA Evolution Strategy on Multimodal Test Functions. Springer Berlin Heidelberg, pp. 282-291. https://doi.org/10.1007/978-3-54030217-9_29

Harris, D., Dias, J.J., 2003. Five-year results of a new total replacement prosthesis for the finger metacarpo-phalangeal joints. J. Hand Surg. Br. Eur. Vol. 28, 432-438. https://doi.org/10.1016/S0266-7681(03)00147-5

Hatch, G.F., Pink, M.M., Mohr, K.J., Sethi, P.M., Jobe, F.W., 2006. The effect of tennis racket grip size on forearm muscle firing patterns. Am. J. Sports Med. 34, 1977-83. https://doi.org/10.1177/0363546506290185

He Huang, H., Ping Zhou, P., Guanglin Li, G., Kuiken, T.A., 2008. An Analysis of EMG Electrode Configuration for Targeted Muscle Reinnervation Based Neural Machine Interface. IEEE Trans. Neural Syst. Rehabil. Eng. 16, 37-45. https://doi.org/10.1109/TNSRE.2007.910282

Hebert, J.S., Lewicke, J., Williams, T.R., Vette, A.H., 2014. Normative data for modified Box and Blocks test measuring upper-limb function via motion capture. J. Rehabil. Res. Dev. 51, 918-932. https://doi.org/10.1682/JRRD.2013.10.0228

Hesam-Shariati, N., Trinh, T., Thompson-Butel, A.G., Shiner, C.T., McNulty, P.A., 2017. A Longitudinal Electromyography Study of Complex Movements in Poststroke Therapy. 1: Heterogeneous Changes Despite Consistent Improvements in Clinical Assessments. Front. Neurol. 8, 340. https://doi.org/10.3389/fneur.2017.00340

Hitchcock, D.R., Sherwood, D.E., 2018. Effects of Changing the Focus of Attention on Accuracy, Acceleration, and Electromyography in Dart Throwing. Int. J. Exerc. Sci. 11, 1120-1135.

Hogrel, J.-Y., 2005. Clinical applications of surface electromyography in neuromuscular disorders. Neurophysiol. Clin. Neurophysiol. 35, 59-71. https://doi.org/10.1016/J.NEUCLI.2005.03.001

Holzbaur, K.R.S., Murray, W.M., Delp, S.L., 2005. A model of the upper extremity for simulating musculoskeletal surgery and analyzing neuromuscular control. Ann. Biomed. Eng. 33, 82940.

Hoozemans, M.J.M., Van Dieën, J.H., 2005. Prediction of handgrip forces using surface EMG of forearm muscles. J. Electromyogr. Kinesiol. 15, 358-366. 
https://doi.org/10.1016/j.jelekin.2004.09.001

Hsiao, L.-P., Cho, C.-Y., 2012. The effect of aging on muscle activation and postural control pattern for young and older computer users. Appl. Ergon. 43, 926-932. https://doi.org/10.1016/j.apergo.2011.12.014

Hu, X., Suresh, N.L., Xue, C., Rymer, W.Z., 2015. Extracting extensor digitorum communis activation patterns using high-density surface electromyography. Front. Physiol. 6, 279. https://doi.org/10.3389/fphys.2015.00279

Hwang, J., Kong, Y.-K., Jung, M.-C., 2010. Posture evaluations of tethering and loose-housing systems in dairy farms. Appl. Ergon. 42, 1-8.

Jakobi, J.M., Edwards, D.L., Connelly, D.M., 2008. Utility of Portable Electromyography for Quantifying Muscle Activity during Daily Use. Gerontology 54, 324-331. https://doi.org/10.1159/000155655

Jarque-Bou, N., Gracia-Ibáñez, V., Sancho-Bru, J.-L., Vergara, M., Pérez-González, A., Andrés, F.J., 2016. Using kinematic reduction for studying grasping postures. An application to power and precision grasp of cylinders. Appl. Ergon. 56, 52-61. https://doi.org/http://dx.doi.org/10.1016/j.apergo.2016.03.003

Jarque-Bou, N.J., Scano, A., Atxori, M., Müller, H., 2019. Kinematic synergies of hand grasps: a comprehensive study on a large publicly available dataset. J. Neuroeng. Rehabil. 16, Article number: 63

Jarque-Bou, N.J., Vergara, M., Sancho-Bru, J.L., Roda-Sales, A., Gracia-Ibáñez, V., 2018. Identification of forearm skin zones with similar muscle activation patterns during activities of daily living. J. Neuroeng. Rehabil. https://doi.org/10.1186/s12984-018-0437-0

Jarrassé, N., Ribeiro, A.T., Sahbani, A., Bachta, W., Roby-Brami, A., 2014. Analysis of hand synergies in healthy subjects during bimanual manipulation of various objects. J. Neuroeng. Rehabil. https://doi.org/10.1186/1743-0003-11-113

Jeannerod, M., 1981. Intersegmental coordination during reaching at natural visual objects. Atten. Perform. 153-168.

Jerde TE, Soechting JF, Flanders M. 2003. Biological constraints simplify the recognition of hand shapes. IEEE Trans Biomed Eng. 50:265-269.

Jo, H.J., Maenza, C., Good, D.C., Huang, X., Park, J., Sainburg, R.L., Latash, M.L., 2016. Effects of unilateral stroke on multi-finger synergies and their feed-forward adjustments. Neuroscience 319, 194-205. https://doi.org/10.1016/j.neuroscience.2016.01.054

Johanson, M.E., Valero-Cuevas, F.J., Hentz, V.R., 2001. Activation patterns of the thumb muscles during stable and unstable pinch tasks. J. Hand Surg. Am. 26, 698-705. https://doi.org/10.1053/jhsu.2001.26188

Johnson, S.S., Mansfield, E., 2014. Prosthetic training: Upper limb. Phys. Med. Rehabil. Clin. N. Am. 25, 133-151. https://doi.org/10.1016/j.pmr.2013.09.012

Johnston, J.A., Winges, S.A., Santello, M., 2009. Neural control of hand muscles during prehension. Adv. Exp. Med. Biol. 629, 577-596.

Jordan, K., Pataky, T.C., Newell, K.M., 2005. Grip width and the organization of force output. J. Mot. Behav. 37, 285-94. https://doi.org/10.3200/JMBR.37.4.285-294

Juul-Kristensen, B., Hansson, G.-Å., Fallentin, N., Andersen, J.H., Ekdahl, C., 2001. Assessment of work postures and movements using a video-based observation method and direct technical measurements. Appl. Ergon. 32, 517-524.

Kamavuako, E.N., Farina, D., Yoshida, K., Jensen, W., 2009. Relationship between grasping 
force and features of single-channel intramuscular EMG signals. J. Neurosci. Methods 185 , 143-150. https://doi.org/10.1016/j.jneumeth.2009.09.006

Kamen, G., Gabriel, D.A., 2010. Essentials of electromyography. Human Kinetics. Champaign, IL (2010)

Kao, H.C., Lin, C.J., Lee, Y.H., Chen, S.H., 2015. The Effects of Direction of Exertion, Path, and Load Placement in Nursing Cart Pushing and Pulling Tasks: An Electromyographical Study. PLoS One 10, e0140792. https://doi.org/10.1371/journal.pone.0140792

Kapandji A.I., 1996. Fisiologia Articular. Miembro Superior -6a ed. Madrid: 2006-2007. Editorial Médica Panamericana, Madrid.

Kaufman, K.R., An, K.N., Litchy, W.J., Cooney, W.P., Chao, E.Y., 1999. In-vivo function of the thumb muscles. Clin. Biomech. (Bristol, Avon) 14, 141-50.

Kerkhof, F.D., Deleu, G., D’Agostino, P., Vereecke, E.E., 2016. Subject-specific thumb muscle activity during functional tasks of daily life. J. Electromyogr. Kinesiol. 30, 131-136. https://doi.org/10.1016/j.jelekin.2016.06.009

Kern, D.S., Semmler, J.G., Enoka, R.M., 2001. Long-term activity in upper- and lower-limb muscles of humans. J. Appl. Physiol. 91, 2224-2232. https://doi.org/10.1152/jappl.2001.91.5.2224

Khokhar, Z.O., Xiao, Z.G., Menon, C., 2010. Surface EMG pattern recognition for real-time control of a wrist exoskeleton. Biomed. Eng. Online 9, 41. https://doi.org/10.1186/1475925X-9-41

Kilbreath, S.L., Gandevia, S.C., 1994. Limited independent flexion of the thumb and fingers in human subjects. J. Physiol. 479, 487-97.

Kinoshita, H., Bäckström, L., Flanagan, J.R., Johansson, R.S., 1997. Tangential torque effects on the control of grip forces when holding objects with a precision grip. J. Neurophysiol. 78, 1619-30.

Klein Breteler, M.D., Simura, K.J., Flanders, M., 2007. Timing of muscle activation in a hand movement sequence. Cereb. Cortex 17, 803-815. https://doi.org/10.1093/cercor/bhk033

Koch, P., Phan, H., Maass, M., Katzberg, F., Mertins, A., 2017. Early prediction of future hand movements using sEMG data, in: 2017 39th Annual International Conference of the IEEE Engineering in Medicine and Biology Society (EMBC). IEEE, pp. 54-57. https://doi.org/10.1109/EMBC.2017.8036761

Konrad, P., 2005. The ABC of EMG A Practical Introduction to Kinesiological Electromyography. Noraxon Inc. USA.

Kumar, D., Poosapadi Arjunan, S., Singh, V., 2013. Towards identification of finger flexions using single channel surface electromyography - able bodied and amputee subjects. J. Neuroeng. Rehabil. 10, 50. https://doi.org/10.1186/1743-0003-10-50

Kutch, J.J., Kuo, A.D., Bloch, A.M., Rymer, W.Z., 2008. Endpoint force fluctuations reveal flexible rather than synergistic patterns of muscle cooperation. J. Neurophysiol. 100, 24552471. https://doi.org/10.1152/jn.90274.2008.

Landis, J., Keselman, I., Murphy, C.N., 2005. Comparison of electromyographic (EMG) activity of selected forearm muscles during low grade resistance therapeutic exercises in individuals diagnosed with lateral epicondylitis. Work 24, 85-91.

Landsmeer, J.M., 1962. Power grip and precision handling. Ann. Rheum. Dis. 21, 164-70.

Lang, C.E., Schieber, M.H., 2004. Human finger independence: limitations due to passive mechanical coupling versus active neuromuscular control. J. Neurophysiol. 92, 2802-2810. 
https://doi.org/10.1152/jn.00480.2004

Laoopugsin, N., Laoopugsin, S., 2012. The study of work behaviours and risks for occupational overuse syndrome. Hand Surg. 17, 205-12. https://doi.org/10.1142/S0218810412500207

Lee, J., Kunii, T.L., 1995. Model-based analysis of hand posture. IEEE Comput. Graph. Appl. 15, 77-86. https://doi.org/10.1109/38.403831

Lee, K.-S., Jung, M.-C., 2015a. Ergonomic evaluation of biomechanical hand function. Saf. Health Work 6, 9-17.

Lee, K.-S., Jung, M.-C., 2015b. Investigation of hand postures in manufacturing industries according to hand and object properties. Int. J. Ind. Ergon. 46, 98-104.

Lee, K.-S., Jung, M.-C., 2014. Common patterns of voluntary grasp types according to object shape, size, and direction. Int. J. Ind. Ergon. 44, 761-768.

Lee, S.W., Chen, H., Towles, J.D., Kamper, D.G., 2008. Effect of finger posture on the tendon force distribution within the finger extensor mechanism. J. Biomech. Eng. Asme 130, 51014.

Lee, S.W., Triandafilou, K., Lock, B.A., Kamper, D.G., 2013. Impairment in task-specific modulation of muscle coordination correlates with the severity of hand impairment following stroke. PLoS One 8, e68745. https://doi.org/10.1371/journal.pone.0068745

Li, Q., Wang, D., Du, Z., Song, Y., Sun, L., 2006. sEMG Based Control for 5 DOF Upper Limb Rehabilitation Robot System, in: 2006 IEEE International Conference on Robotics and Biomimetics. IEEE, pp. 1305-1310. https://doi.org/10.1109/ROBIO.2006.340117

Linderman, M., Lebedev, M.A., Erlichman, J.S., 2009. Recognition of handwriting from electromyography. PLoS One 4. https://doi.org/10.1371/journal.pone.0006791

Liu, Y., Jiang, L., Yang, D., Liu, H., 2016. Analysis of hand and wrist postural synergies in tolerance grasping of various objects. PLoS One 11(8): e0161772.https://doi.org/10.1371/journal.pone.0161772

Lum, P.S., Mulroy, S., Amdur, R.L., Requejo, P., Prilutsky, B.I., Dromerick, A.W., 2009. Gains in Upper Extremity Function After Stroke via Recovery or Compensation: Potential Differential Effects on Amount of Real-World Limb Use. Top. Stroke Rehabil. 16, 237253. https://doi.org/10.1310/tsr1604-237

Lunardini, F., Casellato, C., Bertucco, M., Sanger, T.D., Pedrocchi, A., 2017. Children With and Without Dystonia Share Common Muscle Synergies While Performing Writing Tasks. Ann. Biomed. Eng. 45, 1949-1962. https://doi.org/10.1007/s10439-017-1838-0

Maciejasz, P., Eschweiler, J., Gerlach-Hahn, K., Jansen-Troy, A., Leonhardt, S., 2014. A survey on robotic devices for upper limb rehabilitation. J. Neuroeng. Rehabil. 11, 3. https://doi.org/10.1186/1743-0003-11-3

Maier, M.A., Hepp-Reymond, M.-C., 1995. EMG activation patterns during force production in precision grip. Exp. Brain Res. 103, 108-122. https://doi.org/10.1007/BF00241969

Marneweck, M., Knelange, E., Lee-Miller, T., Santello, M., Gordon, A.M., 2015. Generalization of Dexterous Manipulation Is Sensitive to the Frame of Reference in Which It Is Learned. PLoS One 10, e0138258. https://doi.org/10.1371/journal.pone.0138258

Marras, W.S., Schoenmarklin, R.W., 1993. Wrist motions in industry. Ergonomics 36, 341-51.

Marta, S., Silva, L., Castro, M.A., Pezarat-Correia, P., Cabri, J., 2012. Electromyography variables during the golf swing: a literature review. J. Electromyogr. Kinesiol. 22, 803-13. https://doi.org/10.1016/j.jelekin.2012.04.002

Martelloni, C., Carpaneto, J., Micera, S., 2009. Characterization of EMG patterns from proximal arm muscles during object- and orientation-specific grasps. IEEE Trans. Biomed. Eng. 56, 
2529-2536. https://doi.org/10.1109/TBME.2009.2026470

Mason, C.R., Gomez, J.E., Ebner, T.J., 2001. Hand Synergies During Reach-to-Grasp. J. Neurophysiol. 86, 2896-2910.

Matrone, G.C., Cipriani, C., Carrozza, M.C., Magenes, G., 2012. Real-time myoelectric control of a multi-fingered hand prosthesis using principal components analysis. J. Neuroeng. Rehabil. 9, 40. https://doi.org/10.1186/1743-0003-9-40

Matrone, G.C., Cipriani, C., Secco, E.L., Magenes, G., Carrozza, M., 2010. Principal components analysis based control of a multi-dof underactuated prosthetic hand. J. Neuroeng. Rehabil. 7, 16. https://doi.org/10.1186/1743-0003-7-16

McKiernan, B.J., Marcario, J.K., Karrer, J.H., Cheney, P.D., 1998. Corticomotoneuronal postspike effects in shoulder, elbow, wrist, digit, and intrinsic hand muscles during a reach and prehension task. J. Neurophysiol. 80, 1961-80.

Meulenbroek, R.G., Rosenbaum, D.A., Jansen, C., Vaughan, J., Vogt, S., 2001. Multijoint grasping movements. Simulated and observed effects of object location, object size, and initial aperture. Exp. brain Res. 138, 219-34.

Milner, T.E., Cloutier, C., 1993. Compensation for mechanically unstable loading in voluntary wrist movement. Exp. brain Res. 94, 522-32.

Miyata, N., Kouchi, M., Mochimaru, M., Kurihara, T., 2005. Finger joint kinematics from MR images, in: 2005 IEEE/RSJ International Conference on Intelligent Robots and Systems, IROS. IEEE, pp. 4110-4115. https://doi.org/10.1109/IROS.2005.1545611

Mogk, J.P.M., Keir, P.J., 2003. Crosstalk in surface electromyography of the proximal forearm during gripping tasks. J. Electromyogr. Kinesiol. 13, 63-71.

Mora, M.C., Sancho-Bru, J.L., Perez-Gonzalez, A., 2012. Hand Posture Prediction using Neural Networks within a Biomechanical Model. Int. J. Adv. Robot. Syst. 9. https://doi.org/10.5772/52057

Mottet, D., van Dokkum, L.E.H., Froger, J., Gouaïch, A., Laffont, I., 2017. Trajectory formation principles are the same after mild or moderate stroke. PLoS One 12, e0173674. https://doi.org/10.1371/journal.pone.0173674

Nam, C., Rong, W., Li, W., Xie, Y., Hu, X., Zheng, Y., 2017. The Effects of Upper-Limb Training Assisted with an Electromyography-Driven Neuromuscular Electrical Stimulation Robotic Hand on Chronic Stroke. Front. Neurol. 8, 679. https://doi.org/10.3389/fneur.2017.00679

Nathan, D.E., Johnson, M.J., McGuire, J.R., 2009. Design and validation of low-cost assistive glove for hand assessment and therapy during activity of daily living-focused robotic stroke therapy. J. Rehabil. Res. Dev. 46, 587. https://doi.org/10.1682/JRRD.2008.04.0052

Niechwiej-Szwedo, E., Gonzalez, D., Nouredanesh, M., Tung, J., 2018. Evaluation of the Leap Motion Controller during the performance of visually-guided upper limb movements. PLoS One 13, e0193639. https://doi.org/10.1371/JOURNAL.PONE.0193639

Oatis, C.A., 2009. Kinesiology: the mechanics and pathomechanics of human movement. Lippincott Williams \& Wilkins.

Oess, N.P.N., Wanek, J., Curt, A., 2012. Design and evaluation of a low-cost instrumented glove for hand function assessment. J. neuroengineering ... 9, 2. https://doi.org/10.1186/17430003-9-2

Park, S., 2013. Comparison of Muscle Activation during Dominant Hand Wrist Flexion when Writing. J. Phys. Ther. Sci. 25, 1529-1531. https://doi.org/10.1589/jpts.25.1529

Parker, P., Englehart, K., Hudgins, B., 2006. Myoelectric signal processing for control of powered 
limb prostheses. J. Electromyogr. Kinesiol. 16, 541-548. https://doi.org/10.1016/j.jelekin.2006.08.006

Patel, V., Thukral, P., Burns, M.K., Florescu, I., Chandramouli, R., Vinjamuri, R., 2017. Hand Grasping Synergies As Biometrics. Front. Bioeng. Biotechnol. 5, pages 26 https://doi.org/10.3389/fbioe.2017.00026

Pellegrino, L., Coscia, M., Muller, M., Solaro, C., Casadio, M., 2018. Evaluating upper limb impairments in multiple sclerosis by exposure to different mechanical environments. Sci. Rep. 8, 2110. https://doi.org/10.1038/s41598-018-20343-y

Peters, K.M., Kelly, V.E., Chang, T., Weismann, M.C., Westcott McCoy, S., Steele, K.M., 2018. Muscle recruitment and coordination during upper-extremity functional tests. J. Electromyogr. Kinesiol. 38, 143-150. https://doi.org/10.1016/j.jelekin.2017.12.002

Prevete, R., Donnarumma, F., d'Avella, A., Pezzulo, G., 2018. Evidence for sparse synergies in grasping actions. Sci. Rep. 8, 616. https://doi.org/10.1038/s41598-017-18776-y

Program, O.T., 2006. Jebsen Test of Hand Function. Therapy 2004-2007.

Rajeswaran, A., Kumar, V., Gupta, A., Vezzani, G., Schulman, J., Todorov, E., Levine, S., 2017. Learning Complex Dexterous Manipulation with Deep Reinforcement Learning and Demonstrations.

Reaz, M.B.I., Hussain, M.S., Mohd-Yasin, F., 2006. Techniques of EMG signal analysis: detection, processing, classification and applications (Correction). Biol. Proced. Online 8, 163-163. https://doi.org/10.1251/bpo124

Reissner, L., Fischer, G., List, R., Giovanoli, P., Calcagni, M., 2019. Assessment of hand function during activities of daily living using motion tracking cameras: A systematic review. Proc. Inst. Mech. Eng. Part H J. Eng. Med. 095441191985130. https://doi.org/10.1177/0954411919851302

Ricci, F.P.F.M., Santiago, P.R.P., Zampar, A.C., Pinola, L.N., Fonseca, M. de C.R., 2015. Upper extremity coordination strategies depending on task demand during a basic daily activity. Gait Posture 42, 472-478. https://doi.org/10.1016/j.gaitpost.2015.07.061

Roh, J., Rymer, W.Z., Beer, R.F., 2015. Evidence for altered upper extremity muscle synergies in chronic stroke survivors with mild and moderate impairment. Front. Hum. Neurosci. 9, 1-14. https://doi.org/10.3389/fnhum.2015.00006

Rojas-Martínez, M., Mañanas, M.A., Alonso, J.F., 2012. High-density surface EMG maps from upper-arm and forearm muscles. J. Neuroeng. Rehabil. 9, 85. https://doi.org/10.1186/17430003-9-85

Rota, S., Morel, B., Saboul, D., Rogowski, I., Hautier, C., 2014. Influence of fatigue on upper limb muscle activity and performance in tennis. J. Electromyogr. Kinesiol. 24, 90-7. https://doi.org/10.1016/j.jelekin.2013.10.007

Safavynia, S.A., Torres-Oviedo, G., Ting, L.H., 2011a. Muscle Synergies: Implications for Clinical Evaluation and Rehabilitation of Movement. Top. Spinal Cord Inj. Rehabil. 17, 1624. https://doi.org/10.1310/sci1701-16

Safavynia, S.A., Torres-Oviedo, G., Ting, L.H., 2011b. Muscle Synergies: Implications for Clinical Evaluation and Rehabilitation of Movement. Top. Spinal Cord Inj. Rehabil. 17, 1624. https://doi.org/10.1310/sci1701-16

Sako, S., Sugiura, H., Tanoue, H., Kojima, M., Kono, M., Inaba, R., 2017. Electromyographic analysis of relevant muscle groups during completion of computer tasks using different computer mouse positions. Int. J. Occup. Saf. Ergon. 23, 267-273. https://doi.org/10.1080/10803548.2016.1275140 
Sánchez-Margallo, F.M., Pérez-Duarte, F.J., Sánchez-Margallo, J.A., Lucas-Hernández, M., Matos-Azevedo, A.M., Díaz-Güemes, I., 2014. Application of a motion capture data glove for hand and wrist ergonomic analysis during laparoscopy. Minim. Invasive Ther. Allied Technol. 23, 350-6.

Sanchez-Margallo, F.M., Sanchez -Margallo, J.A., Pagador, J.B.J.B., Moyano, J.L.J.L., Moreno, J., Uson, J., Sánchez-Margallo, F.M., Sánchez-Margallo, J.A., Pagador, J.B.J.B., Moyano, J.L.J.L., Moreno, J., Usón, J., 2010. Ergonomic assessment of hand movements in laparoscopic surgery using the Cyberglove (R), in: Miller, K., Nielsen, P.M.F. (Eds.), Computational Biomechanics for Medicine. Springer New York, NY, pp. 121-128.

Sancho-Bru, J.L., Jarque-Bou, N.J., Vergara, M., Pérez-González, A., 2014. Validity of a simple videogrammetric method to measure the movement of all hand segments for clinical purposes. Proc. Inst. Mech. Eng. H. 228, 182-189. https://doi.org/10.1177/0954411914522023

Sancho-Bru, J.L., Pérez-González, A., Vergara, M., Giurintano, D.J., Vergara-Monedero, M., 2003. A 3D biomechanical model of the hand for power grip. J. Biomech. Eng. 125, 78-83. https://doi.org/10.1115/1.1532791

Sancho-Bru, X., Valero-Cuevas, F.J., Pérez-González, A., Giurintano, D.J., Sánchez-Marín, F.T., Vergara-Monedero, M., 2001. Modelling the metacarpophalangeal joint in a biomechanical model of the index finger, in: Shrive, N.G., Evans, S.L. (Eds.), Computer Methods in Biomedical Engineering. Rome.

SangWook Lee, Landers, K.A., Hyung-Soon Park, 2014. Development of a Biomimetic Hand Exotendon Device (BiomHED) for Restoration of Functional Hand Movement Post-Stroke. IEEE Trans. Neural Syst. Rehabil. Eng. 22, 886-898. https://doi.org/10.1109/TNSRE.2014.2298362

Santello, M., Baud-Bovy, G., Jörntell, H., 2013. Neural bases of hand synergies. Front. Comput. Neurosci. 7, 23. https://doi.org/10.3389/fncom.2013.00023

Santello, M., Flanders, M., Soechting, J.F., 2002. Patterns of Hand Motion during Grasping and the Influence of Sensory Guidance. J. Neurosci. 22, 1426-1435.

Santello, M., Flanders, M., Soechting, J.F., 1998. Postural hand synergies for tool use. J. Neurosci. 18, 10105-10115.

Santello, M., Soechting, J.F., 1998. Gradual molding of the hand to object contours. J. Neurophysiol. 79, 1307-20.

Santos, V.J., Valero-Cuevas, F.J., 2006. Reported anatomical variability naturally leads to multimodal distributions of denavit-hartenberg parameters for the human thumb. IEEE Trans. Biomed. Eng. 53, 155-163.

Sburlea, A.I., Müller-Putz, G.R., 2018. Exploring representations of human grasping in neural, muscle and kinematic signals. Sci. Rep. 8, 16669. https://doi.org/10.1038/s41598-01835018-x

Scano, A., Chiavenna, A., Molinari Tosatti, L., Müller, H., Atzori, M., 2018. Muscle Synergy Analysis of a Hand-Grasp Dataset: A Limited Subset of Motor Modules May Underlie a $\begin{array}{lllll}\text { Large Variety of Grasps. Front. Neurorobot. } & 12,57 .\end{array}$ https://doi.org/10.3389/FNBOT.2018.00057

Scheme, E., Englehart, K., 2011. Electromyogram pattern recognition for control of powered upper-limb prostheses: State of the art and challenges for clinical use. J. Rehabil. Res. Dev. 48, 643. https://doi.org/10.1682/JRRD.2010.09.0177

Schieber, M.H., Gardinier, J., Liu, J., 2001. Tension distribution to the five digits of the hand by neuromuscular compartments in the macaque flexor digitorum profundus. J. Neurosci. 21, 
$2150-8$.

Schieber, M.H., Lang, C.E., Reilly, K.T., McNulty, P., Sirigu, A., 2009. Selective activation of human finger muscles after stroke or amputation. Adv. Exp. Med. Biol. 629, 559-75. https://doi.org/10.1007/978-0-387-77064-2_30

Schieber, M.H., Lang, C.E., Reilly, K.T., McNulty, P., Sirigu, A., 2009. Selective activation of human finger muscles after stroke or amputation. Adv. Exp. Med. Biol. 629, 559-575. https://doi.org/10.1007/978-0-387-77064-2_30

Schultz, A.E., Kuiken, T.A., 2011. Clinical Review: Current Concepts Neural Interfaces for Control of Upper Limb Prostheses: The State of the Art and Future Possibilities. PM R 3, 55-67. https://doi.org/10.1016/j.pmrj.2010.06.016

Seo, N.J., Armstrong, T.J., 2008. Investigation of grip force, normal force, contact area, hand size, and handle size for cylindrical handles. Hum. Factors 50, 734-44.

Shivers, C.L., Mirka, G.A., Kaber, D.B., 2002. Effect of grip span on lateral pinch grip strength. Hum. Factors 44, 569-77.

Smeets, J.B.J., Brenner, E., 2016. Synergies in Grasping, in: Advances in Experimental Medicine and Biology. pp. 21-34. https://doi.org/10.1007/978-3-319-47313-0_2

Söderkvist, I., Wedin, P.A., 1993. Determining the movements of the skeleton using wellconfigured markers. J. Biomech. 26, 1473-7.

Sollerman, C., Ejeskar, A., 1995. Sollerman hand function test: A standardised method and its use in tetraplegic patients. Scand. J. Plast. Reconstr. Surg. Hand Surg. 29, 167-176.

Sorbie, G.G., Hunter, H.H., Grace, F.M., Gu, Y., Baker, J.S., Ugbolue, U.C., 2016. An electromyographic study of the effect of hand grip sizes on forearm muscle activity and golf performance. $\quad$ Res. Sport. Med. 24, 207-218. https://doi.org/10.1080/15438627.2016.1191492

Stillfried, G., Hillenbrand, U., 2014. MRI-Based Skeletal Hand Movement Model. In: Balasubramanian R., Santos V. (eds) The Human Hand as an Inspiration for Robot Hand Development. Springer Tracts in Advanced Robotics, vol 95. Springer, Cham

Stillfried, G., van der Smagt, P., 2010. Movement model of a human hand based on magnetic resonance imaging (MRI), in: International Conference on Applied Bionics and Biomechanics, ICABB.

Straker, L., Burgess-Limerick, R., Pollock, C., Maslen, B., 2009. The influence of desk and display design on posture and muscle activity variability whilst performing information technology tasks. Appl. Ergon. 40, 852-859. https://doi.org/10.1016/j.apergo.2008.09.004

Supuk, T., Kodek, T., Bajd, T., 2005. Estimation of hand preshaping during human grasping. Med. Eng. Phys. 27, 790-7. https://doi.org/10.1016/j.medengphy.2005.03.008

Szeto, G.P.Y., Lin, J.K.M., 2011. A study of forearm muscle activity and wrist kinematics in symptomatic office workers performing mouse-clicking tasks with different precision and speed demands. J. Electromyogr. Kinesiol. 21, 59-66. https://doi.org/10.1016/j.jelekin.2010.06.006

Tagliabue, M., Ciancio, A.L., Brochier, T., Eskiizmirliler, S., Maier, M.A., 2015. Differences between kinematic synergies and muscle synergies during two-digit grasping. Front. Hum. Neurosci. https://doi.org/10.3389/fnhum.2015.00165

Taib, M.F.M., Bahn, S., Yun, M.H., 2016. The effect of psychosocial stress on muscle activity during computer work: Comparative study between desktop computer and mobile computing products. Work 54, 543-555. https://doi.org/10.3233/WOR-162334 
Thakur, P.H., Bastian, A.J., Hsiao, S.S., 2008. Multidigit Movement Synergies of the Human Hand in an Unconstrained Haptic Exploration Task. J. Neurosci. 28, 1271-1281.

Tkach, D.C., Young, A.J., Smith, L.H., Hargrove, L.J., 2012. Performance of pattern recognition myoelectric control using a generic electrode grid with Targeted Muscle Reinnervation patients, in: 2012 Annual International Conference of the IEEE Engineering in Medicine and Biology Society. IEEE, pp. 4319-4323. https://doi.org/10.1109/EMBC.2012.6346922

Todorov, E., Ghahramani, Z., 2004. Analysis of the synergies underlying complex hand manipulation. Conf. Proc. IEEE Eng. Med. Biol. Soc. 6, 4637-40. https://doi.org/10.1109/IEMBS.2004.1404285

Tresch, M.C., Jarc, A., 2009. The case for and against muscle synergies. Curr. Opin. Neurobiol. 19, 601-607. https://doi.org/10.1016/j.conb.2009.09.002

Tsai, C.-L., Lin, C.-F., Lin, H.-T., Liu, M.-F., Chiu, H.-Y., Hsu, H.-Y., Kuo, L.-C., 2017. How kinematic disturbance in the deformed rheumatoid thumb impacts on hand function: a biomechanical and functional perspective. Disabil. Rehabil. 39, 338-345. https://doi.org/10.3109/09638288.2016.1141244

Tsai, M.-J., Lee, H.-W., Chen, H.-C., 2011. Construction of a Realistic Hand Model with 22 Joint Freedoms, in: 13th World Congress in Mechanism and Machine Science.

Tubiana, R., Valentin, P., 1964. The physiology of the extension of the fingers. Surg. Clin. North Am. 44, 909-18.

Ullah, S., Finch, C.F., 2013. Applications of functional data analysis: A systematic review. BMC Med. Res. Methodol. 13, 43. https://doi.org/10.1186/1471-2288-13-43

Valero-Cuevas, F.J., 2000. Predictive modulation of muscle coordination pattern magnitude scales fingertip force magnitude over the voluntary range. J. Neurophysiol. 83, 1469-1479.

Valero-Cuevas, F.J., Venkadesan, M., Todorov, E., 2009. Structured variability of muscle activations supports the minimal intervention principle of motor control. J. Neurophysiol. 102, 59-68. https://doi.org/10.1152/jn.90324.2008

Valero-Cuevas, F.J., ZAJAC, F.E., Burgar, C.G., 1998. Large index-fingertip forces are produced by subject-independent patterns of muscle excitation. J. Biomech. 31, 693-703.

Van Galen, G.P., Müller, M.L.T.M., Meulenbroek, R.G.J., Van Gemmert, A.W.A., 2002. Forearm EMG response activity during motor performance in individuals prone to increased stress reactivity. Am. J. Ind. Med. 41, 406-419. https://doi.org/10.1002/ajim.10051

VencesBrito, A.M., Rodrigues Ferreira, M.A., Cortes, N., Fernandes, O., Pezarat-Correia, P., 2011. Kinematic and electromyographic analyses of a karate punch. J. Electromyogr. Kinesiol. 21, 1023-1029. https://doi.org/10.1016/j.jelekin.2011.09.007

Vergara, M., Agost Torres, M.-J., Gracia-Ibáñez, V., 2016. Comparison of dorsal and palmar aspect dimensions of hand anthropometry. Int. J. Ind. Ergon. En revisió.

Vergara, M., Gracia-Ibáñez, V., Sancho-Bru, J.-L.L., 2015. Evaluation of Hand Functionality during Activities of Daily Living (ADL): A Review, in: Lively, S.T. (Ed.), Activities of Daily Living, Adl: Cultural Differences, Impacts of Disease and Long-Term Health Effects. Nova Science Pub Inc, New York, pp. 103-132.

Vergara, M., Sancho-Bru, J.L., Gracia-Ibáñez, V., Pérez-González, A., 2014. An introductory study of common grasps used by adults during performance of activities of daily living. J. Hand Ther. 27, 1-28. https://doi.org/10.1016/j.jht.2014.04.002

Vigouroux, L., Domalain, M., Berton, E., 2011a. Effect of object width on muscle and joint forces during thumb-index finger grasping. J. Appl. Biomech. 27, 173-80. 
Vigouroux, L., Rossi, J., Foissac, M., Grélot, L., Berton, E., 2011b. Finger force sharing during an adapted power grip task. Neurosci. Lett. 504, 290-294. https://doi.org/10.1016/j.neulet.2011.09.050

Vinstrup, J., Calatayud, J., Jakobsen, M.D., Sundstrup, E., Jørgensen, J.R., Casaña, J., Andersen, L.L., 2018. Hand strengthening exercises in chronic stroke patients: Dose-response evaluation using electromyography. J. Hand Ther. 31, 111-121. https://doi.org/10.1016/j.jht.2017.01.004

von Schroeder, H.P., Botte, M.J., Gellman, H., 1990. Anatomy of the juncturae tendinum of the hand. J. Hand Surg. Am. 15, 595-602.

Wang, H., Hwang, J., Lee, K.-S., Kwag, J.-S., Jang, J.-S., Jung, M.-C., 2014. Upper Body and Finger Posture Evaluations at an Electric Iron Assembly Plant. Hum. Factors Ergon. Manuf. Serv. Ind. 24, 161-171.

Wang, H., Kong, Y.-K., Jung, M.-C., 2015. Postural Evaluation in a Poultry Farm for Broiler Chickens. Int. J. Occup. Saf. Ergon. 18, 67-75.

Watanabe, T., Owashi, K., Kanauchi, Y., Mura, N., Takahara, M., Ogino, T., 2005. The shortterm reliability of grip strength measurement and the effects of posture and grip span. J. Hand Surg. Am. 30, 603-9. https://doi.org/10.1016/j.jhsa.2004.12.007

Weir, P.L., MacKenzie, C.L., Marteniuk, R.G., Cargoe, S.L., Frazer, M.B., 1991. The effects of object weight on the kinematics of prehension. J. Mot. Behav. 23, 192-204.

Weiss, E.J., Flanders, M., 2004. Muscular and Postural Synergies of the Human Hand. J. Neurophysiol. 92, 523-535.

Wells, R., Moore, A., Potvin, J., Norman, R., 1994. Assessment of risk factors for development of work-related musculoskeletal disorders (RSI). Appl. Ergon. 25, 157-64.

WHO | International Classification of Functioning, Disability and Health (ICF), 2001.

Winges, S.A., Furuya, S., Faber, N.J., Flanders, M., 2013. Patterns of muscle activity for digital coarticulation. J. Neurophysiol. 110, 230-242. https://doi.org/10.1152/jn.00973.2012

Wu, G., van der Helm, F.C.T., Veeger, H.E.J.D., Makhsous, M., Van Roy, P., Anglin, C., Nagels, J., Karduna, A.R., McQuade, K., Wang, X., Werner, F.W., Buchholz, B., 2005. ISB recommendation on definitions of joint coordinate systems of various joints for the reporting of human joint motion--Part II: shoulder, elbow, wrist and hand. J. Biomech. 38, 981-992. https://doi.org/10.1016/j.jbiomech.2004.05.042

Wu, J.Z., An, K.-N.N., Cutlip, R.G., Dong, R.G., 2010. A practical biomechanical model of the index finger simulating the kinematics of the muscle/tendon excursions. Biomed. Mater. Eng. 20, 89-97.

Yu, H.-L., Chase, R.A. (Robert A., Strauch, B., 2004. Atlas of hand anatomy and clinical implications. Mosby.

Yun, M.H., 1993. Hand posture measurement system for evaluating manual tool tasks, in: Proceedings of the Human Factors and Ergonomics Society. Publ by Human Factors and Ergonomics Society, Inc., pp. 754-758.

Zariffa, J., Steeves, J., Pai, D.K., 2012. Changes in hand muscle synergies in subjects with spinal cord injury: characterization and functional implications. J. Spinal Cord Med. 35, 310-8. https://doi.org/10.1179/2045772312Y.0000000037

Zuo, K.J., Olson, J.L., 2014. The evolution of functional hand replacement: From iron prostheses to hand transplantation. Plast. Surg. (Oakville, Ont.) 22, 44-51. 

Appendix 



\section{Appendix I. Method for obtaining the position and orientation of joint rotation axes}

This appendix explains the procedure followed for the method of obtaining the position and orientation of the joint axes of the hand, for both 1 and 2 DoF.

The model consists of comparing the matrices that transform the distal coordinate system into the proximal coordinate system (Mdp). Firstly, and at each time, the experimental transformation matrices between the proximal and distal segments were obtained from the 3D coordinates of the tracking markers of both segments, using the method based on the singular value decomposition presented by Söderkvist in a previous work (Söderkvist and Wedin, 1993). Then, a mechanical joint model is assumed, defined by two non-intersecting and non-orthogonal axes (in the case of $2 \mathrm{DoF}$ ). One attached to the proximal segment and the other one attached to the distal segment. In the case of 1 DoF, it is assumed that the axis is fixed to both segments. Therefore, at each time, the matrices between proximal and distal segments were also obtained through this joint model.

The position and orientation of these axes are defined by some parameters. So that, the axis parameters were obtained by matching the experimental transformation matrices to the ones computed with the proposed model

Next, the definition of the mathematical models as well as the parameters used are explained, for 1 and $2 \mathrm{DoF}$.

\section{$2 D o F$}

The Mdp matrix is defined as a series of translation and rotations linking the distal coordinate system (CS_d) with the proximal coordinate system (CS_p). To do this, a series of transformations (Figure A.1) are defined from two rotation axes.

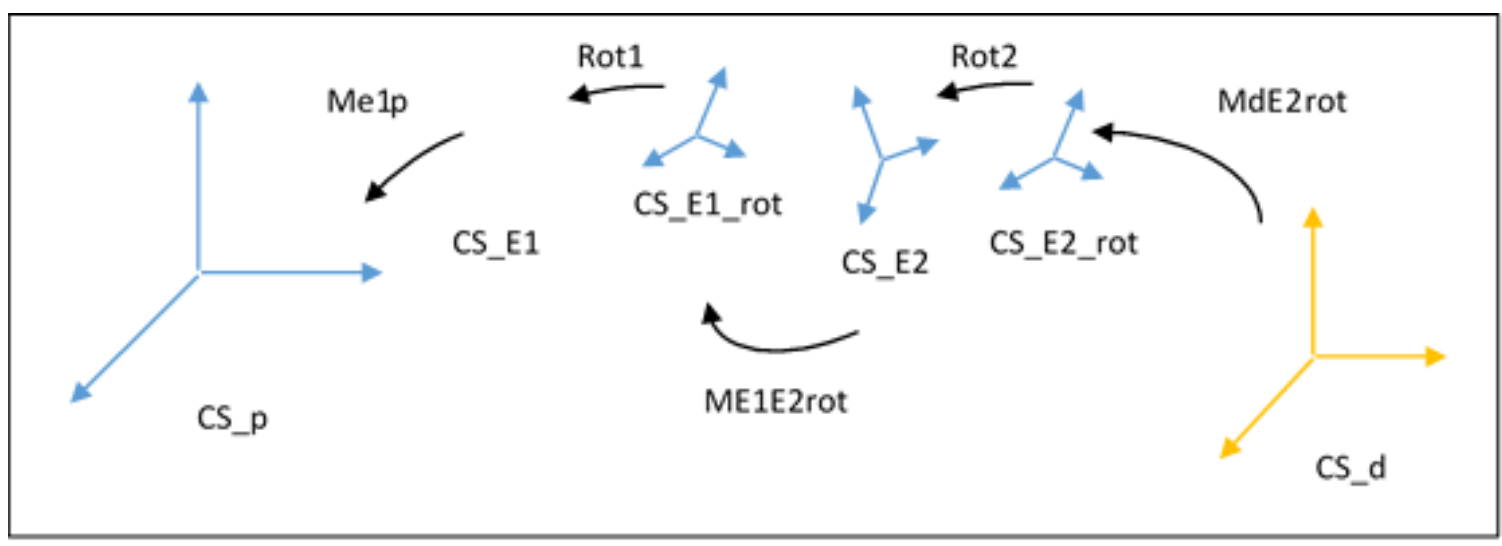

Figure A.1. Transformations linking the distal to the proximal coordinate system 
In this way, the Mdp matrix is defined as:

Mdp=Me1p*Rot1*ME1E2rot*Rot2*MdE2rot

Where Me1p is the transformation matrix that transforms the CS_p in the rotation axis linked to the proximal segment (in this case, it would be the FE axis); Rot1 is the rotation given on this rotation axis; ME1E2rot is the matrix of transformation between the two rotation axes; Rot 2 is the rotation given on the rotation axis linked to the distal segment (in this case, it would be the Ab/Ad axis); and MdE2rot, is the transformation matrix that transforms the coordinate system of the rotation axis linked to the already rotated distal segment (CS_E2_rot) in the CS_d.

In the reference posture, the rotation Rot 1 and Rot 2 are zero, therefore, from equation (1) we can obtain the matrix that links the distal system to the proximal one in this reference posture (Mdp_ref), that is:

$$
\text { Mdp_ref=Me1p* ME1E2rot MdE2rot }
$$

In this way, we obtain:

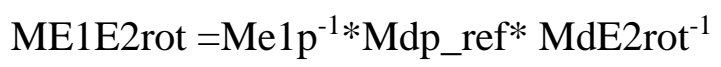

Substituting equation (3) in equation (1), the equation that links the proximal to the distal segment at any instant $\mathrm{i}$ is obtained as:

$$
\operatorname{Mdp}(i)=\operatorname{Me1} 1 * \operatorname{Rot} 1(i) * \operatorname{Me} 1 p^{-1 *} \text { Mdp_ref* MdE2 } \operatorname{rot}^{-1} * \operatorname{Rot} 2(i) * \operatorname{MdE} 2 \operatorname{rot}
$$

The location of the F/E axis with respect to the proximal segment (Me1p) was described by 4 parameters (Figure A.2): coordinates of the intersection of the axis with the sagittal plane ( $T_{x}$ and $\left.T_{y}\right)$; and the inclination angles with respect to the frontal and transversal planes $\left(\alpha_{f}\right.$ and $\left.\alpha_{t}\right)$. 

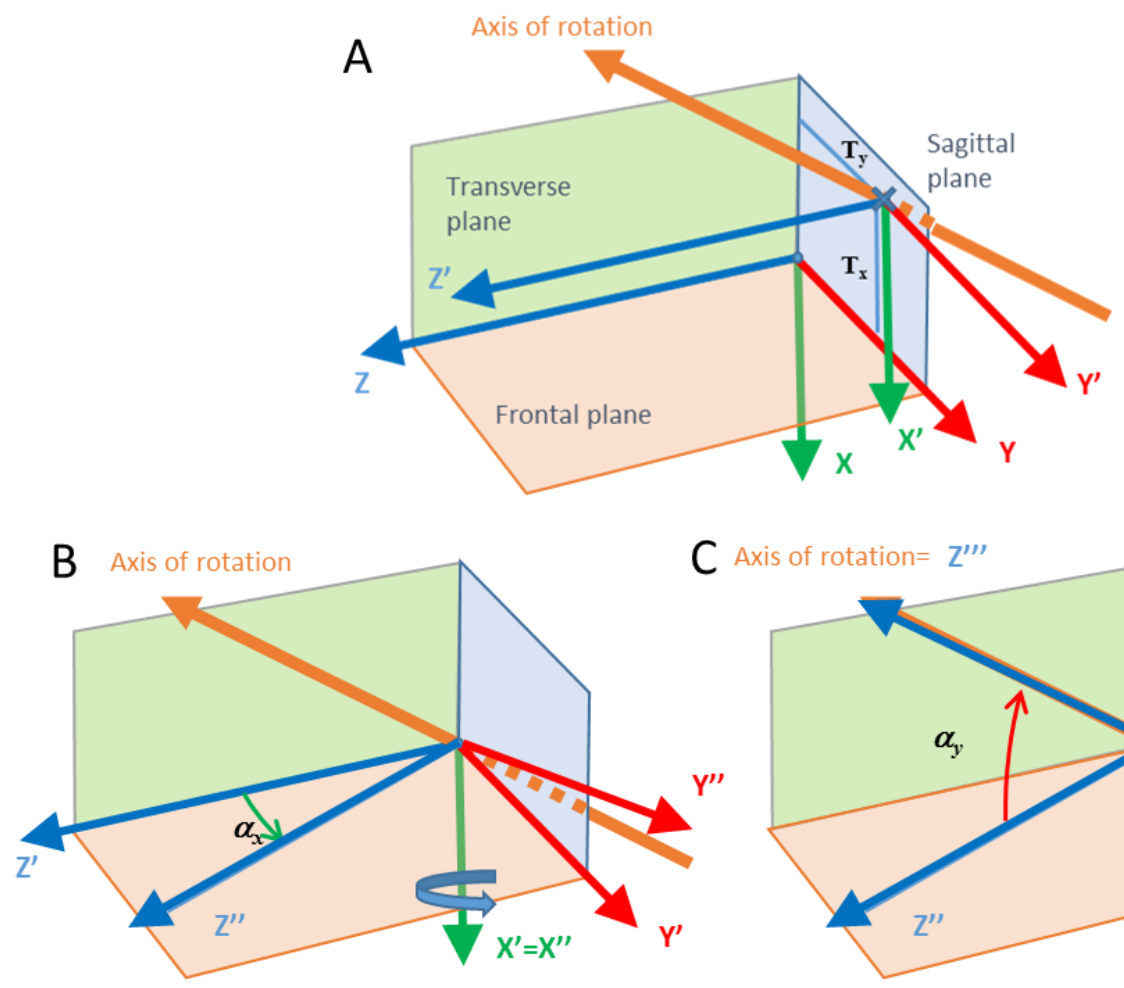

C Axis of rotation $=Z^{\prime \prime \prime}$

Figure A.2 Transformation to get the F/E rotation axis coincident with $Z$ axis: A first translation and the two posterior rotations performed. A: translation (Tx, \& Ty). B: First rotation about X'axis $\left(\alpha_{x}\right)$; $C$ : second rotation $\left(\alpha_{y}\right)$ about $Y$ "' axis

Thus, the Me1p matrix is defined by the translation vector $(\mathrm{T})$ and the product of the two rotations about $\mathrm{X}\left(\mathrm{R}_{\mathrm{x}}, \alpha_{x}\right)$ and about $\mathrm{Y}\left(\mathrm{R}_{\mathrm{Y}}, \alpha_{y}\right)$ :

$$
\begin{aligned}
& \mathrm{T}=\left[\begin{array}{c}
T x \\
T y \\
0
\end{array}\right] ; \mathrm{R}_{\mathrm{x}}=\left[\begin{array}{ccc}
1 & 0 & 0 \\
0 & \cos \left(\alpha_{x}\right) & -\sin \left(\alpha_{x}\right) \\
0 & -\sin \left(\alpha_{x}\right) & \cos \left(\alpha_{x}\right)
\end{array}\right] ; \mathrm{R}_{\mathrm{y}}=\left[\begin{array}{ccc}
\cos \left(\alpha_{y}\right) & 0 & \sin \left(\alpha_{y}\right) \\
0 & 1 & 0 \\
-\sin \left(\alpha_{y}\right) & 0 & \cos \left(\alpha_{y}\right)
\end{array}\right] \\
& \mathrm{Me} 1 \mathrm{p}=\left[\begin{array}{cc}
\mathrm{R}_{x} * \mathrm{R}_{y} & T \\
0 & 1
\end{array}\right]
\end{aligned}
$$

Finally, to define these inclination parameters $\left(\alpha_{x}, \alpha_{y}\right)$, with respect to the frontal and transversal planes $\left(\alpha_{f}, \alpha_{t}\right)$, it can be shown that $\alpha_{\mathrm{x}}$ is directly the angle between the rotation axis and the transverse plane $\left(\alpha_{t}\right)$. On the other hand, $\alpha_{f}$ can be expressed through the parameters of the solution $\left(\alpha_{x}, \alpha_{y}\right)$ by means of the next trigonometric relationship:

$$
\sin \left(\alpha_{f}\right)=\cos \left(\alpha_{t}\right) * \sin \left(\alpha_{\mathrm{y}}\right)
$$

Similarly, the location of the Ab/Ad axis with respect to the distal segment (MdE2rot) was described by the coordinates of the intersection of the axis with the 
Sagittal plane $\left(T_{x}\right.$ and $\left.T_{y}\right)$; and the inclination angles with respect to the frontal and sagittal planes $\left(\alpha_{f}\right.$ and $\left.\alpha_{s}\right)$. (Figure A.3).
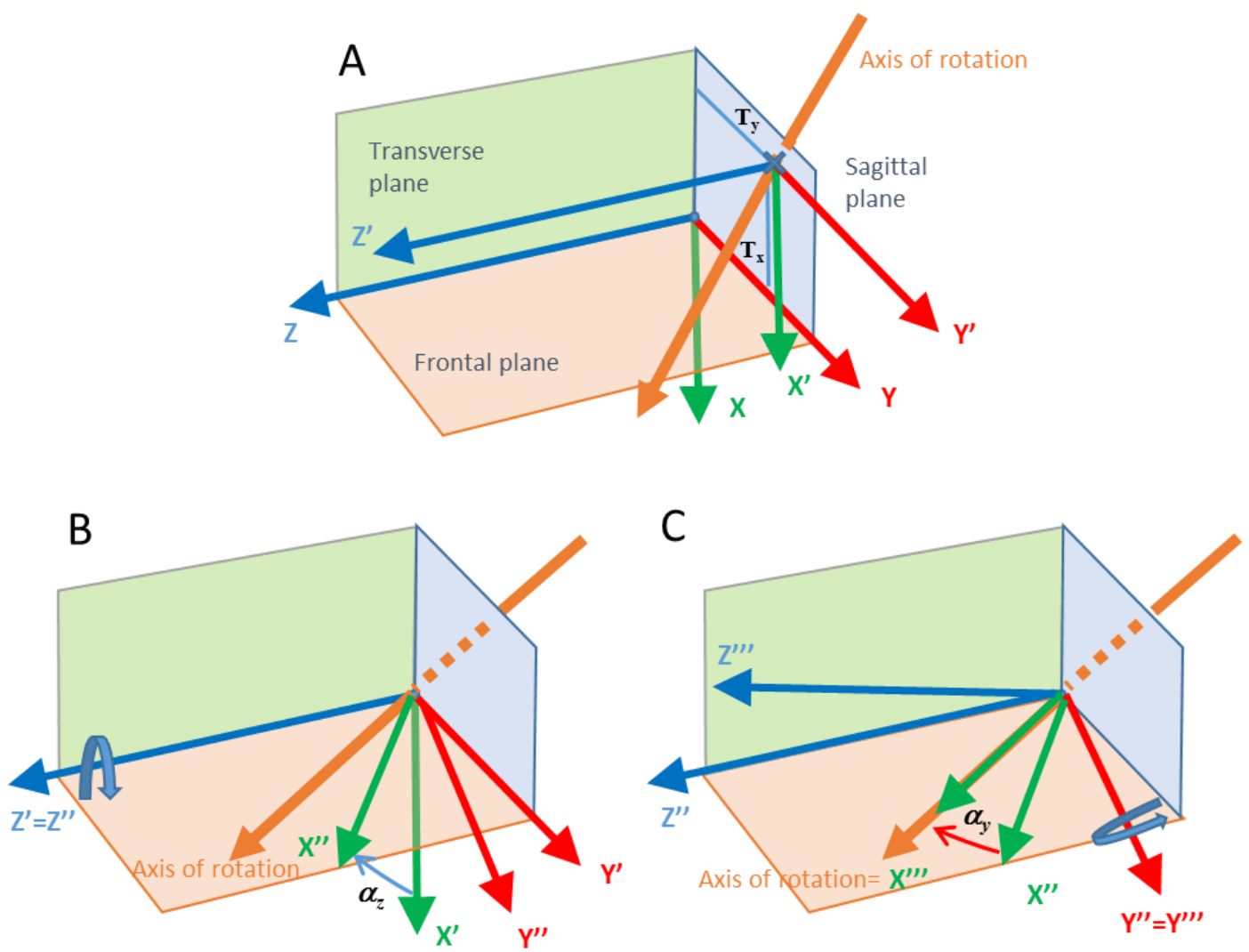

Figure A.3 Transformation to get the Ab/Ad rotation axis coincident with $X$ axis: A: translations (Tx, \& Ty). B: First rotation about $Z$ '-axis $\left(\alpha_{z}\right)$; C: second rotation $\left(\alpha_{y}\right)$ about $Y$ ' 'axis

Thus, the MdE2rot matrix is defined by the translation vector $(\mathrm{T})$ and the product of the two rotations about $\mathrm{Z}\left(\mathrm{R}_{\mathrm{z}}, \alpha_{z}\right)$ and about $\mathrm{Y}\left(\mathrm{R}_{\mathrm{Y}}, \alpha_{y}\right)$ :

$$
\begin{aligned}
& \mathrm{T}=\left[\begin{array}{c}
T x \\
T y \\
0
\end{array}\right] ; \quad \mathrm{R}_{\mathrm{z}}=\left[\begin{array}{ccc}
\cos \left(\alpha_{z}\right) & -\sin \left(\alpha_{z}\right) & 0 \\
\sin \left(\alpha_{z}\right) & \cos \left(\alpha_{z}\right) & 0 \\
0 & 0 & 1
\end{array}\right] ; \quad \mathrm{R}_{\mathrm{y}}=\left[\begin{array}{ccc}
\cos \left(\alpha_{y}\right) & 0 & \sin \left(\alpha_{y}\right) \\
0 & 1 & 0 \\
-\sin \left(\alpha_{y}\right) & 0 & \cos \left(\alpha_{y}\right)
\end{array}\right] \\
& \mathrm{MdE} 2 \mathrm{rot}=\left[\begin{array}{cc}
\mathrm{R}_{z} * \mathrm{R}_{y} & T \\
0 & 1
\end{array}\right]
\end{aligned}
$$

As before explained, to define the inclination angles $\left(\alpha_{z}, \alpha_{y}\right)$, with respect to the transverse and sagittal planes $\left(\alpha_{t}, \alpha_{s}\right)$, it can be shown that $\alpha_{z}$ is directly the angle between the axis of rotation and the transverse plane $\left(\alpha_{t}\right)$. and $\alpha_{s}$ can be defined as:

$$
\sin \left(\alpha_{s}\right)=\cos \left(\alpha_{t}\right) * \sin \left(\alpha_{\mathrm{y}}\right)
$$


1DoF

The Mdp matrix is defined as a series of translation and rotations linking the CS_d with CS_p. To do this, a series of transformations (Figure A.4) are defined from a rotation axis.

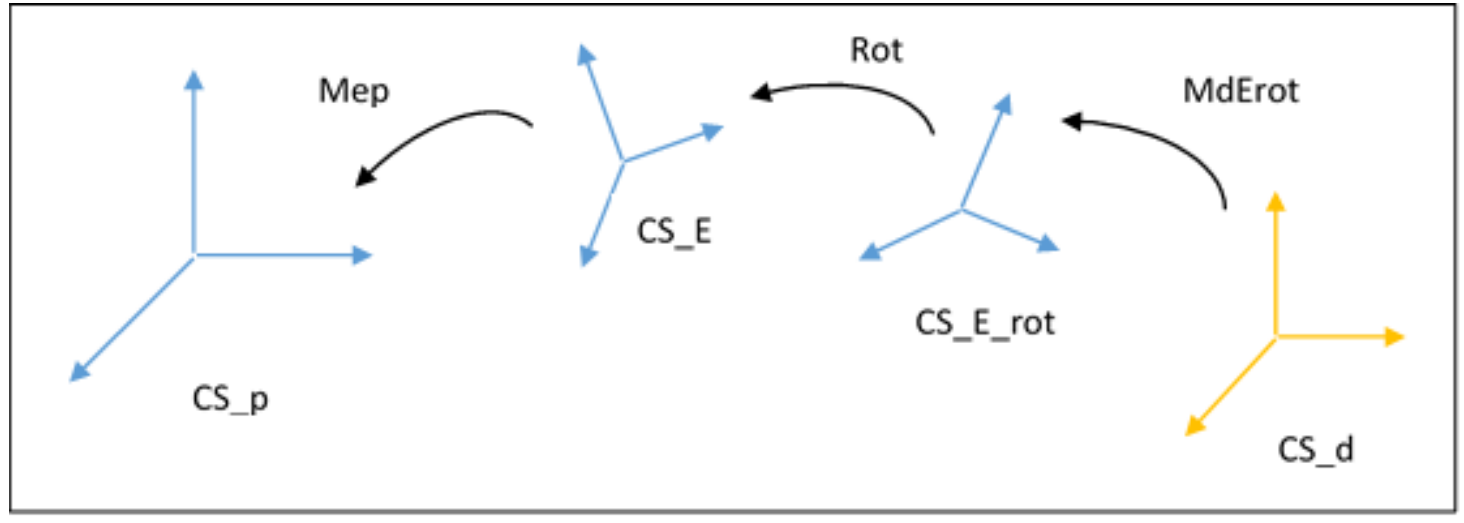

Figure A.4. Transformations linking the distal to the proximal coordinate system

In this way, the Mdp matrix is defined as:

Mdp=Mep*Rot*MdErot

Where Mep is the transformation matrix that transforms CS_p into the rotation axis, Rot is the rotation given on the rotation axis; and MdErot is the transformation matrix that transforms the coordinate system of the rotation axis already rotated (CS_E_rot) in the CS_d.

In the reference posture, the rotation Rot is zero, therefore, from equation (5) we can obtain the matrix that links the distal system to the proximal one in this reference posture (Mdp_ref), that is:

Mdp_ref=Mep*MdErot

Thus, we obtain:

MdErot=Mep- $1 *$ Mdp_ref

Substituting equation 7 in equation 5 , the equation that links the proximal to the distal segment at any instant $i$ is obtained as:

$$
\operatorname{Mdp}(\mathrm{i})=\operatorname{Mep} * \operatorname{Rot}(\mathrm{i}) * \operatorname{Mep}-1 * \text { Mdp_ref }
$$

Finally, The location of the F/E axis with respect to the proximal segment (Mep) was described as in the 2GDL model, by 4 parameters (Figure A.3): coordinates of the intersection of the axis with the sagittal plane $\left(T_{x}\right.$ and $\left.T_{y}\right)$; and the inclination angles with respect to the frontal and transversal planes $\left(\alpha_{f}\right.$ and $\left.\alpha_{t}\right)$. 


\section{Appendix II: Temporal evolution of the reduced kinematic variables during manipulation}
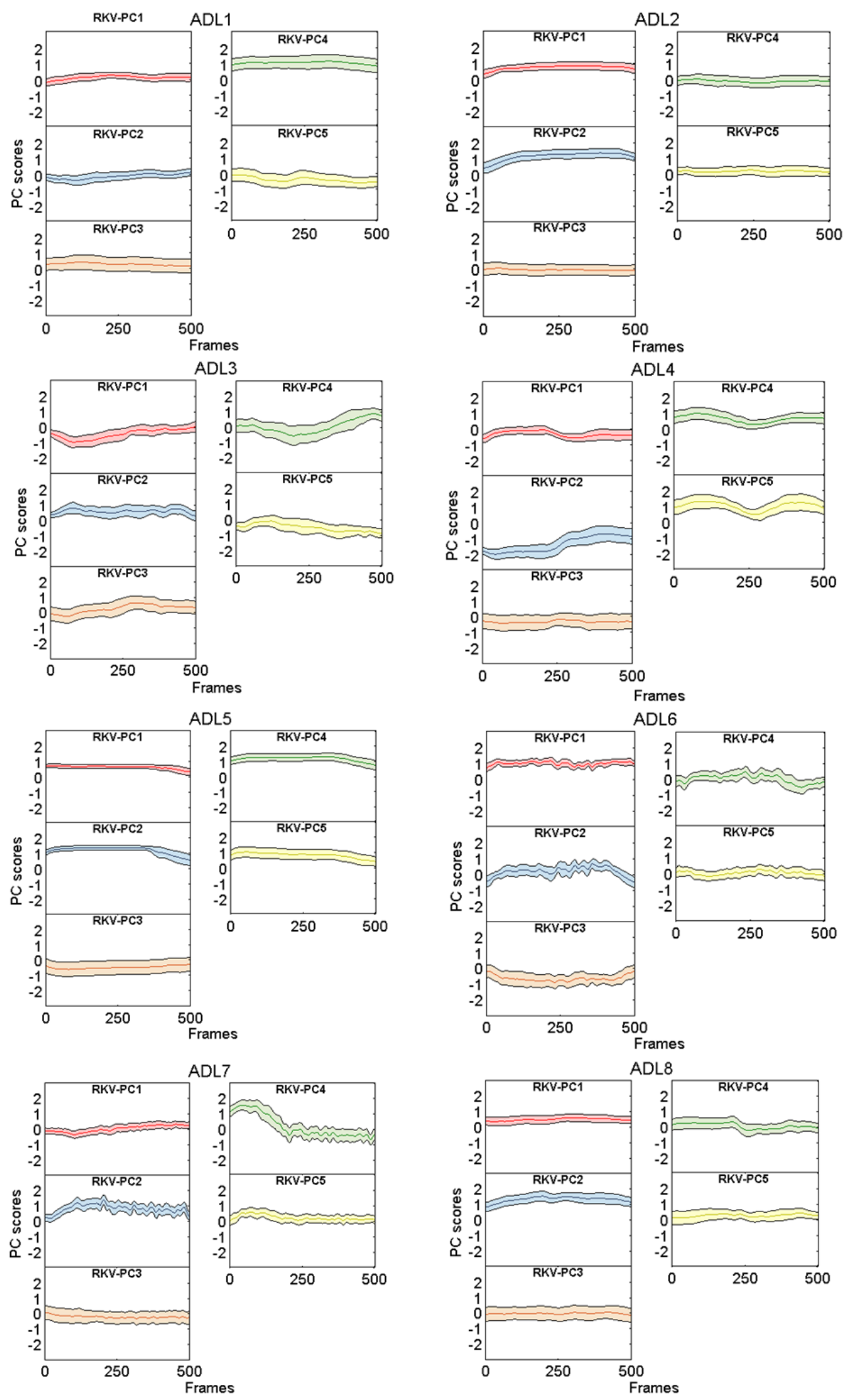

Kinematic and muscular characterisation of the hand during ADL 

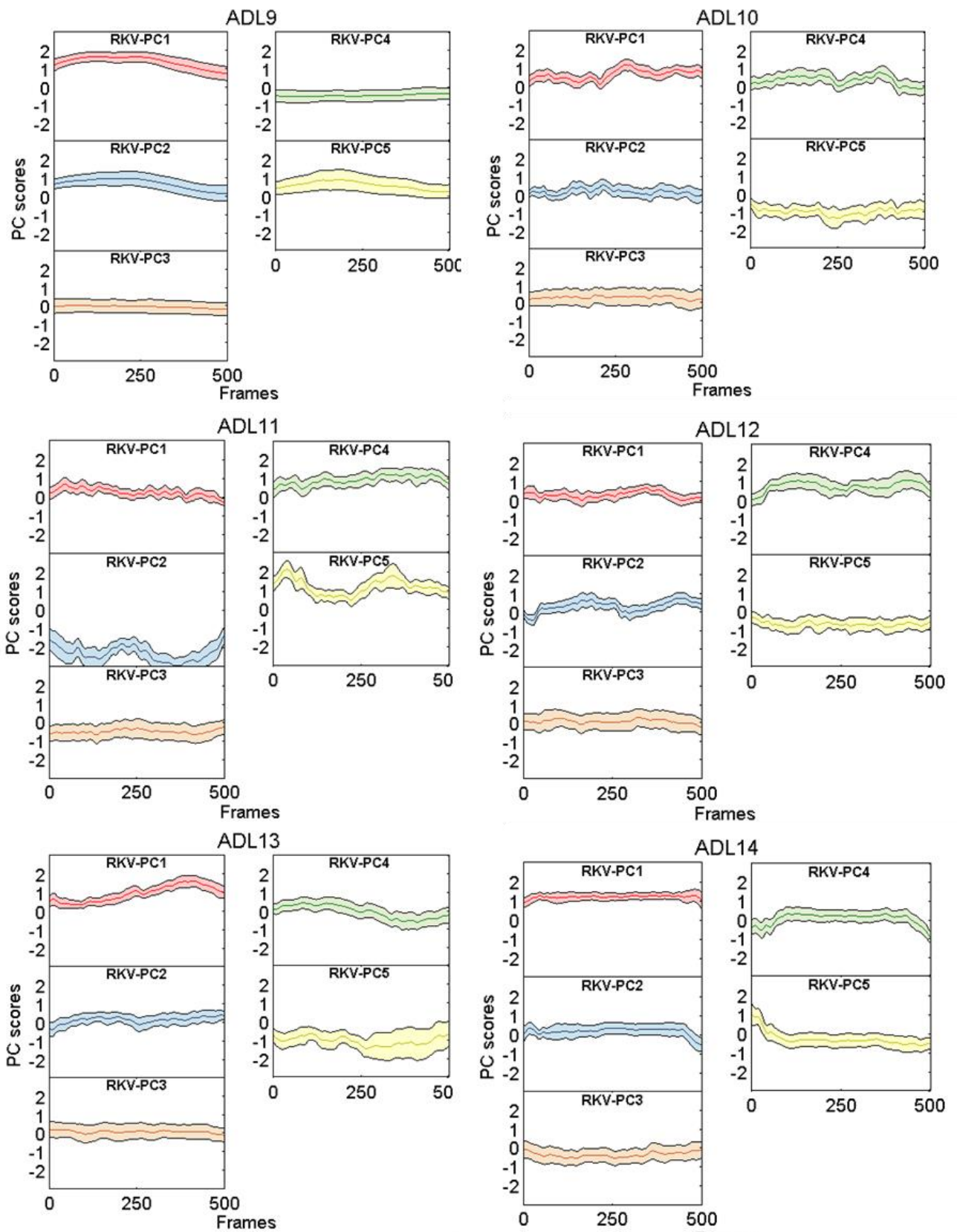

ADL14
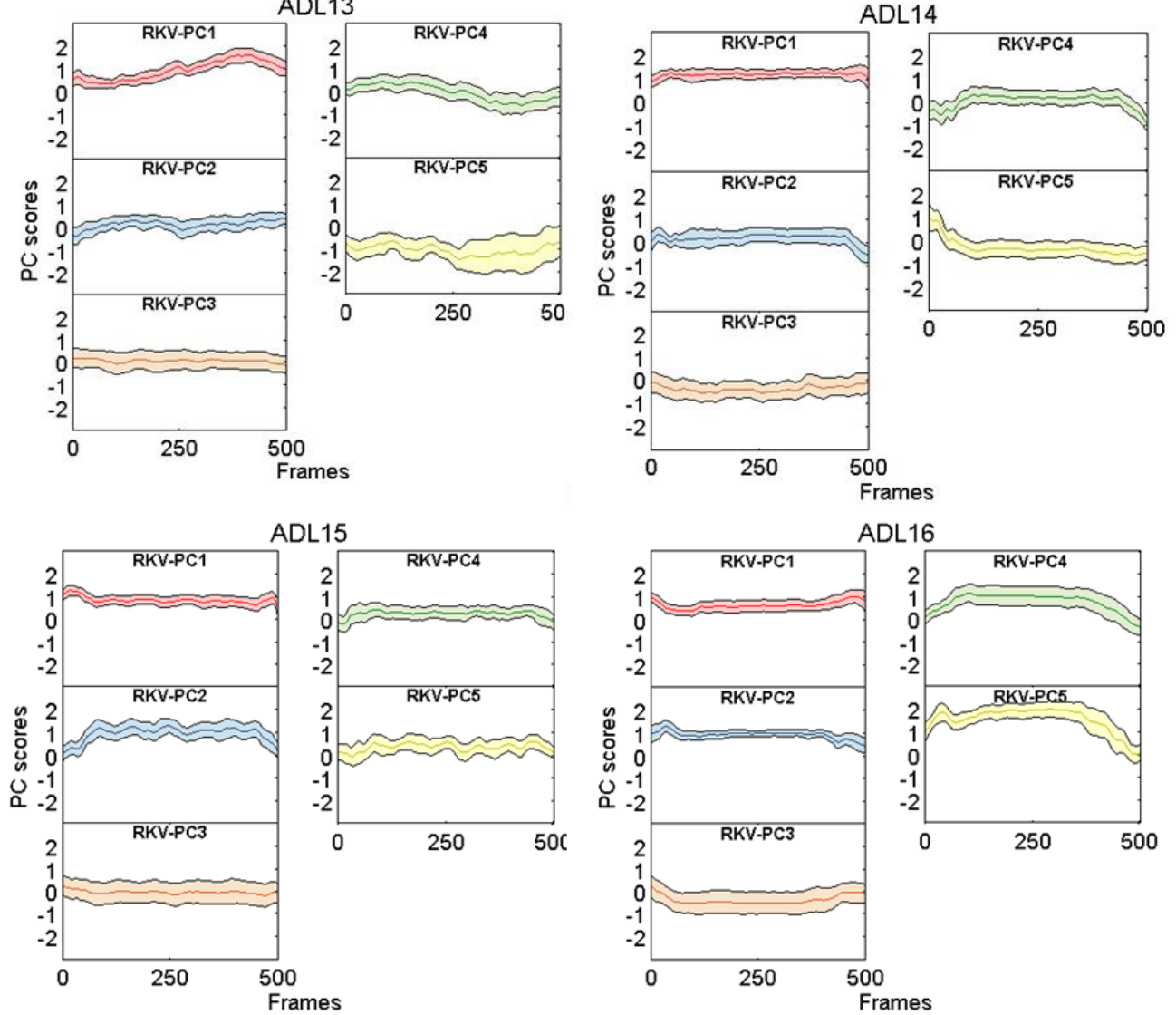

Kinematic and muscular characterisation of the hand during ADL 

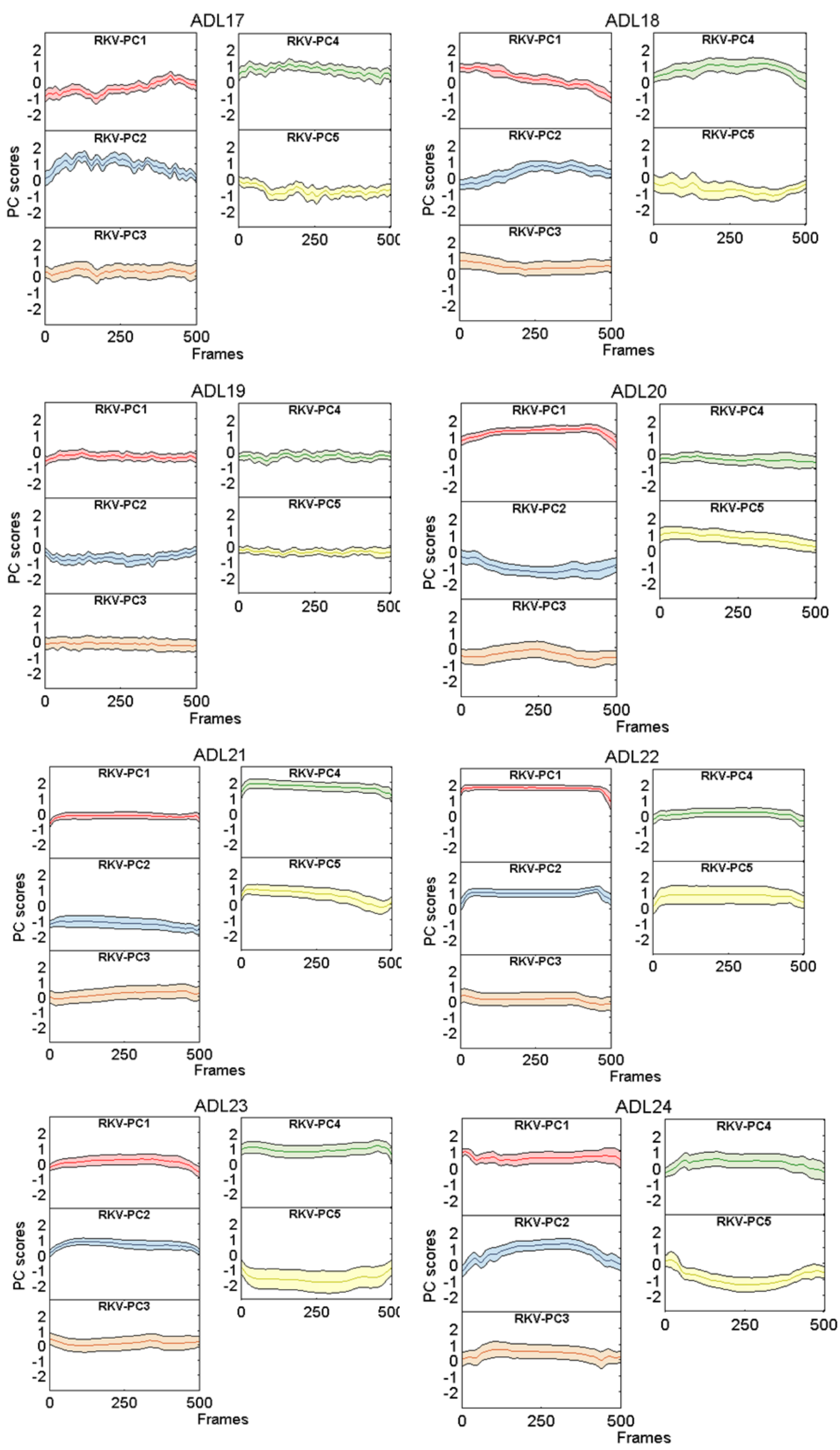

Kinematic and muscular characterisation of the hand during ADL 

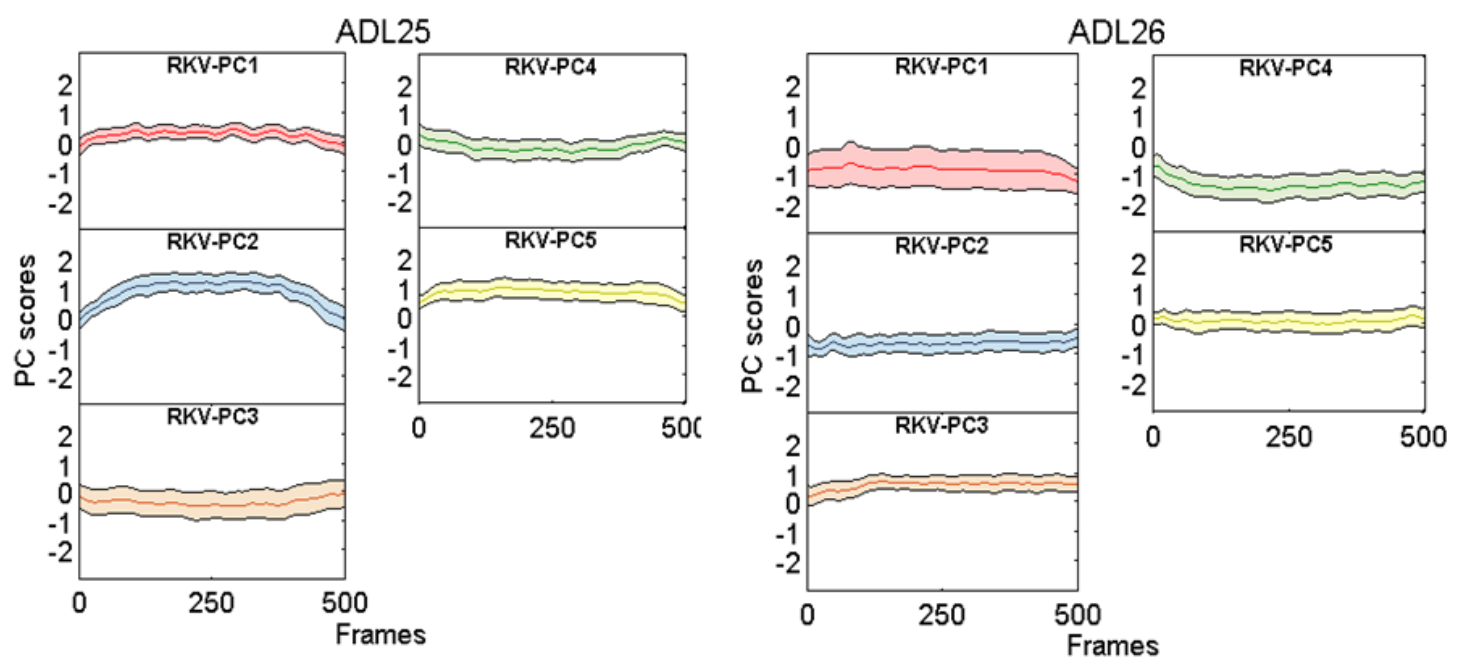

Figure A.5 Temporal evolution of the averaged RKV-PCs and $95 \%$ CI across subjects, differentiating per $A D L$ 


\section{Appendix III: Temporal evolution of the muscle activity of each spot during manipulation}
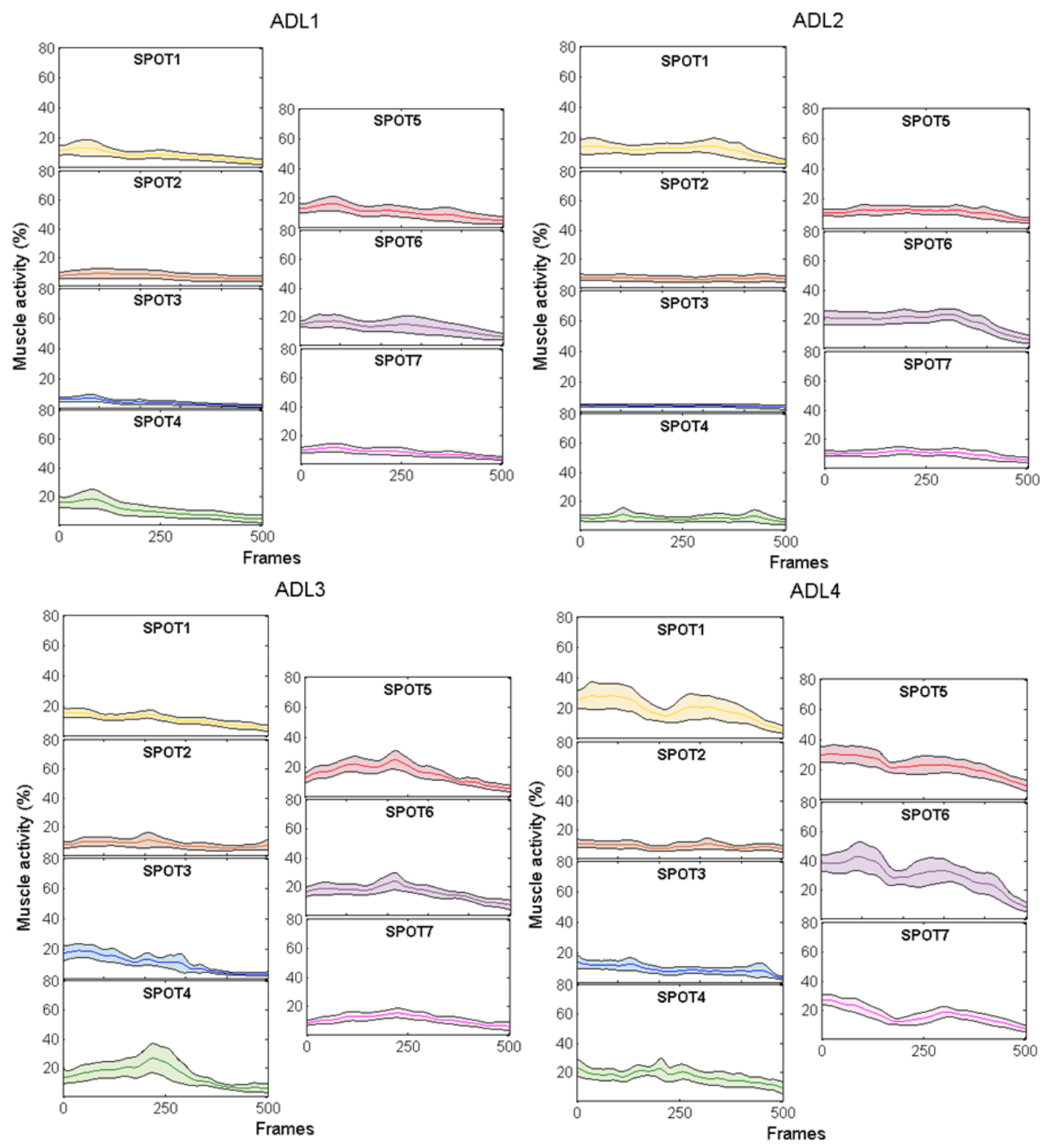

ADL5
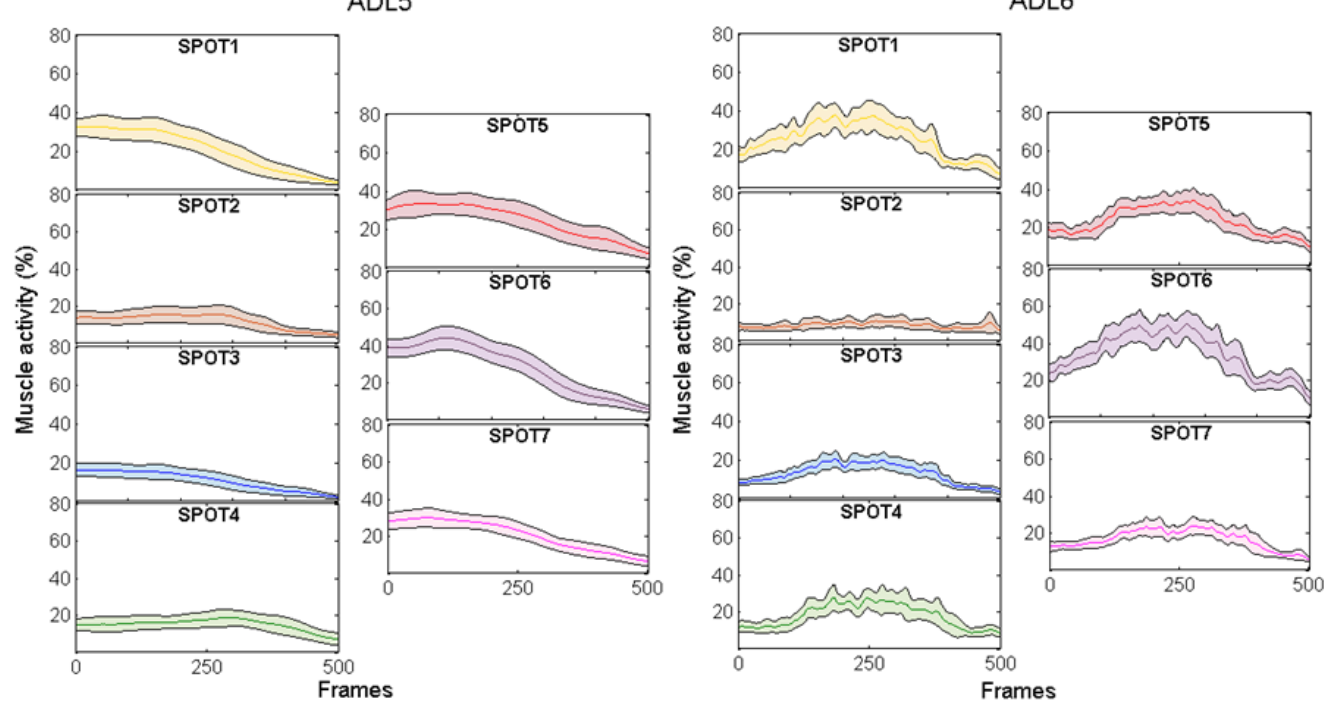

Kinematic and muscular characterisation of the hand during ADL 
ADL7

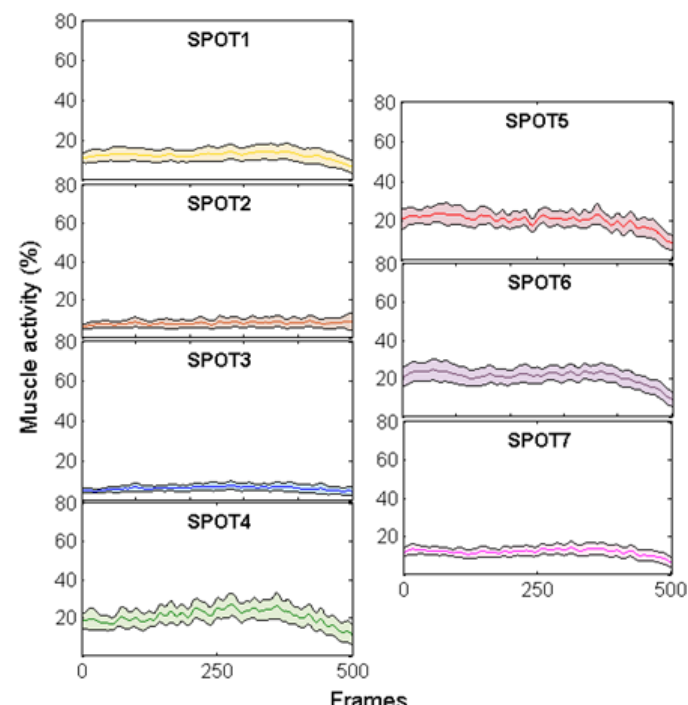

ADL9

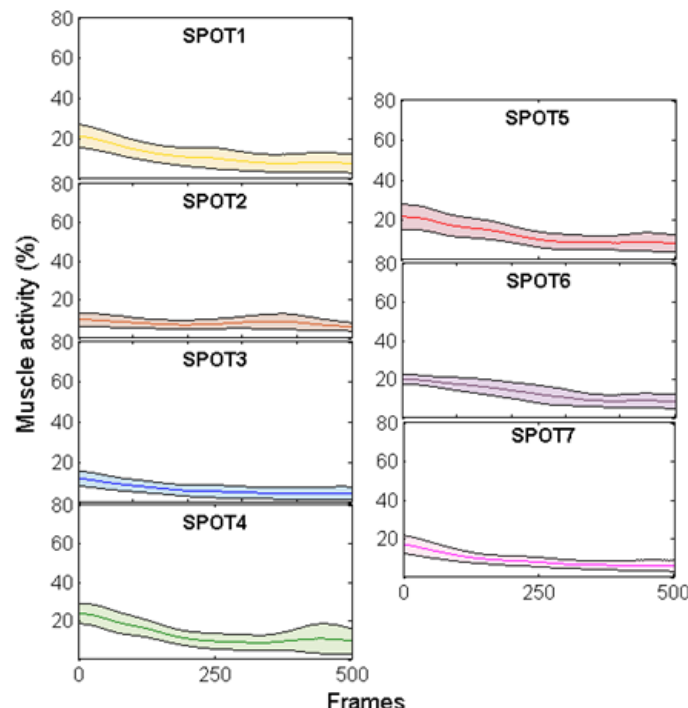

ADL11

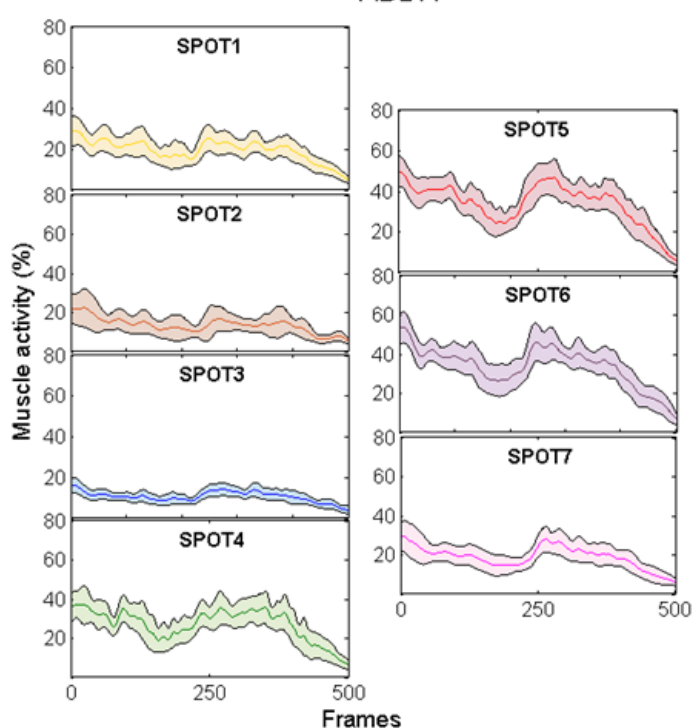

ADL8

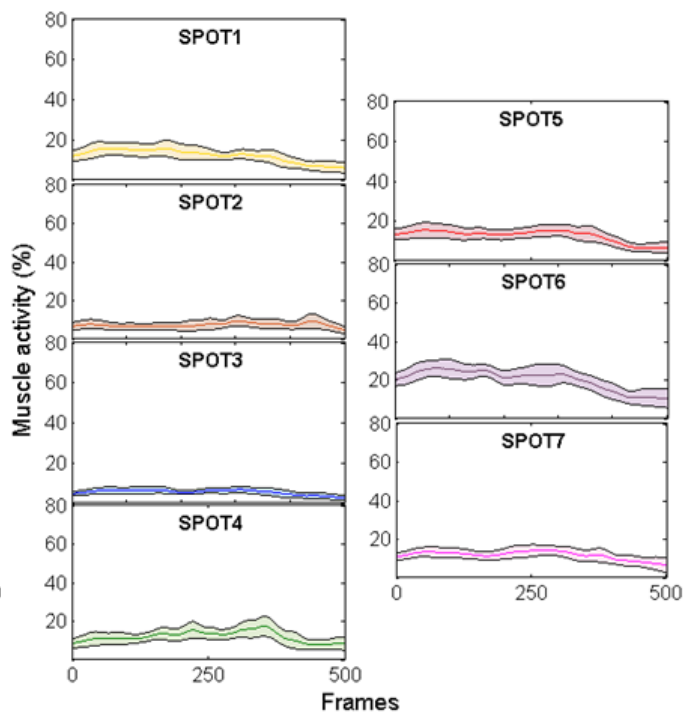

ADL10

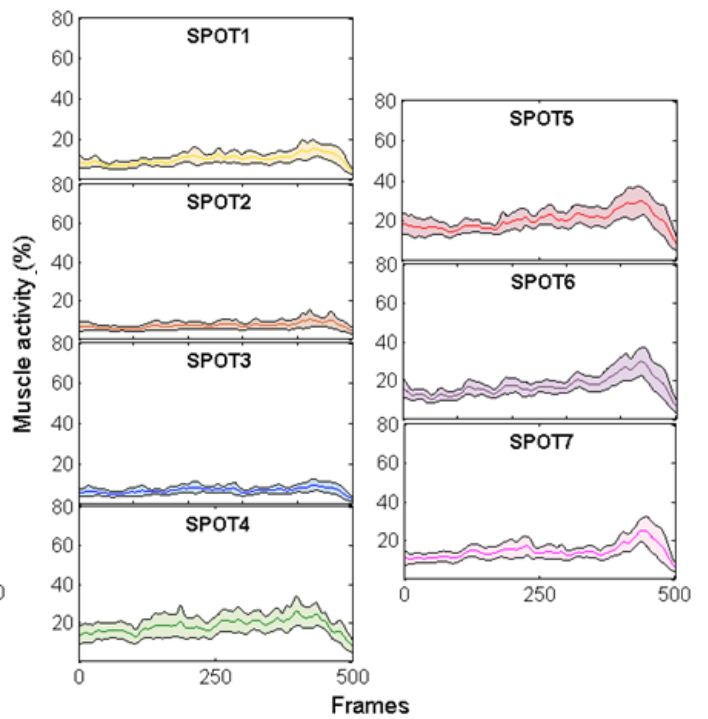

ADL12

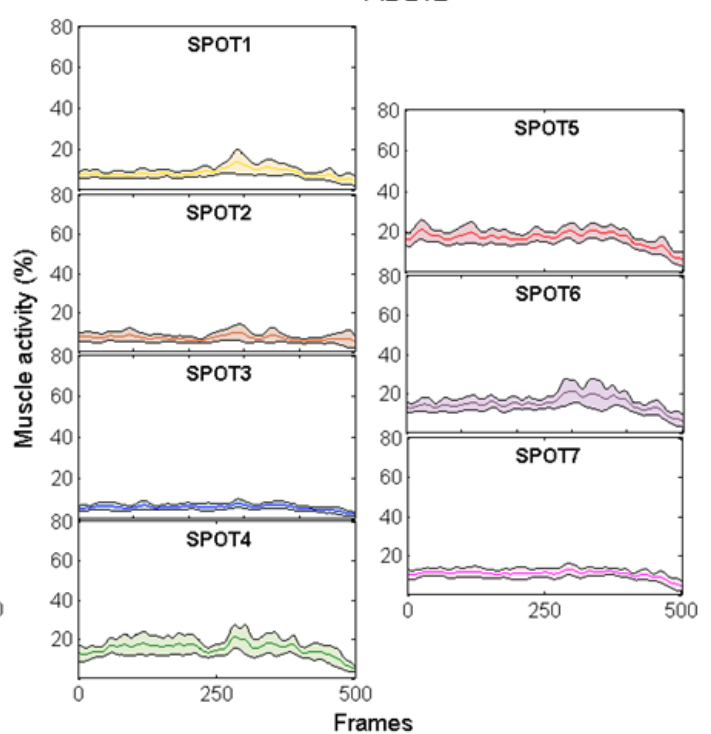

Kinematic and muscular characterisation of the hand during ADL 
ADL13

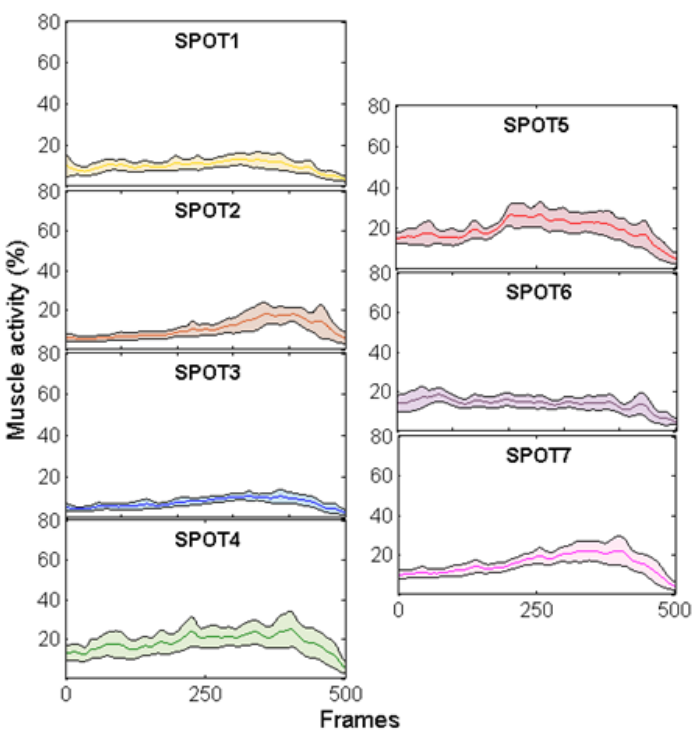

ADL15

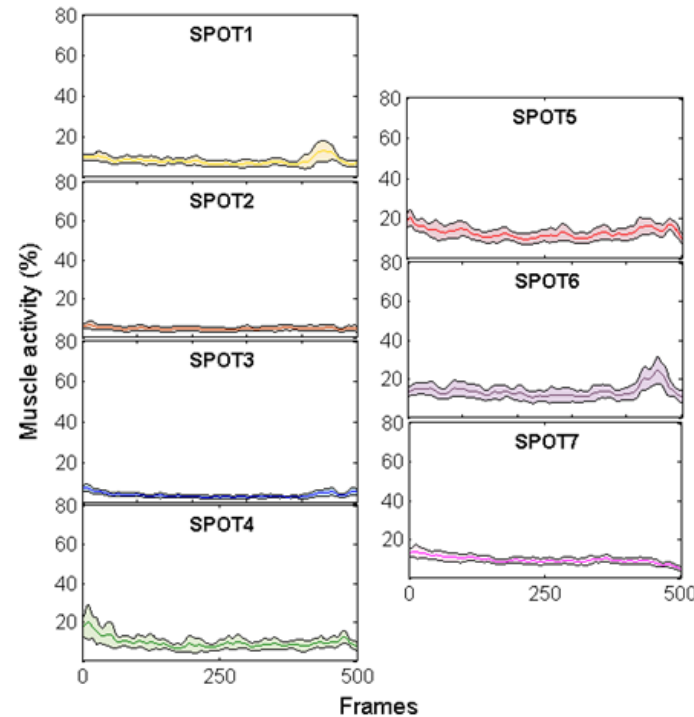

ADL17

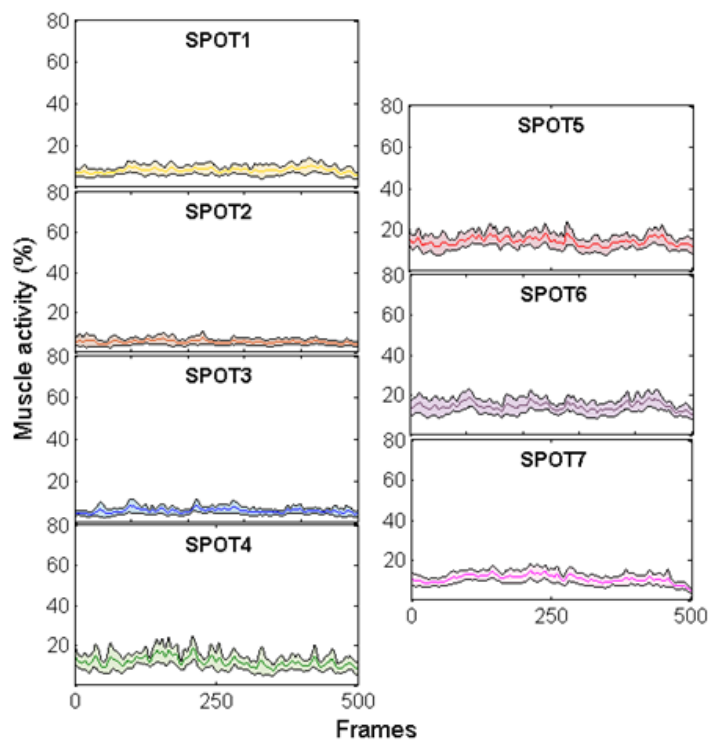

ADL14

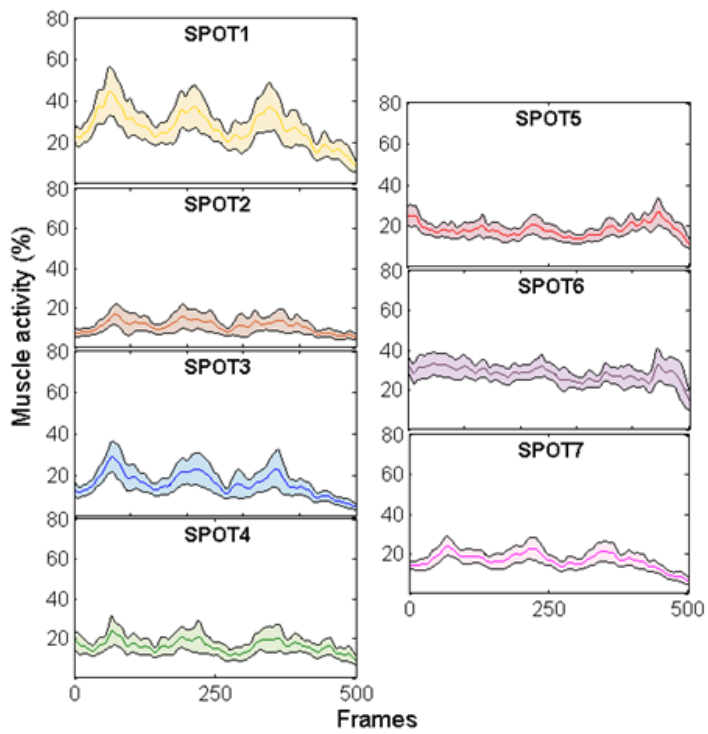

ADL16

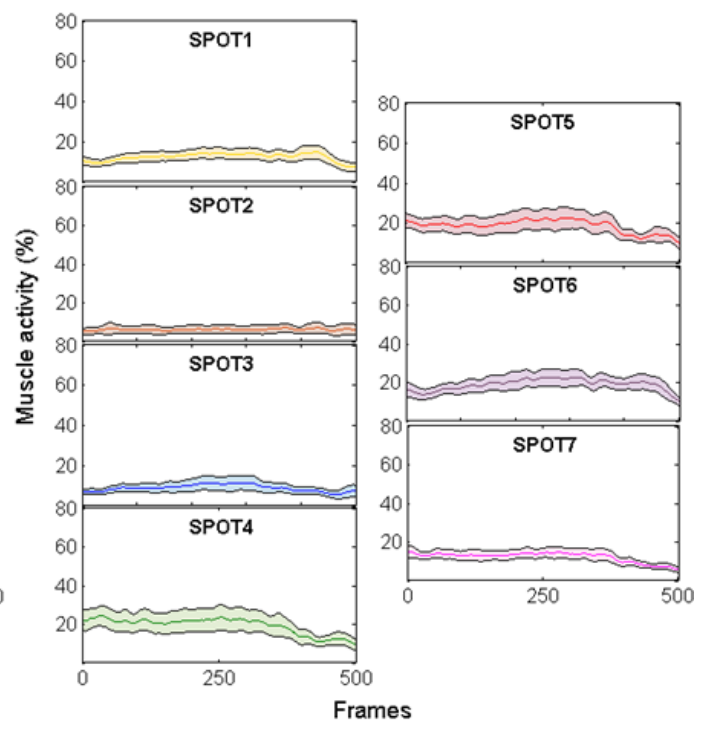

ADL18

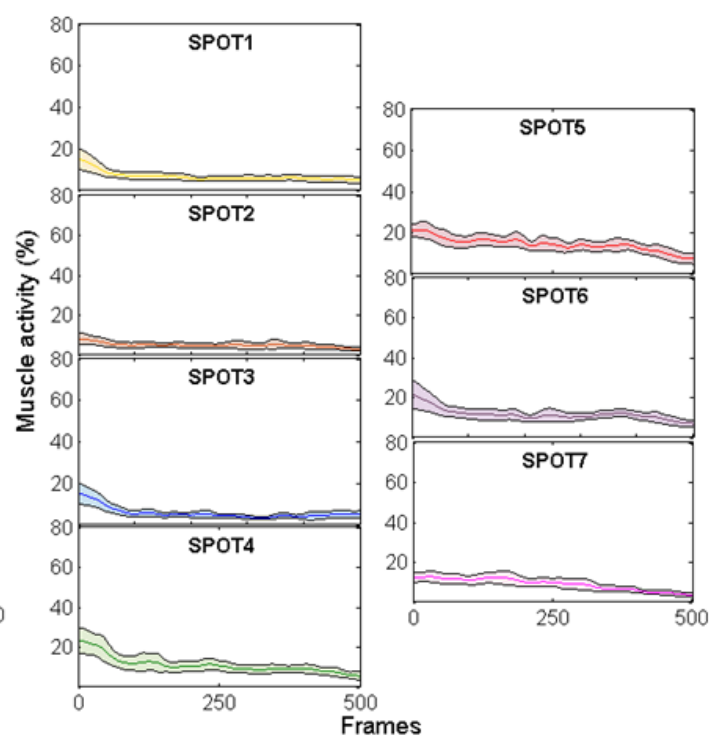

Kinematic and muscular characterisation of the hand during ADL 
ADL19

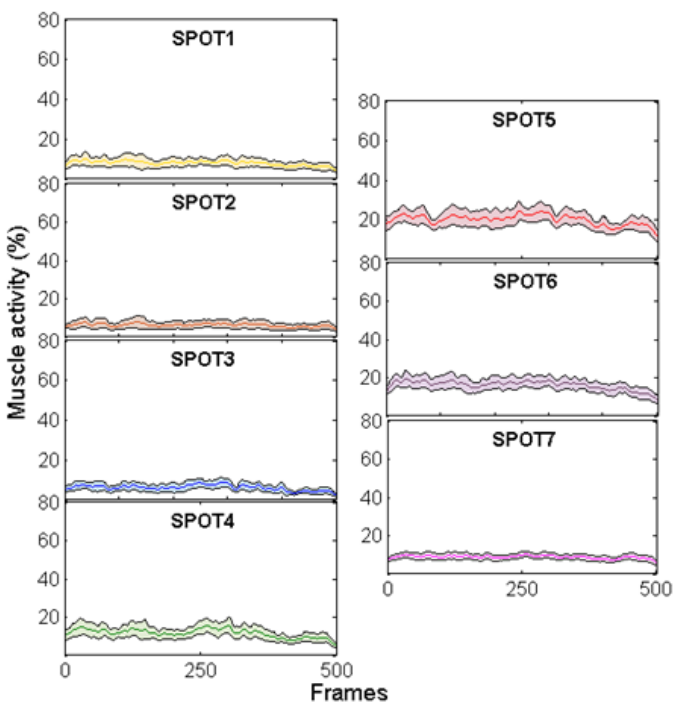

ADL21

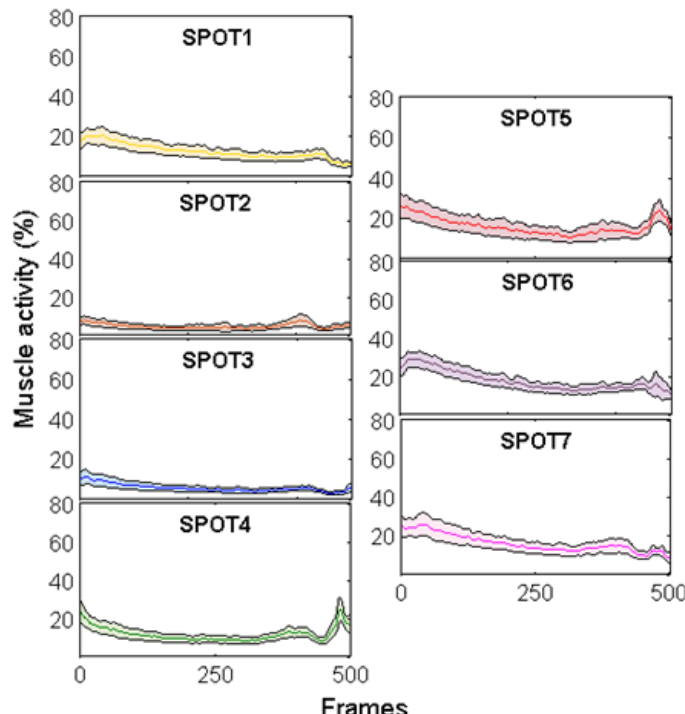

ADL23

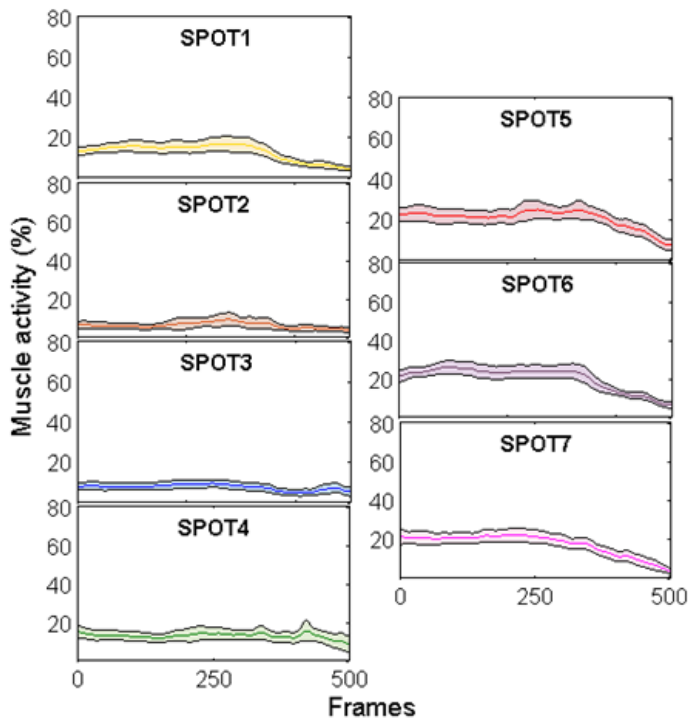

ADL20

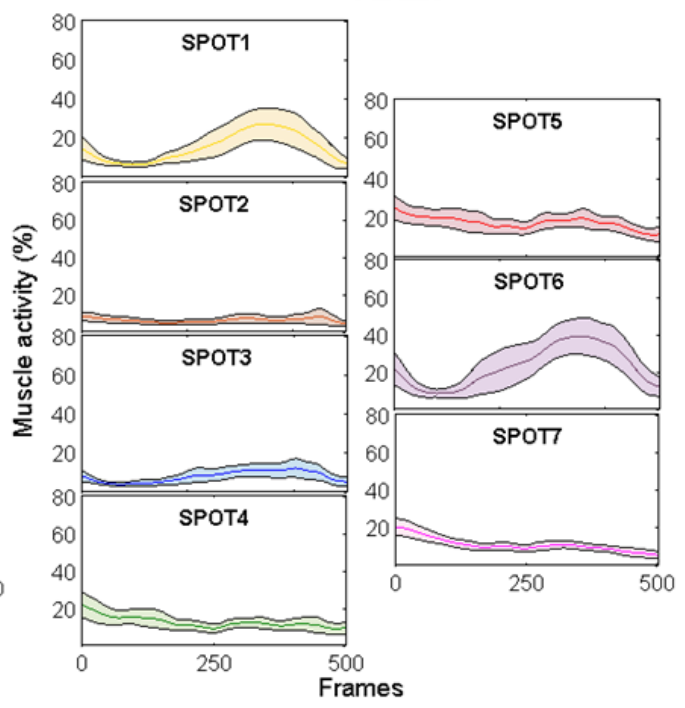

ADL22

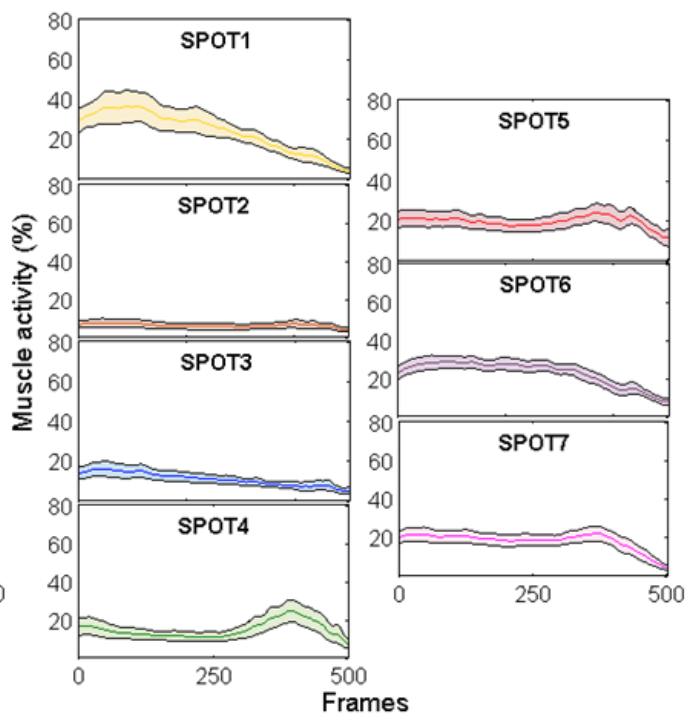

ADL24

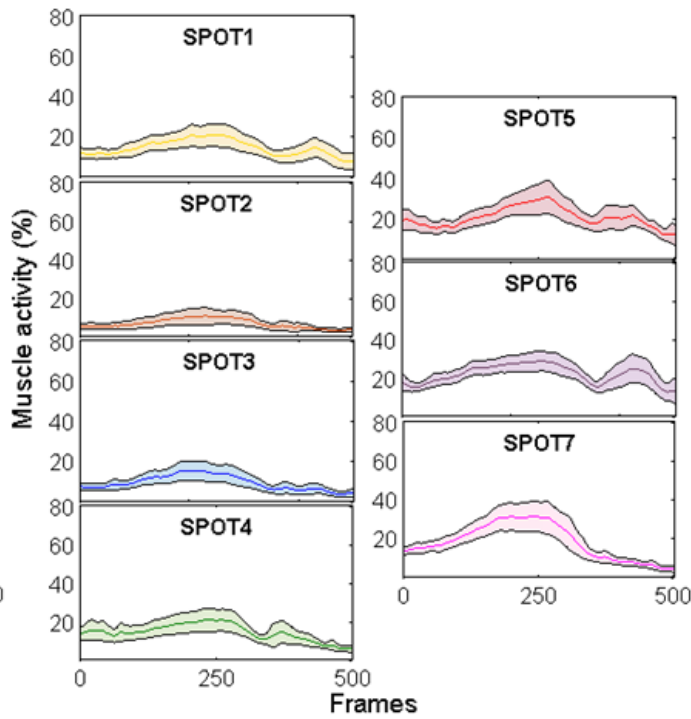

Kinematic and muscular characterisation of the hand during ADL 

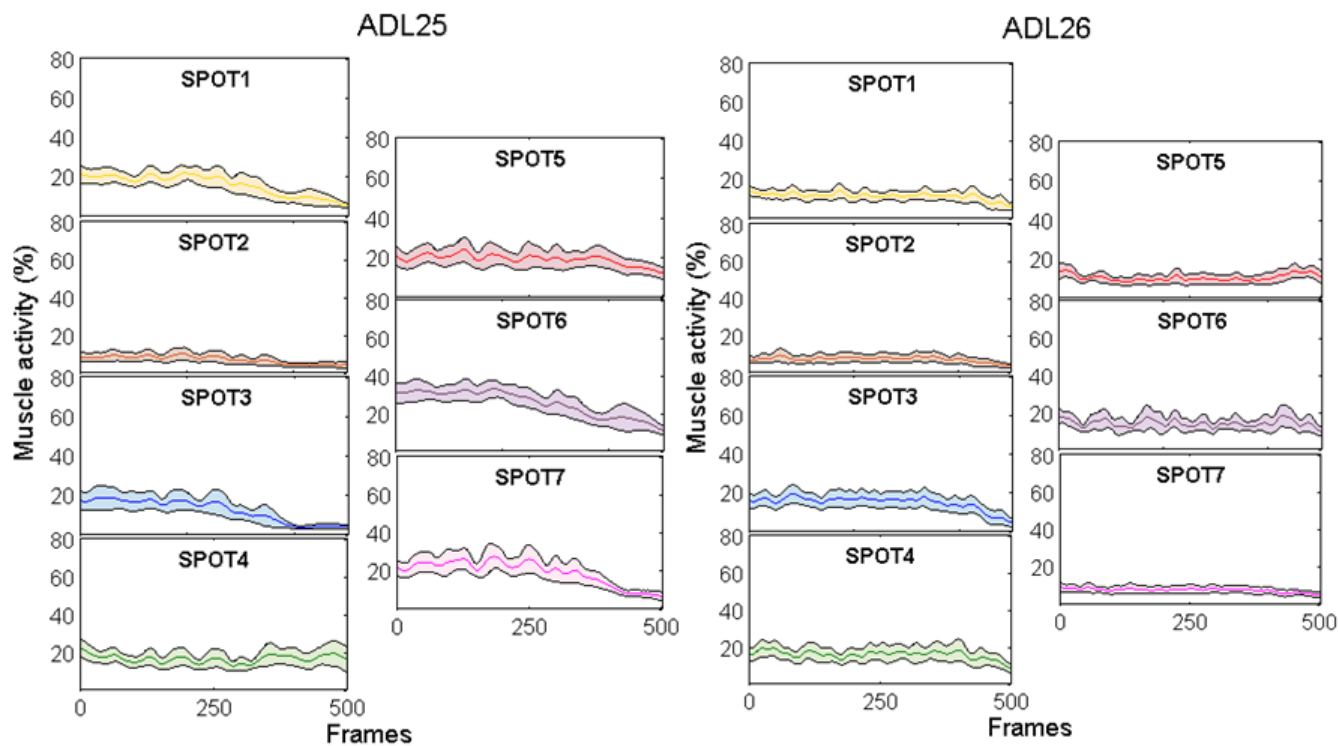

Figure A.6 Temporal evolution of the mean value (across subjects) and 95\% CI of each spot per $A D L$. 

